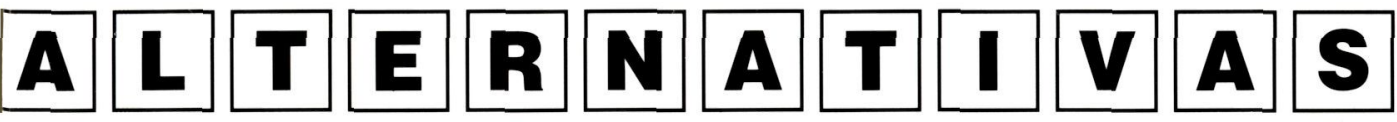

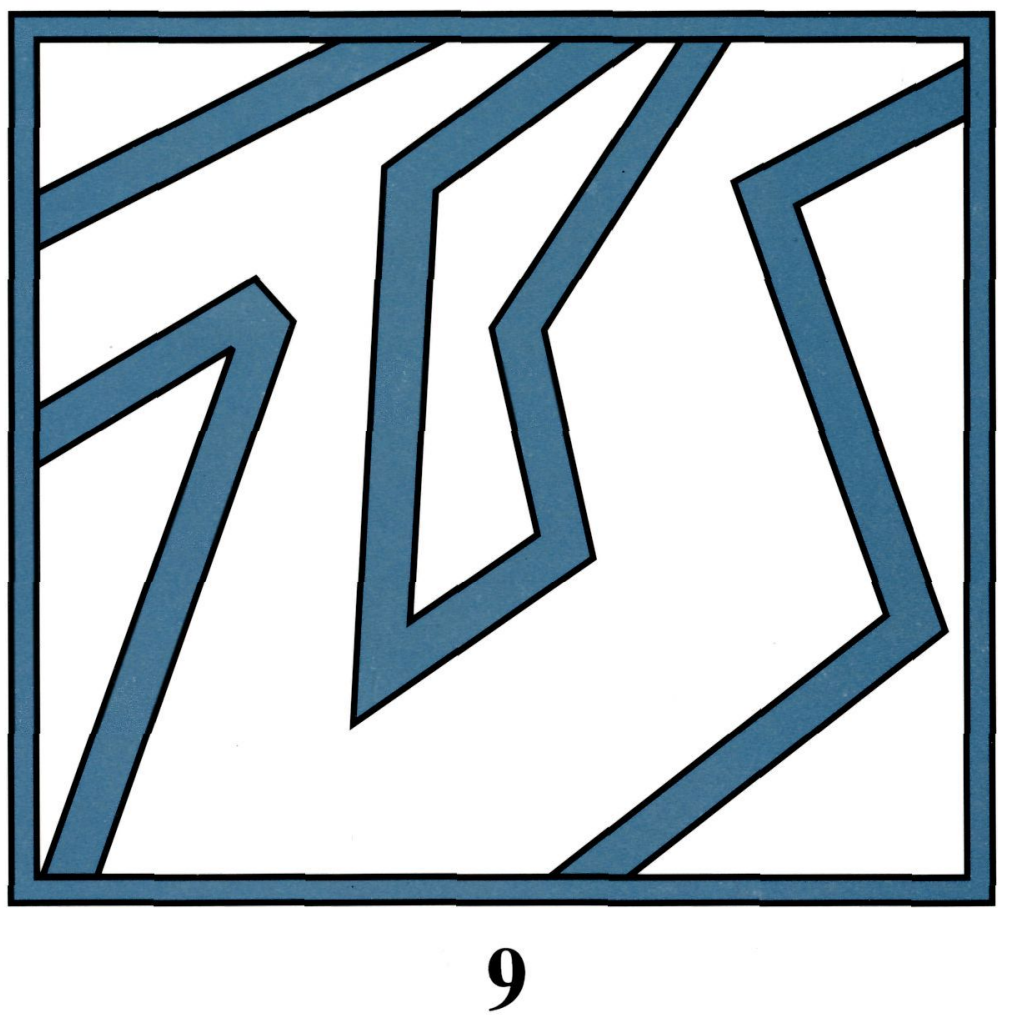

CUADERNOS DE TRABAJO SOCIAL 




\section{ALTERNATIVAS}

\section{CUADERNOS}

DE

TRABAJO SOCIAL 
ALTERNATIVAS. CUADERNOS DE TRABAJO SOCIAL N. ${ }^{\circ}$ 9. Diciembre 2001.

\section{CONSEJO EDITORIAL:}

Directora de la revista: Hortensia Redero Bellido

Directora técnica: M. $\quad$ Asunción Martínez Román

Vocales: Yolanda Domenech López

Carmen López Sánchez

$\mathbf{M}^{\mathrm{a}}$ Teresa Mira-Perceval Pastor

Begoña San Miguel Hoyo

Esther Villegas Castrillo

EDICIÓN Y ADMINISTRACIÓN:

Escuela Universitaria de Trabajo Social. Universidad de Alicante.

03690 San Vicente del Raspeig. Alicante. España.

Telf.: 965903770 - Fax: 965903572

e-mail (Escuela): cu.trabajosocial@ua.es

Depósito Legal: M. 37.152-1992.

I.S.S.N.: $\quad 1133-0473$.

Impresion:

ROMGRAFIC, S.L.

Martínez de Velasco, 17. 03013 Alicante (España)

Telf./Fax: $965201392 \cdot$ e-mail: romgrafic@navegalia.com

Precio del ejemplar: 15 euros

Reservados todos los derechos

Suscripciones y venta:

Librería Compás-Universidad, S.L.

Centro de Servicios Universitarios. Universidad de Alicante.

03690 San Vicente del Raspeig · Alicante (España)

Apdo. de correos n. ${ }^{\circ} 6095 \cdot 03080$ Alicante (España)

Telf.: 965909390 . Fax: 965909391

e-mail: compasuniversid@teleline.es

www.libreriacompas.com

PRÓXIMA SECCIÓN MONOGRÁFICA:

Los desafíos de la violencia. Compromisos del Trabajo Social por una sociedad más justa

IV Congreso de Escuelas de Trabajo Social. 


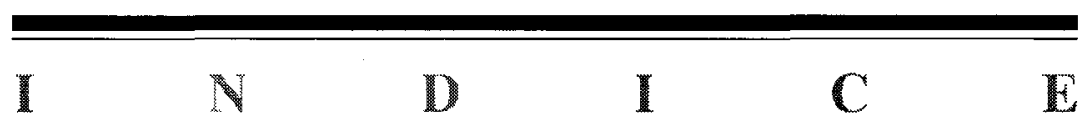



M. a Asunción Martínez Román. Directora técnica del Consejo Editorial de la Revista «Alternativas. Cuadernos de Trabajo Social».

Editorial

\section{Cuando crece la esperanza de vida}

$\mathrm{M}^{\mathrm{a}}$ José González y Begoña San Miguel. Departamento de Sociología II, Psicología, Comunicación y Didáctica. Universidad de Alicante.

El envejecimiento de la población española y sus consecuencias sociales.

Daniel La Parra Casado. Departamento de Sociología II, Psicología, Comunicación y Didáctica. Universidad de Alicante.

Los menores y los mayores: imágenes invertidas de las desigualdades por edad.

Francisco Ródenas Rigla y Jorge Garcés Ferrer. Departamento de Trabajo Social y Servicios Sociales. Universidad de Valencia.

La protección social en el Este. El caso polaco.

M $^{a}$ Asunción Martínez R., Anne-Lotte Kreickemeier, Joaquina Murcia y Hortensia Redero. Departamento de Trabajo Social y Servicios Sociales y Asociación Universitaria para la Promoción del Voluntariado. Universidad de Alicante. Fachhochschule de Darmstadt (Alemania).

Homeshare Europe. Alojamiento compartido a cambio de Ayuda en Europa. 
$\mathrm{M}^{\mathrm{a}}$ Auxiliadora González Bueno. Profesora de Trabajo Social y Servicios Sociales. Universidad de Las Palmas de Gran Canaria.

Programas Universitarios para mayores. La educación para toda la vida: una experiencia en la Universidad de Las Palmas de Gran Canaria.

\section{Tribuna libre}

Pilar Munuera Gómez. Departamento de Trabajo Social y Servicios Sociales. Universidad Complutense de Madrid.

Conversaciones con Mary Richmond.

Javier Domínguez Alonso. Departamento de Trabajo Social y Servicios Sociales. Universidad de Alicante.

Actuaciones preventivas en contextos comunitarios. Una oportunidad, ¿necesidad?, para el trabajo social con enfoque comunitario.

Enrique Pastor Seller. Escuela Universitaria de Trabajo Social. Universidad de Murcia.

Iniciativa social y Trabajo Social comunitario.

José Cabanes Hernández. Sociólogo. Servicios Sociales, Ayuntamiento de Villena.

Mediación social con gitanos en Villena (Alicante).....

Guillén Sádaba, E., de Lucas, F., Pérez Madera, D. y Arias Astray, A. Escuela Universitaria de Trabajo Social. Universidad Complutense de Madrid.

Servicios Sociales e Inmigración: Límites y retos para una nueva Política Social.

Francisco Javier Mira Grau. Patronato Municipal de la Vivienda de Alicante. Departamento de Trabajo Social y Servicios Sociales. Universidad de Alicante.

Territorio, hábitat y vivienda frente a la exclusión social . 


\section{Documentación}

II Plan Estatal del Voluntariado.

IV. Libros

Clarisa Ramos Feijoo. Departamento de Trabajo Social y Servicios Sociales. Universidad de Alicante.

Título: Redes Familiares en el cuidado del Anciano con Demencia. Análisis evolutivo de un estudio poblacional. Autor: Jesús Rivera Navarro. Editorial: Consejo Económico y Social de la Comunidad de Madrid, 2001.

V. Noticias

Crónica de la VI Reunión sobre Universidad y Discapacidad, organizada por el Real Patronato sobre Discapacidad. Universidad Nacional de Educación a Distancia (UNED), Madrid, 17-19 de octubre de 2001.

Conclusiones de las I Jornadas sobre Intervención Familiar en el siglo XXI, La Vila Joiosa, 25, 26 y 27 de octubre de 2001.

Crónica de las $V$ Jornadas del Seminario de Iniciativas sobre Discapacidad y Accesibilidad en la Red (SIDAR) organizadas por el real Patronato sobre Discapacidad, Mar del Plata (Argentina) 25-27 de octubre de 2001.

Celebración del Simposio Impacto de la edad en las deficiencias y discapacidades derivadas, organizado por el Real Patronato sobre Discapacidad en el Congreso Internacional Discapacidad y Envejecimiento, Oviedo, 28,29 y 30 de noviembre y 1 de diciembre de 2001 .

III Jornadas del Mediterráneo sobre Voluntariado Voluntariado y Personas Mayores. Valencia, 12, 13 y 14 de marzo de 2002. 
Congreso Europeo sobre las Personas con Discapacidad. Madrid 20-23 de marzo de 2002.

IV Congreso de Escuelas de Trabajo Social Los desafios de la violencia. Compromisos del Trabajo Social por una sociedad más justa. Se celebrará en Alicante los días 24,25 y 26 de abril de 2002.

\section{Números publicados}

Número 1 (1992)

323

Número 2 (1993)

324

Número 3 (1995)

326

Número 4 (1996)

327

Número 5 (1997)

329

Número 6 (1998)

330

Número 7 (1999)

331

Número 8 (2000)

333

Pautas generales para la presentación de artículos 


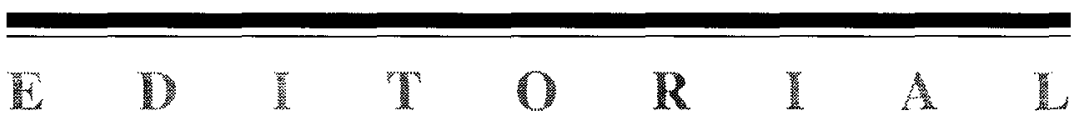





\section{M. ${ }^{a}$ ASUNCIÓN MARTÍNEZ ROMÁN.}

Directora técnica del Consejo Editorial de la Revista «Alternativas. Cuadernos de Trabajo Social».

España será la sede de la Segunda Asamblea Mundial de Naciones Unidas sobre el Envejecimiento (Madrid, 8-12 abril 2002), por lo que el Consejo Editorial de la Revista consideró oportuno este monográfico "Cuando crece la esperanza de vida", asumiendo el objetivo de la estrategia internacional de acción sobre el envejecimiento: "garantizar que las personas de todos los lugares puedan envejecer con seguridad y dignidad y continúen participando en sus sociedades como ciudadanos de pleno derecho". El propósito de la convocatoria de esta asamblea de Naciones Unidas ha sido promover la reflexión en torno a las oportunidades de desarrollo humano que puede brindarnos el aumento de la esperanza de vida y las consecuencias de toda índole que ello puede conllevar, sugiriendo posibilidades para vivir una vida activa y de calidad en torno a tres ejes de prioridades: desarrollo para un mundo que envejece, hacer llegar la salud y el bienestar a la vejez y garantizar entornos que potencien y apoyen.

"Es esencial que el envejecimiento forme parte de la corriente principal de todas las agendas. Es necesario un esfuerzo concentrado para ir hacia una aproximación amplia y equitativa de la integración política. La tarea consiste en vincular el envejecimiento a otros marcos para el desarrollo social y económico y para los derechos humanos. Si bien las politicas específicas variarán según el país y región, el envejecimiento de la población es una fuerza universal que tiene el poder de conformar el futuro tanto como lo tiene la globalización. Es esencial reconocer la capacidad de las personas mayores de contribuir a la sociedad tomando las riendas no sólo para su bien sino también para el del conjunto de la sociedad. Pensar mirando hacia delante nos exige que sumemos el potencial de la población que envejece como una base para el desarrollo futuro" 
Desde esta perspectiva, este número 9 de la Revista Alternativas. Cuadernos de Trabajo Social comienza con el artículo de $\mathrm{M}^{\mathrm{a}}$ José González y Begoña San Miguel "El envejecimiento de la población española y sus consecuencias sociales", en el que nos describen y analizan la situación tanto desde una perspectiva demográfica como en cuanto a sus consecuencias sociales, políticas y económicas. Las autoras consideran que el envejecimiento no debe ser considerado socialmente como algo negativo y que son las respuestas que la sociedad ofrece las que generan los problemas: "el envejecimiento plantea lo que podemos considerar los problemas centrales de nuestras sociedades: el problema de la igualdad, de la solidaridad y del papel que el Estado tiene que jugar en el mantenimiento de la solidaridad intergeneracional". Continuando con una perspectiva sociológica, Daniel La Parra, en "Los menores y los mayores: imágenes invertidas de las desigualdades por edad", analiza la construcción social de los mayores como imagen especular, aunque invertida, de los menores y describe cómo se ha construido históricamente la imagen de los menores y los mayores.

Y en el artículo "La protección social en el Este. El caso pola$c^{\prime \prime}$, Francisco Ródenas y Jorge Garcés analizan las reformas sociales desarrolladas desde 1999 en Polonia en los ámbitos sanitario, laboral y en el sistema de pensiones. Si bien el análisis no se centra únicamente en las personas mayores, este grupo social ocupa un lugar central en el trabajo, debido a factores como el envejecimiento de la población, el incremento de la esperanza de vida, la disminución del apoyo a las personas mayores, el aumento de las tasas de dependencia y las bajas pensiones. Con todo ello, se plantea la difícil situación de las personas mayores y, en consecuencia, los importantes desafíos a los que deben enfrentarse las políticas sociales.

Para finalizar esta sección monográfica, tenemos dos artículos relativos a experiencias prácticas, entre las que se ha optado por experiencias con personas mayores que viven de modo independiente como protagonistas. La primera de ellas se basa en un estudio de ámbito europeo auspiciado por la Unión Europea "Homeshare Europe/Alojamiento a cambio de Ayuda. Promoción de la solidaridad intergeneracional mediante la ayuda mutua", realizado por $\mathrm{M}^{\mathrm{a}} \mathrm{A}$. Martínez, A.L. Kreickemeier, J. Murcia y H. Redero. Se describen y analizan las experiencias de "alojamiento a cambio de ayuda" en Inglaterra, Alemania, Austria y España, estableciendo una comparación entre ellos y finalizando con el directorio de los programas de España. La segunda de las experiencias, "Programas universitarios para mayores. La educación para toda la vida: una experiencia en la Universidad de Las Palmas de Gran Canaria", describe la intervención socioeducativa con personas mayores desde la Universidad como una forma 
de acercar la Universidad a la sociedad. La educación a lo largo de toda la vida, plantea la exigencia de nuevos modelos de atención educativa a los mayores y la propuesta que nos presenta $\mathrm{M}^{\mathrm{a}}$ Auxiliadora González Bueno es una intervención tripartita que abarque la enseñanza, la investigación y el servicio a la colectividad, tal como ha desarrollado la Universidad de Las Palmas.

En la Sección Tribuna Libre, se pueden encontrar diversas colaboraciones de interés. Pilar Munuera "conversa" con Mary Richmond. En el ámbito comunitario, Javier Domínguez muestra la oportunidad/ necesidad del trabajo social con enfoque comunitario y Enrique Pastor analiza el creciente rol de la iniciativa social. Otros dos trabajos se preocupan de las personas de otras culturas, Pepe Cabanes comparte su experiencia en mediación social con gitanos y Encarna Guillén, F. de Lucas, D. Pérez, y A. Arias analizan la política social relativa a las personas inmigrantes, señalando tanto los límites actuales como los retos. Finaliza esta sección con "Territorio, habitat y vivienda frente a la exclusión social", de Javier Mira, en el que describe los principales problemas de los barrios desfavorecidos españoles así como las condiciones para llevar a cabo intervenciones para conseguir un hábitat social e integrador. Y, además, se puede encontrar el II Plan Estatal del Voluntariado, en la Sección de Documentos; la reseña de Libros a cargo de Clarisa Ramos y diversas Noticias sobre acontecimientos de interés que han tenido lugar recientemente o que se celebrarán en un futuro próximo.

Agradecemos todas las colaboraciones y animamos a nuestros lectores para hacernos llegar los trabajos que realizan, así como libros, documentos y noticias de interés para el próximo número: "Los desafios de la violencia. Compromisos del Trabajo Social por una sociedad más justa". IV Congreso de Escuelas de Trabajo Social. 

I. CUANDO CRECE

LA ESPERANZA

DE VIDA 



\title{
EL ENVEJECIMIENTO DE LA POBLACIÓN ESPAÑOLA Y SUS CONSECUENCIAS SOCIALES
}

\author{
Ma JOSÉ GONZÁLEZ \\ BEGOÑA SAN MIGUEL \\ Departamento de Sociología II, Psicología, Comunicación y Didáctica. \\ Universidad de Alicante.
}

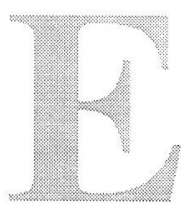

l envejecimiento de la población en los países desarrollados se ha convertido en un tema de atención permanente. Más allá de su dimensión estrictamente demográfica, el envejecimiento preocupa por sus efectos sociales, políticos y económicos. La redefinición del papel del Estado, el crecimiento del gasto social y el descenso de la población activa parecen ser sus consecuencias directas y las que convierten el envejecimiento, en las argumentaciones más frecuentes, en un grave problema social. El artículo se fija, para el caso español, en los cambios que han afectado a la definición social de la vejez en las últimas décadas: demográficos, familiares, culturales, económicos y laborales. La evaluación de estos cambios permite discutir la visión del envejecimiento como problema, para replantearlo en el terreno de la solidaridad social.

\section{PRESENTACIÓN}

El envejecimiento de la población española es un proceso sobradamente conocido y analizado, sobre todo en las dos últimas décadas, cuando el fenómeno se ha intensificado al tiempo que sus consecuencias económicas y sociales se hacían más patentes. Estrictamente, el envejecimiento de la población es fruto de dos procesos distintos: el descenso de la natalidad, por una parte, que hace disminuir el número de efectivos jóvenes, y la prolongación de la esperanza de vida, el aumento de la longevidad, por otro, que induce un crecimiento de la población de más edad. Aunque ambos fenómenos son relativamente independientes, tienen el mismo efecto sobre la estructura por edad: envejecer a la población.

Pero no se trata sólo de que haya más viejos que antes. Lo más 
importante, la idea que debe preceder a cualquier reflexión sobre esta cuestión, es que ahora ese tiempo añadido, esa vida prolongada, se vive con mejor salud física y sobre todo mental. Los pocos viejos que antes resistían se hallaban sujetos a largas enfermedades y sin posibilidades de desarrollar una vida satisfactoria. No hay que olvidar que el envejecimiento de la población, merced al aumento de la esperanza de vida, es sólo una buena noticia, que parece traducir una mejora de la calidad de vida y de las prestaciones sanitarias. Junto a la prolongación de la vida, hay que hablar, además, de una mejora sustancial del bienestar, de una ampliación del ocio y de las posibilidades vitales.

Sin embargo, la vejez se percibe problemáticamente. El envejecimiento es con frecuencia calificado de "problema social", y socialmente parece extenderse el miedo al envejecimiento y el desarrollo de toda una serie de conductas que tratan no sólo de retrasarlo sino de negarlo. Dos parecen ser los motivos que explican esta actitud. Por una parte, como justamente ha señalado Amando de Miguel (2001), las personas que envejecen no perciben que el cambio ha sido una conquista frente a la muerte temprana de antaño, y que el aumento de la longevidad deriva de la mejora de las condiciones de vida respecto al pasado, sino que perciben su propio envejecimiento como una experiencia de deterioro físico y mental, un proceso de decadencia, en una sociedad, por otra parte, que se organiza en torno a los valores juveniles. Es esa experiencia compartida por quienes envejecen y ven envejecer la que impide ver el envejecimiento en sus dimensiones sociales.

Por otra parte, el envejecimiento de la población es considerado un problema social en tanto que plantea la necesidad de respuestas sociales: exige un aumento del gasto en pensiones, hace crecer inevitablemente el gasto sanitario y genera la demanda de nuevos servicios de atención, en la medida en que las mujeres están cada vez menos disponibles para el cuidado de las personas. En resumen, plantea el reto de mantener niveles de protección social para una población que crece numéricamente. Y ello al mismo tiempo que el porcentaje de población activa ha tendido a disminuir -por distintos motivos, y no exclusivamente por el envejecimiento-; $y$, por lo tanto, una proporción cada vez menor de la población tiene que subvenir a las necesidades de grupos dependientes más numerosos. Es decir, el envejecimiento plantea los que podemos considerar los problemas centrales de nuestras sociedades: el problema de la igualdad, de la solidaridad y del papel que el Estado tiene que jugar en el mantenimiento de la solidaridad intergeneracional.

Ahora bien, es necesario establecer una precisión preliminar a este respecto: el envejecimiento, el aumento del número de personas mayo- 
res tanto en términos absolutos como relativos, es en principio un mero fenómeno demográfico que, como los avatares que sufren la natalidad o la mortalidad, no tiene en sí mismo consecuencias sociales y económicas. Es en el orden social donde el fenómeno se produce, las respuestas sociales que se organizan frente a los viejos o los jóvenes y su tratamiento donde se generan las consecuencias que aparecen normalmente como problemas.

En cualquier caso, el cambio no ha sido exclusivamente el aumento de la longevidad. Los ancianos, si es que todos los mayores de 65 años pueden todavía ser etiquetados así, no sólo viven más tiempo, sino que han transformado su forma de vivir y su propia identidad respecto a las generaciones anteriores. La salud, las formas de vida, la consideración de la actividad, los hábitos de ocio, los modelos de familias y de hogares, las relaciones sociales, las formas de consumo, todo ha cambiado en apenas unas décadas. Frente a una visión del envejecimiento como amenaza al bienestar social, como una carga añadida sobre los hombros de los activos, ha ido ganando crédito la noción del derecho a vivir una vida plena más allá del periodo activo, no como una mera antesala de la muerte, sino como un tiempo conquistado a la muerte para ser disfrutado. Si el ansia de realización personal y la aspiración a la felicidad por encima de cualquier noción de deber forman parte de la condición posmoderna (Lipovetsky, 1994), no cabe duda que también los viejos se han apresurado a reivindicar los nuevos valores.

No pretendemos hacer un análisis exhaustivo de todos estos cambios, ni dar respuesta a todos los problemas que han planteado, tan sólo una exposición ordenada de algunos datos relevantes de la cuestión. Para ello, hemos utilizado distintas fuentes de información, tanto estadísticas como de encuestas. Lamentablemente, no siempre los datos están suficientemente actualizados. La disposición de la información del censo 2001, en fase de realización en este momento, permitirá sin duda en un futuro próximo enfrentar un análisis más detallado y revisar el cumplimiento de las proyecciones realizadas hasta el momento.

\section{LA PERSPECTIVA DEMOGRÁFICA}

Antes de adentrarnos en esta perspectiva, parece necesario realizar un par de precisiones sobre el significado y el papel que juegan los factores demográficos en la determinación de la realidad social. Para el análisis sociológico, los grupos de edad no son meramente agregados de personas determinados demográficamente. Más allá, la juventud, como la madurez o la ancianidad, son realidades definidas socialmente. Es el papel de estos grupos y el lugar que ocupan en las relacio- 
nes sociales, junto a las elaboraciones culturales generadas en torno a ellos, los que dotan de contenido e identifican a estos grupos. Se trata de grupos construidos socialmente, más allá de la edad que parece definirlos. Es por ello que su consideración en cada sociedad y en cada periodo histórico ha sido muy disímil. Como acertadamente resume $\mathrm{M}^{\mathrm{a}}$ Teresa Bazo (1992), el envejecimiento de los individuos es un proceso biológico e inevitable, pero la vejez y los contenidos adscritos se definen socialmente.

Ahora bien, no cabe negar que la demografía es un factor relativamente autónomo que ayuda a esa construcción social, pues el número de efectivos, su peso relativo en la estructura así como su evolución plantean problemas y reclaman respuestas sociales que van a configurar la propia construcción social. Así, hay que aceptar que "La demografía opera como las termitas, lenta, tozuda y oscuramente, pero con un poder destructivo equiparable al de la dinamita" (Fernández Cordón y Leguina, 2001). Sin embargo, la consideración exclusiva de las variables demográficas puede conducir a un análisis catastrofista, como el que frecuentemente se realiza sobre el envejecimiento de la población, sin tener en cuenta que los efectos de estos procesos sobre la realidad social dependen de otras variables sociales, económicas y políticas, sobre las que seguramente resulta más sencillo intervenir. La demografía, estrictamente, no crea los problemas, plantea demandas sociales que pueden o no ser atendidas. Sin embargo, su aparente ineluctabilidad la convierte en una apropiada justificación para la elusión de cualquier responsabilidad social o política.

El envejecimiento de la población española no es una novedad de las últimas décadas. Como corresponde a un país que realizó tardíamente su proceso de transición demográfica, el siglo XX se ha caracterizado por un lento y sostenido envejecimiento de la población, sobre la base del descenso continuado de la fecundidad, salvado el breve periodo del baby-boom, y la prolongación de la esperanza de vida, resultado del descenso de la tasa de mortalidad a todas las edades. Estos procesos son consecuencia de factores diversos que abarcan desde los avances científicos y técnicos, nuevos fármacos y nuevas técnicas terapéuticas, hasta la universalización del sistema sanitario y la mejora general de la calidad de vida para la población.

Así, el número de personas mayores de 65 años ha ido creciendo a un ritmo muy superior al crecimiento de la población española, haciendo que la proporción que representan los mayores de 65 años sobre el total de la población haya ido incrementándose a lo largo de todo el siglo, pero sobre todo a partir de 1970. Aunque con retraso, España se suma a un proceso de envejecimiento acelerado de su población que ya están conociendo desde antes el resto de los países desarrollados. 
TABLA 1: Evolución de la población española de 1990-2031

\begin{tabular}{|c|c|c|c|}
\hline Años & Total miles & $65 \mathrm{y}$ + total miles & $\% 65 \mathrm{y}+$ \\
\hline 1990 & 8.618 & 968 & 5,2 \\
\hline 1910 & 19.996 & 1.106 & 5,5 \\
\hline 1920 & 21.390 & 1.217 & 5,7 \\
\hline 1930 & 23.678 & 1.441 & 6,1 \\
\hline 1940 & 25.878 & 1.690 & 6,5 \\
\hline 1950 & 27.977 & 2.023 & 7,2 \\
\hline 1960 & 30.529 & 2.505 & 8,2 \\
\hline 1970 & 34.041 & 3.291 & 9,7 \\
\hline 1981 & 37.683 & 4.237 & 11,2 \\
\hline 1991 & 38.872 & 5.352 & 13,8 \\
\hline 2001 & 40.802 & 6.176 & 15,1 \\
\hline 2011 & 41.184 & 6.277 & 15,2 \\
\hline 2021 & 40.667 & 6.666 & 16,4 \\
\hline 2031 & 39.788 & 7.787 & 19,6 \\
\hline
\end{tabular}

FUENTE: INE: Anuario estadístico, varios años. Proyección de la población española, para el periodo de 1980-2010.

Aquí la intensidad de los cambios demográficos durante las décadas de los 70 y 80 es tal que, al finalizar el siglo, España ha alcanzado niveles de envejecimiento muy similares a los de los países de su entorno.

Este envejecimiento tiene dos rasgos característicos. Por una parte, se ha producido un proceso de sobreenvejecimiento, el envejecimiento del envejecimiento, ya que son precisamente los grupos de edades más elevadas, a partir de 80 años, los que crecen más rápidamente y ganan mayor peso relativo en la estructura por edades. Además, a medida que aumenta la esperanza de vida, este sobreenvejecimiento se hace más notorio. Por otra parte, es posible hablar de un proceso de feminización de la vejez. En España hay 143 mujeres mayores de 65 años por cada 100 hombres de esa misma edad, que se eleva hasta 164 por cada 100 en los grupos entre 75 y 84 años, y 224 por 100 en los mayores de 85 años. Así, el aumento de la longevidad favorece especialmente a las mujeres: cuanto más crece la esperanza de vida para la población, más se alarga la vida de las mujeres con relación a la de los hombres. El debate sobre las causas de la mayor longevidad de las mujeres no está cerrado. Se trate de factores biológicos o se trate de una menor exposición a los riesgos de enfermedad y muerte, determinada por formas de vida y roles sociales distintos, hemos de conformarnos por el momento con señalar el fenómeno de la feminización de la ancianidad. Sólo el futuro, en la medida en que aproxime las formas 
de vida y de actividad laboral, permitirá dilucidar sus causas (De Miguel, 1998).

Como se ha dicho ya al inicio, el proceso de envejecimiento es el resultado de dos factores que han actuado conjuntamente. En primer lugar, y éste es el que ha tenido más influencia, el descenso de la natalidad. Un descenso que en España tiene un carácter sostenido a lo largo del siglo, sólo interrumpido por el baby-boom que se localiza en torno a la década de los 60 , y que genera que el número de nacidos siga creciendo hasta el año 74, aún después de haberse iniciado el descenso de la tasa de fecundidad. A partir de ese momento, la fecundidad va a sufrir una caída acelerada. Así, el índice sintético de fecundidad, que era en España, en esa fecha, de 2.8 hijos por mujer, descendió hasta 2.2 en 1980. A partir de ahí ha caído hasta el 1.15 para 1998 , por debajo del índice necesario para la mera reproducción (2.1 hijos por mujer).

TABLA 2: Número medio de hijos por mujer y crecimiento vegetativo por 1000 habitantes de los países de la Unión Europea (1998)

\begin{tabular}{|l|c|c|}
\hline & $N^{0}$ medio de hijos por mujer & Crecimiento vegetativo \\
\hline UE- 15 & 1,45 & 0,8 \\
\hline Alemania & 1,34 & $-0,9$ \\
\hline Austria & 1,34 & 0,4 \\
\hline Bélgica & 1,53 & 1,0 \\
\hline Dinamarca & 1,72 & 1,4 \\
\hline España & 1,15 & 0,1 \\
\hline Finlandia & 1,70 & 1,5 \\
\hline Francia & 1,75 & 3,4 \\
\hline Grecia & 1,29 & 0,0 \\
\hline Irlanda & 1,63 & 6,0 \\
\hline Italia & 1,93 & $-0,9$ \\
\hline Luxemburgo & 1,19 & 3,5 \\
\hline Países Bajos & 1,68 & 3,9 \\
\hline Portugal & 1,46 & 0,7 \\
\hline Reino Unido & 1,72 & 1,5 \\
\hline Suecia & 1,50 & $-0,5$ \\
\hline
\end{tabular}

FUENTE: EUROSTAT 1997.

En los países de nuestro entorno, por el contrario, el baby-boom se produjo más tempranamente y el descenso posterior de la fecundidad se produjo lentamente hasta estancarse en bajos niveles. España, partiendo de niveles de fecundidad más elevados, consecuencia de su re- 
traso demográfico, ha conseguido, en dos décadas, el raro privilegio de ostentar la tasa de fecundidad más baja de Europa, que es como decir la más baja del mundo.

En estas condiciones de baja fecundidad, y a pesar del persistente descenso de la mortalidad a todas las edades, el crecimiento o el mero sostenimiento de la población está en entredicho, dado que los niveles de crecimiento vegetativo han empezado ya a ser negativos en muchos países de la Unión Europea y muy bajos en el resto. En España, debido al ya aludido retraso demográfico, el efecto de la débil tasa de fecundidad sobre el crecimiento vegetativo se hará más patente a medida que las cohortes cada vez más estrechas de mujeres alcancen la edad reproductiva. No es extraño entonces que los demógrafos, frente a los temores de políticos y ciudadanos, hayan empezado a invocar la inmigración como la única salida al estancamiento, un recurso imprescindible para sostener el crecimiento, dado que además aporta población joven, apta para engrosar la población activa y dispuesta a tener un número de hijos más elevado.

En segundo lugar, el envejecimiento de la población es resultado del crecimiento de la esperanza de vida. En España, la esperanza de vida ha crecido desde los 34 años de 1900 hasta los casi 80 del 2000. Y ello, porque se ha producido un descenso continuado de las tasas de mortalidad a todas las edades que ha alargado enormemente la vida media de los españoles. Si bien es cierto que, en el último periodo, la tasa de mortalidad general se está incrementando por efecto del propio proceso de envejecimiento -los ancianos sufren tasas de mortalidad más elevadas-, la esperanza estadística de vida se prolonga enormemente como resultado del bienestar creciente de las sociedades. A pesar de su retraso demográfico y de haber soportado hasta hace un par de décadas tasas de mortalidad más altas que los países europeos, España tiene en la actualidad una esperanza de vida muy elevada. Como se ha visto, este aumento de la longevidad ha favorecido sobre todo a las mujeres. Según las últimas estimaciones, la longevidad de las mujeres españolas es ya, en 2001, la más elevada de todos los países de la Unión Europea.

En espera de la revisión de las proyecciones que se realicen a partir del censo 2001, las que disponemos en este momento permiten augurar que, en las próximas décadas, mientras la población se estanca, con la única esperanza de alcanzar crecimientos positivos puesta en la inmigración, la población de más edad seguirá aumentando tanto en número de efectivos como en peso relativo dentro del conjunto de la población. De la misma manera, se hará notar el efecto de sobreenvejecimiento en el interior de estos grupos. 
TABLA 3: Esperanza de vida al nacer en los países de la Unión Europea por sexo para 1997

\begin{tabular}{|l|c|c|c|}
\hline & Hombres & Mujeres & Diferencia \\
\hline Alemania & 74,0 & 80,3 & 6,3 \\
\hline Bélgica & 74,1 & 80,6 & 6,5 \\
\hline Dinamarca & 73,6 & 78,4 & 4,8 \\
\hline España & 74,9 & 81,9 & 7,0 \\
\hline Francia & 74,6 & 82,2 & 7,6 \\
\hline Grecia & 75,6 & 80,8 & 5,2 \\
\hline Irlanda & 73,4 & 78,6 & 5,2 \\
\hline Italia & 74,9 & 81,3 & 6,4 \\
\hline Luxemburgo & 74,1 & 79,8 & 5,7 \\
\hline Holanda & 75,2 & 80,5 & 5,3 \\
\hline Portugal & 71,6 & 78,8 & 7,2 \\
\hline Reino Unido & 74,7 & 79,6 & 4,9 \\
\hline Austria & 74,3 & 80,6 & 6,3 \\
\hline Finlandia & 73,4 & 80,5 & 7,1 \\
\hline Suecia & 76,7 & 81,8 & 5,1 \\
\hline
\end{tabular}

FUENTE: EUROSTAT 1997.

TABLA 4: Proyecciones de la esperanza de vida en diferentes países de la UE (1900-2025)

\begin{tabular}{|c|c|c|c|c|c|c|c|c|}
\hline & \multicolumn{2}{|c|}{ España } & \multicolumn{2}{c|}{ Suecia } & \multicolumn{2}{c|}{ Inglaterra Gales } & \multicolumn{2}{c|}{ Francia } \\
\hline Años & $\mathrm{V}$ & $\mathrm{M}$ & $\mathrm{V}$ & $\mathrm{M}$ & $\mathrm{V}$ & $\mathrm{M}$ & $\mathrm{V}$ & $\mathrm{M}$ \\
\hline 1900 & 33.8 & 35.1 & 52.7 & 55.2 & 45.0 & 49.4 & 43.4 & 47.0 \\
\hline 1950 & 59.5 & 64.0 & 69.1 & 72.3 & 66.5 & 71.2 & 62.8 & 68.6 \\
\hline 1975 & 70.3 & 76.2 & 72.9 & 78.4 & 70.1 & 76.2 & 69.3 & 77.1 \\
\hline 1985 & 73.3 & 79.7 & 73.8 & 79.7 & 71.9 & 77.5 & 71.3 & 79.4 \\
\hline 2001 & 76.2 & 82.4 & 76.0 & 81.7 & 74.8 & 80.4 & 74.3 & 81.6 \\
2005 & & & & & & & & \\
\hline 2021 & 77.8 & 83.9 & 79.0 & 83.5 & 76.9 & 82.3 & 76.6 & 83.4 \\
2025 & & & & & & & & \\
\hline
\end{tabular}

FUENTE: $M^{\circ}$ de Sanidad y Consumo. Proyecciones de la población española, 1996. D.G. de Salud Pública.

Las previsiones apuntan, inevitablemente, a un mayor envejecimiento de la población. De un lado, la fecundidad no ha iniciado todavía su esperada recuperación; y, cuando se produzca, este efecto será débil, fácilmente compensado por otros que generan el envejecimiento. Por otra parte, y aun contando con los límites biológicos a esta expansión de la longevidad, cabe esperar que ésta siga creciendo, mucho más si 
pensamos que nos hallamos en el inicio de una auténtica revolución de los conocimientos biomédicos y de sus aplicaciones al tratamiento de muchas enfermedades. Además, la llegada a la edad anciana de las abultadas cohortes del baby-boom, aquellas que nacieron desde mitad de los 50 hasta la mitad de los 70 , inducirá necesariamente un proceso de envejecimiento de la población que no podrá ser compensado por el crecimiento de la natalidad; pues, ni aun en la hipótesis más optimista, el índice sintético de fecundidad podría recuperarse más allá de 2.1 hijos por mujer, necesario para mantener la tasa de reemplazo y, desde luego, para compensar las fuertes tendencias al envejecimiento.

TABLA 5: Proyecciones de población del 2001 al 2020

\begin{tabular}{|l|c|c|c|c|c|}
\hline & 2001 & 2005 & 2010 & 2015 & 2020 \\
\hline 65-69 años & $2.015,966$ & $1.791,620$ & $1.900,484$ & $2.124,237$ & $2.201,833$ \\
\hline $70-74$ años & $1.795,547$ & $1.849,276$ & $1.630,628$ & $1.735,156$ & $1.942,140$ \\
\hline 75 y más & $2.922,089$ & $3.257,859$ & $3.609,417$ & $3.635,952$ & $3.701,154$ \\
\hline
\end{tabular}

FUENTE: Boletín Mensual de Estadística. INE (I de julio de 200I).

La demografía, en conclusión, nos avanza un modelo de sociedades progresivamente envejecidas por lo menos hasta la mitad de este siglo, y seguramente más allá. Sin duda, la prolongación de la vida es la mayor de las conquistas que nuestras sociedades han producido, frente a ese irrefrenable impulso autodestructivo que también parece caracterizarnos. Sólo queda que estas mismas sociedades sepan responder a los retos que sus propios logros les están planteando.

\section{HOGARES, FAMILIAS Y RELACIONES}

Es una idea comúnmente aceptada que el desarrollo de los sistemas de bienestar ha liberado a la familia de sus responsabilidades tradicionales en el cuidado de sus miembros, especialmente de los más dependientes, como los enfermos o los ancianos, que han pasado a ser atendidos por las instituciones públicas y, en menor medida, privadas. Cabe, sin embargo, poner en entredicho esta idea y considerarla como una generalización abusiva de una tendencia que parecía, en un momento del pasado, señalar el itinerario de los cambios sociales.

La que se ha dado en llamar "crisis del estado de bienestar" ha obligado a revisar más detenidamente esta noción en muchos sentidos: ni la tendencia se ha desarrollado por igual en todas las sociedades, atendiendo a la diversidad de los modelos de familia y de Estado de Bienestar; ni la familia ha perdido esencialmente su competencia en el 
cumplimiento de sus funciones de solidaridad, antes bien las ha ampliado en ciertos campos en estos últimos años; ni el Estado ha respondido a la generación de nuevas necesidades sociales surgidas de nuevas realidades, como la incorporación masiva de las mujeres al mercado de trabajo, el retraso de la incorporación de los más jóvenes o el aumento de la longevidad.

La existencia de instituciones no quiebra el principio de solidaridad familiar, sino que ofrece un nuevo marco para su desarrollo, simplemente descarga a las familias de algunas tareas y obligaciones que antes desempeñaban, sin que desaparezca la responsabilidad sobre sus miembros (Alberdi, 1999). La familia, y más notoriamente en los países del Sur de Europa, se ha mantenido como el elemento clave del sistema de bienestar, ocupándose de todos sus miembros y, especialmente, de aquellos en situación de mayor vulnerabilidad. Por otra parte, el protagonismo de la familia en el bienestar se ha demostrado relativamente autónomo de la evolución del gasto social. Y ello, porque su compromiso con la defensa de sus miembros no se rige por criterios económicos, sino por un sentido de la responsabilidad fundado en los afectos que escapa a la lógica del cálculo mercantil, pero que asigna recursos afectivos y materiales esenciales para el bienestar (Pérez Díaz, Álvarez Miranda y Chuliá, 1998).

Dos tendencias se han manifestado en la composición de los hogares en estas últimas décadas: los jóvenes continúan viviendo por más tiempo en los hogares de origen, con cargo a sus presupuestos, al tiempo que los ancianos se mantienen independientes durante más tiempo. La permanencia de los ancianos en sus propios hogares no es tanto el signo de su abandono por parte de la familia como la prueba de que la longevidad ha ido acompañada de una mejora de la salud y la calidad de vida. Son estos avances los que permiten a un número creciente de ancianos, y durante un periodo progresivamente más largo, mantener su independencia. Cabría decir que uno de los rasgos más destacados de las familias españolas en este fin de siglo es que con los viejos se coexiste más y se convive menos. Ahora bien, en las situaciones de necesidad, cuando sus capacidades físicas se deterioran o no tienen recursos económicos, la familia sigue mayoritariamente haciéndose cargo del cuidado de los ancianos.

El proceso de envejecimiento ha tenido, por ello, consecuencias sobre la configuración de la estructura y las características de los nuevos hogares. Efectivamente, el envejecimiento de la población explica, parcialmente, el descenso del tamaño medio y el consiguiente crecimiento del número de hogares que se ha producido en los últimos años. La permanencia de un número creciente de ancianos en sus propios hoga- 
res ha generado el crecimiento del número de hogares bipersonales y sobre todo unipersonales, integrados mayoritariamente por mujeres, dada la feminización del envejecimiento a la que se ha aludido.

En cualquier caso, y aunque estos fenómenos se han producido a ritmo fuerte en España en las dos últimas décadas, el porcentaje de los hogares unipersonales sigue siendo aquí muy pequeño: $13.4 \%(9.6 \%$ de mujeres y sólo $3.8 \%$ de hombres). A pesar de su rápido incremento, España se aleja mucho del $44.8 \%$ de hogares unipersonales de Dinamarca, el 33.9 de Alemania, o el 32.3 de Holanda. Además del envejecimiento, otros fenómenos como el descenso de la nupcialidad y sobre todo el aumento del divorcio alimentan la formación de hogares unipersonales, de ahí su fuerte incremento. Sin embargo, en España, el retraso sostenido de la emancipación actúa como contrapeso a estas tendencias, de ahí su menor frecuencia. De hecho, sólo el $6.6 \%$ de los hogares unipersonales corresponden a menores de 30 años, frente al 24.8 de Holanda o el 22.4 de Dinamarca.

Ahora bien, entre los hogares unipersonales, el 58,5\% son hogares de personas mayores de 65 años. Respecto al total de hogares españoles, los unipersonales de mayores de 65 años representan un 7,8\%. Si consideramos ahora, a partir de datos de encuesta, la distribución de las personas mayores de 65 años según el tipo de hogar donde residen, la conclusión nos aleja mucho de la idea extendida según la cual la soledad es el necesario correlato del envejecimiento.

En nuestro país, sólo el 14\% de las personas mayores de 65 años viven solas. Además, en su mayoría se trata de mujeres. Entre los hogares de ancianos, la situación más frecuente es el hogar compartido por la pareja, donde reside el $41 \%$ de los mayores. Hay, por otra parte, un $27 \%$ que vive en su casa pero con pareja e hijos (14\%), o con hijos (13\%). Sin duda, el fenómeno ya aludido del retraso de la emancipación induce este hecho. La imagen del anciano que se va a vivir con los hijos para recibir atención y cuidados ha sido sustituida por los hijos jóvenes no emancipados que permanecen en el hogar de origen con padres mayores de 65 años. De hecho, entre los mayores de 65 años, sólo una minoría vive en el hogar de los hijos: el $2 \%$ con su pareja en casa de los hijos y $8 \%$ con hijos en casa de hijos.

Sin embargo, la independencia residencial no es igual a todas las edades. La mayoría de los ancianos que vive en casa de sus hijos lo hace a partir de los 80 años, una edad que parece representar una frontera significativa de la independencia residencial. Si desde los 70 años aumenta suavemente el porcentaje de individuos que viven solos, esta proporción empieza a disminuir a partir de los 80 años. Las pirámides que representan los hogares en los que viven los ancianos de más 
TABLA 6: Lugar de residencia de las personas mayores de 65 años

\begin{tabular}{|l|r|}
\hline Solo & $14 \%$ \\
\hline Con su cónyuge o pareja & $41 \%$ \\
\hline Con su pareja e hijos en casa del entrevistado & $14 \%$ \\
\hline Con su pareja e hijos en casa de sus hijos & $2 \%$ \\
\hline Con su pareja y otros familiares & $1 \%$ \\
\hline Con hijos en casa del entrevistado & $13 \%$ \\
\hline Con hijos en casa de hijos & $8 \%$ \\
\hline Con otros familiares en casa del entrevistado & $4 \%$ \\
\hline Con otros familiares en casa de familiares & $2 \%$ \\
\hline Con empleado/a de hogar & $1 \%$ \\
\hline Otras respuestas & $1 \%$ \\
\hline (N) & $(2430)$ \\
\hline
\end{tabular}

FUENTE: Estudio CIS -Instituto de Migraciones y Servicios Sociales: $2279,1998$.

de 80 años nos muestran la elevada frecuencia en ellos de adultos de 45 a 65 años.

La soledad es, sin embargo, una de las cuestiones que más preocupa a los ancianos. Todas las encuestas realizadas en las últimas décadas y en distintos países muestran que, después de la salud, el temor a la soledad es la mayor preocupación de los ancianos.

TABLA 7: En este momento ¿qué es lo más importante para usted?

\begin{tabular}{|l|r|}
\hline La salud & $86 \%$ \\
\hline El no sentirse solo/a & $6 \%$ \\
\hline El amor & $3 \%$ \\
\hline El dinero & $1 \%$ \\
\hline Otras respuestas & $2 \%$ \\
\hline NS/NC & $1 \%$ \\
\hline (N) & $(2198)$ \\
\hline
\end{tabular}

FUENTE: Estudio CIS-Instituto de Migraciones y Servicios Sociales: 2279, 1998.

Siempre según la misma encuesta del CIS, entre los que viven solos, nadie parece haber optado voluntariamente por la soledad: el $36 \%$ admite que se ha adaptado a esta situación obligado por las circunstancias, pero la mayoría -el 59\% - declara que preferiría vivir con hijos o familiares. Sin embargo, el grado de satisfacción entre estas personas que viven solas es elevado. Incluso si consideramos que las personas que viven solas se han visto forzadas a esa opción, el $56 \%$ se declara 
satisfecho o muy satisfecho de su situación, al $15 \%$ le es indiferente, el $23 \%$ se declara insatisfecho y sólo el $6 \%$ muy insatisfecho.

La soledad, que parece ser un destino asumido al tiempo que el temor más extendido entre los ancianos, no constituye sin embargo un problema real para la mayoría de los mayores de 65 años en nuestro país: sólo el $12 \%$ se siente bastante o muy solo según los datos de la misma encuesta. Por otra parte, incluso entre los que declaran sentirse solos, el sentimiento de soledad es de carácter transitorio, son muy pocos los que se sienten permanentemente solos, la mayoría de ellos localizan exclusivamente el sentimiento de soledad en determinados momentos, básicamente, por la noche o cuando están enfermos, es decir, en aquellas situaciones de mayor indefensión.

En cualquier caso, y como bien recuerda Algado (1997), a partir del análisis de distintas encuestas, el sentimiento de soledad no es una mera respuesta a una situación objetiva, sino que es el resultado de un conjunto diverso de características y condiciones de vida de la población. Así, la variable "sentimiento de soledad" aparece fuertemente correlacionada con la autopercepción de la salud. Dicha relación actúa independientemente del sexo, la edad y el estado civil, pero conjuntamente con la clase social y el nivel de estudios. Otros sentimientos negativos ligados al envejecimiento, además de la soledad, y que guardan relación con el estado subjetivo de la salud son la sensación de inutilidad, el desencanto y el pesimismo. Este último sentimiento, es, para todos los autores, el que de forma más estrecha guarda relación con la salud.

Que, a pesar del temor manifiesto, el sentimiento de soledad sea compartido por un número relativamente reducido de ancianos tiene que ver, por otra parte, con la frecuencia e intensidad de la vida social de un número importante de ellos, tal y como se han encargado de establecer las encuestas.

Como se observa en la tabla 8 , tomando la última semana como

TABLA 8: Durante la última semana, ¿cuántas veces pasó algún tiempo o fue a visitar a alguna persona con la que no vive?

\begin{tabular}{|l|r|}
\hline Todos los días & $45 \%$ \\
\hline Entre dos y seis veces & $26 \%$ \\
\hline Una vez & $14 \%$ \\
\hline Ninguna vez & $15 \%$ \\
\hline $\mathrm{NC}$ & $1 \%$ \\
\hline$(\mathrm{N})$ & $(2189)$ \\
\hline
\end{tabular}

FUENTE: Estudio CIS-Instituto de Migraciones y Servicios Sociales: 2279, 1998. 
TABLA 9: Frecuencia de contactos con familiares y amigos

\begin{tabular}{|l|c|c|c|c|c|c|}
\hline & $\begin{array}{c}\mathrm{N}^{0} \text { personas } \\
\text { (miles) }\end{array}$ & $\begin{array}{c}\text { Mayoría } \\
\text { de días }\end{array}$ & $\begin{array}{c}1 \text { ó 2 veces } \\
\text { por semana }\end{array}$ & $\begin{array}{c}\text { I ó } 2 \text { veces } \\
\text { al mes }\end{array}$ & $\begin{array}{c}\text { menos } 1 \text { vez } \\
\text { mes o nunca }\end{array}$ & No consta \\
\hline Total Varones & $15.189,5$ & 69,6 & 21,1 & 5,9 & 2,0 & 1,4 \\
\hline Varones de 65 $y+$ & 2627,4 & 70,0 & 19,7 & 7,6 & 2,4 & $0,3^{*}$ \\
\hline Total Mujeres & $16,420,0$ & 68,8 & 21,7 & 6,2 & 2,4 & 0,9 \\
\hline Mujeres de 65 y+ & $3.654,7$ & 66,4 & 20,8 & 7,7 & 4,3 & $0,8^{*}$ \\
\hline
\end{tabular}

FUENTE: Panel de Hogares de la Unión Europea, 1996.

* El dato corresponde a celdas con menos de 20 observaciones muestrales.

referencia, la frecuencia de contactos fuera del círculo de la convivencia es muy alta. Tan sólo un $15 \%$ de los entrevistados no mantuvo relaciones fuera de su hogar durante esa semana. Además, según los datos de la tabla 9, si se compara la frecuencia de las relaciones sociales de las personas mayores con las del resto de la población, se observa que, prácticamente, coinciden los resultados.

En congruencia con esta suficiente intensidad de relaciones sociales entre la mayoría de los ancianos, el nivel de satisfacción con dichas relaciones también es muy alto.

TABLA 10: ¿Hasta qué punto está satisfecho con sus relaciones sociales (con su familia, amigos, vecinos)?

\begin{tabular}{|l|r|}
\hline Muy satisfecho & $36 \%$ \\
\hline Bastante satisfecho & $54 \%$ \\
\hline Regular & $8 \%$ \\
\hline Poco o nada satisfecho & $2 \%$ \\
\hline$(\mathrm{N})$ & $(2197)$ \\
\hline
\end{tabular}

FUENTE: Estudio CIS-Instituto de Migraciones y Servicios Sociales: 2279, 1998.

Como concluye Inés Alberdi (1999), más allá de las ambigüedades de las percepciones y las opiniones, las encuestas de opinión realizadas en los últimos años permiten caracterizar la situación de las personas mayores a través de tres rasgos esenciales: 1) la mayoría de los individuos desea vivir de un modo independiente el mayor tiempo posible; 2) la mayoría de la población desea que sean sus familiares, a ser posible sus hijos, los que le atiendan cuando necesiten ayuda en su vejez; 3) la mayoría de los ancianos dependientes reciben ayuda de su entorno familiar, muy frecuentemente pasando a vivir en el hogar de sus hijos. El envejecimiento de la población no transformará básicamente este modelo, sino que tenderá a acentuarlo, aumentando el número de hogares de ancianos y prolongando la autonomía residencial a periodos más largos. De hecho, cuando la población no anciana es requerida 
TABLA 11: ¿En el futuro cuando llegue

a la edad de jubilación, ¿dónde le gustaría vivir?

\begin{tabular}{|l|r|}
\hline En su casa de siempre & $75 \%$ \\
\hline Con sus hijos/as u otros familiares & $12 \%$ \\
\hline Regresar al lugar de origen familiar & $3 \%$ \\
\hline En una residencia & $3 \%$ \\
\hline $\begin{array}{l}\text { En una urbanización o ciudad residencial sólo para personas mayores } \\
\text { en las que existan programas de ocio y recreativos }\end{array}$ & $4 \%$ \\
\hline NS/NC & $3 \%$ \\
\hline (N) & $(2491)$ \\
\hline
\end{tabular}

FUENTE: Estudio CIS, 2.291, junio de 1998 .

* Esta pregunta es de un cuestionario del CIS pero la contestan todos, de 18 en adelante.

sobre sus preferencias para el futuro, la opción mayoritaria es la independencia.

El problema más acuciante, como la misma Alberdi (1999) se encarga de señalar, es que la ayuda familiar que reciben los ancianos actualmente, y que nadie parece desear que disminuya en el futuro, a tenor de las encuestas, recae básicamente sobre las mujeres de mediana edad, que ven por ello reducirse enormemente sus posibilidades de bienestar y de vida activa. El crecimiento de las tasas de actividad para las mujeres españolas en estas dos últimas décadas está dificultando, y lo hará más en el futuro, la continuidad de estos cuidados. Es indudable que ello exige de las familias transformaciones profundas que afecten a la redefinición de los roles y al reparto del trabajo en su interior, pero también a políticas sociales imaginativas que faciliten la adaptación a las nuevas condiciones, sobre todo en el caso de los ancianos dependientes.

\section{BIENESTAR Y PROTECCIÓN SOCIAL}

Como es sabido, España es, con la excepción de Irlanda, el país de la Unión Europea que dedica un porcentaje menor de su riqueza a la protección social: sólo el $21.6 \%$, frente al $27.7 \%$ medio de la Unión Europea. Incluso un país más pobre y con tardío desarrollo del sistema de bienestar como Portugal ha superado a España en su nivel de gasto social. Por otra parte, si bien España desde los años setenta realizó un importante esfuerzo por crear un sistema de protección social, haciendo evolucionar el gasto hasta niveles cercanos a los de los países de su entorno, en los últimos años el gasto social no se ha incrementado al mismo ritmo que su PIB. Como conclusión, precisamente uno de los periodos de más crecimiento económico de nuestra historia reciente ha 
TABLA 12: Gastos totales de protección social en los países de la Unión Europea

\begin{tabular}{|l|c|c|c|c|}
\hline & 1990 & 1996 & 1997 & 1998 \\
\hline Bélgica & 26,4 & 28,8 & 28,5 & 27,5 \\
\hline Dinamarca & 28,7 & 31,4 & 31,4 & 30,0 \\
\hline Alemania & 25,4 & 30,0 & 29,9 & 29,3 \\
\hline Grecia & 23,2 & 23,1 & 23,6 & 24,5 \\
\hline España & 20,5 & 22,5 & 21,4 & 21,6 \\
\hline Francia & 27,6 & 31,0 & 30,8 & 30,5 \\
\hline Irlanda & 18,7 & 18,5 & 17,5 & 16,1 \\
\hline Italia & 24,3 & 25,2 & 25,9 & 25,2 \\
\hline Luxemburgo & 22,6 & 25,2 & 24,8 & 24,1 \\
\hline Holanda & 32,4 & 30,1 & --- & 28,5 \\
\hline Austria & 26,7 & 29,6 & 28,8 & 28,4 \\
\hline Portugal & 15,8 & 22,0 & 22,5 & 23,4 \\
\hline Finlandia & 25,1 & 31,6 & 29,9 & 27,2 \\
\hline Suecia & 33,1 & 34,5 & 33,7 & 33,3 \\
\hline Reino Unido & 22,9 & 28,0 & 26,8 & 26,8 \\
\hline UE & 25,4 & 28,6 & ---- & 27,7 \\
\hline
\end{tabular}

FUENTE: EUROSTAT 1997.

coincidido con la generación de un auténtico déficit social.

Este descenso del gasto social ha sido debido a factores positivos, como el crecimiento del PIB y el descenso del desempleo con la consiguiente reducción del gasto en prestaciones dedicadas a la protección de los parados. Todo ello, acompañado de una política presupuestaria de contención del gasto social, que ha pasado así de representar el $24 \%$ del PIB, en 1994, al 21.6 de 1998. En lugar de converger socialmente con la UE, España ha transferido estos fondos para cubrir el déficit presupuestario público español, objetivo primordial del gobierno actual (Navarro, 2001). Este descenso del nivel de protección social ha tenido rápidamente efectos sobre el bienestar de la población. Así, según el Informe sobre el Desarrollo Humano 2000, recién presentado, que elabora el PNUD con datos del 1998, España a pasado de ocupar el puesto $11^{\circ}$ en la clasificación por Índice de Desarrollo Humano, según los datos de 1996 , al puesto $21^{\circ}$, según los de 1988. Es precisamente el indicador de desigualdad de las rentas entre los más ricos y los más pobres el que ha resultado más desfavorable para nuestro país y nos ha hecho retroceder en el Índice de Desarrollo Humano.

En el caso de las pensiones, el gasto español para 1988 representó el $8 \%$ del PIB, frente al $11 \%$ medio de la Unión Europea, una diferencia importante, aunque, hay que reseñarlo, las disparidades son más agudas en el caso de la protección de las familias $(0.4 \%$ frente a $2.2 \%)$, 
que afecta en gran medida al bienestar de los ancianos dado que incluye gastos de ayuda a domicilio para discapacitados y ancianos; y la exclusión social $(0.2 \%$ frente a $0.4 \%)$. Sólo fijándonos en la asistencia a domicilio a los ancianos, únicamente el 1.4 de los ancianos españoles está asistido por algún tipo de servicio a domicilio, frente al $7 \%$ de Francia, el 8\% de Holanda o el 9\% del Reino Unido (Navarro, 2001).

Es evidente que el gasto en pensiones, aunque en menor medida que en los países de nuestro entorno, se ha elevado mucho. Y ello, sobre todo, porque se ha incrementado enormemente el número de pensionistas, efecto necesario de la prolongación de la esperanza de vida, pero también, como veremos más adelante, del recurso frecuente a la jubilación anticipada.

TABLA 13: Pensiones contributivas de jubilación y viudedad

\begin{tabular}{|l|c|c|c|c|}
\hline & \multicolumn{2}{|c|}{$\mathrm{N}^{0}$ (miles) } & \multicolumn{2}{c|}{ Pensión media (miles) } \\
\hline AÑO & Jubilación & Viudedad & Jubilación & Viudedad \\
\hline 1991 & $2.877,6$ & $1.595,9$ & 55,2 & 34,5 \\
\hline 1992 & $2.963,8$ & $1.652,0$ & 59,5 & 38,0 \\
\hline 1993 & $3.058,3$ & $1.710,6$ & 64,1 & 40,4 \\
\hline 1994 & $3.176,4$ & $1.777,8$ & 68,4 & 42,7 \\
\hline 1995 & $3.265,2$ & $1.817,5$ & 73,0 & 45,1 \\
\hline 1996 & $3.350,3$ & $1.856,9$ & 77,8 & 47,7 \\
\hline 1997 & $3.502,5$ & $1.897,5$ & 81,1 & 49,3 \\
\hline 1998 & $4.400,9$ & $1.936,7$ & 82,0 & 50,9 \\
\hline 1999 & $4.450,2$ & $1.973,3$ & 84,8 & 52,4 \\
\hline 2000 & $4.496,2$ & $2.011,7$ & 89,1 & 55,2 \\
\hline 2001 & $4.543,2$ & $2.040,5$ & 93,8 & 57,9 \\
\hline
\end{tabular}

FUENTE: Anuario de Estadísticas Laborales y Asuntos Sociales. Ministerio de Trabajo y Asuntos Sociales.

El total de pensiones contributivas ascendía en 1999 hasta un total de 7.509.280. Las de jubilación, las más numerosas, han crecido a lo largo de toda la última década desde los apenas tres millones hasta 4.543.291 del año 2001. Igualmente, las de viudedad, en el mismo periodo, se han incrementado en casi medio millón. Por otra parte, además de su número, el coste de las pensiones se ha elevado naturalmente.

Ahora bien, el número de pensiones no contributivas ha ido descendiendo a lo largo del mismo periodo, lo que explicaría parcialmente el fuerte crecimiento de las contributivas.

Sin embargo, si atendemos a la evolución de las prestaciones en dinero por persona mayor de 65 años, se observa que en el mismo periodo la evolución no ha sido tan positiva como los datos brutos pare- 
TABLA 14: Pensiones asistenciales por año de vejez y enfermedad

\begin{tabular}{|l|c|c|c|}
\hline & Total & Vejez & Enfermedad \\
\hline 1993 & 272,3 & 116,9 & 155,5 \\
\hline 1994 & 227,5 & 94,3 & 133,3 \\
\hline 1995 & 190,8 & 75,7 & 115,1 \\
\hline 1996 & 154,5 & 59,1 & 95,4 \\
\hline 1997 & 123,2 & 46,1 & 77,1 \\
\hline 1998 & 99,8 & 36,1 & 63,7 \\
\hline 1999 & 82,2 & 27,9 & 54,2 \\
\hline 2000 & 68,1 & 21,5 & 46,6 \\
\hline
\end{tabular}

FUENTE: INE: Anuario Estadístico de España.

TABLA 15: Variación porcentual de las prestaciones en dinero por persona de 65 año o más sobre el año anterior

\begin{tabular}{|l|r|r|r|r|r|r|r|l|}
\hline 1992 & 1993 & 1994 & 1995 & 1996 & 1997 & 1998 & 1999 & 2000 \\
\hline 3,36 & 1,34 & -2.29 & $-0,70$ & 2,38 & 0,60 & 0,35 & 0,46 & 2,98 \\
\hline
\end{tabular}

FUENTE: Anuario de Estadisticas Laborales y de Asuntos Sociales. Ministerio de Trabajo y Asuntos Sociales.

\section{cen indicar.}

En cualquier caso, y por muchas carencias e insuficiencias que se puedan establecer, sobre todo en el caso de las mujeres, cuyas pensiones de viudedad son, tal y como queda reflejado en la tabla, muy bajas, lo cierto es que los últimos años los ancianos en su conjunto han mejorado enormemente sus condiciones de vida. De hecho, si la pobreza tendía a localizarse apenas hace unas décadas con preferencia entre los más ancianos, hoy la situación se ha invertido y la pobreza se localiza con mucha más frecuencia entre los jóvenes. Según el último estudio realizado por EDIS para la Fundación Foessa, 1998, sólo el 20,3\% del total de pobres en España tenía más de 55 años, mientras que el $44,2 \%$ del total de los pobres tenía menos de 25 años. Cabe concluir que el sistema de pensiones, unido a una fuerte solidaridad familiar tanto en el cuidado como en el sostenimiento de muchos ancianos, han permitido mejorar enormemente sus condiciones de bienestar social.

Puesto que de bienestar se trata, y no sólo de retribuciones, hay que señalar que, seguramente, la verdadera carencia de los ancianos hoy no es tanto la escuálida pensión, casi siempre susceptible de ser complementada con la ayuda de la familia, sino la pobreza de recursos educativos, que limita severamente sus posibilidades de prácticas sociales, culturales y de ocio más ricas. Por otra parte, la escasez de sus recursos educativos, resultado del escaso esfuerzo que el franquismo hizo por asimilar el nivel de estudios de los españoles al resto de Europa, así como la escasa y tardía inversión pública en el sistema educati- 
vo, ha facilitado la exclusión del mercado de trabajo de los más mayores, al dificultar sus posibilidades de adaptación a las nuevas condiciones de la producción.

TABLA 16: Nivel de estudios completados de los mayores de 65 años

\begin{tabular}{|l|c|c|c|}
\hline & Total & Varones & Mujeres \\
\hline $\mathrm{N}^{\circ}$ personas (miles) & $6.282,1$ & $2.627,4$ & $3.654,7$ \\
\hline Estudios primarios y sin estudios & 87,9 & 83,5 & 91,2 \\
\hline $1^{\circ}$ Nivel de enseñanza secundaria & 4,9 & 5,0 & 4,9 \\
\hline F.P. I grado & $0,8 *$ & ---- & --- \\
\hline F.P. Superior & ---- & ---- & ---- \\
\hline $2^{\circ}$ nivel de enseñanza secundaria & 2,5 & $3,9 *$ & $1,4 *$ \\
\hline Estudios universitarios de ciclo corto & 1,6 & $1,7 *$ & $1,4 *$ \\
\hline Estudios universitarios de ciclo largo & 1,8 & $3,7 *$ & --- \\
\hline
\end{tabular}

FUENTE: Encuesta Panel de Hogares. INE.

* El número de observaciones muestrales está comprendido entre 20 y 49, por lo que esta cifra es poco fiable y hay que interpretarla con cautela.

En congruencia, y a pesar del esfuerzo que algunos sectores de ancianos están invirtiendo en mejorar su nivel cultural, sus prácticas de ocio siguen estando muy limitadas:

TABLA 17: De las siguientes actividades, ¿cuáles realizó durante la última semana?

\begin{tabular}{|l|r|c|}
\hline & $\%$ Sí & $(\mathrm{N})$ \\
\hline Ver la TV & 97 & $(2195)$ \\
\hline Oír la radio & 71 & $(2195)$ \\
\hline Ir al parque & 70 & $(2192)$ \\
\hline Hacer compras, recados & 69 & $(2189)$ \\
\hline Leer & 51 & $(2188)$ \\
\hline Ir al bar, cafetería & 32 & $(2187)$ \\
\hline Acudir a un club, hogar sociedad recreativa, asociación de mayores & 24 & $(2186)$ \\
\hline Hacer algún deporte & 7 & $(2186)$ \\
\hline Asistir a espectáculos & 7 & $(2179)$ \\
\hline Ir a conferencias y conciertos & 4 & $(2177)$ \\
\hline
\end{tabular}

FUENTE: Estudio CIS-Instituto de Migraciones y Servicios Sociales: 2279, 1998.

Los problemas de salud, el temor a la soledad, la limitación de recursos económicos y culturales, o el sentimiento generalizado de no obtener el suficiente reconocimiento social no empañan, sin embargo, la extendida conciencia entre los ancianos de que el balance es para ellos claramente positivo. Cuando se les pide que valoren su situación con relación a la de sus padres, sólo un $5 \%$ considera que la suya es peor. 
TABLA 18: Habitualmente cuando está solo ¿qué es lo que se le ocurre hacer?

(Sólo los que se sienten solos en alguna ocasión)

\begin{tabular}{|l|r|}
\hline Pone la radio o la TV & $28 \%$ \\
\hline Sale a pasear & $24 \%$ \\
\hline Se resigna & $11 \%$ \\
\hline Practica un hobby & $8 \%$ \\
\hline Reza & $8 \%$ \\
\hline Habla con los vecinos & $5 \%$ \\
\hline Llama por teléfono & $4 \%$ \\
\hline Va al hogar del jubilado & $2 \%$ \\
\hline Va de visita & $2 \%$ \\
\hline Va a la iglesia & $1 \%$ \\
\hline Va al bar, cafetería & $1 \%$ \\
\hline Habla solo & $1 \%$ \\
\hline NS/NC & $6 \%$ \\
\hline (N) & $(918)$ \\
\hline
\end{tabular}

TABLA 19: Cómo valoran las personas mayores su situación actual en comparación con la de sus padres.

\begin{tabular}{|l|r|}
\hline Es mejor & $70 \%$ \\
\hline Es igual & $15 \%$ \\
\hline Es peor & $5 \%$ \\
\hline Sus padres no vivían a esa edad & $9 \%$ \\
\hline NC & $1 \%$ \\
\hline (N) & $(2197)$ \\
\hline
\end{tabular}

FUENTE: Estudio CIS-Instituto de Migraciones y Servicios Sociales: 2279, 1998.

FUENTE: Estudio CIS-Instituto de Migraciones y Servicios Sociales: 2279, 1998.

\section{EL FIN DEL TRABAJO: JUBILADOS Y OCIOSOS}

Si un cambio ha merecido la atención del pensamiento social en estas dos últimas décadas, éste ha sido la pérdida de la centralidad de la noción del trabajo en las sociedades industriales tardías. Aunque una parte de las argumentaciones en torno al fin del trabajo pueden ser consideradas como meras legitimaciones de la evolución de los mercados de trabajo, hay que admitir que el trabajo define cada vez en menor medida tanto las identidades sociales como las trayectorias vitales (Offe, 1992). La discontinuidad de las biografías y de las identidades, un fenómeno que parece caracterizar a las sociedades actuales (Gil Calvo, 2001), tiene mucho que ver con las transformaciones del trabajo, que han afectado a la concepción misma de la carrera laboral y generado ese fenómeno que Sennet (1998) brillantemente ha calificado de "corrosión del carácter".

Es cierto que estas transformaciones admiten valoraciones muy distintas. En la práctica han sido interpretadas bien como la institucionalización de la precariedad y la inestabilidad, o bien como el fin de las constricciones del trabajo y el acceso a una mayor libertad para definir la propia trayectoria y el propio trabajo más creativamente. En cualquier caso, lo cierto es que esta pérdida de centralidad del trabajo afecta, sin duda, a la consideración de la jubilación y de los ancianos en tanto que excluidos del mercado de trabajo. Como recuerda Amando 
de Miguel (2001), en estas condiciones, es preciso revisar la idea aceptada de que la situación del jubilado sea marginal o estigmatizada, aunque sólo sea por el mero hecho de que, en términos numéricos, respecto al conjunto de los habitantes, los que tienen una ocupación fija empiezan a ser una auténtica minoría.

La jubilación ha sido hasta hace poco considerada de una manera ambigua. Por una parte, como una conquista social importante que liberaba a las personas al inicio de su decadencia física de la pesada carga del trabajo, asegurándoles a través de las pensiones un periodo de descanso y bienestar relativo, un periodo que progresivamente se ha ido convirtiendo en la conquista del derecho al ocio. Por otra parte, la jubilación, percibida como lo que es, la exclusión forzosa del mercado de trabajo, a cambio de una compensación económica inferior casi siempre a la remuneración por el trabajo, era una forma de invalidación personal y social, generadora por tanto de estigma y pérdida de consideración en sociedades regidas por el principio del trabajo. En resumen, un decreto "envejecimiento civil" forzoso. La desigualdad social, por otra parte, que supone acceso a trabajos de desigual calidad y desigual retribución antes y después de la jubilación, determinaba en gran medida percepciones distintas en los distintos grupos sociales.

Sin embargo, este modelo, con sus ambigüedades, empieza a quebrarse desde los años setenta. El crecimiento de la esperanza de vida y la sensible mejora de la salud para la población anciana, es decir, el marcado retraso del envejecimiento biológico, hubieran hecho esperar una prolongación de la vida laboral, cuanto menos una prolongación selectiva para aquellas personas o en aquellas ocupaciones -por otra parte, cada vez más numerosas- donde el vigor físico no fuera necesario. No sólo no ha ocurrido así, sino que, bien al contrario, la jubilación se ha anticipado en todos los países de nuestro entorno; y no lo ha hecho como resultado de decisiones planificadas y legisladas, sino que se ha impuesto a través de un proceso aparentemente espontáneo de reconversión del trabajo en las empresas, pero que ha sido, si no auspiciado, cuanto menos consentido por los poderes públicos.

En el caso de España, la evolución de las tasas de actividad entre los grupos de más edad muestra claramente cuáles han sido los efectos de este proceso.

Para la población activa masculina, la tendencia desde los años setenta ha sido el descenso de su tasa de actividad, resultado del retraso en la incorporación de los más jóvenes y la retirada anticipada de los más mayores. Así, la tasa de actividad masculina era en 1980 del 72,2\%, y descendió hasta el 62,7 de 1994, que representa una pérdida de 10 puntos porcentuales. En la década de los noventa, después de un fuer- 
TABLA 20: Tasas de actividad masculina. Porcentajes de activos según edad.

\begin{tabular}{|l|c|c|c|c|c|c|}
\hline & $50-54$ & $55-59$ & $60-64$ & $65-69$ & $70 y+$ & $16 y+$ \\
\hline 1987 & 88,5 & 75,6 & 48,2 & 8,2 & 1,9 & 67,6 \\
\hline 1988 & 89,1 & 75,4 & 47,6 & 8,3 & 1,7 & 66,5 \\
\hline 1989 & 88,6 & 76,1 & 48,6 & 8,3 & 1,6 & 66,8 \\
\hline 1990 & 89,5 & 76,8 & 46,4 & 8,0 & 1,3 & 66,5 \\
\hline 1991 & 88,8 & 76,8 & 47,2 & 7,5 & 1,1 & 65,5 \\
\hline 1992 & 88,0 & 73,6 & 46,3 & 6,9 & 1,1 & 64,4 \\
\hline 1993 & 88,7 & 72,7 & 44,1 & 6,1 & 1,2 & 64,0 \\
\hline 1994 & 88,0 & 71,6 & 40,9 & 5,5 & 1,3 & 62,7 \\
\hline 1995 & 87,9 & 71,4 & 41,4 & 5,7 & 1,5 & 62,8 \\
\hline 1996 & 88,6 & 72,9 & 42,5 & 4,9 & 1,2 & 63,2 \\
\hline 1997 & 88,3 & 74,9 & 41,7 & 5,1 & 1,1 & 63,1 \\
\hline 1998 & 89,3 & 75,5 & 40,1 & 4,9 & 1,0 & 63,2 \\
\hline 1999 & 88,6 & 74,7 & 40,6 & 5,3 & 1,1 & 63,3 \\
\hline 2000 & 88,2 & 75,6 & 44,2 & 5,7 & 0,90 & 63,9 \\
\hline $2001^{*}$ & 88,2 & 74,4 & 47,1 & 5,4 & 1,0 & 64,4 \\
\hline
\end{tabular}

FUENTE: Encuesta de población activa.

* Se recogen los datos del ultimo trimestre para cada año, salvo el año 2001 que los datos corresponden al tercer trimestre.

te descenso de las tasas de actividad en todos los grupos de edad, debido al impacto de la recesión de los primeros años, se ha producido en el último periodo una recuperación de la tasa de actividad, aunque muy limitada, al tiempo que han descendido sensiblemente las tasas de paro.

Si nos fijamos exclusivamente en las tasas de actividad de la población mayor de 50 años, vemos que los grupos de más edad se han beneficiado de este mismo proceso. A partir de 1996, aunque con incrementos débiles, se invierte por primera vez la tendencia al descenso continuado de la tasa de actividad de los hombres que tienen entre $50 \mathrm{y}$ 65 años. A partir de los 65 años, sin embargo, a pesar de la evolución positiva del mercado de trabajo, las tasas de actividad han seguido descendiendo. Dado que los indicadores económicos y del mercado de trabajo no han sido favorables en los últimos meses, cabe pensar que esta débil recuperación de la tasa de actividad pueda invertirse para volver a los niveles anteriores.

En cualquier caso, y en lo que concierne a nuestros intereses, lo reseñable es que la tasa de actividad se mantiene relativamente elevada hasta los 54 años, en valores cercanos al $90 \%$. Sin embargo, a partir de ese momento, sufre una caída espectacular, y ello a pesar de la mejora del último quinquenio. Entre los 60 y 64 años, antes de la edad preceptiva para la jubilación, la tasa de actividad se ha situado en torno 
TABLA 21 : Tasas de actividad femenina. Porcentajes de activos según edad.

\begin{tabular}{|l|c|c|c|c|c|c|}
\hline & $50-54$ & $55-59$ & $60-64$ & $65-69$ & $70 y+$ & $16 \mathrm{y}+$ \\
\hline 1987 & 27,4 & 22,9 & 15,8 & 5,1 & 0,9 & 32,1 \\
\hline 1988 & 27,1 & 23,3 & 16,0 & 4,4 & 0,9 & 32,3 \\
\hline 1989 & 28,8 & 24,0 & 14,9 & 4,1 & 0,7 & 32,9 \\
\hline 1990 & 30,2 & 22,5 & 15,7 & 3,9 & 0,7 & 33,5 \\
\hline 1991 & 31,3 & 23,4 & 16,0 & 3,0 & 0,6 & 33,9 \\
\hline 1992 & 32,5 & 24,9 & 16,4 & 3,6 & 0,6 & 34,4 \\
\hline 1993 & 32,2 & 23,9 & 16,6 & 3,6 & 0,5 & 35,2 \\
\hline 1994 & 34,1 & 23,6 & 15,0 & 3,0 & 0,5 & 35,8 \\
\hline 1995 & 35,4 & 25,9 & 15,4 & 2,9 & 0,6 & 36,5 \\
\hline 1996 & 36,6 & 26,0 & 15,7 & 2,7 & 0,2 & 37,2 \\
\hline 1997 & 37,7 & 26,8 & 16,0 & 2,4 & 0,2 & 37,8 \\
\hline 1998 & 38,4 & 27,6 & 15,8 & 2,1 & 0,3 & 37,9 \\
\hline 1999 & 39,3 & 27,8 & 15,5 & 2,5 & 0,4 & 39,1 \\
\hline 2000 & 41,6 & 29,1 & 17,6 & 2,3 & 0,3 & 39,9 \\
\hline $2001^{*}$ & 43.5 & 31,2 & 17 & 2,3 & 0,2 & 40,1 \\
\hline
\end{tabular}

FUENTE: Encuesta de Población activa.

* Se recogen los datos del último trimestre para cada año, salvo el año 2001 que los datos corresponden al tercer trimestre.

al $40 \%$, para elevarse al $47 \%$ en este último año. Por encima de los 65 años, las tasas de actividad son insignificantes y han sido muy poco sensibles a la mejora del mercado de trabajo en los últimos años

La tasa de actividad femenina ha tenido, por el contrario, una evolución positiva. Aunque con retraso respecto a los países de nuestro entorno, las mujeres españolas se han incorporado al mercado de trabajo en proporciones todavía inferiores a las europeas, pero que han representado un avance importante para España. Así, aún en 1980, la tasa de actividad femenina representaba el $27,1 \%$, y se ha elevado hasta el 40,1 en estas dos décadas.

Para el conjunto de las mujeres, por tanto, no se ha verificado un proceso de exclusión temprana del mercado de trabajo, simplemente porque las proporciones de mujeres activas en las edades más altas eran, en el inicio del proceso, insignificantes. Por otra parte, las jubilaciones anticipadas entre el restringido sector de las activas se han compensado con la entrada de un número elevado de mujeres en el mercado de trabajo, lo que ha determinado un incremento de la actividad global. Las bajísimas tasas de actividad entre las mujeres mayores de 50 años no son entonces el resultado de un proceso de expulsión del mercado de trabajo, como ha ocurrido en el caso de los hombres, sino de la tardía incorporación al trabajo asalariado de las mujeres españolas. 
Cabe concluir que la jubilación anticipada ha sido un instrumento, entre otros, de gestión de la mano de obra masivamente utilizado en el último cuarto de siglo. Los trabajadores de mayor edad, normalmente los más protegidos, han sido expulsados en gran número del mercado de trabajo para ser sustituidos por trabajadores más jóvenes y mujeres bajo nuevas condiciones de flexibilidad laboral. Las altas tasas de paro que afectaban a todos los grupos de edad legitimaban a los poderes públicos y a los propios sindicatos para apoyar estas medidas, bajo el argumento de favorecer el empleo de los más jóvenes o los que tenían responsabilidades familiares. Así, mientras se endosaban los costes al Estado, con cargo al seguro de desempleo o al presupuesto de las pensiones, se facilitaba el proceso de reconversión sin la oposición de nadie, incluso, con la relativa aquiescencia de los propios trabajadores

Además de sus mayores niveles de protección, los trabajadores de más edad tenían más dificultades para adaptarse a las nuevas condiciones y formas de trabajo, en un periodo de cambio tecnológico acelerado, modernización del tejido productivo y formas de organización novedosas que hubieran requerido un esfuerzo de reciclaje. Resultaba más sencilla su sustitución sin coste alguno para las empresas, aunque este camino pudiera poner en peligro la propia pervivencia del sistema de pensiones, en condiciones además de envejecimiento de la población. Los factores demográficos venían así a justificar una amenaza de quiebra que se gestaba, sin embargo, sobre todo en la gestión del mercado de trabajo.

A los años de vida inactiva conquistados a la muerte se han añadido así los años de inactividad impuesta. Si tenemos en cuenta, además, el retraso de los jóvenes en la incorporación al trabajo mediante la prolongación del tiempo de estudio, el resultado ha sido un descenso de la tasa de actividad que, sólo parcialmente, ha sido compensado con la entrada de mujeres en el mercado de trabajo. Los sectores inactivos han crecido respecto a los activos, elevando así la tasa de dependencia y dificultando el mantenimiento del sistema de seguridad social, dependiente de la población ocupada, y ello a pesar de la evolución favorable de los últimos cinco años. Todo ello, por otra parte, ha tendido a erosionar la solidaridad intergeneracional, o cuanto menos a ponerla en entredicho. Entre la población activa, la sospecha de que está contribuyendo al sostenimiento de un modelo de pensiones del que probablemente no podrá beneficiarse en el futuro, y el esfuerzo por constituir formas de ahorro privado frente los avatares del sistema de protección social, favorece el resentimiento y la insolidaridad.

Son estas consideraciones las que apoyan la idea, compartida por muchos autores, de que se ha producido, en expresión de Gil Calvo 
(2001), una auténtica "invención social de la vejez", tal y como antes se produjo la invención de la juventud. La vejez es una etapa vital, mantiene Gil Calvo, creada como resultado de la prolongación de la inactividad poslaboral, una inactividad impuesta artificialmente, pues en las actuales condiciones la mayoría de los ancianos están en condiciones de trabajar y, además, muchos de ellos desearían seguir haciéndolo, sobre todo cuando sus actividades son contempladas como formas, aun contradictorias, de obligación pero también de realización personal. Que la inactividad se haya ampliado al mismo tiempo que la longevidad parece una contradicción cuyas consecuencias seguramente nos van a acompañar las próximas décadas.

En cualquier caso, el problema no es la tasa de dependencia ni la esperanza de vida, el problema que alienta y oscurece la polémica es del reparto de la riqueza social y la fijación de los niveles de solidaridad. Parece necesario admitir que la innovación tecnológica genera, en un plazo, un aumento de la productividad del trabajo que forzosamente ha de traducirse en una disminución del trabajo global. Esta disminución puede ser gestionada socialmente de muchas maneras, y permitir formas más creativas y flexibles de participación en la actividad. El tiempo de la inactividad puede ser empleado, como en parte viene ocurriendo, en mejorar la formación o en prácticas de ocio o convivencia social.

No cabe duda de que, más allá de la actividad productiva, los ancianos pueden, y de hecho realizan, muchas otras actividades importantes y que merecen mayor valoración social. Por ejemplo, su contribución a la solidaridad familiar, pasando a cumplir algunas funciones de las mujeres en el cuidado de los nietos y el trabajo doméstico: casi el $40 \%$ de los mayores de 65 años declara ayudar a sus hijos en estas tareas con frecuencia. Por ejemplo, su dedicación al voluntariado social, la creación del movimiento de los profesionales senior, su demanda de actividades formativas, etc. Todo ello constituye, sin duda, un proyecto de continuidad de una vida que, más allá del trabajo, puede ser productiva socialmente y enriquecedora personalmente.

La cuestión, entonces, es qué nivel de inactividad puede mantener una sociedad sin condenar a sus inactivos, sean ancianos, jóvenes o mujeres, a la pobreza o a la exclusión social. El problema no es la jubilación anticipada, sobre todo si es aceptada, sino que la jubilación sea el inicio de un proceso de exclusión social cuando a los jubilados se les deniega el acceso a los ingresos y otros aspectos ventajosos de carácter económico, social y psicológico relacionados con el trabajo (Bazo, 2001). El problema es cuando se fuerza a un número creciente de personas a depender del Estado, al tiempo que el Estado es 
deslegitimado para cumplir la función de su sostenimiento en condiciones de dignidad. El problema es cuando la longevidad diferencial de las mujeres se convierte en uno de los factores que alimenta la feminización de la pobreza. El problema, en fin, es que la supuesta pérdida de centralidad del trabajo en nuestras sociedades sirva para justificar la exclusión del derecho al trabajo de grupos más numerosos de personas, al tiempo que los beneficios del trabajo se siguen distribuyendo, cada vez más desigualmente, a través de la participación selectiva en el trabajo.

En palabras de Gil Calvo, el siglo XXI será el siglo de una nueva revolución biográfica: la invención de la vejez. Puede que sea cierto, pero lo que queda por dilucidar es el signo y el carácter de dicha revolución: la vejez será una nueva etapa vital, liberada parcialmente de la carga del trabajo, pero optativamente activa y rica en posibilidades de relación, cultura y ocio; o será una edad de privación del derecho al trabajo y de sus beneficios, dependiente de un magro Estado incapacitado para asegurar su sostenimiento y, por tanto, sujeta a la pobreza, a la disminución del consumo y a la pérdida de consideración social.

\section{BIBLIOGRAFIA}

ALBERDI, I.: La nueva familia española. Taurus, Madrid, 1999.

ALGADO, M. ${ }^{a}$ T.: Envejecimiento de sociedad. Una sociología de la vejez. Instituto de Cultura Juan Gil-Albert, Alicante, 1997.

BAZO, M. ${ }^{a}$ T.: "La nueva sociología de la vejez: de la teoría a los métodos", REIS 60, octubre 1992 (75-90).

BAZO, M. ${ }^{\mathrm{T}}$.: La institución social de la jubilación: de la sociedad industrial a la postmodernidad. Nau Llibres, Valencia, 2001.

DE MIGUEL, A.: La vida cotidiana de los españoles en el siglo XX. Planeta, Barcelona, 2001.

DE MIGUEL, J.M.: Estructura y cambio social en España. Alianza, Madrid, 1998.

GIL CALVO, E.: Nacidos para cambiar. Cómo construimos nuestras biografias. Taurus, Madrid, 2001.

FERNÁNDEZ CORDÓN, J.A. y LEGUINA, J.: "La termita demográfica", El País, 3 de febrero, 2001.

LIPOVETSKY, GILLES: El crepúsculo del deber. La ética indolora de los nuevos tiempos democráticos. Anagrama, Barcelona, 1994.

OFFE, CLAUS: La sociedad del trabajo. Problemas estructurales y perspectivas de futuro. Alianza, Madrid, 1992. 
NAVARRO, V: "El déficit social", El País, 13 de febrero, 2001 (pp.11-12).

PÉREZ DÍAZ, V.; ÁLVAREZ MIRANDA, B. y CHULIÁ, E.: "La familia en el sistema de bienestar español. Una reflexión general y una discusión empírica", Papeles de Economía, 77 (págs. 24-41), 1998.

SENNET, R.: La corrosión del carácter. Las consecuencias personales del trabajo en el nuevo capitalismo. Anagrama, Barcelona, 1998. 



\title{
LOS MENORES Y LOS MAYORES: IMÁGENES INVERTIDAS DE LAS DESIGUALDADES POR EDAD
}

\author{
DANIEL LA PARRA CASADO \\ Departamento de Sociología II, Psicología, Comunicación y Didáctica. \\ Universidad de Alicante.
}

\section{RESUMEN}

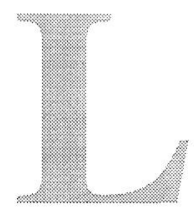

os procesos sociales de construcción de la infancia y la senectud pueden ser resultado de un mismo grupo de factores sociales (demográficos, económicos, ideológicos). En el artículo se analiza el modo en que se ha definido la participación en la sociedad de los menores y los mayores por parte de instituciones sociales como el Estado, el mercado de trabajo y los hogares. Se exploran las consecuencias en niños y mayores de la "exclusión" del mercado de trabajo, del acceso a los recursos sociales a través de las redes de solidaridad familiar y las implicaciones de las políticas sociales dirigidas a los menores y los mayores. Se observan los efectos de la definición social de la infancia y la senectud en la distribución de la renta, las oportunidades educativas y la atención a la salud dentro de estos grupos de edad. Se extrae la conclusión de que la representación de los menores y los mayores como "excluidos" del mercado laboral y protegidos por las relaciones de parentesco determina el tipo de soluciones que la política social y económica plantea para estos colectivos.

\section{INTRODUCCIÓN}

Para comprender las líneas principales que orientan la forma de plantearnos los problemas que afectan al mundo de los menores y los mayores, propongo introducir una especie de juego de espejos. Lo que pretendo es relacionar los procesos de construcción social de la imagen de los menores y los mayores estructurándolos dentro de una misma lógica. El objetivo es que al final de esta propuesta sean más visibles los aspectos esenciales que guían la problematización de la vida de 
los mayores y los menores. Cuando utilizo el vocablo problematización me refiero al hecho concreto de que nuestra forma de plantearnos los problemas está guiada por las representaciones generales que nos hacemos sobre el modelo de vida que deben tener las personas mayores (aquéllos a los que se suele llamar ancianos, tercera edad o mayores de 65 años) y los que son menores de edad (niños, infancia, adolescentes, menores de 18 años...). El interés de conocer la influencia de las representaciones culturales en los procesos de problematización es que éstas pueden estar guiando las políticas sociales con respecto a estos grupos de edad. Conocer dichas representaciones puede servir por tanto para adquirir autoconciencia sobre decisiones que por el momento se toman de forma automática por parte de cualquiera de los actores participantes en la intervención social (desde el trabajador social, hasta el Ministerio de Trabajo y Asuntos Sociales). Una mayor autoconciencia puede proporcionar las bases para un trabajo de autocrítica y el desarrollo de iniciativas más innovadoras. Por otro lado, la descripción de los procesos que están detrás de la construcción de nuestras ideas de infancia y senectud pueden servir para denunciar los principales mecanismos de creación de desigualdades por edad que afectan a estos grupos.

Habitualmente se presentan los procesos sociales que dieron lugar a las representaciones que actualmente compartimos sobre los menores y los mayores como procesos paralelos sin ningún tipo de conexión entre ellos. No obstante, la idea que aquí se defiende es que ambos procesos son resultado de una misma lógica y que en realidad ambos están intrínsecamente relacionados. Para argumentar esta idea se procederá a describir las principales características del proceso de construcción social de la imagen de los menores, para buscar posteriormente su reflejo en la construcción de la imagen de los mayores y, por último, tratar de esclarecer el tipo de lógica que explica la simetría entre ambas. Se avanza, no obstante, que dicha lógica tiene que ver con el modo en que la participación de la sociedad de los diferentes tipos de ciudadanos ha sido definida por parte de instituciones sociales como el Estado, el mercado de trabajo y los hogares.

\section{LA CONSTRUCCIÓN SOCIAL DE LA INFANCIA}

Si seguimos la propuesta (ya clásica) del historiador francés Ariès (1973), la idea de infancia no siempre estuvo presente en todas las sociedades. Más concretamente tal y como el autor argumenta los sentimientos actuales hacia la infancia no existían en el Antiguo Régimen. Éstos se fueron desarrollando paulatinamente durante la moder- 
nidad a medida que se va construyendo una nueva sociedad que implica todo tipo de cambios sociales provocados por procesos tales como la industrialización y la urbanización. Entre ellos cabe destacar, por su relevancia en la construcción social de la infancia, los cambios en las formas de vida familiar y más concretamente el origen de la familia nuclear (formada por el esposo, la esposa y los hijos que constituyen un grupo primario). Esta innovación crea el espacio social necesario (la vivienda en el ámbito urbano) para desarrollar una idea de la infancia ligada a la responsabilidad paterna y sobre todo materna (frente a las abundantes fuentes de sociabilidad de las que disponía un niño en las sociedades agrícolas del antiguo régimen) y centrada en la idea de protección del niño (frente a la indiferenciación entre niños y adultos en el trabajo y en el trato propia de la explotaciones agrícolas familiares del antiguo régimen).

En efecto, tal y como Rodríguez Pascual (2000) plantea en un artículo de revisión de estudios sobre la génesis del estatus del menor, los diferentes autores coinciden en señalar que revoluciones burguesa e industrial transformaron la realidad social creando toda una serie de cambios que confluyeron en la formación de la idea de infancia tal y como hoy la conocemos. Por un Iado encontramos que se desencadena un cambio demográfico de gran magnitud. Como resultado, la esperanza de vida crece de forma continua de manera que existen más años en la vida de una persona. De esperanzas de vida al nacer entre los treinta y cuarenta años, se llega a las actuales esperanzas de vida de más de setenta años, que ofrecen una amplitud vital necesaria para la creación de etapas como la infancia, la adolescencia o la juventud. La transformación demográfica está totalmente relacionada con una transformación social en el papel jugado por los niños en la economía doméstica. Tal y como Kingsley Davis se encargó de demostrar los niños en un contexto de baja mortalidad y de transformaciones en la economía (el trabajo empieza a desarrollarse de forma asalariada y no lo organiza la unidad doméstica lo que hace que se retrase el inicio de la edad productiva del niño) suponen un coste creciente para los hogares, además de que una amplia descendencia provoca problemas de competencia por los recursos. Así en países como Francia los hogares que reducen el número de hijos aumentan sus probabilidad de movilidad social ascendente (Iglesias de Ussel, 1998). Todo ello lleva a cambiar la consideración del niño, quien pasa de ser tratado como un bien de producción a ser visto como un bien de consumo. El niño, alejado temporalmente de los procesos productivos, se empezará a ocupar en una nueva actividad: la educación.

De hecho, además de los cambios demográficos y económicos se han de destacar cambios culturales, sobre todo los que se enmarcan 
dentro del movimiento ilustrado, que dan lugar a obras como L'Émile (1762) de Jean-Jacques Rousseau, quien desde el naturalismo pedagógico se ocupa de la educación del ser humano desde que nace hasta que se instala plena y activamente en la comunidad mediante el trabajo y la formación de una familia. El siglo XIX y XX, según los países, han sido los siglos de la expansión del sistema educativo. Dicha expansión responde tanto a la extensión de las ideas ilustradas como sobre todo a las nuevas necesidades propias de la sociedad industrial. A medida que la industrialización avanza las necesidades educativas aumentan. Para las clases dirigentes porque la técnica, la legislación y las fórmulas aplicadas en la organización de la actividad industrial y comercial son cada vez más complejas y sólo pueden ser aprendidas dentro del sistema educativo. Para las clases obreras, porque las sociedades industriales necesitan de una mano de obra cualificada, alfabetizada y, por supuesto, disciplinada y obediente (dedicada y responsable en el lenguaje de las ofertas de empleo). El curriculum escolar de los niños de las clases populares estará impregnado a lo largo de este período de contenidos destinados a convertir al niño en un trabajador disciplinado tanto por los contenidos explícitos, como por los implícitos y por los universos simbólicos a través de los que se suele transmitir este conocimiento. Las ideas nacionalistas y religiosas fueron de gran utilidad a la hora de ofrecer un marco en el que situar esta nueva pedagogía. Ya en Rousseau se encuentra la idea de la utilidad pública de la educación (instalar al niño en la comunidad a través del trabajo y la formación de una familia). Desde un primer momento la educación obligatoria estuvo orientada a la inserción laboral y a los contenidos de tipo moralista. Aún hoy se entiende que la principal función del estudio es conseguir una mejor inserción laboral. La idea de que el sistema educativo pudiera servir para el desarrollo de la capacidad creativa, del sentido crítico o la autonomía de los individuos quedaba en un segundo lugar e incluso podía ser directamente perseguida. No se buscaba producir artistas, políticos o ciudadanos reivindicativos, sino honrados trabajadores.

La expansión del sistema educativo es una de las claves para comprender nuestro modelo actual de infancia. Se trata de una edad de la vida en la que el niño recibe de las generaciones adultas su formación. En la que tanto el hogar como el Estado han de encargarse de garantizar esa transmisión de conocimientos (a través de fórmulas como la escolarización gratuita y la prohibición del trabajo de los menores). La idea principal detrás de este planteamiento es que el niño ha de formarse para garantizar su inserción profesional. La desviación de esta norma (el fracaso escolar) se considera un aspecto negativo para el niño.

Dentro del sistema educativo las opciones no fueron, ni son iguales para todas las clases sociales. Por un lado se destaca la distinción 
entre escuelas de elite y escuelas populares, las cuales no siempre se corresponden con la división privada-pública. Por otro lado, la distinción entre el bachillerato y la universidad frente a la formación profesional, aunque dentro estos grupos también se producen interesantes elementos de estratificación.

La responsabilidad sobre la infancia aparecerá como resultado de todo este proceso ligada al hogar y a la escuela. Esta idea quedará incluso sancionada en las ciencias sociales por autores como Durkheim o Parsons quienes sitúan al hogar junto a la escuela como principales instancias en el proceso socializador, pero también penetra el conjunto de las ciencias que se desarrollan para atender a la infancia. La psicología, la pedagogía y hasta la pediatría han reforzado la idea de la responsabilidad paterna sobre los niños.

\section{LA CONSTRUCCIÓN DE LA REPRESENTACIÓN SOCIAL DE LOS MAYORES COMO IMAGEN INVERTIDA DE LA INFANCIA}

Entre las características básicas de la senectud (en el sentido positivo del término) se suele coincidir en señalar que en esta edad de la vida se produce un cambio en la posición de las personas en la actividad económica (la jubilación), que existen cambios en las relaciones familiares (los mayores pierden progresivamente su posición central con respecto a los hijos, ya sea porque éstos se emancipan o porque son los hijos quienes empiezan a organizar la vida en la unidad doméstica) reforzados en ocasiones por cambios en el estatus marital (viudedad). También puede ser representada como una edad en la que se deteriora de forma progresiva el estado de salud.

Si bien esta descripción repite en muy pocos puntos los señalados para la infancia, existen algunas coincidencias evidentes. Una de ellas es el hecho de que para que haya surgido la idea de que existe una edad tras la etapa adulta es necesario que la esperanza de vida sea mayor. También destaca que esta edad de la vida se caracteriza, al igual que la infancia, por la inactividad (laboral) y que ello ha sido posible, en los países industrializados, gracias a que la economía ha sido lo suficientemente productiva como para mantener a estos colectivos.

Más allá de estas coincidencias básicas en las formas, puede haber una serie de coincidencias más profundas en nuestra forma de representarnos a estos grupos de edad. Una de las primeras coincidencias tiene que ver precisamente con utilizar la edad como criterio clasificatorio. La edad sirve como una variable estructuradora de las oportuni- 
dades, capacidades y recursos con las que cuentan las personas. Esta forma moderna de estratificación social tiene que ver fundamentalmente con la posibilidad de participar en el mercado de trabajo, siendo el Estado el que actúa como principal actor a la hora de sancionar los límites inferior y superior de edad en los que se puede trabajar. No obstante, es destacable que las propias empresas podrán alterar dichos límites bien decidiendo contratar gente con una cierta experiencia profesional (esto es, gente con más edad del mínimo exigido para poder trabajar), bien cuando toman la opción de jubilar a despedir a los trabajadores mayores de una determinada edad. Es cierto que el proceso de estratificación por edad es mucho más intenso en los menores que en los mayores. Los niños llegan hasta el punto de ser clasificados por su año de nacimiento dentro del sistema educativo, pero lo relevante para la descripción que aquí se realiza es la constatación de que la edad pueda servir como un criterio para definir el acceso al mercado de trabajo para los mayores y los menores.

Parece por tanto que estos dos colectivos están excluidos del mercado laboral, sin embargo, lo cierto es que tanto los ancianos como niños acaban siendo clasificados en función de su relación con el trabajo. En los menores lo que se convierte en determinante es su trayectoria educativa dentro del sistema educativo. Se distingue entre aquéllos que han fracasado en el sistema escolar y los que no lo hacen. Dentro de los que siguen una trayectoria educativa exitosa se preparan para diferentes tipos de inserción profesional. Se les clasifica por tanto de forma anticipada en función de lo que podrán llegar a ser en el mundo laboral. Una situación totalmente invertida se encuentra en el caso de las personas mayores. Para ellos lo relevante no son ya la expectativas laborales, sino su historia laboral. El sistema de prestaciones sociales distingue entre aquéllos que han sido trabajadores activos (y entre ellos premia a los que estuvieron en mejores puestos de trabajo) y los inactivos (con derecho únicamente a pensión de tipo no contributivo). El equivalente al niño que fracasa en el sistema escolar es la persona mayor que por haber dedicado su vida a trabajos no mercantiles (tareas domésticas) e, incluso, esporádicamente a trabajos productivos, no llegan a contribuir lo suficiente como para percibir una pensión contributiva, sino una de una cuantía económica muy inferior (de tipo no contributivo).

Mayores y menores están estratificados en relación con el mercado de trabajo pero no participan directamente de él. La participación en el consumo de estos colectivos puede producirse por dos mecanismos principales. El primero (el predominante en los niños) es su integración en una familia, el segundo (válido para las personas mayores que han trabajado) las prestaciones por jubilación. En el caso de las 
personas mayores que no han trabajado se prevé una ayuda económica de marcado carácter asistencialista (la pensión no contributiva) y también la integración en el hogar. Esta dependencia de otros familiares de las personas ancianas (sobre todo mujeres) está de hecho reconocida en la llamada pensión de viudedad. Ésta se percibe en virtud de la relación de parentesco que une al beneficiario con alguien que ha fallecido. Esto es, el Estado sustituye la función económica dejada por el desaparecido "cabeza de familia", exactamente igual que en el caso de las pensiones de orfandad.

La responsabilidad de la institución familiar será por tanto la de integrar en los procesos de consumo. No obstante, una segunda responsabilidad para las familias se dibuja incluso con mayor fuerza. El hogar debe añadir dos elementos esenciales para la atención de los menores y los mayores (éstos últimos sólo cuando tienen problemas de salud): un volumen considerable de trabajo no mercantil y mecanismos de apoyo social informal. Se trata de garantizar la seguridad, las atenciones (limpieza, comidas, higiene) y el entorno afectivo necesarios para que el niño pueda crecer o los cuidados de salud que necesita una persona cuando padece alguna enfermedad de tipo crónico. Esta responsabilidad de los hogares (en especial de las mujeres) sobre los menores y los mayores está estrechamente vinculada a las transformaciones en las formas familiares que están detrás del origen de la infancia.

El desarrollo histórico de la idea de infancia se relaciona con la aparición y definición del rol materno. El desarrollo del modelo actual de infancia consolida nuevas funciones para las mujeres. A lo largo del proceso sumarán a sus anteriores obligaciones en la economía doméstica, mayores responsabilidades en la crianza de los hijos (mucho más allá de las funciones meramente biológicas) y sobre todo en la educación y protección de los mismos. Todo ello sin que se haya alterado su situación subordinada con respecto al marido dentro del hogar. Se llega incluso, sobre todo en la segunda mitad de este siglo, a que incorporen incluso obligaciones como trabajadoras asalariadas.

De forma análoga a lo que ocurre en la infancia, se encuentra que si las personas mayores se convierten en personas dependientes debido al deterioro de la capacidad física o cognitiva también se esperará que sea la familia la que resuelva sus problemas. Esta labor se realizará de forma prioritaria por parte del propio cónyuge de la persona anciana con problemas de salud (sobre todo cuando es mujer) o por parte de las hijas de la persona anciana.

Se ha argumentado que el mercado de trabajo y las relaciones de parentesco actúan como nexo de unión entre las situaciones vividas 
por los menores y los mayores. Todavía se puede encontrar un tercer nexo en la forma en que el Estado plantea su política social en favor de estos colectivos. En este caso la definición predominante por parte de la política pública hacia estos colectivos se ha centrado en la idea de que son dependientes. En el caso de los niños la idea de dependencia se materializa sobre todo en la consideración de la infancia como una edad a proteger. En los casos como el español en los que las iniciativas en política familiar son tan limitadas (Iglesias de Ussel, 1998) esta orientación es perceptible en el desarrollo legislativo, en actuaciones concretas como la retirada de la tutela de los hijos o la persecución del maltrato infantil o en el establecimiento de ayudas económicas en favor de los menores (becas escolares, ayudas económicas por hijo o familia numerosa). Esta idea de dependencia se encuentra de forma en el caso de las personas mayores, tal y como argumenta Guillemard (1992) al analizar las políticas de vejez aplicadas en Europa tras la II Guerra Mundial, se ha convertido a lo que se ha llamado "Tercera Edad" en una edad dependiente. La autora señala que las iniciativas políticas se han centrado en aspectos tales como la institucionalización de las personas mayores o su medicalización.

Otros aspectos culturales unen las representaciones sociales de la infancia y la senectud. Algunos de ellos pueden parecer meramente anecdóticos o simplemente lógicos, pero en cualquier caso revelan la fuerza de las representaciones sociales. Estas edades de la vida presentan por ejemplo muy bajos niveles de nupcialidad. En el caso de los menores simplemente porque los matrimonios están prohibidos, pero en el caso de los mayores la prohibición legal no actúa. Son excepcionales los célibes, divorciados y viudos que a estas edades de la vida deciden unirse en matrimonio. De igual modo es llamativo que el celibato propio de los menores se extienda entre los más jóvenes quienes retrasan su edad hasta los treinta años. Quizá todos estos fenómenos tengan que ver con las responsabilidades que los actores sociales estamos asignando a los matrimonios en edad de procreación.

De igual modo se pueden destacar la semejanza entre las pautas de sociabilidad de los niños y los ancianos. Sobre todo en la primera infancia el círculo de relaciones sociales se limita a su círculo familiar. Tal y como señalaba Ariès esta pauta de sociabilidad en la infancia es típica de nuestras sociedades urbanizadas (e industrializadas) en las que la vida familiar dentro del hogar adquiere una especial densidad. De forma análoga en las personas mayores, la desvinculación del trabajo productivo puede suponer una reducción en los niveles de sociabilidad, que suelen verse muy afectados sobre todo en caso de enfermedad crónica hasta reducirse únicamente a las relaciones familiares. Por supuesto esto no ocurre en todos los casos, más aún cuando las perso- 
nas mayores no padecen procesos de enfermedad o cuando cuentan con otras fuentes de sociabilidad (por ejemplo, la de los vecinos, aunque esta es más fácil en el ámbito rural) o con redes de amistades que no estaban vinculadas al trabajo, sino al consumo cultural (lo que es más propio de clases sociales con altos niveles adquisitivos) (Due, 1999; Matthews, 1999; Requena, 1991 y 1996; Rosengren, 1993 y Stansfeld, 1999).

Después de la enumeración de las coincidencias existe al menos un punto en el que el tratamiento de la infancia y la vejez son claramente diferentes. En el campo de la educación se dibuja una diferencia fundamental puesto que mientras la infancia está marcada por la institución escolar apenas existen intentos de insertar a la población mayor en los procesos formativos (con excepciones como la Universidad Permanente en la Universidad de Alicante destinada a las personas mayores). En ocasiones incluso se han transmitido ideas sobre la incapacidad para aprender en esta edad. La falta de insistencia en la formación parece más relacionada con el valor laboral que se ha concedido a la educación por encima de otros valores como pueda ser la de desarrollo personal.

\section{REPERCUSIONES SOCIALES DE LAS REPRESENTACIO- NES SOCIALES DE LOS MENORES Y LOS MAYORES}

Una de las consecuencias de la definición de la infancia y la senectud como edades dependientes, y sobre todo, de su exclusión del mercado de trabajo, es que dependen de los sistemas de solidaridad que se establezcan para participar del consumo. Esto tiene importantes consecuencias. Las estadísticas sobre pobreza muestran de forma repetida que los niños y los ancianos tienen mayor probabilidad de situarse bajo la línea de pobreza (definida como la mitad de la mediana del ingreso disponible por hogar) en nuestro país y en la mayoría de los países de nuestro entorno (Smeeding, 1997). La situación de los menores y los mayores puede variar de unos países a otros en función de cómo se defina esta dependencia. En concreto en algunos países es la solidaridad familiar la que se supone que ha de atender las situaciones de los niños y ancianos, de manera que los ingresos de estos colectivos dependen de la redistribución en el interior de los hogares. En otros países sin embargo es el Estado mediante su política social el que se sitúa como primer responsable. De hecho es interesante observar como en algunos países no se cumple la norma de que los niños tengan una mayor vulnerabilidad frente a la pobreza. Uno de los casos más interesantes lo ofrece Finlandia, donde los hogares con niños tienen menor 
riesgo de estar bajo la línea de pobreza. Este hecho se puede relacionar con la existencia de toda una serie de subsidios universales (en forma de ayudas económicas y servicios sociales) destinados a la protección de la infancia y al estímulo de la incorporación de la mujer al trabajo (Gornick, 1997, 1998a y 1998b). Föster (1994) muestra que en países como Suecia, Holanda y el Reino Unido este tipo de ayudas suponen grandes reducciones en el índice Sen de pobreza de los hogares monoparentales. En Suecia este tipo de hogar llega a contar con niveles de pobreza inferiores a los de la media de la población. Por el contrario, en países como Estados Unidos, Australia y Canadá los impuestos y los subsidios sólo reducen muy ligeramente la pobreza de los hogares monoparentales. Este mismo autor ha mostrado que para 13 países de la OCDE existe una relación lineal entre el porcentaje que los gastos sociales suponen en el PIB y el porcentaje de hogares que se sitúan por debajo de la línea de pobreza. En el caso de los ancianos podemos encontrar que también se trata de un colectivo muy vulnerable frente a la pobreza (Rodríguez, 1994). En España la situación de los ancianos en los últimos años ha mejorado gracias a la consolidación de los sistemas de pensiones y a iniciativas como la posibilidad de acceder a pensiones no contributivas a partir de los 65 años, gracias a la reforma legal del año 1990 (Ley 26/1990). Es decir, la situación ha ido mejorando conforme el sistema ha pasado de la confianza en la solidaridad intergeneracional y en el salario familiar aportado por el marido, a un sistema que ha crecido de forma modesta en el reconocimiento de los derechos universales de las personas mayores.

TABLA 1. Porcentaje de hogares bajo la línea de pobreza.

\begin{tabular}{|l|c|c|c|c|c|}
\hline & Año & Todos & Mayores de 65 años & Adultos & Niños \\
\hline España & 1990 & 10,4 & 11,4 & 9,2 & 12,8 \\
\hline Finlandia & 1991 & 6,2 & 14,4 & 5,8 & 2,7 \\
\hline Noruega & 1991 & 6,6 & 13,5 & 5,4 & 4,9 \\
\hline Reino Unido & 1991 & 14,6 & 23,9 & 10,7 & 18,5 \\
\hline EE.UU. & 1994 & 19,1 & 19,6 & 16,4 & 24,9 \\
\hline
\end{tabular}

La línea de pobreza se establece en la mitad de la mediana del ingreso disponible por hogar ajustado por tamaño del hogar. El ajuste se realiza utilizando $E=0.5$, donde el ingreso ajustado es igual al ingreso total dividido por el tamaño del hogar elevado a E. Ingreso ajustado=ingreso total $/ S^{E}$. Elaboración a partir de datos del Luxembourg Income Study. Smeeding (1997).

Más allá de la riqueza de rentas, se puede observar el bienestar de los menores y los mayores en términos de capacidades. Entre ellas podemos seleccionar el caso de la educación para los menores y de la atención a la salud en el caso de los mayores. Si observamos las trayectorias en el sistema educativo de las niñas y niños españoles se 
puede comprobar que existen grandes diferencias en los niveles de realización escolar. En la tabla 2 se puede observar en qué medida el nivel de estudios del padre (el Instituto Nacional de Calidad y Evaluación no proporciona datos sobre la madre) determina las posibilidades educativas del niño. En concreto, mientras un $78 \%$ de las hijas de universitarios accede a la Universidad, sólo un $19 \%$ de las hijas de padres analfabetos o con estudios incompletos lo hace. Más interesante aún que este extraordinario nivel de desigualdad en la realización es el hecho de que mientras que un $85 \%$ de las hijas de universitarios que han completado los estudios que dan acceso a la Universidad finalmente acceden a la misma, entre las hijas de padres analfabetos sólo acceden un 55\% de las que podrían hacerlo. Evidentemente en esta elección no están incidiendo los niveles académicos, pues se cuenta con el nivel adecuado para acceder, sino otro tipo de condicionantes. Las causas, tal y como Boudon (2000) brillantemente ha explicado para el caso francés, se relacionan con el hecho de que los estudiantes toman esta

TABLA 2. Porcentaje de alumnos con posibilidad de acceder y que accede a la Universidad según el nivel de estudios del padre, 1987 y 1997.

Nivel de estudios del padre en 1987

\begin{tabular}{|c|c|c|c|c|c|}
\hline & & $\begin{array}{l}\text { Analfabetos } \\
\text { o con estudios } \\
\text { incompletos }\end{array}$ & $\begin{array}{l}\text { Estudios } \\
\text { primarios }\end{array}$ & $\begin{array}{l}\text { Estudios } \\
\text { medios }\end{array}$ & $\begin{array}{c}\text { Estudios } \\
\text { universitarios }\end{array}$ \\
\hline \multirow[t]{2}{*}{$\%$ con posibilidad de acceso } & Varones & 13 & 34 & 67 & 82 \\
\hline & Mujeres & 20 & 45 & 78 & 88 \\
\hline \multirow[t]{2}{*}{ \% que accede a la Universidad } & Varones & 5 & 15 & 41 & 64 \\
\hline & Mujeres & 9 & 25 & 53 & 69 \\
\hline \multirow[t]{2}{*}{ Relación acceso-posibilidad } & Varones & 36 & 45 & 62 & 78 \\
\hline & Mujeres & 44 & 56 & 68 & 79 \\
\hline
\end{tabular}

Nivel de estudios del padre en 1997

\begin{tabular}{|l|l|c|c|c|c|}
\hline & & $\begin{array}{c}\text { Analfabetos } \\
\text { o con estudios } \\
\text { incompletos }\end{array}$ & $\begin{array}{c}\text { Estudios } \\
\text { primarios }\end{array}$ & $\begin{array}{c}\text { Estudios } \\
\text { medios }\end{array}$ & $\begin{array}{c}\text { Estudios } \\
\text { universitarios }\end{array}$ \\
\hline \% con posibilidad de acceso' & Varones & 21 & 42 & 68 & 87 \\
\cline { 2 - 7 } & Mujeres & 34 & 58 & 82 & 91 \\
\hline \multirow{2}{*}{ \% que accede a la Universidad } & Varones & 9 & 21 & 43 & 67 \\
\cline { 2 - 7 } & Mujeres & 19 & 34 & 60 & 78 \\
\hline Relación acceso-posibilidad & Varones & 45 & 50 & 64 & 76 \\
\cline { 2 - 7 } & Mujeres & 55 & 58 & 73 & 85 \\
\hline
\end{tabular}

1. Con posibilidad de acceso: jóvenes de 19 a 23 años con el nivel de estudios requerido para acceder a la Universidad.

FUENTE: INCE, Sistema Estatal de Indicadores de la Educación, 2000. 
decisión haciendo una valoración de los costes económicos que supondría continuar con los estudios. La relación entre ventajas y costes es desfavorable en el caso de las hijas e hijos en familias con bajos ingresos y por ello renuncian a continuar los estudios incluso cuando ello sería posible. La necesidad de depender del hogar para las posibilidades educativas es la que determina el nivel de éxito en el sistema educativo, incluso una vez anulado el filtro de las calificaciones.

En el caso de la atención a la salud de las personas mayores podemos ver que se produce una situación similar en la medida que el nivel de atención que reciben también puede estar en relación con la posición socioeconómica del hogar en que se insertan. En el caso de las personas mayores con problemas de incapacidad física o psíquica la ayuda prestada por familiares es esencial para el mantenimiento de un determinado nivel de calidad de vida. Al menos así lo sugieren los datos de una encuesta estatal realizada por el INSERSO en 1995, según la cual las personas mayores de 65 años que necesitaban ayuda la recibían principalmente de familiares $(86,5 \%)$, en un $6,6 \%$ contratando empleados de hogar y en un 4,7\% de los servicios sociales públicos (Instituto Nacional de Servicios Sociales, 1995). En este sentido tiene gran relevancia la pregunta sobre en qué medida puede variar el grado de apoyo familiar recibido en función del nivel socioeconómico del hogar en el que se vive. Ofrecer datos concretos sobre este particular supone una gran dificultad dada la escasez de fuentes estadísticas que aporten información en un mismo cuestionario sobre la persona cuidadora, la persona dependiente y que, a la vez, determinen con suficiente precisión el nivel socioeconómico del hogar. El Panel de Hogares de 1994 puede servir modestamente a este propósito en la medida que al tratarse de una encuesta de presupuestos familiares permite clasificar a los individuos según el nivel de ingresos del hogar (en ingresos por unidad de consumo del hogar); es posible a su vez identificar a las personas con mala salud (las que señalan tener alguna incapacidad que le limita intensamente en su actividad diaria o las que dicen tener mala o muy mala salud) y, por último, puesto que se pregunta al conjunto de miembros de cada hogar, se puede identificar en qué hogares hay una persona prestando cuidados de salud y en cuáles no.

A partir de esta información se ha construido la tabla que se incluye a continuación. En ella se observa que, excluyendo a las personas que prestan cuidados de salud, hay un $4,5 \%$ de personas que viven en hogares en los que nadie presta cuidados de salud y, sin embargo, dicen padecer alguna incapacidad que les condiciona intensamente en su actividad diaria (tabla 3). Este fenómeno es producido por el gradiente social en la prevalencia de las discapacidades, esto es, porque existe una mayor concentración de personas con un grado intenso de limitación en su 
actividad diaria entre las personas con menos ingresos (Navarro y Benach, 1996; Regidor, 1994), pero también puede relacionarse con la menor capacidad de los hogares con menos ingresos para movilizar la solidaridad familiar. El resultado es que la probabilidad de encontrarse con un problema de salud grave y sin cuidados en la clase social baja es mayor que en las clases sociales altas. En concreto, esto le ocurre al $5,2 \%$ de las personas entrevistadas con un bajo nivel de ingreso, frente al 2,8\% de las personas con un alto nivel de ingreso. En esta tabla no se desglosan los datos para varones y mujeres dado que el número de casos en alguna de las celdas era excesivamente reducido.

TABLA 3. Porcentaje de personas mayores de 65 años con un problema de salud que les limita intensamente en su actividad diaria y que viven en hogares en los que no hay ninguna persona prestando cuidados de salud. Panel Europeo de Hogares para España, 1994. PHOGUE 1994.

\begin{tabular}{|l|c|c|c|c|c|}
\hline \multicolumn{5}{|c|}{ Cuartil de ingresos del hogar } \\
\cline { 2 - 6 } & Alto & Medio-alto & Medio-bajo & Bajo & Total \\
\hline Total & $2,8 \%$ & $4,2 \%$ & $5,7 \%$ & $5,2 \%$ & $4,5 \%$ \\
\hline
\end{tabular}

FUENTE: fichero de microdatos PHOGUE (elaboración propia).

Los ejemplos sobre la distribución de la renta, las oportunidades educativas o el grado de acceso al apoyo de los familiares en caso de enfermedad pueden servir para ilustrar en qué medida los datos contradicen en algunos puntos las visiones habituales sobre el papel que juegan las familias en estas edades de la vida. En el discurso político (en las representaciones socialmente compartidas) es habitual escuchar que la renta se redistribuye hacia los niños a través de los padres, que las redes de solidaridad familiar se estrechan y se hacen más sólidas en las clases desfavorecidas (también denominadas trabajadoras, populares, obreras, pobres, excluidas en función de los lenguajes, las teorías y las ideologías) o que existe igualdad de oportunidades educativas. Además de los datos aquí aportados, las investigaciones sobre distribución de la renta, sobre el sistema educativo y, en menor medida, sobre la familia, se han encargado de desmentir cada uno de estos puntos o al menos los han matizado considerablemente, sin embargo, siguen pensando en la configuración de las políticas hacia los mayores y los menores.

\section{MENORES Y MAYORES: IMÁGENES INVERTIDAS PRO- YECTADAS SOBRE UN MISMO ESPEJO}

La infancia y la jubilación se presentan como excluidas del mercado de trabajo. La valoración de esta exclusión puede variar. En algunos 
casos se contempla como derechos adquiridos en esas edades de la vida (protección de la infancia, derecho al descanso y a la protección de la salud en la última edad de la vida), en otras casos la falta de participación en el mercado de trabajo se interpreta como una limitación injustificada de la libertad y de las oportunidades vitales (sobre todo en el caso de la jubilación). Con independencia de la valoración que cada uno haga de esta exclusión, como se ha argumentado, se puede discutir el que realmente estos colectivos estén excluidos del mercado laboral. Desde el inicio de la edad escolar y de forma mucho más evidente, desde el final de la escolarización obligatoria toda persona sigue una trayectoria educativa que va definiendo su identidad como trabajador (el tipo de oficio, o mejor dicho, de oficios que desempeñará), pero también y sobre todo el tipo de condiciones de trabajo a las que puede aspirar. Por su parte, para las personas mayores existe una relación directa entre su trayectoria laboral y la pensión que reciben, los planes de pensiones privados de los que algunos disfrutan, el seguro médico que les atiende o los niveles de servicios que les garantizan sus mutuas o la seguridad social. La relación es aún más evidente para las que no tuvieron una trayectoria laboral reconocida por las instituciones por dedicarse al trabajo doméstico o a actividades informales o interrumpidas por las obligaciones familiares, sobre todo mujeres. La idea de exclusión puede llevar a una percepción equivocada de las luchas de intereses que se enfrentan al abordar las políticas dirigidas a los menores y los mayores. Cuando se planifica una reforma del sistema educativo, cuando se alteran los sistemas de acceso a los diferentes tipos de estudio, cuando se deciden las fuentes de financiación para las escuelas públicas y privadas se están definiendo la estructura del mercado de trabajo en los próximos años. Así los grandes saltos cualitativos y cuantitativos entre los niveles de calidad de las enseñanzas profesionales y universitarias responden a la distinción ya clásica entre trabajos manuales y no manuales, la cual contribuyen a reforzar. De igual modo dentro de la enseñanza universitaria las diferencias entre las distintas carreras en los niveles de financiación, de dotación de infraestructuras y de profesorado (por ejemplo a través del reconocimiento de diferentes grados de experimentalidad), en el establecimiento de números límites de admisión, en la duración de los ciclos formativos o de posibilidades de obtención de becas de investigación son un reflejo de las diferentes posiciones ocupadas en el mercado de trabajo por las distintas profesiones. Las reformas educativas contribuyen a aumentar las diferencias o a disminuirlas, de ahí su importancia y el debate que suscitan.

Lo mismo ocurre en el caso de las personas mayores. Los debates sobre la política de pensiones no pueden entenderse sin referencia al 
mercado de trabajo. La alteración en las prestaciones económicas (la cuantía de las pensiones) o sociales (como el seguro de dependencia) recibidas por las personas mayores supone directamente una alteración de las condiciones del mercado de trabajo, de los sistemas de protección establecidos para los trabajadores, de las formas de contratación, de las obligaciones fiscales para trabajadores y empresas. De hecho esto es algo reconocido en la medida que se reconoce como interlocutores válidos en las mesas de negociación sobre pensiones a sindicatos y patronal.

Pero entonces, ¿por qué seguir hablando de exclusión del mercado de trabajo de los menores y los mayores?. Sin entrar en las motivaciones que puede haber detrás de la enunciación de una idea, sin duda variadas, el mantenimiento del pensamiento de que estos grupos de edad no están relacionados con el mercado de trabajo contribuye en poco a reducir las desigualdades que se producen en el interior de estos grupos (en niveles de consumo, en oportunidades educativas, en protección frente a la pobreza, en calidad de vida).

Cuando la conexión con el mercado de trabajo no es visible las soluciones a plantear para la resolución de los problemas que afectan a la infancia y a la senectud se reducen a la política social y a las posibilidades que ofrezca la solidaridad familiar.

En el plano ideológico una de las soluciones más frecuentemente planteadas para resolver los problemas de los menores y los mayores es reforzar, incentivar o mantener los actuales niveles de solidaridad familiar. En sus formas más acentuadas el familismo defendería que la reciprocidad familiar es la forma de extensión del bienestar y los beneficios obtenidos por los trabajadores hacia los niños, los ancianos y las mujeres (inactivas). Esta ideología se ve correspondida en países como España por una realidad empírica en la que se encuentran sólidos lazos familiares que actúan protegiendo a dichos colectivos. Desde esta perspectiva la política social cumpliría la función de cumplimentar los huecos no cubiertos por la solidaridad familiar. La casuística de grupos a proteger puede variar, pero normalmente tiende a incluir: niños en "familias desestructuradas", niños víctimas de la violencia, niños huérfanos, ancianos sin familia o las viudas. Las medidas que se arbitran tienen un carácter limitado: pensiones no contributivas de baja remuneración (en España en el año 2000 la cuantía era de 40.260 ptas/mes), acogimientos familiares, prever (un bajo número de) plazas en residencias públicas para ancianos sin familia (Pérez Díaz, 1998; Defensor del Pueblo, 1990).

Si bien se ha comentado que el familismo en el caso español cuenta con el apoyo de que en la realidad social española la familia proporcio- 
na una amplia red de solidaridad, no obstante puede obviar toda una serie de costes sociales y deficiencias de un sistema de bienestar que confía en los hogares. En primer lugar se puede destacar el amplio coste (a menudo invisible) que recae en las mujeres, sobre todo debido a cuestiones tales como la crianza de niños o la atención a personas mayores que suponen importantes limitaciones en sus oportunidades laborales, en su independencia económica y en su disponibilidad de tiempo (Durán, 1999). En segundo lugar, los hogares con menos ingresos tienen menos recursos para la movilización de la solidaridad familiar. Las clases sociales desfavorecidas cuentan por ello con menores oportunidades educativas para sus hijos, menor nivel de atención familiar cuando se es una persona mayor enferma o la necesidad de realizar mayores inversiones de tiempo a la hora de atender a familiares ancianos o enfermos (La Parra, 2001).

La visión de los menores y los mayores como grupos caracterizados por la edad ha contribuido a hacer menos visibles las desigualdades que se dan en el interior de estos colectivos. Dichas desigualdades están relacionadas, por un lado, con las particulares formas de adscripción de estos colectivos al mercado de trabajo. Por otro lado, se relacionan con las desiguales capacidades de los hogares, las familias si se prefiere, para proporcionar las mismas oportunidades a los niños, o los mismos niveles de atención a la salud a los mayores. Sin embargo, la existencia de estas amplias redes de solidaridad familiar en el caso español tienen el efecto de hacer invisibles las desigualdades que se derivan de fundamentar la participación en la sociedad de estos grupos de edad en las relaciones familiares. La política social puede contribuir a la reproducción de estos esquemas o a su sustitución por nuevas formas de definir la participación de las personas, más concretamente de los menores y los mayores, en la sociedad.

En el primer caso (el familista), como se ha visto, se definirán medidas políticas destinadas a cubrir los casos en los que la red familiar no cubre su "función". En un segundo caso, de carácter más universalista, según la clasificación de (Esping Andersen -1993-), las medidas adoptadas se entienden como derechos compartidos por todos los menores o los mayores, cualesquiera que sea su situación familiar, social o económica. Esta forma de protección propia de los países nórdicos europeos garantiza unos elevados niveles de calidad de vida, así como unas bajas tasas de pobreza en los menores y los mayores, y mayores oportunidades vitales para las mujeres. 


\section{BIBLIOGRAFÍA}

ARIÈS, P.: L'enfant et la vie familiale sous L'Ancian Régime. Seuil, París, 1973.

BOUDON, R., CUIN, CH. y MASSONT, A.: L'axiomatique de l'inégalité des chances. L'Harmattan, París, 2001.

CASTELLS, M. y ORTIZ, LP.: Análisis de las políticas de vejez en España en el contexto europeo. Ministerio de Asuntos Sociales, Instituto Nacional de Servicios Sociales, Madrid, 1992

DEFENSOR DEL PUEBLO: Residencias públicas y privadas de la Tercera Edad. Madrid, 1990.

DUE, P. et al.: "Social Relations: network, support and relational strain", Social Science and Medicine, 1999, 48: 661-673.

DURÁN, MA.: Los costes invisibles de la enfermedad. Fundación BBV, Madrid, 1999.

ESPING-ANDERSEN, G.: Los tres mundos del estado del bienestar. Alfons el Magnànim, Institució Valenciana d'Estudis i Investigació, Valencia, 1993.

FÖRSTER, MF.: "Measurement of low incomes and poverty in a perspective of international comparisons", OCDE Labour market and social policy occasional papers, 1994, n¹4, OCDE/GD (94) 10.

GORNICK, JC. y JACOBS, JA.: "Gender, the Welfare State, and Public Employment: A Comparative Study of Seven Industrialized Countries", American Sociological Review, 1998, 53: 688-710.

GORNICK, JC., MEYERS, MK. y ROSS, KE.: "Public policies and the Employment of Mothers: A Cross-National Study". Social Science Quaterly, 1998, 79:35-54.

GORNICK, JC., MEYERS, MK. y ROSS, KE.: "Supporting the employment of mothers: policy variation across fourteen welfare states", Journal of European Social Policy, 1997, 7: 45-70.

GUILLEMARD, AM.: Análisis de las políticas de vejez en Europa. Ministerio de Asuntos Sociales. Instituto Nacional de Servicios Sociales, Madrid, 1992.

IGLESIAS DE USSEL, J.: La familia y el cambio político en España. Tecnos, col. de Ciencias Sociales, Madrid, 1998.

INSTITUTO NACIONAL DE SERVICIOS SOCIALES: Cuidados en la vejez. El apoyo informal. Ministerio de Asuntos Sociales, Madrid, 1996.

LA PARRA CASADO, D.: "Contribución de las mujeres y de los hogares más pobres a las producción de cuidados de salud informales", Gaceta Sanitaria, 2001, 15: 498-505.

MATTHEWS, S., STANSFELD, S. y POWER, C.: "Social support at 33: the 
influence of gender, employment status and social class", Social Science and Medicine, 1999, 49: 133-142.

NAVARRO, V. y BENACH, J.: "Informe de la Comisión Científica de Estudios de las Desigualdades Sociales en Salud en España”, Revista de Salud Pública, 1996, 70: 505-636.

PÉREZ DÍAZ, C., CHULIÁ, E., y ÁLVAREZ MIRANDA, E.: Familia y sistema de bienestar. La experiencia española en el paro, las pensiones, la sanidad y la educación. Argentaria, Madrid, 1998.

REGIDOR, E., GUTTÉRREZ-FISAC, JL. y RODRÍGUEZ, C.: Diferencias y desigualdades en salud en España. Díaz de Santos, Madrid, 1994.

REQUENA SANTOS, F.: Redes sociales y cuestionarios. CIS, Cuadernos metodológicos, Madrid, 1996.

REQUENA SANTOS, F.: Redes sociales y mercado de trabajo. CIS/ Siglo XXI, Madrid, 1991.

RODRÍGUEZPASCUAL, I.: “ ¿Sociología de la infancia? Aproximaciones a un campo de estudio difuso". Revista Internacional de Sociología, 2000, 26 : 99-124.

RODRÍGUEZ, JA.: Envejecimiento y familia. CIS, Madrid, 1994.

ROSENGREN, A., ORTH-GOMER, K., WEDEL, H. y WILHELMSEN, L.: "Stressful life events, social support, and mortality in men born in 1933". British Medical Journal, 1993, 307: 1102-105.

SMEEDING, TM.: "Financial Poverty in Developed Countries: the Evidence From the Luxembourg Income Study", Poverty and Human Development, Human Development Report Office, the United Nations Development Programme, New York, 1997.

STANSFELD, SA.: "Social support and social cohesion", en Marmot, M. y Wilkinson, RG. (eds.) Social Determinants of Health. Oxford University Press, New York, 1999. 


\title{
LA PROTECCIÓN SOCIAL EN EL ESTE DE EUROPA: EL CASO POLACO
}

\author{
FRANCISCO RÓDENAS RIGLA ${ }^{1}$ \\ JORGE GARCÉS FERRER ${ }^{2}$ \\ Unidad de Investigación Políticas de Bienestar Social. Universitat de València.
}

\section{INTRODUCCIÓN}

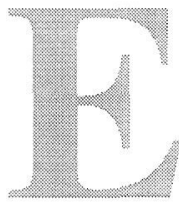

n Polonia existe un sistema democrático que, tras cuatro procesos electorales (el más reciente celebrado el pasado 8 de octubre de 2000 que concluyó con la reelección de Kwasniewski como presidente), comienza a estabilizarse y permite la coexistencia de partidos políticos de ideología muy variada (Szczerbiak, 1999). Asimismo, cuenta con un marco constitucional muy reciente (la última Constitución data de 1997) que reconoce la separación de poderes y recoge los principales derechos sociales junto a los derechos políticos e individuales. Respecto al ámbito institucional es importante destacar la progresiva creación de las estructuras necesarias para hacer frente al cambio drástico que ha vivido el pueblo polaco, ya que en una década se ha destruido la organización del régimen comunista y se está creando una nueva estructura "ad hoc".

Sus indicadores macroeconómicos, tras la aplicación de la terapia de choque auspiciada por Balcerowicz, nos muestran un país que se sitúa a la cabeza de los estados de Europa del Este dispuesto a entrar en el mercado de la Unión Europea (UE) a cualquier precio ${ }^{3}$. Es más, Polonia es considerada por diferentes organismos internacionales -FMI, Banco Mundial o OCDE-, pese a sus desequilibrios regionales (Despiney,

Titular E.U., Facultad de Ciencias Sociales, Universitat de València. E-mail: Francisco.Rodenas@uv.es

2 Catedrático E.U., Facultad de Ciencias Sociales, Universitat de València. E-mail: Jordi.Garces@uv.es

3 Sobre este tema pueden consultarse AHIJADO, M. y OSUNA, R. (1999): Unión Económica y Monetaria Europea. La ampliación al Este I, II, Pirámide, Madrid; BLAZYCA, G. (1999): "Polish Socioeconomic Development in the 1990s and Scenarios for EU Accession", Europe-Asia Studies, vol. 51, n 5, p. 799-819. 
1999), una de las economías en transición más exitosa y abierta dado su elevado nivel de crecimiento económico (superior al 5\% desde 1993 hasta 1999), la drástica reducción de su inflación (del 585\% en 1990 al $5.6 \%$ en 1999) y la disminución de su déficit público (próximo al $3 \%$ del PIB en 1998) y de la deuda externa (46.8\% del PNB). Asimismo, ha llevado a cabo procesos de liberalización de precios, diversas reestructuraciones fiscales y monetarias, un amplio plan de privatizaciones, una reorganización de su sistema financiero y una apertura al comercio exterior. Pero aquí no acaba todo. ¿Cuál ha sido y está siendo el precio que tiene que pagar el pueblo polaco?

Estos datos contrastan con algunos indicadores socioeconómicos que dejan entrever una degradación del nivel de vida en Polonia. De esta forma, observamos como entre 1989 y 1997 ha aumentado en un $21.5 \%$ la desigualdad en la distribución de los ingresos, se ha abierto más la brecha que separa el acceso al consumo entre la población más pobre y la más rica (el $10 \%$ más rico tiene acceso al $22.1 \%$ del consumo total, mientras que el $10 \%$ más pobre se queda con el $4 \%$ del mismo) y ha emergido la pobreza, representada en el $23.8 \%$ de la población situada por debajo del mínimo de subsistencia nacional o en el $15.1 \%$ de la misma con menos de dos dólares al día para sobrevivir, según los indicadores de Desarrollo Mundial 1999 del Banco Mundial ${ }^{4}$. Además, durante la transición se han reducido los ingresos de la población polaca vía salarios, al mismo tiempo que crecía el desempleo, éste último compensado en parte al facilitar el acceso a diversas prestaciones sociales (subsidios de paro, pensiones de jubilación, invalidez o enfermedad y subsidios familiares) que han incrementado la presión sobre el gasto social. Aunque es cuestionable la contribución de estas ayudas económicas al mantenimiento del nivel de renta de la población polaca, dada la escasa cuantía de las mismas y su degradación progresiva respecto a los salarios medios.

En relación con la oferta pública, es decir, la distribución del gasto social, destaca la retirada del Estado como principal responsable de la financiación del sistema de Seguridad Social, que pasa a depender de las aportaciones de empresarios y trabajadores, el incremento de las transferencias en metálico relativas a beneficios sociales (especialmente pensiones) y el descenso de las subvenciones en especie (alimentación,

4 El Fondo Monetario Internacional ha realizado diversos informes sobre el aumento de la desigualdad en Polonia. KEANE, M. \& PRASAD, E. (1999): "Consumption and Income Inequality in Poland During the Economic Transition", IMF Working Paper, WP/99/14; KEANE, M. \& PRASAD, E. (2000): “Inequality, Transfers and Growth: New Evidence from the Economic Transition in Poland", IMF Working Paper, WP/00/ 117. 
transporte público o conservación de la vivienda) (Erdmann, 1998). Los datos del Informe Mundial de la Salud 2000 de la OMS nos indican que el gasto sanitario, en relación con el PIB, disminuye y se privatiza. Paralelamente, el presupuesto de la Administración destinado a políticas activas de empleo se estanca y se reduce la aportación pública dirigida a mantener las medidas de garantía de rentas (en particular la destinada a sufragar programas de jubilación anticipada).

Entre los cambios que se están produciendo en la demanda, es decir, las características sociodemográficas en Polonia, destacamos el envejecimiento de la población -mayoritariamente femenina- (entre 1999 y el año 2050 se duplicará la población mayor de 60 años, pasando a representar un tercio del total de población), el incremento de la esperanza de vida (situada en 1998 en 68 años para varones y 77 para mujeres), el descenso de la ratio de apoyo potencial a los mayores de 65 años (de 6 personas entre 15 y 64 años en 1999, se pasará a sólo 2 personas de esa edad en 2050 que podrán atender a cada mayor de 65 años) y la entrada en el mercado de trabajo de las nuevas generaciones, resultado de periodos de fuerte natalidad (entre 1999 y el año 2010 la oferta de mano de obra se incrementará anualmente en más de 500.000 jóvenes). En definitiva el gobierno polaco deberá hacer frente a un aumento de las tasas de dependencia vinculadas al incremento de la población mayor, junto a la demanda de más servicios sociosanitarios y a las presiones sobre el mercado de trabajo de las nuevas generaciones.

Ante esta situación la Administración polaca, siguiendo las recomendaciones de diversos organismos internacionales, apuesta por modelos neoliberales de privatización tanto en el sistema de pensiones como en el sanitario. Estos cambios no beneficiarán en los próximos años a la población, en especial a los mayores, dados sus escasos recursos económicos (bajas pensiones, que tienen que complementar con actividades laborales a tiempo parcial) y la mayor incidencia de problemas degenerativos y enfermedades crónicas propias del envejecimiento. Además, en una etapa en la que los trabajadores necesitan más protección pública, las autoridades polacas apuestan por posturas corporatistas que implican una menor participación del Estado en la regulación del mercado de trabajo, que deja la negociación relativa al ámbito laboral en manos de los representantes sindicales y empresariales que no cuentan con la suficiente experiencia, representatividad e interés por el diálogo social. 


\section{PRINCIPALES REFORMAS SOCIALES}

En 1999 el gabinete del Primer Ministro -Jerzy Buzek-, además de un proceso de descentralización administrativa, puso en marcha un programa de transformación de los principales sectores públicos, entre los que se incluyen: la educación, el cuidado de la salud y las pensiones de jubilación. En este trabajo se analizará la reforma de los dos últimos, junto a los cambios introducidos en el mercado de trabajo.

La primera reforma que se implantó a principios de 1999 fue la de la propia Administración, alterando las formas de financiación de las instituciones públicas y estableciendo una nueva división administrativa del país. Los principales cambios en la Administración del Estado consisten en la descentralización del poder y en la modificación de los mecanismos de distribución de los recursos presupuestarios. Se pretende dotar a las comunidades locales de un mayor margen de independencia en su gestión y de una mayor participación en las decisiones relativas a la distribución de los fondos económicos. Esta reforma está motivada por la experiencia de ocho años de autonomía municipal que ha corroborado el hecho de que las autoridades locales, elegidas democráticamente, son más competentes que la Administración Central al tratar los asuntos públicos de su ámbito territorial y gestionar el dinero de los contribuyentes.

La reforma respeta el nivel municipal ("gminas") e introduce dos nuevos niveles: el distrito ("poviats") y la región ("voivodship"). En lugar de los anteriores 49 voivodships se establecen 16 grandes regiones desde las que lanzar los programas de desarrollo económico y social. Estas nuevas regiones son: Dolnoslaskie, Kujawsko-Pomorskie, Lodzkie, Lubelskie, Lubuskie, Malopolskie, Mazowieckie, Opolskie, Podkarpackie, Podlaskie, Pomorskie, Slaskie, Swietokrzyskie, Warminsko-Mazurskie, Wielkopolskie y Zachodniopomorskie. La nueva estructura administrativa no implica teóricamente una reducción de las responsabilidades municipales, sino una descentralización de competencias - con la consiguiente dotación económica- desde la Administración Central hacia las autoridades de los distritos y regiones. Sin embargo, estos cambios, en especial la reorganización provincial, despiertan cierta desconfianza entre la población temerosa de que su región pierda parte de su influencia en el ámbito nacional.

El anterior sistema educativo polaco ha sido criticado desde diversos organismos internacionales por reforzar las desigualdades sociales y no contribuir a reducir el desempleo. Por ello el objetivo principal de la reforma de este sistema, iniciada en septiembre de 1999 y que se prolongará aproximadamente hasta el año 2004, es elevar el grado de for- 
mación de la generación más joven y equiparar las oportunidades educativas de los jóvenes pertenecientes a diferentes grupos sociales ${ }^{5}$. Los cambios afectan especialmente a la enseñanza primaria-que tiene una duración de 6 años-y secundaria donde se establece la posibilidad, tras los tres primeros años de formación genérica, de pasar a un ciclo de formación especializada de tres años o a un centro de formación profesional durante dos años. Además, para superar los estudios es necesario aprobar un examen final establecido por una comisión externa. La reforma educativa también significa un cambio de currículum, desde un conocimiento enciclopédico a una formación más práctica y adaptada al contex to económico, social y político. Asimismo, en este nuevo marco se liberaliza la enseñanza privada.

Como resultado de la reforma de la Administración se pretende que la mayoría de los centros educativos sean transferidos a los municipios y distritos, incrementando la influencia de las comunidades locales en el funcionamiento de los mismos. Los autogobiernos locales serán responsables de las competencias educativas en su área, gestionando para ello los recursos presupuestarios necesarios. No obstante, el gobierno polaco se enfrenta al descontento de los profesionales de este sector que reivindican desde hace años una mejora de sus condiciones salariales ${ }^{6}$.

En el ámbito de la salud la privatización del sistema sanitario, con la introducción de fondos regionales de salud y la firma de contratos con entidades privadas y profesionales del sector, se está realizando en un contexto en el que el gobierno debe hacer frente a los problemas derivados de una infraestructura muy deteriorada, que cuenta con escasos recursos, y al descontento generalizado de los diferentes grupos de profesionales sanitarios (motivado, principalmente, por sus bajos salarios). La reforma de las pensiones se apoya, como veremos, en tres pilares: a) el flujo de primas de los trabajadores hacia los pensionistas (sustentado en el anterior sistema de reparto), b) la creación de fondos privados de pensiones y c) la promoción adicional de planes de pensiones. El cambio progresivo desde un sistema de reparto a otro de capitalización pretende financiarse, fundamentalmente, mediante una parte de los ingresos obtenidos en el proceso de privatización. Vamos a ir desgranando todas estas cuestiones progresivamente.

5 Sobre la reforma del sistema educativo polaco es interesante consultar el trabajo de STEIERJORDAN, S. (1999): "Educational System and Educational Reform in Poland: Change and Continuity", in Osteuropa, Vol. 49, $\mathrm{n}^{\circ} 2$, p. 130-144.

- Según datos de la Oficina Central de Estadísticas Polaca el salario medio neto en el sector educativo en 1999 era un $12.7 \%$ más bajo que el salario medio para toda la economía (1049,61 y 1202,24 zl, respectivamente). 


\subsection{Programa de reestructuración del sistema nacional de salud.}

En los primeros años de la transición el sistema polaco de sanidad heredado del régimen comunista, pese a estar basado en el principio de universalidad y gratuidad, fue testigo del crecimiento de las desigualdades regionales y del progresivo recorte del gasto público, con el consiguiente deterioro de la calidad de los cuidados sanitarios (Chawla, Berman \& Kawiorska, 1998). Para resolver esta situación el gobierno ha ido introduciendo diversas reformas dirigidas básicamente a destruir el monopolio estatal en el ámbito de la salud, especialmente a través de la transferencia de competencias a las regiones y ayuntamientos, y a permitir la entrada del sector privado en la provisión de servicios sanitarios. Así, en Polonia el total de gasto sanitario en 1995 representaba un $6 \%$ del PIB y el sector público cubría el $83 \%$ del mismo $(5.0 \%$ sobre el PIB), tres años después la aportación pública había descendido situándose en el $71.2 \%$ (4.2\% sobre el PIB) ${ }^{7}$ (tabla 1 ).

TABLA 1: Gasto sanitario en los países de Europa del Este

\begin{tabular}{|l|c|c|c|c|c|c|}
\hline \multirow{2}{*}{ Países } & \multicolumn{2}{|c|}{ Gasto sanitario per cápita } & \multicolumn{4}{|c|}{ Gasto en sanidad 1998 } \\
\cline { 2 - 7 } & PPP \$ 1998 & $\$ 1998$ & $\begin{array}{c}\text { Todal } \\
(\% \text { delPB) }\end{array}$ & $\begin{array}{c}\text { Gastopúblico } \\
(\% \text { delPIB) }\end{array}$ & $\begin{array}{c}\text { Gastoprivado } \\
\text { (\% delPIB) }\end{array}$ & $\begin{array}{c}\text { Sector público } \\
\text { (\% de total) }\end{array}$ \\
\hline Polonia & 449 & 242 & 5.9 & 4.2 & 1.7 & $71,2 \%$ \\
\hline Hungría & 638 & 290 & 6.4 & 4.1 & 2.0 & $64,1 \%$ \\
\hline República Checa & 865 & 384 & 7.0 & 6.4 & 0.6 & $91,4 \%$ \\
\hline Eslovenia & 1.115 & 768 & 7.8 & 6.8 & 1.0 & $87,2 \%$ \\
\hline Estonia & 492 & 230 & 6.4 & 5.1 & 1.4 & $79,7 \%$ \\
\hline
\end{tabular}

* PPP $=$ Paridad de poder adquisitivo (Purchasing Power Parities)

FUENTE: The World Bank, World Development Indicators, 2000; WHO, The World Healt Report, 2000.

En 1999 la Administración polaca puso en marcha un programa de reestructuración del sistema de salud desde el ámbito regional, motivado por el aumento de los gastos generados por la necesaria introducción de nueva tecnología, la evolución de la demanda debida al proceso de envejecimiento y la exigencia de la población de más y mejores servicios. Los objetivos de este programa, en teoría, son:

a) Una descentralización de la política regional de sanidad hacia el ámbito local, teniendo en cuenta los cambios sociodemográficos y la situación económica regional.

${ }^{7}$ Según datos de la OMS en 1996 el porcentaje de gasto sanitario en Polonia sobre el total del gasto público era del $9.5 \%$, esta cifra se situaba, por ejemplo, en el $16.5 \%$ en Alemania y en el $13.3 . \%$ en España. 
b) La reorganización de los recursos sanitarios, considerando la existencia de servicios sanitarios privados.

c) La activación de un plan de privatización.

d) La puesta en marcha de un programa de renovación de la atención primaria en el ámbito local.

e) La reestructuración de la plantilla y la cualificación del personal en coordinación con las oficinas regionales de trabajo.

Para aplicar este programa las instituciones sanitarias pueden solicitar ayudas dirigidas a la investigación, la compra de material médico o la modernización de sus unidades e infraestructuras. Asimismo, se crean Grupos Regionales de Apoyo constituidos por expertos exteriores y empresas de consulting para ayudar a preparar los programas en cada región. La distribución de los recursos económicos entre estas últimas se establece de la siguiente forma ${ }^{8}$ :

- El 70\% se determina a través de un algoritmo diseñado por el Ministerio de Sanidad que, entre otras variables, utiliza el número de habitantes de cada región.

- El 30\% restante depende de la calidad del programa y de los informes de las juntas regionales, de distrito y locales.

El presupuesto destinado por la Administración pública en el año 2000 al programa de reestructuración del sistema sanitario, según datos del ZUS (Consejo de Seguridad Social Polaco), fue de 355 millones de zl, repartidos de la siguiente forma: 177 millones para gastos de inversión, 148 para gastos corrientes y 30 millones para otros gastos (reestructuración de plantillas, etc.). El Banco Mundial aportó un crédito adicional de 50 millones de $z l$ dirigidos, principalmente, a crear nuevos centros especializados - como hospitales para crónicos- y a ofrecer formación a los profesionales del sector.

Por otra parte, la reforma sanitaria de 1999 introdujo un nuevo sistema de seguro de enfermedad que funciona a través de fondos de salud regionales ${ }^{9}$, supuestamente sin ánimo de lucro, que recogen las primas de los trabajadores y desde los que se pagan los beneficios médicos al asegurado. La nueva estructura de fondos de salud está integrada por 16 fondos regionales (cada uno de ellos cubre un mínimo de un millón

8 El Comité Nacional de Dirección y Valoración del Prograna Regional prepara la propuesta de distribución de recursos, aunque es el Ministerio de Sanidad quien toma la decisión definitiva.

9 Ley $\mathrm{n}^{\circ}$ 929, de 9 de noviembre de 1998, de corrección de la ley que establece el sistema Universal de Seguros de Salud (Dziennik Ustaw, 1998-11-27, n/144). Ley n 153, de 6 de febrero de 1996, que establece el Seguro Nacional de Salud (Dziennik Ustaw, 1997-0326, n/ 28). 
de asegurados) más un fondo "categorial" suplementario, que actúa a escala nacional (OCDE, 2000). Este último ha sido creado para cubrir a los trabajadores de los Ministerios de Defensa, Interior, Justicia y Transportes. Los fondos de salud son directamente financiados por las primas del seguro de enfermedad recogidas por el ZUS y el KRUS (Fondo de Seguros Sociales de los agricultores), que las canalizan automáticamente hacia el fondo seleccionado por el contribuyente, así como por las subvenciones eventuales ingresadas por el Ministerio de Sanidad en concepto de programas particulares y la participación de los fondos de compensación.

Con esta reforma también se pretende que los asegurados puedan elegir médico e institución sanitaria en la que quieren ser atendidos, y que la nómina de personal médico quede condicionada a la calidad de su trabajo y al número de pacientes que atiendan. Paralelamente, se separan las funciones de comprador y proveedor de servicios de salud para promover la competencia entre estos últimos.

El control del funcionamiento del nuevo sistema de fondos se realiza a través de Consejos de Vigilancia Regionales, compuestos por representantes de los asegurados y de las autoridades locales y regionales. Complementariamente, se crea una Oficina de Vigilancia del Seguro de Enfermedad que ejerce el control global de la gestión financiera del conjunto de fondos. Las competencias de esta Oficina abarcan los siguientes aspectos: validar los estatutos y las resoluciones preparadas por los consejos de los fondos, verificar el respeto de los contratos entre éstos y los prestadores, aprobar los informes financieros de los fondos, efectuar auditorías, poner en marcha y hacer cumplir un procedimiento de ajuste, en función de los riesgos, entre los diferentes fondos, y controlar la recogida de primas y la transferencia de las cotizaciones del ZUS y del KRUS.

Entre los puntos conflictivos de esta reforma se encuentran: el diseño de los dispositivos de pago por la prestación de servicios; la definición operativa de lo que constituye el conjunto mínimo garantizado de prestaciones, sin el que es difícil concebir una fórmula contractual entre los fondos y los proveedores de servicios; y la necesidad de asegurar la igualdad entre regionales. Por otra parte, no se han determinado claramente las estrategias de control del gasto que aplicarán los fondos. El proyecto inicial de reformas preveía permitir la creación de nuevos fondos y posibilitar la competencia en la búsqueda de "clientes", a partir del año 2001, como medio para estimular la disciplina financiera. Pero dicha competencia entre aseguradores conlleva efectos perversos como la selección de las personas que presentan un menor riesgo. Organizaciones internacionales, entre ellas la $\mathrm{OCDE}$, recomiendan utilizar otros 
sistemas de control, en particular aquellos que impliquen aumentar la responsabilidad del equipo de gestión del fondo respecto a sus resultados financieros y la satisfacción de sus asegurados, introduciendo incentivos ante resultados positivos y sanciones en caso contrario.

En definitiva, el gobierno polaco apuesta por una menor presencia pública en el sistema sanitario, dejado en manos del mercado tanto la gestión económica del seguro de enfermedad como la prestación de los servicios de salud.

\subsection{La reforma del sistema de pensiones de jubilación.}

En el primer informe de la OCDE de 1992 sobre Polonia ya se señalaba que el sistema de pensiones de jubilación por reparto, de cobertura casi universal, no era viable dada su utilización política para mitigar las presiones del mercado de trabajo (en la tabla 2 se aprecia el incremento considerable del número de pensionistas durante los primeros años de la transición que no se corresponde con el crecimiento de la población mayor de 60 años en ese período) ${ }^{10}$. En respuesta a esta situación el Estado ha ido impulsando diversas medidas para reducir la generosidad del mismo, pero la reforma del conjunto del sistema ha sido postergada de forma reiterada. Hasta finales de 1996 no se lanzó una actuación más amplia que incluía la elaboración de un proyecto completo de reforma. Y aunque ésta debía iniciarse en enero de 1999, las principales leyes fueron adoptadas en $1997^{11}$.

TABLA 2: Media anual de jubilados y pensionistas polacos (en miles)

\begin{tabular}{|l|r|r|r|r|r|r|r|r|r|r|c|}
\hline Pensionistas & 1990 & 1991 & 1992 & 1993 & 1994 & 1995 & 1996 & 1997 & 1998 & 1999 & $2000 \%$ \\
\hline $\begin{array}{l}\text { Asslariados } \\
\text { (profesionales) }\end{array}$ & 5.598 & 6.154 & 6.505 & 6.703 & 6.873 & 7.036 & 7.172 & 7.313 & 7.466 & 7.524 & 7.551 \\
\hline Variaciónanual & & $9,9 \%$ & $5,7 \%$ & $3,0 \%$ & $2,5 \%$ & $2,4 \%$ & $1,9 \%$ & $2,0 \%$ & $2,1 \%$ & $0,8 \%$ & $0,4 \%$ \\
\hline Agriculiores & 1.506 & 1.790 & 1.990 & 2.027 & 2.046 & 2.049 & 2.028 & 2.001 & 1.969 & 1.929 & 1.907 \\
\hline Variaciónanual & & $18,9 \%$ & $11,2 \%$ & $1,9 \%$ & $0,9 \%$ & $0,1 \%$ & $-1,0 \%$ & $-1,3 \%$ & $-1,6 \%$ & $-2,0 \%$ & $-1,1 \%$ \\
\hline Total & 7.104 & 7.944 & 8.495 & 8.730 & 8.919 & 9.085 & 9.200 & 9.314 & 9.435 & 9.453 & 9.458 \\
\hline Variaciónanual & & $11,8 \%$ & $6,9 \%$ & $2,8 \%$ & $2,2 \%$ & $1,9 \%$ & $1,3 \%$ & $1,2 \%$ & $1,3 \%$ & $0,2 \%$ & $0,1 \%$ \\
\hline
\end{tabular}

* Datos referidos a enero y febrero.

FUENTE: Datos anuales recogidos en Statistical Bulletin, Oficina Central de Estadística Polaca.

to En Polonia el gasto público en pensiones respecto al PIB en 1995 era del $14.4 \%$, por encima de otros países como Hungría (9.7\%) o la República Checa (8.3\%). En cuanto al gasto total del gobierno polaco, en ese mismo año éste suponía el $28.9 \%$ (17.7\% y $18.0 \%$ en Hungría y la República Checa, respectivamente) (Castello, 1998).

"La primera hacía referencia a la organización y el funcionamiento de los fondos de pensiones privados, la segunda regulaba los programas de pensiones de los asalariados y 
El nuevo sistema implantado en 1999 está constituido por tres pilares, los dos primeros obligatorios: a) un organismo de seguros sociales reformado basado en el modelo de reparto, b) unos fondos de pensiones privados y c) unos seguros complementarios. Como novedad respecto al sistema anterior se establece en el primer pilar un vínculo directo y transparente entre las cotizaciones y las pensiones futuras, con una fuerte incitación a la jubilación tardía. El segundo pilar reposa sobre la capitalización y debe ser implementado de forma progresiva, creando fondos de pensiones privados y un organismo que los controle. El tercer pilar, facultativo, se compone de planes de jubilación de empresa y de dispositivos de ahorro de carácter comercial. Este último ya existe, pero será potenciado a través de beneficios fiscales. Por último, hay que señalar que la reforma en curso no modifica directamente la estructura esencial de las pensiones de los agricultores, que continúan siendo atendidos por el KRUS.

Respecto al primer pilar, el ZUS ${ }^{12}$ ha abierto cuentas individuales a los ciudadanos en edad de trabajar menores de 50 años, donde se ingresan las cotizaciones patronales y salariales. Sin embargo, la acumulación de capital es ficticia ya que los ingresos no son reinvertidos sino entregados a los pensionistas actuales. El montante de la pensión se determinará en el momento en el que el trabajador acceda a la jubilación, para ello el capital acumulado se dividirá por la esperanza de vida media para el conjunto de la población de su edad.

Sin embargo, el aspecto más destacado de la reforma del sistema de pensiones de jubilación en Polonia es la creación de los fondos privados de pensiones (en su mayoría vinculados a empresas de seguros occidentales). Una quinta parte de la cotización actual que recoge el ZUS es transferida a estos fondos siempre con su intermediación (OCDE, 2000). El asalariado debe notificar la elección de un fondo de pensiones al ZUS y puede cambiar de fondo sin penalización después de un período de afiliación de dos años o más. Asimismo, se ha creado un nuevo organismo: la Oficina de Control de los Fondos de Pensiones (UNFE) que supervisa la actividad de sus gestores. En el momento de la jubilación el asalariado utilizará el capital acumulado para adquirir una renta vitalicia a través de una compañía de seguros de vida especializada. Estas compañías no comenzarán a operar hasta que los primeros so-

la tercera determinaba cómo el producto de las privatizaciones contribuiría a la financiación de la reforma.

12 Las pensiones de jubilación, excepto para el sector agrícola, son administradas por el Consejo de Seguridad Social o ZUS (Zaklad Ubezpieczen Spolecznych) dependiente del Ministerio de Trabajo y Política Social, y se prestan a través del Fondo de Seguros Sociales (FUS). 
cios de los fondos de pensiones se aproximen a la edad mínima de jubilación, es decir, alrededor del año 2010.

Pero para una parte de la población polaca los derechos a una pensión adquiridos en el contexto del primer y segundo pilar no serán suficientes a la hora de asegurarles una renta adecuada en el momento de su jubilación. Ante esta situación la diferencia será aportada por el Estado con cargo a su presupuesto, garantizando una pensión mínima para $\operatorname{todos}^{13}$ siempre que se cumplan las condiciones de edad (65 años) y antigüedad (25 años de actividad). De esta forma, se pretende que el Estado conserve cierta función redistributiva.

En definitiva, en el sistema anterior las pensiones de jubilación eran pagadas con las primas de la generación activa. En el nuevo sistema una parte de estas pensiones se obtiene de aquéllos que están trabajando y la otra del capital acumulado por los pensionistas durante su vida activa.

Dada la progresividad de la reforma, los dispositivos previstos para el primer pilar no se aplicaron a las personas que tenían más de 50 años en 1999, ni a aquéllas que habían perdido su trabajo y pertenecían a regímenes de jubilación especiales, siempre y cuando hubiesen trabajado durante el tiempo suficiente para acceder a una pensión. El paso al segundo pilar era facultativo para la población activa con una edad comprendida entre los 30 y los 50 años en 1999. La totalidad de las personas menores de 30 años en 1999, obligatoriamente, fueron incluidas en el nuevo sistema, así como aquéllas que han entrado a formar parte de la población activa a partir de ese año.

Entre los costes de la reforma, según la OCDE (1998), algunos son puntuales como los gastos necesarios para la informatización del sistema contable del ZUS (aproximadamente un 0.2\% del PIB en 1998), mientras que otros se arrastrarán durante años. En esta última situación se encuentra el paso al segundo pilar que costará aproximadamente un $0.7 \%$ del PIB en los primeros años y dos veces más en el curso de los próximos quince. De hecho, esta transición hace visible la deuda de jubilación hasta ahora implícita, es decir, la deuda legada por las generaciones actuales a sus descendientes.

La financiación del cambio de sistema está siendo, en parte, compensada con el endurecimiento de las condiciones de acceso a la jubilación, en particular la sustitución de la edad mínima de jubilación o la prohibición para las personas con invalidez de acogerse a la jubilación 
anticipada. Pero, se pretende sufragar principalmente con el producto del proceso de privatización de bienes públicos. En esta línea, el gobierno polaco aprobó en 1998 un Plan de Privatización vinculado con la reforma de las pensiones. El gabinete de Jerzy Buzek adoptó un plan para vender la mayoría de los bienes que seguían en posesión del Estado antes de 2002. Entre las empresas de propiedad estatal que han sido o están siendo privatizadas se encuentran algunas de las compañías más grandes de Polonia, como las acerías - Huta Katowice y Huta Sendzimera-, la compañía telefónica y algunas refinerías de petróleo. También, han seguido este camino la empresa aérea nacional LOT y la aseguradora PZU. El plan se completa con la privatización de los ferrocarriles y los últimos bancos que continúan siendo de propiedad estatal (la caja de ahorros PKO BP y el grupo de cooperativas agrícolas BGZ). Según datos de la Comisión Europea (1999) se espera que los ingresos totales del Plan de Privatización, que afectaría a unas 1.800 empresas y al $35 \%$ de los trabajadores polacos, ascienda aproximadamente a 100.000 millones de zl (25.000 millones de ecus). Para evitar que los retrasos eventuales en el proceso de privatización dificulten las reformas sociales, el Estado ha emitido obligaciones reembolsables en participaciones públicas en las empresas inmersas en dicho proceso.

\subsection{La reforma del mercado laboral polaco.}

En el último estudio de la OIT (2000) se pone de manifiesto el elevado desempleo y subempleo en los países de Europa Central y Oriental, junto al incremento de la exclusión social que se deriva de unas oportunidades de acceso al mercado laboral limitadas (tabla 3 ). Como consecuencia, contrariamente a los inmensos beneficios obtenidos por algunos grupos muy minoritarios, la mayoría de la población de estos países experimenta espectaculares y penosos descensos en su nivel de vida.

TABLA 3: Tasa de desempleo anual registrado (\%)

\begin{tabular}{|l|r|r|r|r|r|r|r|r|r|}
\hline Países & 1989 & 1990 & 1991 & 1992 & 1993 & 1994 & 1995 & 1996 & 1997 \\
\hline Polonia & - & 3.4 & 9.2 & 12.9 & 14.9 & 16.5 & 15.2 & 14.3 & 11.5 \\
\hline Hungría & 0.4 & 0.8 & 8.5 & 12.3 & 12.1 & 10.4 & 10.4 & 10.5 & 10.4 \\
\hline República Checa & - & 0.3 & 2.6 & 3.1 & 3.0 & 3.3 & 3.0 & 3.1 & 4.3 \\
\hline Eslovenia & 2.9 & 4.7 & 8.2 & 11.5 & 14.4 & 14.4 & 13.9 & 13.9 & 14.4 \\
\hline Estonia & - & - & - & - & 3.9 & 4.4 & 4.1 & 4.4 & 4.0 \\
\hline
\end{tabular}

FUENTE: EBRD (1998).

En Polonia el desempleo comenzó a decrecer de forma regular a mediados de 1994. No obstante, en los últimos dos años el descenso del paro no ha continuado a un ritmo tan rápido dada la reducción de la tasa 
anual de creación de empleo, la extensión del proceso de reestructuración empresarial, el crecimiento del paro no declarado (particularmente en las zonas rurales) y la variación de las condiciones sociodemográficas (tabla 4).

TABLA 4: Mercado de trabajo en Polonia

\begin{tabular}{|c|c|c|c|c|c|c|}
\hline \multicolumn{2}{|c|}{ Indicadores laborales } & 1995 & 1996 & 1997 & 1998 & 1999 \\
\hline \multicolumn{2}{|c|}{ Población > 15 años (en miles) } & 29.108 & 29.337 & 29.628 & 29.955 & 30.137 \\
\hline \multicolumn{2}{|c|}{ Población activa (en miles) } & 17.148 & 17.076 & 17.100 & 17.172 & 17.082 \\
\hline \multicolumn{2}{|c|}{ Población ocupada (en miles) } & 14.918 & 14.969 & 15.177 & 15.356 & 14.941 \\
\hline \multicolumn{2}{|c|}{ Población desempleada (en miles) } & 2.230 & 2.108 & 1.923 & 1.816 & 2.141 \\
\hline \multicolumn{2}{|c|}{ Tasa de actividad } & $58.9 \%$ & $58.2 \%$ & $57.7 \%$ & $57.3 \%$ & $56.7 \%$ \\
\hline \multicolumn{2}{|c|}{ Tasa de ocupación } & $51.3 \%$ & $51.0 \%$ & $51.2 \%$ & $51.3 \%$ & $49.6 \%$ \\
\hline \multirow[t]{3}{*}{ Tasa de paro } & Total & $13.0 \%$ & $12.3 \%$ & $11.2 \%$ & $10.6 \%$ & $12.5 \%$ \\
\hline & Mujeres & $14.5 \%$ & $13.9 \%$ & $13.2 \%$ & $12.3 \%$ & $13.5 \%$ \\
\hline & Varones & $11.8 \%$ & $11.0 \%$ & $9.6 \%$ & $9.2 \%$ & $11.7 \%$ \\
\hline
\end{tabular}

FUENTE: Oficina Central de Estadística polaca, 2000.

Durante la transición las autoridades polacas han puesto en marcha diversas iniciativas referidas al mercado de trabajo. Estas iniciativas, en principio, priorizaron la reducción de la oferta de mano de obra (utilizando de forma masiva la jubilación anticipada y las pensiones de invalidez), pero desde mediados de los años 90 , dada la experiencia adquirida por las instituciones implicadas y las presiones internacionales, el gobierno decidió poner el acento sobre la flexibilización del mercado de trabajo y su desregulación.

La OCDE (1998 y 2000) ha estudiado las estrategias, basadas en un crecimiento de la producción, que permitirían a la Administración polaca influir en el mercado de trabajo. Sus recomendaciones están orientadas a: cambiar los mecanismos de formación de los salarios y de los costes laborales, aumentar la flexibilidad del tiempo de trabajo y la legislación relativa a la protección del mismo, reducir la cuña fiscal y el sistema de transferencias y revisar las políticas activas de empleo. Junto a ellas se examinan otros aspectos más generales, aunque no menos importantes a largo plazo, como los cambios en el sistema educativo, la competencia en el mercado de productos (por la lentitud del proceso de desregulación de ciertos sectores), el desarrollo de empresas (estableciendo ventajas fiscales y subvenciones destinadas a completar préstamos del Fondo de Trabajo) y, por último, el incremento de la inversión en tecnología e innovación. En nuestro análisis nos centraremos en las medidas implementadas por la Administración polaca, siguiendo las directrices propuestas por la OCDE, orientadas a reforzar la capacidad de adaptación del mercado de trabajo. 
a) La formación de los salarios.

El marco institucional en el que se inscribe la formación de los salarios ha evolucionado sensiblemente desde principios de los años 90 . El sistema actual de negociación colectiva en el sector público se estableció en 1994, creándose una Comisión Tripartita compuesta por representantes del Estado, los sindicatos y los empresarios. Esta Comisión debe fijar cada año, antes de finales de agosto, un baremo trimestral que recoja los aumentos salariales máximos para el siguiente año, teniendo en cuenta las previsiones del gobierno relativas al crecimiento del PIB, la inflación y la evolución de los sueldos de los funcionarios. Si la Comisión no llega a un acuerdo, como fue el caso de agosto de 1997 , es el gobierno quien decide de manera unilateral la tabla salarial. En este contexto, el gobierno juega un doble papel: como principal empresario y árbitro. Sin embargo, la progresión real del salario medio en el sector público ha superado sistemáticamente las directrices establecidas en la norma de contención de la mencionada Comisión ${ }^{14}$.

En este contexto general, las negociaciones salariales se realizan principalmente en el ámbito local o de empresa. No obstante, los convenios colectivos concertados a un nivel superior (para 500.000 asalariados o al menos un $10 \%$ de los trabajadores de ese sector) pueden ser extendidos a los trabajadores de empresas no signatarias. Además de los salarios, los convenios colectivos abarcan habitualmente otros aspectos como las condiciones de trabajo, las prestaciones sociales, la representación sindical y los mecanismos de regulación de los conflictos.

Por otra parte, el salario mínimo es negociado y fijado por el gobierno, los sindicatos y los empresarios en períodos regulares (todos los trimestres hasta 1996 y todos los semestres a partir de ese año) ${ }^{15}$. Este límite salarial se aplica a todos los trabajadores del sector público y privado, sin establecer diferencias entre regiones. En los últimos años el salario mínimo ha aumentado casi al mismo ritmo que el salario medio, de tal forma que en 1999 el salario mínimo representaba el $45 \%$ del

14 En este sector los salarios, directamente controlados por el gobierno y vinculados a las directrices de la Comisión Tripartita, se han situado por debajo de los del sector privado aunque ambos tienden a equipararse (en 1997 representaban el $87 \%$ de la media en dicho sector).

15 Para profundizar sobre este tema puede consultarse el trabajo de HAGEMEJER, K. (1998): "¿Cuál es el papel del salario mínimo en el nuevo mercado de trabajo polaco?", en STANDING, G. y VAUGHAN-WHITEHEAD, D. (direct.): Los salarios mínimos en la Europa Central y Oriental: de la protección a la exclusión, Tirant lo Blanch, Valencia, p. 117-139. 
salario medio (por encima de la situación de Hungría y la República Checa).

Desde finales de 1999 el gobierno polaco está estudiando poner en marcha una nueva ley de salarios mínimos que conllevaría la eliminación de su negociación y su fijación periódica por cada gobierno regional, permitiendo de esta forma la existencia de diferencias regionales con la intención supuesta de adecuarlo a los mercados de trabajo locales.

\section{b) Flexibilidad del tiempo de trabajo.}

La legislación polaca establece diversas normas que afectan especialmente a la organización del tiempo de trabajo de los asalariados a tiempo completo. Por ejemplo, su duración no debe, generalmente, sobrepasar las 8 horas diarias y las 42 horas semanales de media (para un período de tres meses). No obstante, algunos sectores vinculados a los servicios están autorizados a alcanzar jornadas laborales de hasta 12 horas, siempre que la media no supere los límites legales.

Desde el comienzo de la transición se ha observado un incremento en las horas semanales de trabajo de la población polaca asalariada; éste está vinculado, en parte, al aumento del pluriempleo que se encuentra sometido a escasas restricciones reglamentarias (en 1996 afectaba a más de 1.2 millones de personas). En este contexto, en junio de 1999 el Ministro de Trabajo y Política Social polaco presentó un proyecto de ley en el que se planteaba una reducción de la duración del tiempo de trabajo semanal en dos horas - pasando a ser de 40 horas semanales-y un aumento del número máximo de horas extraordinarias autorizadas.

\section{c) Impuestos y transferencias.}

Ya en 1993 la OCDE recomendó a Polonia que, siempre que las condiciones presupuestarias lo permitiesen, debía reducir la presión impositiva sobre el trabajo para promover la creación de empleo. La cuña fiscal media de Polonia, próxima al 45\% en 1996, es una de las más elevadas de los países de la OCDE (sólo por debajo de Francia, Finlandia, Alemania, Hungría, Italia, Suecia y Bélgica), principalmente por el peso de las cotizaciones a la Seguridad Social, característica que también encontramos en Hungría y la República Checa.

El $45 \%$ de las cotizaciones sociales, que son aportadas mayoritariamente por los empresarios, están destinadas al ZUS, a lo que hay que añadir un 3\% para el Fondo de Trabajo y un $0.18 \%$ para el Fondo de Garantía de Prestaciones Salariales (OCDE, 1998). La base sobre la 
que se establecen las cotizaciones sociales fue ampliada a mediados de 1997 y ahora alcanza a la mayor parte de las categorías de primas y de pagos en especie, además del salario propiamente dicho. Ante esta situación, en su campaña para reducir la carga fiscal el gobierno polaco, junto a sus asesores internacionales, esgrime que el deseo de escapar de ellas es una de las principales razones para que las empresas estén pasándose a la economía sumergida ${ }^{16}$.

Por otra parte, utilizando planteamientos neoliberales las autoridades polacas comienzan a argumentar que las indemnizaciones de paro (junto a la jubilación anticipada, los seguros de enfermedad y las prestaciones de invalidez) si bien atenúan la pérdida de ingresos como resultado de la salida del mercado de trabajo, pueden desincentivar la búsqueda activa de empleo y ejercer presiones para elevar los salarios. Sin embargo, según el "Índice Global de Generosidad de las Prestaciones" definido por la OCDE, que tienen en cuenta la tasa de compensación y la duración de las prestaciones para diferentes categorías de familias, Polonia con aproximadamente un $30 \%$ se sitúa en la zona intermedia de los Estados de la OCDE (por debajo de la República Checa -superior al 60\%- o países de la UE como España -por encima del 30\%-).

En Polonia las condiciones para obtener la prestación por desempleo se han ido endureciendo desde el comienzo de los años noventa (Adamchik, 1999; Puhani, 2000); lo que explica, en parte, el descenso del porcentaje de solicitantes de empleo con prestación, que ha pasado del $80 \%$ en 1991 a menos del $25 \%$ en el año 2000 (tabla 5). Esta prestación, indexada sobre el IPC trimestralmente, tiene una duración que varía entre los 6 y los 18 meses en función de la tasa de paro de cada región, con una cuantía que se situaba, por ejemplo, en 1997 en el 30\% del salario medio. Por otra parte, se ha incrementado la frecuencia de las visitas obligatorias a las oficinas locales de empleo y la cuantía del subsidio ha sido disociada de las ganancias anteriores.

En 1996 se introdujeron nuevas modificaciones que afectaban, en particular, a los desempleados más jóvenes. Así, se sustituyeron los subsidios dirigidos a jóvenes que habían acabado su proceso educativo por un programa en el que el pago de prestaciones estaba ligado a la inscripción en acciones de formación (esta estrategia ha tenido su continuación a través del programa "Diplomados 98"17).

16 Si bien, las tasas de cotización son muy bajas en ciertos casos, como en la agricultura, en los trabajadores independientes o en algunas categorías de trabajadores con bajo salario.

17 Con este programa los estudiantes que finalizan la enseñanza secundaria se inscriben voluntariamente en las agencias locales de empleo para beneficiarse de servicios de orientación laboral, formación profesional $y$, en algunos casos, empleos subvenciona- 
Además de las prestaciones vinculadas al seguro de desempleo existen otras transferencias sociales. Por ejemplo, la ayuda social para personas que viven en condiciones de extrema pobreza (las prestaciones permanentes o temporales están condicionadas a la existencia de recursos y su cuantía queda limitada al $28 \%$ del salario medio); o las transferencias en especie dirigidas, entre otros grupos de población, a parados de larga duración que han agotado su derecho al seguro de desempleo, de tal forma que sus ingresos pueden ser complementados con subsidios familiares y de alojamiento. En definitiva, si se tienen en cuenta las diversas prestaciones la tasa global de compensación de ayuda social en Polonia se sitúa entre el 30 y el $36 \%$ del salario medio según la situación familiar.

TABLA 5: Incidencia del paro por regiones en Polonia (febrero 2000)

\begin{tabular}{|l|c|c|c|}
\hline Regiones & $\begin{array}{c}\text { Población } \\
\text { desempleada } \\
\text { (en miles) }\end{array}$ & $\begin{array}{c}\text { Tasa de paro } \\
\text { (en \%)* }\end{array}$ & $\begin{array}{c}\text { Porcentaje de personas sin derecho } \\
\text { a beneficios sociales sobre el total } \\
\text { de desempleados }\end{array}$ \\
\hline Dolnoslaskie & 219,8 & 16,9 & 74,9 \\
\hline Kujawsko-Pomorskie & 167,6 & 17,6 & 73,9 \\
\hline Lubelskie & 158,1 & 13,5 & 81,2 \\
\hline Lubuskie & 81,1 & 18,7 & 73,6 \\
\hline Lódzkie & 197,1 & 15,1 & 75,1 \\
\hline Malopolskie & 171,1 & 11,0 & 77,0 \\
\hline Mazowieckie & 266,8 & 10,2 & 76,9 \\
\hline Opolskie & 64,4 & 14,2 & 77,6 \\
\hline Podkarpackie & 174,9 & 15,2 & 75,5 \\
\hline Podlaskie & 77,1 & 13,1 & 81,9 \\
\hline Pomorskie & 134,1 & 15,2 & 72,3 \\
\hline Slaskie & 232,5 & 10,9 & 81,8 \\
\hline Swietokrzyskie & 114,4 & 15,8 & 75,0 \\
\hline Warminsko-Mazurskie & 152,1 & 24,0 & 73,7 \\
\hline Wielkopolskie & 177,2 & 11,4 & 75,1 \\
\hline Zachodniopomorskie & 139,8 & 18,5 & 74,7 \\
\hline Polonia & $2.528,1$ & 13,9 & 76,3 \\
\hline
\end{tabular}

* Porcentaje sobre población activa.

FUENTE: Oficina Central de Estadística Polaca, 2000.

\section{d) Políticas activas del mercado de trabajo.}

Dentro de las políticas activas figuran, de forma general, la ayuda a la búsqueda de empleo, los programas de formación y el apoyo finan- 
ciero a los creadores potenciales de empresas, así como los programas de creación de empleo en el sector público y las subvenciones al empleo en el sector privado. El gobierno polaco en 1997 destinó a estas políticas el $14 \%$ del total del gasto público dirigido a mejorar el mercado de trabajo (tabla 6). Sin embargo, el número de personas beneficiarias de las mismas fue bastante limitado (el $8 \%$ de los parados inscritos durante ese año).

Las políticas activas son organizadas por la Oficina Nacional de Empleo y desde ella se impulsa la creación de puestos de trabajo de interés público, los empleos subvencionados, las actividades de formación, las bolsas de trabajo, los préstamos para parados que creen su propio empleo o los programas de asesoramiento en la búsqueda de empleo (Kluve, Lehmann \& Schmidt, 1999). En Polonia la mayor parte de los recursos se dirigen a la creación de empleo subvencionado que, en los últimos años, ha beneficiado a un total anual de entre $100.000 \mathrm{y}$ 200.000 personas. Los participantes reciben un salario subvencionado por la oficina de empleo de una cuantía igual a la prestación por desempleo y el empresario percibe una prima si el contrato se prolonga más de 6 meses. Los responsables de las agencias locales de empleo son los encargados de elegir las empresas y los trabajadores en paro que participan en el programa. Sin embargo, la decisión final de contratar a uno u otro trabajador recae en la práctica en las empresas y solamente una minoría de los participantes permanece en la misma entidad más allá del tiempo mínimo establecido, lo que parece indicar que estas subvenciones al empleo tienen un importante efecto de sustitución.

Aunque en los últimos años se ha incrementado el gasto en políticas activas ${ }^{18}$ hace falta mejorar la evaluación y seguimiento de los programas para hacerlos más eficaces en relación con los costes. Diversos estudios sobre Polonia indican que la influencia sobre el empleo de la mayoría de las políticas activas es escasa, a menudo inexistente (Olearry, kolodziejczyk \& Lazar, 1998). Algunos de estos programas son eficaces en el sentido de mejorar la empleabilidad, como es el caso de la formación. Pero ésta es ofertada frecuentemente a personas que habrían encontrado un empleo de todas formas (Gora et. al., 1996). Además, el conjunto de medidas no está adecuadamente orientado hacia los grupos con problemas específicos de acceso al mercado de trabajo, ya que, por ejemplo, las mujeres y las personas con una baja cualificación profesional no son objeto de una atención suficiente (Puhani et

18 Según datos de la Agencia Nacional para el Empleo Polaca, el gasto dedicado a medidas activas del mercado de trabajo representaba el $10.9 \%$ del gasto total en $1996(806,1$ millones de zl), en 1998 alcanzó el 25.8\% (1.241,8 millones de zl.) y en 1999 se situó en el $19.9 \%$ ( $1.160,5$ millones de $\mathrm{zl}$.). 
TABLA 6: Gasto público en programas relativos al mercado de trabajo en Polonia (\% del PIB)

\begin{tabular}{|c|c|c|c|c|c|c|}
\hline Programas & 1992 & 1993 & 1994 & 1995 & 1996 & 1997 \\
\hline 1. Administración y servicios públicos de empleo & 0,02 & 0,02 & 0,01 & 0,01 & 0,02 & 0,02 \\
\hline 2. Formación profesional de parados y trabajadores & 0,02 & 0,03 & 0,03 & 0,02 & 0,02 & 0,02 \\
\hline 3. Medidas dirigidas a jóvenes & 0,15 & 0,09 & 0,07 & 0,08 & 0,10 & 0,01 \\
\hline 3.1. Jóvenes desempleados y desfavorecidos & & & 0,01 & 0,02 & 0,03 & 0.04 \\
\hline $\begin{array}{l}\text { 3.2. Ayudas al aprendizaje y otras formas de formación } \\
\text { de carácter general }\end{array}$ & 0,15 & 0,09 & 0,06 & 0,06 & 0,06 & 0,06 \\
\hline 4. Medidas de ayuda a la contratación & 0,08 & 0,20 & 0,24 & 0,21 & 0,16 & 0,19 \\
\hline 4.I. Subvenciones al empleo en el scctor privado & 0,05 & 0,10 & 0,13 & 0,12 & 0,08 & 0,07 \\
\hline 4.2. Ayuda al autoempleo entre parados & 0,01 & 0,02 & 0,02 & 0,02 & 0,02 & 0,02 \\
\hline $\begin{array}{l}\text { 4.3. Creación directa de empleo (sector público y } \\
\text { organizaciones no lucrativas) }\end{array}$ & 0,02 & 0,08 & 0,10 & 0,08 & 0,07 & 0,09 \\
\hline 5. Medidas en favor de los discapacitados & 0,04 & 0,05 & 0,04 & 0,01 & 0,01 & \\
\hline 5.1. Reciclaje profesional & & 0,01 & 0,01 & & & \\
\hline 5.2. Empleos destinados a discapacitados & 0,04 & 0,04 & 0,03 & 0,01 & 0,01 & \\
\hline 6. Prestaciones por desempleo & 1,71 & 1,72 & 1,77 & 1,88 & 1,77 & 1,19 \\
\hline $\begin{array}{l}\text { 7. Jubilación anticipada por motivos ligados al } \\
\text { mercado de trabajo }\end{array}$ & 0,77 & 0,15 & 0,10 & 0,05 & 0,05 & \\
\hline TOTAL & 2,80 & 2,25 & 2,27 & 2,27 & 2,14 & \\
\hline MEDIDAS ACTIVAS (1-5) & 0,32 & 0,38 & 0,39 & 0,34 & 0,32 & \\
\hline GARANTÍA DE RENTAS (6y 7$)$ & 2,49 & 1,87 & 1,87 & 1,93 & 1,82 & \\
\hline
\end{tabular}

FUENTE: Études Économiques de l'OCDE, 1998. Oficina Central de Estadística Polaca.

Steiner, 1997). No obstante, como señala la OCDE (2000) la falta relativa de efectividad de los programas de política activa de empleo en Polonia puede deberse, en parte, a la baja preparación y experiencia de las instituciones implicadas acerca de los mecanismos utilizados y a la ausencia de un control adecuado en la aplicación de las normas necesarias. Además, algunos de estos programas son simplemente demasiado recientes para poder evaluar correctamente sus efectos.

Durante los últimos dos años el gobierno polaco ha tratado de mejorar la coordinación entre proveedores y consumidores de acciones de formación, ha reducido el programa destinado a crear puestos de trabajo de interés público y ha abierto nuevas líneas de crédito para las PYME que creen empleo (especialmente en las zonas rurales y entre los desempleados de larga duración), activando la iniciativa "Orientación de las acciones del gobierno a favor de las PYME 2000-2002"19.

19 EI Parlamento adoptó en noviembre de 1999 un proyecto de ley sobre la actividad cmpresarial que debe reemplazar a las anteriores normas sobre actividad cconómica y sociedades con participación extranjera. 
Al mismo tiempo la Administración ha diseñado una "Estrategia nacional para el empleo y el desarrollo del capital humano 2000-2006", con la que se pretende poner en marcha las recomendaciones de los diferentes organismos internacionales.

Los resultados de estos programas dependen en gran medida de la eficacia de los servicios de empleo públicos. En este ámbito desde 1990, con ayuda financiera internacional, se ha ido creando en Polonia una red de agencias regionales y locales de empleo que no está todavía consolidada. En la actualidad están en funcionamiento 16 agencias regionales y 322 de distrito. Esta estructura es financiada por la Administración Central, pero las decisiones en materia de gasto son tomadas por las colectividades locales. El actual proceso de configuración de la red de oficinas de empleo dificulta la evaluación de las estrategias puestas en marcha, ya que, por ejemplo, no todas ellas están totalmente informatizadas. Además, la rápida creación de agencias privadas de colocación (en 1998 había más de 300 en funcionamiento) pone de manifiesto que el servicio público de empleo no es en todos los casos el intermediario más utilizado.

Por otra parte, diversas organizaciones internacionales están poniendo en marcha programas de apoyo al gobierno polaco en su lucha por reactivar el mercado de trabajo (por ejemplo, los programas PHARE de la $\mathrm{UE}^{20}$ ). En esta línea, la OIT (1999) a través del Programa Principal 280 ("Programa de actividades prácticas en Europa y Asia Central y del Este") pretende lograr que los gobernantes de la región, entre ellos los de los países de Europa del Este, puedan llevar a cabo los cambios necesarios en el mercado de trabajo, las administraciones vinculadas al mismo y los sistemas de protección social. Para ello se les presta asistencia mediante diversas actividades, entre las que se incluyen la difusión de informaciones, la organización de seminarios y coloquios y la prestación de servicios de asesoramiento y formación.

Así pues, el mercado de trabajo en Polonia no sólo ha conocido en la última década la lacra social del paro sino que se ha subido al carro de la flexibilización y desregulación que promueven los defensores neoliberales de la economía de mercado. 


\section{CONCLUSIONES}

El nuevo modelo sanitario introduce criterios de competencia en la gestión de los servicios de salud, en la determinación de los salarios y la conservación del puesto de trabajo de los profesionales sanitarios, y plantea la financiación del sistema a través de seguros de enfermedad que operan por medio de fondos de salud regionales. La reforma del esquema de pensiones polaco se aleja del modelo de reparto y se ubica directamente en un modelo de capitalización, basado en fondos privados de pensiones y sistemas comerciales complementarios. Mientras que el mercado de trabajo ve resquebrajarse sus cimientos con la introducción de criterios de flexibilidad y desregulación (cambios en los mecanismos de formación de los salarios, aumento de la flexibilidad del tiempo de trabajo y en la legislación de protección del mismo, reducción de la presión fiscal sobre los empresarios o endurecimiento de las condiciones de acceso a las prestaciones por desempleo).

En resumen, como ocurre en otros países de su entorno (Garcés, Ródenas, Sánchez y Verdeguer, 1999) la población polaca es la principal víctima de la destrucción del monopolio estatal en el ámbito de la protección social y de la experimentación occidental de nuevas políticas sociales que, paradójicamente, no pueden ser desarrolladas en su totalidad en países como los de la Unión Europea, dadas las presiones sociales a las que se encuentran sometidos sus gobiernos.

\section{BIBLIOGRAFÍA}

ADAMCHIK, V. (1999): "The effect of Unemployment Benefits on the Probability of Reemployment in Poland", in Oxford Bulletion of Economics and Statistics, Vol. 61, n 1, pp. 95-ss.

CASTELLO BRANCO, M. (1998): "Pension Reform in the Baltics, Russia and other Countries of the Former Soviet Union (BRO)", WP/98/II, International Monetary Fund.

COMISIÓN EUROPEA (1999): Informe periódico 1998 de la Comisión sobre los progresos realizados por Polonia en vía de adhesión, Oficina de $\mathrm{Pu}-$ blicaciones Oficiales, Luxemburgo.

CHAWLA, M.; BERMAN, P. \& KAWIORSKA, D. (1998): "Financing Health Services in Poland: New Evidence on Private Expenditures", Health Economics, $\mathrm{n}^{\circ} 7$, p. 337-346.

DESPINEY, B. (1999): "Les disparités régionales en Pologne à la veille de son adhésion à l'Union Européenne", Le courrier des pays de l'Est, n 437, p. 45-59. 
ERDMANN, Y.(1998): "The Development of Social Benefits and Social Policy in Poland, Hungary and the Slovak Republic since the System Transformation", East European Quarterly, vol 32, n³ 3, p. 301-314.

GARCÉS, J.; RÓDENAS, F.; SÁNCHEZ, S. y VERDEGUER, I. (1999): Politica social, exclusió i pobresa a Rússia, Afers, Valencia.

GORA, M. et.al. (1996): "Labour Market Policies in Poland", in Lessons from Labour Market Policies in the Transition Countries, OECD Proceedings, CCET, París, pp. 151-76.

KLUVE, J.; LEHMANN, H.; \& SHCMIDT, C.M. (1999): “Active Labor Market Policies in Poland", in Journal of Comparative Economics, Vol. 27, $\mathrm{n}^{\circ}$ 1, pp. 61-89.

OCDE (1998): Pologne 1997-1998, Études Ëcnomiques de l'OCDE, París.

OCDE (2000): Pologne 1999-2000, Études Ëcnomiques de l'OCDE, París.

OIT (1999): Studies on the social dimensions of globalization - Poland, OIT, Ginebra.

OIT (2000): Informe sobre el empleo en el mundo 1998-1999, OIT, Ginebra.

OLEARY, C.J.; KOLODZIEJCZYK, P.; LAZAR, G. (1998): "The Net Impact of Active Labor Programs in Hungary and Poland", in International Labour Review, Vol. 137, n³, pp. 321-ss.

PUNAHI, P. \& STEINER, V. (1997): "The Effectiveness and Efficiency of Active Labour Market Policies in Poland", in Empirica, Vol. 24, pp. 209-231.

PUHANI, P. (2000): "Poland on the dole: The Effect of Reducing the Unemployment Benefit Entitlement Period During Transition", Journal of Population Economics, $n^{\circ} 13$, p. 35-44

SZCZERBIAK, A. (1999): "Interests and Values: Polish Parties and their Electorates", European-Asia Studies, vol. 51, nº 8, p. 1401-1432. 


\title{
HOMESHARE EUROPE. ALOJAMIENTO COMPARTIDO A CAMBIO DE AYUDA EN EUROPA
}

\author{
Ma ASUNCIÓN MARTÍNEZ ROMÁN* \\ ANNE-LOTTE KREICKEMEIER** \\ JOAQUINA MURCIA*** \\ HORTENSIA REDERO* \\ * Departamento de Trabajo Social y Servicios Sociales y Asociación Universitaria para \\ la Promoción del Voluntariado. Universidad de Alicante. \\ *** Fachhochschule. Darmstadt (Alemania). \\ ** Departamento de Trabajo Social y Servicios Sociales. Universidad de Alicante.
}

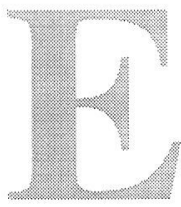

n este artículo se describen y analizan experiencias que contribuyen a promover la solidaridad intergeneracional entre personas mayores y estudiantes universitarios proporcionándoles opciones de ayudarse mutuamente para favorecer su desarrollo humano y social. Como desarrollo humano y social entendemos la propuesta de Naciones Unidas, por lo que partimos de las orientaciones contenidas en el Plan de Acción de la Cumbre Mundial de Desarrollo Social (Copenhague, 1995) y de la evaluación de los progresos realizada en la Asamblea General Extraordinaria de Ginebra en la que se reafirman los compromisos iniciales, invitando a todas las personas y a todos los países a sumarse para conseguir un mundo más justo y equitativo:

"Promover la integración social fomentando sociedades estables, seguras y justas, que estén basadas en la promoción y protección de todos los derechos humanos, así como en la nodiscriminación, la tolerancia, el respeto de la diversidad, la igualdad de oportunidades, la solidaridad, la seguridad y la participación de todas las personas, incluidos los grupos y las personas desfavorecidas y vulnerables" ( $4^{\circ}$ compromiso $\left.{ }^{1}\right)$.

Entre las actuaciones para conseguirlo se destaca la importancia de la participación en la vida social de todos y todas los/as ciudadanos/as, con especial referencia a la cooperación entre gobierno y sociedad civil, la contribución del voluntariado a la creación de sociedades que se

1 Naciones Unidas (2000) Nuevas iniciativas en pro del desarrollo social. A/RES/S-24/2. 
preocupen de las necesidades de sus diversos grupos, el apoyo a la familia en sus funciones de apoyo y "promover la plena integración y la continuación de las personas de edad en la sociedad como actores de pleno derecho en el proceso de desarrollo".

Una sociedad integrada e integradora, tal como la define Naciones Unidas, precisa "inversiones en instituciones sociales y para la promoción social, que se mejoren las redes de contacto y las relaciones sociales, se consiga el consenso y se aumente la capacidad de las personas, las organizaciones y las instituciones dentro de un marco propicio de cooperación mundial"2. Sin un entorno propicio no sólo será difícil la integración social sino que, además, tendremos personas y grupos en situación de vulnerabilidad que les colocará en riesgo de iniciar procesos de exclusión social. Situación de vulnerabilidad que no suele ser suficientemente considerada ni por las políticas públicas, cuando no se prima la prevención, ni por la sociedad que suele desconocer la vulnerabilidad en que viven personas y grupos por lo que no demanda atención. Lo cierto es que las personas mayores y los jóvenes son grupos sociales vulnerables y en riesgo de exclusión social por razón de edad y un modo de contribuir a reducir este riesgo es promover un mejor conocimiento de los obstáculos que encuentran para su desarrollo humano, fomentar la solidaridad y la participación social.

La eliminación de los obstáculos que las personas mayores y los jóvenes encuentran para su desarrollo humano es tarea de todos, del gobierno, de la sociedad y, por supuesto, de las propias personas interesadas, todos somos corresponsables. Desde esta perspectiva, las experiencias de ayuda mutua que vamos a comentar conciben la ayuda mutua (que se concreta en un intercambio de apoyo afectivo, social y económico) como un medio de ejercer esa responsabilidad compartida desde una posición de igualdad, de relaciones simétricas que permiten encontrar respuestas a necesidades personales de modo solidario mediante un intercambio, a través de actuaciones de mediación realizadas por terceros que intervienen como intermediarios, con el objetivo de promover la solidaridad intergeneracional. En ningún modo se trata de sustituir la responsabilidad de las políticas públicas ni la responsabilidad de la sociedad ni la de las familias o redes informales, no sustituye a otros recursos posibles sino que los complementa. Son experiencias innovadoras que contribuyen a prevenir la exclusión social de las personas mayores y jóvenes.

2 Naciones Unidas. Consejo Económico y Social (1998). Promoción de la integración y participación social de toda la gente, incluidos los grupos y personas desfavorecidos y vulnerables. Comisión de Desarrollo Social. E/CN.5/1998/2. 


\section{ALOJAMIENTO COMPARTIDO A CAMBIO DE AYUDA EN EUROPA}

El Proyecto "Homeshare Europe", cofinanciado por la Comisión Europea (diciembre 1999 - noviembre 2000), ha permitido conocer experiencias que se están desarrollando en Europa en el ámbito del Alojamiento Compartido. El Proyecto ha sido coordinado por The Foundation for European Initiatives (Reino Unido) y han participado Homeshare International (Reino Unido), la Asociación Universitaria para la Promoción del Voluntariado (Universidad de Alicante), Fachhoschule Darmstadt y Cruz Roja de Darmstadt (Alemania) y Odyssee (Holanda).

Alojamiento Compartido es un concepto muy amplio. Al hablar de Alojamiento Compartido a Cambio de Ayuda, nos referimos a una situación de intercambio entre iguales, en el que una persona mayor ofrece alojamiento a un/una joven a cambio de un tipo de ayuda acordada previamente. Se trata de una modalidad de ayuda mutua en la que las dos partes implicadas manifiestan desear satisfacer unas necesidades ofreciendo algo a cambio. Estos programas se inician en Europa al comenzar la década de los 90, siendo los países pioneros Alemania y España, seguidos de Gran Bretaña y Austria. España destaca por ser el país con mayor número de programas.

En todos los países las personas mayores desean continuar viviendo en su propio domicilio en el que suelen tener espacio suficiente para más de una persona. Algunas de estas personas mayores necesitan, o podrían necesitar en el futuro próximo, algún tipo de ayuda para las tareas cotidianas y, en muchos casos, desean vivir en compañía de otra persona para disminuir su soledad. Por otra parte, muchos jóvenes manifiestan dificultades para satisfacer su necesidad de encontrar un alojamiento a un precio asequible. En este contexto, las experiencias de Alojamiento Compartido a Cambio de Ayuda realizan actuaciones de mediación entre las personas mayores y los jóvenes para ayudarles a encontrar la mejor respuesta a sus necesidades mediante un intercambio de ayuda mutua, tras una elección en total libertad. Con el tiempo, se ha ampliado la posibilidad de beneficiarse de este nuevo recurso a las personas que tienen discapacidades y la familias con un solo progenitor y con cargas familiares.

Las experiencias estudiadas muestran una gran diversidad, con una mayor similitud entre Alemania, Austria y España, lo que parece deberse al hecho de ser iniciativas surgidas de las Universidades con la intención de promover la ayuda mutua y la solidaridad intergeneracional. Las experiencias inglesas difieren en su origen y diseño. 
Por ser experiencias innovadoras hay que invertir tiempo en su promoción, siendo la mejor propaganda la que realizan las personas mayores y los jóvenes que han participado. Las actividades de mediación (selección, emparejamiento, inicio de la convivencia y seguimiento) deben ser realizadas por profesionales cualificados y, además, puede ser muy enriquecedor contar con la colaboración de personas mayores.

\section{LOS PROGRAMAS DE ALOJAMIENTO COMPARTIDO A CAMBIO DE AYUDA EN ESPAÑA}

Los programas de Alojamiento Compartido entre personas mayores y estudiantes universitarios se inician en Europa al comenzar la década de los 90, siendo los países pioneros Alemania y España, seguidos de Gran Bretaña y Austria. En España, el primer programa de alojamiento compartido entre personas mayores y estudiantes universitarios se inicia en 1991 en la Universidad de Granada, por iniciativa de dos trabajadoras sociales del gabinete de atención social al estudiante. Actualmente, España tiene 17 programas consolidados que se desarrollan en 28 provincias y están en su inicio en otras 4 provincias más ${ }^{3}$, resultando ser el país de Europa con mayor número de este tipo de programas que promueven la solidaridad intergeneracional a través del alojamiento compartido entre personas mayores y estudiantes universitarios. Hay que recordar que estos datos se refieren a un estudio realizado en el año 2000 , considerando los programas que llevaban más de dos años en vigor, por lo que actualmente su número será superior ${ }^{4}$.

\subsection{Quién gestiona los programas}

En España, los programas de alojamiento a cambio de ayuda son gestionados de diversos modos, siendo lo más frecuente un sistema mixto en el que una Universidad, una entidad pública o una entidad privada sin ánimo de lucro asume la responsabilidad principal con la coparticipación de una o varias entidades más. Una característica en

3 Cronológicamente: 1991: Granada. 1992-93: Sevilla, Cádiz-Jerez de la Frontera, Córdoba, Málaga, Alicante, León y Albacete. 1995-96: Almería, Jaén (no contesta cucstionario), Navarra (desaparecido), Donosita-San Sebastián, Murcia y Las Palmas de Gran Canaria. 1996-97: Valladolid (Palencia, Segovia y Soria), Madrid y Cataluña. 1997-98: Santiago de Compostela. 1998-99: Bilbao-Deusto.

4 Martínez Román, M ${ }^{x}$ A. y Murcia Rodríguez, J. "Programas de alojamiento compartido a cambio de ayuda en España”, en Kreickemeier, A.L y Martínez Román, $\mathrm{M}^{a}$ A. (Dirs) Alojamiento compartido a cambio de ayuda en Europa, Alicante, Universidad de Alicante, 2001, págs. 21-34 
España es que en todos participa una Universidad y docentes y profesionales vinculados al Trabajo Social. Las entidades públicas implicadas son bien del gobierno local (Ayuntamiento, Diputación) o bien del gobierno autonómico (Consejerías de Comunidades Autónomas). En cuanto a las entidades privadas sin ánimo de lucro, se trata de asociaciones y organizaciones de voluntariado. También hay una entidad de ahorro que asume la gestión directamente en colaboración con Universidades y Ayuntamientos.

Las Universidades desarrollan estos programas como un medio de promover la solidaridad intergeneracional ya que pueden ofrecer información a los estudiantes sobre posibles alojamientos mediante un servicio de "bolsa de alojamiento" convencional. El servicio que presta la Universidad con esta bolsa de alojamiento se diferencia claramente de los Programas de ayuda mutua a los que nos referimos, cuando las personas mayores se inscriben en esta bolsa como potenciales alojadoras lo hacen con la finalidad de obtener un ingreso económico extra, mediante el alquiler de una habitación a los estudiantes y la Universidad simplemente ofrece una información sin más intervención posterior.

En cambio, los programas que nos ocupan vinculan el hecho de compartir un alojamiento a la oportunidad de convivir solidariamente con una persona mayor y a la promoción de un acercamiento generacional, todo ello basado en la ayuda mutua. Es decir, si cada una de las partes tiene carencias que puede satisfacer la otra parte y ambas partes tienen actitudes solidarias, pero se desconocen entre sí, la introducción de una figura mediadora puede crear un nuevo recurso social "no convencional". Este recurso beneficia tanto a las personas mayores, porque pueden permanecer en su domicilio a la vez que se sienten útiles (incluso rejuvenecidas) compartiendo su vivienda con estudiantes, como a los jóvenes que pueden disponer de un alojamiento a la vez que se sienten solidarios. Sin embargo, no se trata de una varita mágica que solucione todos los problemas de las personas mayores que quieren permanecer en su domicilio ni de los jóvenes que buscan alojamiento, en ambos casos es una modalidad selectiva por lo que no se debe valorar en términos cuantitativos sino cualitativos. Es una opción más entre otras, a las que nunca debe excluir.

\subsection{Perfil de las personas mayores alojadoras y de las/los estu- diantes}

El perfil de la persona que ofrece un alojamiento a cambio de ayuda es el de una mujer, viuda, mayor de 70 años (entre 60 y 90 años), de nivel socioeconómico medio y medio-bajo, que quiere vivir en su propio domicilio, puede cuidarse de modo independiente, pero tiene alguna di- 
ficultad que va en aumento debido a la edad. Sobre todo quiere compañía y tiene miedo a vivir sola, especialmente, miedo a estar sola por las noches.

Y el perfil de la persona que ofrece ayuda a cambio de alojamiento es el de una estudiante mujer, mayor de 25 años, que cursa primeros cursos o post-grado, con escasos ingresos, que busca alojamiento y está dispuesta a hacer compañía compatible con sus estudios.

\subsection{En qué consiste el intercambio de ayuda que se realiza}

Las personas mayores ofrecen alojamiento y reciben compañía y pequeñas ayudas en las tareas cotidianas, dependiendo del acuerdo previo entre ambas partes. Se insiste a las personas mayores en que esta modalidad de convivencia se basa en la ayuda mutua y no es un medio para obtener un pequeño ingreso económico adicional. Sin embargo, para que todas las personas mayores puedan beneficiarse de este programa, cuando una persona mayor tiene bajos ingresos y no puede afrontar los gastos que le ocasionaría otra persona en el hogar, puede recibir una pequeña cuantía económica como compensación de esos pequeños gastos adicionales de agua, electricidad y gas. Esta ayuda económica puede quedar a cargo del propio estudiante o ser alguna entidad social pública o privada la que financie estos gastos. Un caso especial es la Diputación Foral de Donostia-San Sebastián que, tras cinco años de experiencia, acaba incluyendo el programa de convivencia de estudiantes con personas mayores en su oferta de recursos sociales, pudiendo percibir la persona mayor una ayuda económica para compensar al estudiante que le dedica más tiempo de compañía y cuidados especiales ${ }^{5}$.

Los/as estudiantes proporcionan compañía a las personas mayores a cambio del alojamiento (se suele garantizar acompañamiento las noches de la semana lectiva) y ayuda en pequeñas tareas cotidianas. Hay programas que ofrecen al estudiante otras pequeñas compensaciones como becas de comedor o ayudas económicas para los gastos de transporte, tasas académicas o compra de libros escolares. En algunos casos, los/as estudiantes abonan directamente a la persona mayor la parte proporcional de los gastos de agua, electricidad y gas. Hay algunos Programas que se ocupan también de personas mayores dependientes en los que los estudiantes han de comprometerse a proporcionar determinados cuidados a las personas mayores y reciben por ello una peque- 
ña compensación económica que financia alguna entidad social pública o privada, si bien nunca se trata de una remuneración o salario.

En ningún caso las personas mayores ni estudiantes tienen que abonar cantidades económicas a las entidades responsables de los programas por el servicio recibido.

En todos los casos, los gastos de manutención son a cargo del estudiante alojado y se establece un periodo de prueba.

\subsection{Criterios de selección.}

Las personas mayores deben tener más de 60 años, desear compartir la vivienda y convivir con jóvenes, ofreciéndose mutua compañía y apoyo. No importa el nivel de ingresos económicos de las personas mayores si bien, en igualdad de condiciones, parece que se puede dar preferencia a las personas con menores ingresos económicos.

Los/as estudiantes deben estar matriculados en las Universidades relacionadas con los programas y desear compartir el alojamiento que le ofrece una persona mayor seleccionada por el programa a cambio de ofrecerle su compañía y/o cuidados. No importa el nivel de ingresos de los/as alumnos, si bien, en igualdad de condiciones, también se tiende a dar preferencia a aquellos/as con menores ingresos económicos familiares o sin derecho a alguna modalidad de beca para alojamiento.

Para todo ello se establece un acuerdo previo entre ambas partes. En todos los casos las entidades responsables de estos programas realizan tareas de mediación entre las posibles "parejas" que pueden llegar a convivir.

Se realizan entrevistas personales para seleccionar tanto a las personas mayores como a los/as estudiantes. En el caso de las personas mayores hay que realizar entrevistas en el domicilio para conocer las características de la vivienda. Una vez seleccionados los potenciales participantes se une a cada pareja y se inicia la convivencia con un periodo de prueba. Superado el periodo de prueba, se realiza un seguimiento durante todo el periodo temporal que dure la convivencia a fin de garantizar que se cumplen los objetivos del programa, actuando de mediadores en el caso de que surjan dificultades.

En la selección de las parejas intervienen mayoritariamente trabajadores sociales y en algunos programas también psicólogos (Albacete, Cataluña, Murcia, Santiago de Compostela y Sevilla). En cuanto al seguimiento de la convivencia, también se lleva a cabo mayoritariamente por trabajadores sociales. 


\subsection{Financiación actual del Programa}

Todas las Universidades contribuyen ofreciendo infraestructura básica, aportan también recursos humanos técnicos (Bilbao-Deusto, Granada, Las Palmas de Gran Canaria, Málaga, Murcia, Sevilla y Valladolid) y otros apoyos, como ayudas económicas puntuales o becas de comedor, transporte o libros (Alicante, Almería, Granada, Las Palmas de Gran Canaria, Murcia, Valladolid). Junto con las Universidades actúan como co-financiadoras otras entidades públicas o privadas: hay co-financiación de entidades públicas del gobierno autonómico (Andalucía, Valladolid), de la Administración Local (Albacete, Almería, Donostia-San Sebastián, Madrid, Murcia, Santiago de Compostela). En Las Palmas de Gran Canaria la Entidad co-financiadora es Cruz Roja.

Cuando la iniciativa y desarrollo del Programa se deben fundamentalmente a una entidad privada sin ánimo de lucro en colaboración con una Universidad, las entidades privadas aportan financiación propia y recursos humanos (técnicos con relación laboral y voluntarios), interviniendo también en la co-financiación del programa otras entidades públicas y entidades de ahorro, Caja de Ahorros del Mediterráneo, en el caso de Alicante, y, en Madrid, Caja Madrid. El Programa de Cataluña es financiado por Caixa-Cataluña en colaboración con Universidades y Ayuntamientos. Sólo un programa carece de ayuda financiera, aunque manifiesta estar gestionando financiación del gobierno autonómico (León).

\subsection{Obstáculos y apoyos encontrados}

Entre los obstáculos se señala que:

- Resulta difícil comenzar algo nuevo y sin precedentes. Hay que hacer mucho esfuerzo para difundirlo y captar potenciales personas alojadoras y alojables. Cuesta abrir camino. Durante su desarrollo, sigue siendo difícil la difusión de este recurso social, unas veces aumenta la demanda de estudiantes y no hay suficiente demanda de personas mayores y, otras veces, ocurre lo contrario. Se precisa mucha dedicación para el desarrollo de un programa de calidad y, generalmente, faltan más recursos humanos cualificados porque falta apoyo financiero.

- También hay muchas personas mayores que, a pesar de sentir soledad, no quieren compartir su vivienda o no tienen una vivienda adecuada aunque deseen compartirla. Hay casos en los que los hijos no aceptan que su madre comparta su domicilio con personas ajenas a la familia.

- Puede haber desconfianza mutua entre personas mayores y estu- 
diantes por desconocimiento intergeneracional y miedo de ambos a perder libertad. Hay diferencias de hábitos de vida cotidiana entre personas mayores y estudiantes.

- Suele ser difícil realizar emparejamientos entre diferentes sexos. Las señoras potenciales alojadoras suelen pedir una chica y suelen excluir a los varones, sin embargo, cuando los aceptan establecen muy buenas relaciones.

- Puede haber condicionamientos debidos a la estructura temporal del curso académico que resulten un inconveniente para la persona mayor.

Como facilitadores se señalan:

- Los recursos humanos que la entidad pone a disposición del programa, el apoyo de la Universidad y la coordinación entre entidades copartícipes en el programa.

- El apoyo de trabajadores sociales de los Servicios Sociales básicos y especializados.

- Una buena selección y un buen seguimiento garantiza el éxito de la convivencia.

- Hay que realizar una buena difusión del programa en los medios de comunicación por ser una experiencia innovadora y la mejor difusión es la que realizan los propios participantes en el programa, tanto personas mayores como estudiantes, que han tenido una buena experiencia.

\subsection{Algunos "consejos" para quien inicie nuevos programas}

- Invertir tiempo y esfuerzos en la difusión del programa y en la captación de potenciales personas interesadas. Es importante la colaboración de los medios de comunicación.

- Comprender que el programa es muy específico, siendo más importante lograr una convivencia duradera de las parejas que un gran número de ellas.

- Realizar una cuidadosa selección y emparejamiento entre las personas demandantes. No tener prisa y asegurarse de las posibilidades de éxito de la convivencia para evitar experiencias negativas en el inicio. Invertir todo el tiempo que sea necesario en la formacióninformación de las parejas para prevenir dificultades en la convivencia ayudándoles a aceptarse mutuamente.

- Realizar un seguimiento continuado de la convivencia ofreciendo una amplia franja horaria de atención por parte de los profesionales que ejecutan el programa. 
- Ampliar la oferta de compañía y apoyo, como personas alojadoras, a personas con discapacidades, enfermedades crónicas y padres/ madres con personas dependientes a cargo y jóvenes inmigrantes o queriendo acceder a un empleo.

- Que las personas potencialmente alojadoras y alojadas comprendan y acepten que es un programa de solidaridad y ayuda mutua, por lo que es indispensable la generosidad y la comprensión de ambas partes.

- Informarse sobre las experiencias que ya se han consolidado.

III. COMPARACIÓN ENTRE LOS PROGRAMAS DE ALOJAMIENTO COMPARTIDO A CAMBIO DE AYUDA DE ESPAÑA, REINO UNIDO, ALEMANIA Y AUSTRIA?

\subsection{Modos de financiación}

Las fuentes de financiación son muy heterogéneas tanto entre países como entre programas del mismo país. Generalmente, no hay una única entidad (pública o privada) que se responsabilice de la total financiación del programa, por el contrario, se establecen diferentes modalidades de acuerdos que implican contribuir a hacer viable el desarrollo del programa aportando alguno o varios de los siguientes tipos de recursos: económicos, humanos (profesionales técnicos y personas voluntarias) y también la infraestructura física y material necesaria (despachos, teléfonos, difusión, etc).

En el caso de Gran Bretaña, hay programas que fueron apoyados en su inicio financieramente por organizaciones privadas no lucrativas pero, actualmente, se autofinancian en parte con las aportaciones que reciben tanto de las personas alojadoras como de las alojadas, sin que ello cubra la totalidad del coste del programa. En España y Gran Bretaña hay programas que también se ocupan de personas mayores que necesitan cuidados especiales y, en estos casos, la persona alojada recibe una compensación por los cuidados extra, que puede estar financiada por los Servicios Sociales de la Administración pública o por una

- Más información: $M^{3}$ Asunción Martínez Román. Asociación Universitaria para la Promoción del Voluntariado. Edificio de Ciencias Sociales. Universidad de Alicante. Apdo. Correos 99.03080 Alicante. E-mail: masun.martinez@ua.es.

7 Kreickemeier, A.L y Martínez Román, $M^{2}$ A. "Comparación entre los países", en Kreickemeier, A.L y Martínez Román, $\mathrm{M}^{a} \mathrm{~A}$. (Dirs) Alojamiento compartido a cambio de ayuda en Europa. Alicante, Universidad de Alicante, 2001, págs. 49-57. 
entidad privada sin ánimo de lucro (por ejemplo, asociaciones de voluntariado y cajas de ahorro). Nos parece destacable que uno de los programas españoles se encuentre incluido entre los recursos sociales disponibles en la red pública de Servicios Sociales de su territorio como una de las modalidades posibles de acogimiento familiar.

Sin embargo, muchos de los programas no tienen suficiente financiación y manifiestan que con mayores recursos económicos podrían garantizar un mayor tiempo de dedicación por parte de profesionales cualificados y, de este modo, podrían incluir en el programa un mayor número de personas mayores y jóvenes y dedicarles una más amplia atención. Los profesionales de los Servicios Sociales públicos que están implicados en el desarrollo de estos programas remarcan que se trata de una muy buena alternativa para ayudar a las personas mayores a permanecer en sus domicilios y que la Administración pública debería potenciar su desarrollo apoyando con su financiación.

\subsection{Perfil y función de los coordinadores del programa}

En la mayoría de los programas los coordinadores son técnicos en Ciencias Sociales, principalmente trabajadores sociales. Su función es la siguiente:

- Asesorar a las personas interesadas en el "alojamiento compartido".

- Evaluar a las personas candidatas al programa.

- Poner en contacto y formar parejas entre personas propietarias interesadas en compartir su hogar, y personas interesadas en encontrar alojamiento.

- Realizar tareas de supervisión y seguimiento.

- Ofrecer el apoyo que garantice la estabilidad y afianzamiento del programa.

Además, serán quienes se encarguen de fomentar el desarrollo del programa. Para llevar a cabo esta tarea es necesario realizar un buen trabajo en relaciones públicas.

\subsection{Naturaleza del intercambio}

La idea básica de todos los programas es un intercambio basado en relaciones de reciprocidad en el que una parte ofrece alojamiento y la otra parte ofrece ayuda, pero las condiciones para que este intercambio tenga lugar varían considerablemente:

En Reino Unido -en términos generales-, la persona alojadora y la alojada pagan una cantidad mensual a la entidad que forma las parejas. 
La persona alojada ofrece además ayuda a la persona alojadora. Una ayuda que tiene distintas variaciones:

- En unos casos, se establecen 10 horas semanales de ayuda en tareas cotidianas, permaneciendo en la casa una media de 4 noches por semana y parte del fin de semana, además de pagar una cantidad a la organización.

- En otros, una ayuda a tiempo completo, prestando cuidados a largo plazo para atender las necesidades de personas mayores con bajo nivel de autonomía, a cambio de un alojamiento gratuito y una compensación económica.

- Una tercera modalidad es la posibilidad de recibir el alojamiento gratuito a cambio de 10 horas semanales de ayuda en tareas cotidianas.

En otros países europeos, las personas alojadoras ofrecen alojamiento a cambio de un precio muy bajo o inexistente. A cambio, las personas alojadas facilitan ayuda, por ejemplo: acompañamiento y pasar la noche en casa; prestar ayuda en casa y en el jardín, cuidar los animales y/o la casa cuando las personas alojadoras están fuera; en Alemania y Austria, una hora de ayuda por cada metro cuadrado de habitación por mes.

\subsection{Criterios de selección}

A) Para las personas alojadoras.

\section{En Reino Unido:}

- Facilitar una habitación independiente.

- Tener una edad comprendida entre los 50 o los 55 años y/o padecer una minusvalía física o sensorial.

- Tener evaluadas e identificadas sus necesidades.

\section{En España, Alemania y Austria:}

- Aceptar la idea del intercambio de ayuda mutua a través del alojamiento compartido.

- La casa debe reunir las condiciones que permitan ofrecer un alojamiento apropiado al estudiante.

- No deben necesitar otro tipo de cuidados. Algunos programas ofrecen sin embargo, este cuidado.

- Deben respetar las horas de estudio de la persona alojada.

- Deben ser personas mayores. Algunos programas extienden la ayuda a familias monoparentales y a personas con problemas de discapacidad. 
B) Para las personas alojadas.

\section{En Reino Unido:}

- Tener una edad mínima de 23 años y ser soltero.

- Ser personas autónomas, trabajadores o estudiantes (para uno de los programas).

- Haber sido entrevistados, evaluados y valoradas sus referencias.

- Comprometerse por un periodo mínimo de 6 meses.

\section{En España, Alemania y Austria:}

- En términos generales, son estudiantes.

- Estar interesados en establecer contacto con personas mayores, o bien tener experiencia como voluntarios.

- Considerar su permanencia en la casa por un periodo mínimo, por ejemplo, igual a un año académico.

- Existen otras limitaciones en lo que respecta a la edad.

3.5. Perfil de las personas alojadoras y de las personas alojadas

\section{Personas alojadoras:}

En todos los países los programas tienen como destinatarios las personas mayores. Alemania y Austria también ofrecen estos programas a familias y familias monoparentales. En España, los programas se dirigieron inicialmente a personas mayores que vivían solas, posteriormente, algunos programas han ido ampliando la figura de la persona alojadora haciendo accesible el programa también a familias, familias con padre o madre solos con personas a su cargo, y a las personas con alguna discapacidad. En Reino Unido también hay programas que van a ampliar su actuación a personas con discapacidad física o de aprendizaje.

En cuanto a la edad de las personas mayores, en Alemania y Austria son personas mayores-jóvenes que pueden valerse por sí mismas, mientras que en España se trata de una población de más edad (media superior a 75 años) con tendencia a un mayor envejecimiento y a necesitar mayor apoyo. En Gran Bretaña, dos de los programas atienden a personas mayores cada vez más jóvenes y tienen proyectado ofrecer el programa a personas menores de 50 años.

La mayoría de las personas mayores son mujeres. En España suele resultar difícil que acepten a estudiantes varones. Sin embargo esto no ocurre así en Alemania donde incluso las mujeres alojadoras valoran las capacidades de los hombres para realizar este tipo de tarea.

Personas alojadas:

En cuanto a las características de las personas alojadas, predomina 
la participación de estudiantes universitarios. En España, las Universidades exigen como requisito ser estudiante universitario. También en Alemania y Austria la mayoría de las veces se alojan estudiantes, por el contrario, en Gran Bretaña suelen ser jóvenes trabajadores aunque también estudiantes. La edad media de estos jóvenes suele oscilar entre 20 y 30 años y, en algunos casos, se exige una edad mínima o máxima para participar.

El número de parejas que se han establecido en cada programa es variable y no se dispone de datos suficientes para realizar la comparación. En general los datos muestran que el número de parejas se ha ido incrementando a lo largo del desarrollo de cada programa. En Alemania es destacable la existencia de parejas que no están incluidas en las estadísticas porque después de haber recibido asesoramiento intensivo de los coordinadores de los programas, son capaces de encontrar pareja por sí mismos. Esto demuestra que el programa promueve realmente la autoayuda.

\subsection{Aspectos que facilitan o dificultan el desarrollo del programa}

El alojamiento compartido ofrece múltiples posibilidades. La idea básica es sencilla y puede ajustarse a muy distintas situaciones, siendo esenciales los conceptos "ayuda mutua" y "solidaridad entre generaciones".

Los programas representan un desafío para quienes los coordinan, que son en su mayoría profesionales de las Ciencias Sociales (trabajadores sociales y psicólogos): Cuanto mejor sea la selección y preparación de las personas que van a participar en el programa, cuanto mejor se consiga satisfacer las necesidades de ambos, persona alojadora y persona alojada, y cuanto mayor sea la competencia profesional de la persona que realiza el seguimiento de las parejas, mayores serán las posibilidades de que las experiencias sean positivas.

El alojamiento compartido estimula e incluso demanda la cooperación de organizaciones e instituciones que representan y trabajan por los intereses de personas mayores y jóvenes.

Las experiencias positivas de convivencia entre las parejas son la mejor forma de promover el programa, difundiendo su éxito entre las personas de su entorno, así como desde los medios de comunicación.

En el momento actual algunos aspectos han frenado una rápida difusión del programa. El principal problema radica en la insuficiente financiación, de modo que no existe dotación de personal cualificado que garantice el desarrollo y calidad de los programas. 
Esta una de las razones por las que es difícil aprovechar y dar respuesta a potenciales usuarios del programa, así como realizar un seguimiento en profundidad de las parejas.

Deben ser eliminados los prejuicios que las personas mayores y sus familiares tienen acerca de los jóvenes, para animarles a formar parte de esta innovadora forma de vivir.

Otras dificultades a nivel estructural son: al inicio del curso existe una mayor demanda de alojamiento por parte de los estudiantes; la demanda de chicas y chicos para alojamiento compartido no es la misma; algunos programas no reúnen la adecuada infraestructura para garantizar un trabajo más eficiente.

\subsection{Sugerencias para personas interesadas en iniciar un progra- ma}

Es necesario que el nuevo programa forme parte de las actividades de una organización o entidad que garantice una infraestructura adecuada para poder ofrecer atención personal y telefónica diaria así como un equipo de profesionales cualificados.

Es importante que se seleccione a profesionales cualificados y que presten la dedicación necesaria para recibir e informar a las personas interesadas, seleccionar cuidadosamente, establecer las parejas más adecuadas y llevar a cabo un seguimiento individualizado y continuo.

Otras personas mayores pueden actuar como voluntarios, colaborando con el equipo de profesionales.

La organización o entidad que desarrolle el programa debe coordinarse con otras instituciones que trabajen con personas mayores y jóvenes.

Hay que invertir tiempo y esfuerzo en la difusión del programa para asegurarse de que su información llega hasta las potenciales personas interesadas. En esta difusión es muy importante el papel de los medios de comunicación.

Los inicios son difíciles. No hay que tener prisa ni esperar grandes resultados a corto plazo. Es mejor asegurarse de las posibilidades de éxito de la convivencia para evitar experiencias negativas en el inicio.

El programa no es la mejor opción para todas las personas. Es un recurso minoritario y es más importante obtener buenos resultados cualitativos que cuantitativos. El objetivo es lograr una buena convivencia intergeneracional y no un registro con un gran número de parejas.

Se puede dirigir la oferta del programa a otras personas que puedan 
precisar en algún momento ayuda y estén dispuestos también a ofrecerla, como personas con discapacidades, padres/madres con personas dependientes a su cargo, y otros.

En definitiva, todas las partes involucradas deben aceptar que se trata de un programa de ayuda mutua y de solidaridad intergeneracional.

\section{CONCLUSIONES}

Todos los países estudiados coinciden en destacar el hecho de que, por una parte, las personas mayores manifiestan que su deseo es continuar viviendo en su propio domicilio en el que suelen tener espacio suficiente para más de una persona. Algunas de estas personas mayores necesitan, o podrían necesitar en el futuro, ayuda para las tareas cotidianas y, en muchos casos, desean vivir en compañía de otra persona para disminuir su soledad. Y, por otra parte, hay evidencia de que muchos jóvenes manifiestan dificultades para satisfacer su necesidad de encontrar un alojamiento a un precio asequible.

Las experiencias de Alojamiento Compartido a Cambio de Ayuda estudiadas realizan actuaciones de mediación entre las personas mayores y los jóvenes para ayudarles a encontrar una respuesta a sus necesidades mediante un intercambio de ayuda mutua, siendo esencial que ambas partes, personas mayores y jóvenes, acepten este intercambio como una ayuda mutua con total libertad.

La creación de estas experiencias y su desarrollo muestran una interesante diversidad. Se advierte una mayor similitud (a pesar de evidentes diferencias) entre los programas de España, Alemania y Austria, lo que parece deberse al hecho de ser iniciativas surgidas desde las Universidades con la intención de promover la solidaridad y la ayuda mutua entre generaciones.

Por ser experiencias innovadoras hay que invertir tiempo en su promoción, con el fin de dar a conocer su existencia a las personas mayores y a los jóvenes. La mejor promoción de estos programas se obtiene mediante la difusión personal que realizan las personas mayores y los jóvenes que han tenido una experiencia de convivencia positiva, así como por la repercusión que ello puede tener en los medios de comunicación.

Las actividades de mediación entre personas mayores y jóvenes (selección, emparejamiento, inicio de la convivencia y seguimiento) deben ser realizadas por profesionales cualificados. Además de estos profesionales, puede ser muy enriquecedor contar con la colaboración de 
personas voluntarias.

Un problema común es el relativo a la financiación de estos Programas. Muchos de ellos tienen problemas para obtener la financiación necesaria que garantice la continuidad de los profesionales cualificados.

Es importante establecer una adecuada coordinación entre la organización que promueve un Programa de Alojamiento Compartido a Cambio de Ayuda y otras organizaciones relacionadas con las personas mayores y con los jóvenes.

En conclusión, podemos destacar dos ideas importantes. En primer lugar, que los Programas de Alojamiento Compartido a Cambio de Ayuda pueden ser un excelente medio para promover la ayuda mutua y la solidaridad intergeneracional. Por lo tanto, son elementos a tener en cuenta en la prevención y la lucha contra la exclusión social de las personas mayores y de los jóvenes. Y, en segundo lugar, los resultados de esta investigación pueden servir para introducir en el Alojamiento Compartido a Cambio de Ayuda a nuevos promotores, a los que se les brinda una magnífica oportunidad de conocer la experiencia de quienes llevan ya tiempo trabajando en este campo.

\section{ANEXO I. PROGRAMAS ESTUDIADOS.}

\section{ESPAÑA}

1. "Convivencia entre Personas Mayores y Jóvenes Estudiantes. Alojamiento Alternativo" Ayuntamiento de Albacete. Albacete.

2. "Alojamiento por Compañía. Programa de Ayuda Mutua entre Personas Mayores y Estudiantes Universitarios". Asociación Universitaria para la Promoción del Voluntariado. Universidad de Alicante. Alicante.

3. "Programa de Alojamiento de Estudiantes Universitarios con Personas Mayores". Universidad de Almería. Almería.

4. "Alojamiento Alternativo: Convivencia Intergeneracional y Ayuda Mutua". Universidad de Deusto. Bilbao.

5. "Programa de Convivencia de Estudiantes con Personas Mayores". Diputación Foral de Guipuzkoa. Departamento de Servicios Sociales. Donostia-San Sebastián.

6. "Programa de Convivencia de Jóvenes Universitarios con Personas Mayores y/o Discapacitadas". Consejería de Asuntos Sociales. Delegación Provincial de Cádiz. Cádiz y Jerez de la Frontera.

7. "Viure y Conviure-Vive y Convive". Caixa de Catalunya-Obra Social. Barcelona, Girona, Lérida, Manresa, Sant Cugat, Cerdanyola del Vallès, 
Tarragona, Terrasa, Vic y Universidades.

8. "Programa de Alojamiento de Universitarios con Personas Mayores y/ o con Discapacitados". Consejería de Asuntos Sociales. Delegación Provincial de Córdoba. Universidad de Córdoba.

9. "Alojamiento Alternativo: Tercera Edad-Estudiantes". Universidad de Granada. Gabinete de Atención Social al Estudiante. Granada.

10. "Servicio de Alojamiento Alternativo". Universidad de Las Palmas de Gran Canaria. Las Palmas de Gran Canaria.

11. "Servicio de Convivencia Ancianos-Universitarios". Escuela Universitaria de Trabajo Social "Ntra. Sra. del Camino". León.

12. "Vivienda Compartida entre Personas Mayores y Estudiantes". Asociación "Solidarios para el Desarrollo"-Universidad Complutense. Madrid.

13. "Programa de Alojamiento de Estudiantes Universitarios con Personas Mayores". Universidad de Málaga. Málaga.

14. "Convivencia entre Generaciones. Programa de Alojamientos Compartidos entre Jóvenes Universitarios y Ancianos de la Región de Murcia". Universidad de Murcia. Murcia.

15. "Convivencia Intergeneracional". Instituto Gerontológico Gallego (IGG). Santiago de Compostela.

16. "Programa de Alojamiento de Universitarios/as con Personas Mayores, Discapacitadas y Padres/Madres con hijos a cargo". Universidad de Sevilla. Sevilla.

17. "Programa de Acercamiento Intergeneracional". Universidad de Valladolid. Valladolid, Palencia, Segovia, Soria.

\section{REINO UNIDO}

1. "Personal Services Society" (PSS). Liverpool (Ruthin, Halton, Kerkintillock).

2. "Homeshare-London". Londres (Hertfordshire, Brighton \& Hove, Bristol, Oxford, Colchester)

3. "Housewise". Northampton.

\section{ALEMANIA}

1. "Wohnen für Hilfe". Universidad de Ciencias Aplicadas de Darmstadt y Cruz Roja. Darmstadt.

2. "Wohnraum für Hilfe". Centro de Personas Mayores (Seniorentreff Neuhausen") y Asociación de Estudiantes de la Universidad de Munich. Munich.

\section{AUSTRIA}

1. "Wohnen für Hilfe". Asociación de Estudiantes Mayores de la Universidad de Graz. Graz 


\title{
PROGRAMAS UNIVERSITARIOS PARA MAYORES. LA EDUCACIÓN PARA TODA LA VIDA: UNA EXPERIENCIA EN LA UNIVERSIDAD DE LAS PALMAS DE GRAN CANARIA
}

\author{
$M^{\mathrm{a}}$ AUXILIADORA GONZÁLEZ BUENO \\ Profesora Titular de Trabajo Social y Servicios Sociales. \\ Universidad de Las Palmas de Gran Canaria.
}

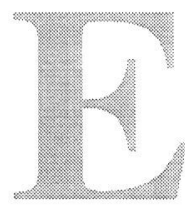

1 presente artículo intenta dar a conocer una experiencia de intervención socio-educativa que pone en marcha la Universidad de Las Palmas de Gran Canaria y que se enmarca dentro de la educación para toda la vida, como medida de protección social y atención a la tercera edad del nuevo milenio. Una experiencia de intervención socio-educativa desde el nivel superior de la enseñanza, como una forma de acercamiento de la Universidad a la realidad social.

Jacques Delors $(1999)^{1}$ manifiesta que frente a los numerosos desafíos del porvenir, la educación constituye un instrumento indispensable para que la humanidad pueda progresar hacia los ideales de paz, libertad y justicia social, como una vía al servicio del desarrollo humano más armonioso, más genuino, para hacer retroceder la pobreza, la exclusión, las incompetencias, las opresiones, las guerras, etc.

Este último cuarto de siglo ha estado marcado por notables descubrimientos y progresos científicos, muchos países han salido del subdesarrollo, el nivel de vida ha continuado su progresión con ritmos muy diferentes según los países. Y sin embargo, un sentimiento de desencanto parece dominar y contrasta con las esperanzas nacidas inmediatamente después de la última guerra mundial.

Ha quedado de manifiesto que el crecimiento económico a ultranza

1 VV.AA (1996): La educación encierra un tesoro. Informe a la Unesco de la Comisión Internacional sobre educación para el siglo XXI, presidida por Jacques Delors. Madrid. Santillana. Unesco. 
no se puede considerar ya el camino más fácil hacia la conciliación del progreso material y la equidad, el respeto de la condición humana y del capital natural que debemos transmitir en buenas condiciones a las generaciones futuras.

Todo convida entonces a revalorizar los aspectos éticos y culturales de la educación, atendiendo las misiones que debe cumplir la educación al servicio del desarrollo económico y social. Un sistema más flexible que permita la diversidad de estudios. La imaginación humana, precisamente para crear esta sociedad, debe adelantarse a los progresos tecnológicos si queremos evitar que se agraven el desempleo y la exclusión social o las desigualdades en el desarrollo.

\section{CONSIDERACIONES GENERALES DEL INFORME A LA UNESCO DE LA COMISIÓN INTERNACIONAL SOBRE LA EDUCACIÓN PARA EL SIGLO XXI}

La educación ocupa un lugar cada vez mayor en la vida de los individuos a medida que aumenta su función en la dinámica de las sociedades modernas. La división tradicional de la existencia en periodos claramente separados ha dejado de corresponder a las realidades de la vida contemporánea y se ajusta aún menos a los imperativos del futuro. Nadie puede hoy esperar que el acervo inicial de conocimientos constituido en la juventud le baste para toda la vida, pues la rápida evolución del mundo exige la actualización permanente del saber. Por otra parte, el acortamiento del periodo de actividad profesional, la disminución del volumen total de horas de trabajo remuneradas y la prolongación de la vida después de la jubilación aumentan el tiempo disponible para otras actividades.

Para organizar este proceso hay que dejar de considerar que las diversas formas de enseñanza y aprendizaje son independientes y, en cierta manera, imbricadas, si no concurrentes y, en cambio, tratar de realzar el carácter complementario de los ámbitos y los periodos de la educación moderna.

En primer lugar, como ya se ha indicado, la transformación del proceso de producción en aras de una mayor competitividad ha determinado que los saberes y las técnicas de cada individuo, adquiridos durante la formación inicial, pierdan rápidamente vigencia y se acentúe la necesidad de desarrollar la capacitación profesional permanente. La formación permanente responde en gran medida a un imperativo de orden económico. Por otra parte, brinda a los individuos la oportunidad de actualizar sus conocimientos y vislumbrar posibilidades de ascenso. 
Según la Comisión debe imponerse el concepto de educación durante toda la vida con sus ventajas de flexibilidad, diversidad y accesibilidad en el tiempo y el espacio. Debe ser una estructuración continua de la persona, de su conocimiento y sus aptitudes, pero también de su facultad de juicio y acción. Debe permitirle tomar conciencia de sí misma y de su medio ambiente e invitarla a desempeñar su función social en el trabajo y la ciudad. No es menos cierto que para poder utilizar bien ese potencial la persona debe poseer todos los elementos de una educación básica de calidad.

Para ello, nada puede reemplazar al sistema formal de educación en que cada uno se inicia en las materias del conocimiento en sus diversas formas.

En efecto, la Comisión piensa en una educación que genere y sea la base de este espíritu nuevo, lo que no quiere decir que haya descuidado los otros tres pilares de la educación que, de alguna forma, proporcionan los elementos básicos para aprender a vivir juntos.

La educación a lo largo de la vida se basa en cuatro pilares:

- Aprender a conocer, combinando una cultura general suficientemente amplia con la posibilidad de profundizar los conocimientos en un pequeño número de materias. Lo que supone, además, aprender a aprender para poder aprovechar las posibilidades que ofrece la educación a lo largo de la vida.

- Aprender a hacer a fin de adquirir no sólo una cualificación profesional sino, más generalmente, una competencia que capacite al individuo para hacer frente a gran número de situaciones y a trabajar en equipo. Pero, también, aprender a hacer en el marco de las distintas experiencias sociales o de trabajo que se ofrecen a los jóvenes y adolescentes, bien espontáneamente a causa del contexto social o nacional, bien formalmente gracias al desarrollo de la enseñanza por alternancia.

- Aprender a vivir juntos desarrollando la comprensión del otro y la percepción de las formas de interdependencia, realizar proyectos comunes y prepararse para tratar los conflictos respetando los valores de pluralismo, comprensión mutua y paz.

- Aprender a ser para que florezca mejor la propia personalidad y se esté en condiciones de obrar con creciente capacidad de autonomía, de juicio y de responsabilidad personal. Con tal fin, no menospreciar en la educación ninguna de las posibilidades de cada individuo: memoria, razonamiento, sentido estético, capacidades físicas, aptitudes para comunicar.

Todo este proceso lleva aparejado un proceso de reforma en todos 
los ámbitos educativos, y es necesario ir respondiendo a los interrogantes que se plantean en cada uno de sus ámbitos. Desde la Universidad se puede contribuir a esta reforma diversificando su oferta:

- Como lugar de ciencia y fuente de conocimiento que llevan a la investigación teórica o aplicada, o a la formación de profesores.

- Como medio de adquirir calificaciones profesionales conforme a unos estudios universitarios y unos contenidos adaptados constantemente a las necesidades de la economía, en los que se aúnen los conocimientos teóricos y prácticos a un alto nivel.

- Como plataforma privilegiada de la educación durante toda la vida, al abrir sus puertas a los adultos que quieran reanudar los estudios, adaptar y enriquecer sus conocimientos, o satisfacer sus ansias de aprender en todos los ámbitos de la vida cultural.

- Como interlocutor privilegiado en una cooperación internacional que permita el intercambio de profesores y estudiantes, y facilite la difusión de la mejor enseñanza mediante cátedras internacionales.

La Comisión se ha hecho eco de otra utopía: la sociedad educativa basada en la adquisición, la actualización y el uso de los conocimientos. La educación debe permitir que todos puedan aprovechar esta información, recabarla, seleccionarla, ordenarla, manejarla y utilizarla. Por consiguiente, la educación tiene que adaptarse en todo momento a los cambios de la sociedad.

Ahora bien, la educación a lo largo de la vida, en el sentido que le da la Comisión, va aún más lejos. Debe dar a cada individuo la capacidad de dirigir su destino en un mundo en el que la aceleración del cambio, acompañada del fenómeno de mundialización, tiende a modificar la relación de hombres y mujeres con el espacio y el tiempo. La educación a lo largo de la vida ha de brindar a cada cual los medios para alcanzar un mejor equilibrio entre el trabajo y el aprendizaje, y para el ejercicio de una ciudadanía activa.

La educación a lo largo de la vida representa para el ser humano una construcción continua de sus conocimientos y aptitudes y de su facultad de juicio y acción. El saber, el «saber hacer», el «saber ser» y el «saber convivir» en sociedad constituyen los cuatro aspectos, íntimamente enlazados, de una misma realidad. Combina el conocimiento formal y no formal, el desarrollo de aptitudes innatas y la adquisición de nuevas competencias. Además de ser una experiencia singular de cada persona, es también la más compleja de las relaciones sociales, pues abarca a la vez los ámbitos cultural, laboral y cívico. La educación durante toda la vida se presenta como una de las llaves de este siglo XXI. Se trata de aprender a vivir juntos conociendo mejor a los demás, 


\section{LA FORMACIÓN DE MAYORES EN EL ÁMBITO UNIVER- SITARIO}

La mayor esperanza de vida, la disminución de la tasa de natalidad y la jubilación anticipada, entre otros factores, están aumentando de forma absoluta y relativa a otros colectivos sociales, el número de personas «mayores» en nuestra sociedad. Personas mayores jubiladas, que no viejos, que disfrutan de tiempo libre y que exigen más cuota de participación social y en la solución de sus propios problemas (Lemiex 1997). ${ }^{3}$

Según describen Guirao y Sánchez-Martínez $(1997)^{3}$ para el caso español, se trata de una masa social de personas que no pudieron embarcarse en unos estudios universitarios: «Estamos hablando de generaciones de españoles que tuvieron que sufrir las repercusiones de nuestra guerra y posguerra civil, en un momento de desarrollo de España en el que la educación universitaria era un coto reservado para una elite de afortunados. Ahora es un buen momento para invitar a estas personas a cumplir lo que para muchos fue sólo un sueño: asistir a la Universidad».

La atención educativa a los mayores ha ido evolucionando desde las primeras experiencias de enseñanza para mayores en Norteamérica (1927) que no eran más que reuniones organizadas de personas mayores; les sigue la formación de las personas que intervienen en el entorno a los mayores, hasta la creación, en 1973, de la primera Universidad de la Tercera Edad en Toulouse por el profesor Pierre Vellas. Asistimos a la tercera generación en el modelo de atención educativa a los mayores, la de la Orientación Gerontológica y que se caracteriza y diferencia de otras iniciativas en que las Universidades ofrecen programas de enseñanza, investigación y de servicio a la colectividad. ${ }^{4}$

Ante la puesta en marcha de un programa universitario de atención a la tercera edad se recomienda, que atendiendo a este modelo de

2 Lemiex, A. (1997). Los Programas Universitarios para Mayores Enseñanza e Investigación. Ministerio de Trabajo y Asuntos Sociales (IMSERSO), Madrid. 163 pags.

3 Guirao, M. y Sánchez-Martínez, M. (1997). Los programas universitarios para mayores en España. En: Los Programas Universitarios para Mayores. Enseñanza e Investigación (André Lemiex, Editor), pp. 145-153. Ministerio de Trabajo y Asuntos Sociales (IMSERSO), Madrid.

4 Al definir el programa como un servicio a la colectividad evitamos desviaciones, por otra parte bastante frecuentes en las Universidades, hacia formas educativas más relacionadas con la Educación Superior como la organización de master, proycctos de investigación, departamentos universitarios especializados que no permiten el acceso de los actores principales del problema. 
tercera generación, se oferte una intervención tripartita que abarque la enseñanza, la investigación y el servicio a la colectividad.

A. Con respecto a la enseñanza:

- Que las Universidades continúen ocupándose de la educación de adultos hasta alcanzar a las personas mayores.

- Que para hacer esto se desarrolle un certificado de formación general para adultos mayores, al igual que se ha hecho (por otras instancias) para el primer ciclo educativo.

- Que en la formación de maestros y en el segundo ciclo se prevean acciones encaminadas a favorecer posteriormente un mejor entendimiento de los escenarios alternativos, salud, vivienda, tiempo libre, jubilaciones y roles sociales relacionados con la edad.

B. Con respecto a la investigación:

- Que se estimule la producción de memorias de masters y tesis doctorales en el área de la tercera edad.

- Que se estimule la producción científica en el área de la tercera edad.

C. Con respecto a los servicios a la colectividad:

- Que sea cual sea la forma en que se haga (programa de formación, centro de estudios universitarios, proyectos de investigación, etc.) se haga como un servicio de orden educativo y social destinado a la atención a mayores.

- Que se favorezca el acercamiento a los individuos y los organismos del entorno.

En España, las ofertas de actividades de carácter educativo y cultural dirigidas a los adultos mayores son de tres tipos: a) la de agrupaciones y asociaciones de difusión cultural, de formación permanente o denominación semejante, b) aulas, agrupaciones y asociaciones de extensión universitaria y c) la que constituyen los programas universitarios para alumnos mayores que se realizan en las propias universidades.

La Universidad de Las Palmas de Gran Canaria se decanta por esta tercera opción sin discriminar las anteriores, puesto que las mismas no se contraponen ni desvirtúan entre sí, sino que tratan conjuntamente de ampliar el panorama de una oferta solidaria para que la persona mayor pueda elegir con más libertad la opción que mejor atienda sus aspiraciones, necesidades y posibilidades. 


\section{PROGRAMA DE MAYORES DE LA UNIVERSIDAD DE LAS PALMAS DE GRAN CANARIA "PERITIA ET DOCTRINA"}

El programa Peritia et Doctrina es el resultado del compromiso adquirido por el equipo rectoral de la ULPGC a través del vicerrectorado de estudiantes y la Dirección General de Servicios Sociales de la Consejería de Empleo y Asuntos Sociales del Gobierno de Canarias. Surge hace tres años, en el curso 1998/1999 y en favor de una mayor implicación social, la ULPGC asume el reto de crear una iniciativa encaminada a dar asistencia educativa y permitir el acceso a la Universidad a sectores de la población distintos al tradicional.

Se constituye como una alternativa al colectivo de "mayores" como medida de protección social y atención a la tercera edad del nuevo milenio. Una experiencia de intervención socio-educativa desde el nivel superior de la enseñanza, como una forma de acercamiento de la Universidad a la realidad social. El programa de formación de mayores se concibe, por tanto, como la contribución de las Universidades a la atención social solidaria que, además, forman y con ello aumentan el nivel cultural de la comunidad.

El programa asume todos aquellos argumentos que hablan en favor de una mayor implicación social de la Universidad. Y es, desde este principio, que se considera los programas de formación de mayores como la contribución de las Universidades a atención social solidaria que, además, forman y con ello aumentan el nivel cultural de la comunidad.

El nombre del proyecto surge de la idea de combinar la Peritia: «la experiencia y el saber que traen los mayores por formación previa y/o edad» y Doctrina «el conocimiento que aún pueden adquirir"s.

\subsection{Objetivos del programa:}

1. Ser un servicio a la colectividad.

2. Complementar la oferta de formación y participación social de los mayores de 55 años.

3. Formar sobre temas específicos de la edad.

4. Formar sobre temas que permitan mejor adaptación a los cambios sociales, culturales y tecnológicos.

5. Integrar a los mayores de 55 años en la comunidad universitaria: para que conozcan la (su) Universidad y que el contacto permita el entendimiento intergeneracional. 


\subsection{Estructura del programa}

El programa no da lugar a competencias profesionales pero tiene organización administrativa y académica similar a las de las titulaciones de la Universidad. El alumno debe inscribirse, matricularse, asistir a clases en los centros de la Universidad y, sobre todo, aplicarse y rendir para titular.

Se estructura en tres años académicos con un total de 600 horas. Los cursos se desarrollan en dos trimestres, más un mes del período de formación permanente. Los alumnos reciben un total de 200 horas por curso, de las que un $70 \%$ son clases teóricas y el resto actividades dirigidas, trabajos prácticos, visitas culturales, incluso actividades y cursos de extensión universitaria. Los alumnos cursarán al menos diez materias por curso, de las cuales seis son obligatorias y doce optativas.

Las materias obligatorias tienen contenidos relacionados con la edad, mientras que las materias optativas abordan eminentemente aspectos culturales, sociales y tecnológicos que permitan una mejor adaptación a la sociedad moderna.

Las asignaturas del programa responden a las grandes áreas de la

CUADRO 1: Organización del título y materias.

\begin{tabular}{|l|}
\hline OBLIGATORIAS \\
\hline PRIMER CURSO \\
\hline Psicología de la madurez \\
Sistemas de Protección Social en la Edad Adulta \\
Estrategias para el desarrollo personal \\
Historia del Arte \\
Lengua y Literatura \\
Historia de España \\
\hline SEGUNDO CURSO \\
\hline Habilidades sociales II \\
Biología Vegetal y Naturaleza Canaria \\
Las telecomunicaciones en el nuevo milenio \\
Ciencia y Sociedad una relación permanente \\
Introducción al Derecho \\
Contaminación \\
\hline TERCER CURSO \\
\hline Solidaridad, Asociacionismo y Voluntariado \\
Movimiento y mecánica corporal \\
Historia de Canarias II \\
Marco jurídico específico del mayor \\
Biología del Sistema Nervioso \\
Dilemas éticos \\
\hline
\end{tabular}

\begin{tabular}{|l|}
\hline OPTATIVAS \\
\hline Informática básica \\
Introducción a la Sociología \\
Taller de musicoterapia \\
Energías alternativas \\
La pervivencia del pensamiento \\
y de la cultura grecolatina en el \\
mundo actual \\
Nutrición y dietética \\
Accesibilidad, barreras arquitec- \\
tónicas, urbanísticas y de trans- \\
porte \\
La salud en la edad adulta \\
Riesgos y cuidados sanitarios en \\
las actividades de la vida diaria \\
Historia de la música \\
Internet y las nuevas comunica- \\
ciones \\
Relaciones humanas (interperso- \\
nal y grupal)
\end{tabular}


Universidad. De esta manera se abordan materias relacionadas con las disciplinas Humanístico-Lingüísticas, Científicas, Tecnológicas, de la Salud, del Deporte y del Derecho, entre otras. Los tres cursos se desarrollan en el área de San Cristóbal (nuevo centro destinado a dicha formación).

Fruto del alto interés mostrado y a demanda del alumnado, se ha generado una nueva oferta de formación más específica y a la que denominamos periodo de formación permanente, cuyo objetivo es ofrecer módulos de especialización en relación con las materias cursadas o temas de interés del momento (gestión de asociaciones en Canarias, acercamiento a las matemáticas en su año internacional, la inmigración en Canarias y su perspectiva social, etc:).

\subsection{Evaluación}

La evaluación intenta medir el grado de logro alcanzado por los estudiantes a lo largo del curso y la consecución o no de los objetivos planteados inicialmente. Asimismo, consideramos que la evaluación debe medir el rendimiento del estudiante de forma continua. La metodología a seguir durante el curso se centra en la participación e implicación activa de los alumnos en su proceso de aprendizaje.

Las clases compaginarán la aportación de conocimientos teóricos por parte del profesor/a con clases prácticas a través de los diferentes trabajos grupales que se puedan ir realizando de los diferentes temas tratados, como vía de profundización del alumno. Se exige la asistencia al $80 \%$ de las horas lectivas para obtener el diploma acreditativo del curso.

\subsection{Perfil de alumnado}

El programa cuenta con 200 alumnos matriculados en los tres cursos del programa. La edad media de los mismos se sitúa en torno a los 65,43 situando el rango de edad entre los 55 y los 87 años. Se trata de personas integradas en la comunidad y residentes en su mayoría en la ciudad de Las Palmas.

En relación a la variable sexo nos encontramos con una mayor presencia de mujeres, con un $62 \%$ frente a un $38 \%$ de hombres, donde el estado civil es variado, predominando las categorías casados y viudos.

El nivel de estudios y el tipo de profesión ejercida también es variado, existiendo una mayor proporción de personas con estudios primarios, seguido de los estudios medios, tales como maestros, enfermeras, etc. En relación a la actividad profesional abunda la formación profesional no reglada (técnicos en general y profesionales del sector servi- 
cios) y profesiones liberales (pequeños y medianos empresarios).

En relación a la asistencia nos encontramos con un alto índice de participación, con un $87 \%$ de alumnos que asisten regularmente y un $10 \%$ de ausencias justificadas. El abandono es bastante bajo, con un $3 \%$ de los matriculados.

\subsection{Líneas futuras de actuación}

Nuestras líneas futuras de actuación tendrán una doble vertiente: en primer lugar, y a nivel académico, seguir actuando en la consecución de los objetivos del programa, mejorando y potenciando las tres grandes áreas propuestas:

- Con respecto a la educación, seguir ampliando la optatividad de formación básica y los módulos de formación especializados.

- En relación a la investigación, continuar con el apoyo y fomento de líneas investigadoras "con" y "para" este colectivo.

- Y, en último lugar, y dentro del apartado de servicios a la comunidad, fomentar el asociacionismo de los mayores y su participación activa en la comunidad.

Por otra parte, y a nivel institucional, seguir consolidando el programa en el engranaje de la Universidad hasta lograr la plena integración del programa, así como la introducción del mismo en las redes nacionales e internacionales de formación de mayores.

\section{EN CONCLUSIÓN}

Como conclusiones generales a los programas de mayores en las Universidades españolas aportamos el trabajo conjunto en el V Encuentro Nacional de Programas Universitarios para Mayores, celebrado en Tenerife en abril de 2001. Entre las conclusiones alcanzadas se destacan:

\section{A) Acuerdos generales:}

- Constituir la comisión nacional de programas universitarios para mayores como órgano de coordinación entre los distintos programas universitarios. Dicha comisión tendrá, entre otras, la función de preparar el próximo encuentro nacional.

- Enfatizar la dimensión universitaria de los programas para mayores y, por tanto, destacar la formación científica y humanista de los mismos.

- Estimular al profesorado universitario de los programas para que impulsen investigaciones en el marco de estos programas con el fin 
de que permitan conocer con mayor profundidad sus diversos aspectos.

- Favorecer los procesos de evaluación de los programas como una manera de mejorar la calidad de los mismos.

- Actualizar el censo de programas y que éste se incluya en la guía de programas universitarios para mayores que edita el IMSERSO.

- Potenciar el intercambio con instituciones europeas similares a los programas para mayores a través de acciones que, como el Grundtvig, pueden posibilitar el intercambio de alumnado y profesorado de la Unión Europea.

- Favorecer el uso de las nuevas tecnologías desde los programas para mayores.

- Reconocer el carácter social de los programas para mayores y, en este sentido, solicitar la colaboración del IMSERSO y que esta institución esté abierta a la colaboración con las nuevas iniciativas que se presenten y a potenciar, en la medida de lo posible, el desarrollo de las ya existentes.

b) Acuerdo del alumnado

- Solicitar de las Universidades el reconocimiento oficial que posibilite, tras haber superado los tres cursos correspondientes, el acceso a la Universidad reglada sin otro requisito.

- Que el alumnado participe oficialmente en la decisión, tanto de las materias a impartir en las clases como del profesorado.

- Que se regulen los planes de estudio de forma que el primer ciclo conste de tres años como mínimo.

- Que exista en el órgano de gobierno de la Universidad la correspondiente presencia institucionalizada (con voz y voto) del alumnado mayor.

- Que el alumnado, una vez acabado el primer ciclo, tenga la posibilidad de asistir a cursos monográficos y/o diversificados.

c) Acuerdos de las asociaciones

- Necesidad de que se organicen asociaciones de alumnado mayor en aquellas Universidades donde no existan.

- Independencia de las asociaciones en sus propuestas y actos.

- Que las asociaciones tengan la oportunidad de federarse.

d) Acuerdos de la federación

- Necesidad de integración en la federación nacional de todas las asociaciones de programas universitarios.

- Formar parte en la formación y desarrollo de programas universitarios para mayores. 
- Integración en los órganos de gobierno de las Universidades y entidades colaboradoras con los programas.

En último lugar y aterrizando en la Universidad de Las Palmas de Gran Canaria, destacamos que, tras tres años de andadura, hemos comprobado cómo el programa "Peritia et Doctrina" no sólo se configura como un espacio académico donde un grupo de personas mayores se encuentran para mantener frescas y ágiles sus mentes, sino que por el contrario se ha configurado como un grupo de participación social ciudadana, surgiendo del mismo una asociación cultural de ocio y tiempo libre, además de lograr la participación e implicación de otros organismos y entidades socio-económicas en actividades de tipo educativo.

Podríamos afirmar que este tipo de programas comienzan a configurarse como nuevas medidas de protección social hacia un colectivo con necesidades sociales muy diversas y cambiantes, por lo cual es necesario arbitrar políticas sociales concretas que den soluciones al nuevo colectivo de mayores al que nos enfrentamos en el nuevo milenio, un colectivo con mucho más peso social y sobre todo más implicado en la sociedad a la que pertenece.

\section{BIBLIOGRAFÍA}

DE CASTRO, A. (1990): La Tercera Edad: Tiempo de ocio y cultura. Madrid. Narcea.

DOCUMENTACIÓN SOCIAL (1992): La Animación de los Mayores. Revista de Estudios Sociales y de Sociología Aplicada, nº 86.

GUIRAO, M. y SÁNCHEZ MARTÍNEZ, M. (1998): La oferta Gerontológica. Universidad de Granada. Editorial Universitaria.

KARLHEINZ, A. y MARIANNE HEGE (1997): Acción Socioeducativa: Modelos, métodos y técnicas. Madrid. Narcea.

LEMIEUX ANDRÉ (1997): Los programas Universitarios para mayores: Enseñanza e investigación. Bilbao. Imserso.

MARION L. BEAVER y DON A. MILLER (1998): La práctica clínica del Trabajo Social con las personas mayores. Barcelona. Paidós.

MEDINA FERNÁNDEZ, O. (1997): Modelos de educación de personas adultas. Universidad de Las Palmas de Gran Canaria. Roure.

VELÁZQUEZ y FERNANDEZ, C. (1998): Las Universidades de mayores una aventura hecha realidad. Universidad de Sevilla. Secretariado de Publicaciones.

VV.AA (1996): La educación encierra un tesoro. Informe a la Unesco de la Comisión Internacional sobre educación para el siglo XXI, presidida por Jacques Delors. Madrid. Santillana. Unesco. 


\section{TRIBUNA LIPRE}





\title{
CONVERSACIONES CON MARY RICHMOND: UN SIGLO DESPUÉS EL «DIAGNÓSTICO SOCIAL»
}

\author{
PILAR MUNUERA GÓMEZ \\ Profesora del Departamento de Trabajo Social y Servicios Sociales. \\ Universidad Complutense de Madrid.
}

\section{PRESENTACIÓN}

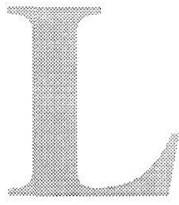

a historia puede a veces jugarnos una mala pasada porque oculta a los autores en tanto que personas, para que escuchemos con mayor atención lo mejor de su obra, lo que ellos han descubierto y consideran fundamental. Pero esta dificultad hace que cada uno de nosotros tenga que trazar su propio "viaje" en busca de la verdad.

Hace varios años que estoy profundizando sobre los contenidos del libro "Diagnóstico Social" y creo que en esta obra Mary Richmond ha dejado un importante legado para el Trabajo Social. Las dificultades de la traducción y la imposibilidad de contar con la autora para contrastar los contenidos hacen que en muchos casos se produzcan interpretaciones divergentes.

Basándome en los contenidos del libro "Diagnóstico Social" he perfilado una entrevista imaginaria a Mary Richmond, tratando de dar respuesta a algunos de los interrogantes que nos permitan entender mejor su obra. Esta propuesta se continúa en la invitación a debatir y profundizar en los orígenes de nuestra profesión, tarea a la que animo a todos y todas nuestros/as colegas.

ENTREVISTA A MARY RICHMOND, CAMINANDO HACIA EL CENTENARIO DEL "DIAGNÓSTICO SOCIAL"

Historia del Trabajo Social ¿Quiénes fueron los precursores?

Los primeros intentos de introducir la investigación en el tratamiento de la pobreza en Inglaterra estuvieron en manos de reformadores so- 
ciales que eran principalmente economistas. Ellos pusieron un sesgo cuantitativo a la investigación que se llevaba a cabo, pero dejaron de lado la comprensión de las capacidades potenciales que existían en las personas para resolver sus problemas. Esta comprensión implica el reconocimiento de bazas y dificultades, es la que verdaderamente da sentido al Diagnóstico Social que identifica a nuestra profesión.

Las reformas caritativas que se intentaron en el primer cuarto del siglo XIX dieron lugar a la frase «una investigación completa». Thomas Chalmers la usó en Glasgow ya en 1823 en relación con su trabajo parroquial, y después fue utilizada en Alemania por Elberfeld y sus seguidores. Por otro lado, los reformadores de la Ley de Pobres de 1834 dieron la espalda a la idea de la investigación completa, teniendo en cuenta como requisito para entrar en el asilo de pobres solamente la buena voluntad que haría la investigación individualizada innecesaria. A menudo los partidarios de la investigación en esos primeros momentos sólo tenían en mente los aspectos económicos de una situación humana dada, y, cuando se les pedía que explicaran su frase, «una investigación completa,» no resaltaban ningún recurso salvo los ingresos económicos, ninguna obligación salvo aquéllas de los que estaban a cargo de parientes por ayuda o reembolso. Por consiguiente, el tratamiento que ellos contemplaron se fijó en la represión de demandas juzgadas como innecesarias, la regeneración del carácter, la multiplicación de oportunidades sanitarias, las oportunidades para la formación, y aspectos similares.

Sin embargo, Chalmers era un hombre de genio y visión que vio la necesidad de fomentar los poderes de la autoayuda y la ayuda mutua dentro de la misma gente, y comprendió la parte que el servicio personal debería tener en esta tarea. Pero él no tenía entonces a mano la mayoría de los materiales sobre los que el diagnóstico social moderno y el tratamiento social están construyéndose. Para cada cosa que podría hacerse entonces sobre la actitud de un hombre hacia su vida y sus relaciones sociales, sobre su salud, vivienda, trabajo, y ocio, hay ahora una docena de acciones para desarrollar. El poder para analizar estrechamente una situación humana, a diferencia del viejo método de recurrir a unas clasificaciones generales, crece con la conciencia de saber cómo y para qué intervenir.

\section{¿Dónde están los comienzos de la Organización de Caridad (C.O.S.)?}

La Sociedad de Organización de Caridad de Londres, heredera de las ideas de Chalmers y del sistema de Elberfeld, incluyó desde el comienzo, entre sus miembros, un pequeño grupo de reformadores socia- 
les. Estaban convencidos de la necesidad de regular las ayudas, e interesados en las personas necesitadas. De esta manera podrían estudiar y dar a conocer las posibilidades latentes en las personas. En este punto se produce una división en el movimiento de organización de caridad entre lo que puede calificarse como método comprensivo de investigación y de tratamiento y el exclusivamente económico.

¿Que relación existe entre la Organización de Caridad y el Diagnóstico Social?

Resumiendo los principales factores de la relación de la Organización de Caridad con el Diagnóstico Social, puede decirse:

- Primero, que el movimiento se desarrolló y luchó para comenzar este proceso de diferenciación entre método compresivo y método exclusivamente económico.

- Segundo, que algunos de sus primeros líderes habían tomado la idea del estudio comprensivo del individuo en su ambiente social.

- Tercero, que esta concepción, imperfectamente entendida, fue rechazada a menudo por la predominante creencia en la exclusiva importancia de los datos económicos.

- Cuarto, ese progreso en el diagnóstico esperó necesariamente el desarrollo de métodos de tratamiento variados, mientras no había otro programa de tratamiento aceptado al principio que el de daro no ayudas.

- Quinto, que la promoción de medidas preventivas que hicieron posible el tratamiento variado, sobre todo de aquéllas enfocadas a la vivienda y salud de las personas, llegó a ser una parte importante del trabajo de las organizaciones de caridad.

¿De qué situación se parte? ¿Por qué el libro de Diagnóstico Social?

Aunque las "friendly visitors" han ganado un grado de reconocimiento por estar comprometidas en una ocupación útil a la comunidad, están limitadas por el hecho de que "su público" no es sensible a la diferencia entre la solicitud de ayuda como trámite y lo que implica el proceso de ayuda en el Trabajo Social.

Por consiguiente, debemos dar la bienvenida al deseo evidente en esos primeros trabajadores sociales de abandonar la intervención basada en buenas intenciones; por sinceros intentos de someter los procesos de su tarea al análisis crítico y a la elaboración de normas proporcionadas por la experiencia. He aquí el punto de partida para una inter- 
vención profesional.

Los asistentes sociales de los Estados Unidos forman un grupo profesional amplio. Una mayoría de ellos está comprometida en el trabajo social que tiene como objetivo inmediato la mejora de individuos o familias. Este trabajo se plantea uno por uno, a diferencia de la mejora en su conjunto. La mejora masiva y la mejora individual son interdependientes, sin embargo, la reforma social y el trabajo social actúan progresivamente juntos por necesidad. Esta verdad fundamental aparecerá repetidamente conforme la presente discusión del diagnóstico social avance.

Ya que el trabajo social es un tema demasiado amplio para ser cubierto en un volumen, el asunto del Diagnóstico Social será exclusivamente su proceso inicial.

Cuando un ser humano, cualquiera que sea su situación económica, desarrolla alguna forma marcada de dificultad y necesidad social, ¿ qué tenemos que saber sobre él y sobre su dificultad o dificultades, antes de que podamos llegar a una forma de satisfacer su necesidad? El problema puede ser de niñez o vejez, de enfermedad, de explotación, o de oportunidad desaprovechada, pero en cuanto que atañe a un individuo en sus relaciones sociales no es extraño al Trabajo Social. El esfuerzo por llegar a los hechos esenciales que llevan a las dificultades sociales de un hombre normalmente se ha llamado «investigación», pero el término que aquí se adopta como un sustituto-diagnóstico social-tiene la ventaja que desde el primer momento fija la mente del trabajador social en el fin de desarrollar la personalidad.

Gran parte del proceso descrito en él es indudablemente aplicable, con modificaciones, a situaciones humanas que no están ahora dentro de la esfera de la asistencia social organizada. El campo concreto de Diagnóstico Social reside en el Trabajo Social. Está destinado además a ser un complemento en los campos de medicina, educación, jurisprudencia e industria.

\section{¿Cuándo surge la necesidad de crear un «método» en Trabajo Social?}

En esta nueva disciplina, como en cada una de las otras, los descubrimientos que hicieron con dolor y dificultad los pioneros de una generación se han vuelto áreas comunes de pensamiento en la siguiente. Hay medio siglo de empeño social entre la desesperada exclamación de Edward Denison - «Cada chelín que yo regalo hace cuatro centavos de bien ayudando a mantener sus [sus beneficiarios] cuerpos miserables vivos, y ocho centavos de mal ayudando a destruir sus 
almas miserables »- y la demanda hecha hace unos años por un médico Boston. Este médico había visto en su práctica profesional el servicio excelente dado por los asistentes sociales especializados del Hospital resolviendo las dificultades sociales de sus pacientes. Esto le motivó para pedir a su superior que le permitiera contratar a uno de ellos para dar servicio privado a un paciente con posibilidad de pagar, y cuya posibilidad de beneficiarse del tratamiento médico dependía de recibir tratamiento social. La sección de servicio social del hospital no podía prescindir de un trabajador de su plantilla, pero recomendó uno con las calificaciones requeridas perteneciente a una sociedad de ayuda.

El hecho destacable es que los hábiles métodos que hicieron posible esta tarea habían sido construidos laboriosamente por aquéllos que habían compartido el planteamiento de Denison y después por algunos grupos de trabajadores sociales que avanzaron independientemente.

Se han hecho importantes contribuciones al diagnóstico social desde las experiencias de tres movimientos identificados con la caridad, los tribunales de menores y el campo médico-social.

En el primero de estos movimientos el interés en el diagnóstico muestra dos impulsos divergentes: uno desde el énfasis en la situación económica a la exclusión de otros aspectos igualmente importantes sobre cuestiones humanas; el otro hacia una concepción más amplia, que llevó a sus partidarios desde el principio - aunque sin preparación y con pocos recursos- a tener en cuenta al hombre en su totalidad. En el movimiento de los tribunales de menores algunos de los métodos de psicología experimental se adaptaron a las necesidades de la investigación social. El movimiento médico-social está modificando de una manera llamativa la práctica médica y social.

\section{¿Cuando comienza el proceso de investigación que trata el libro?}

En 1902 comencé a tomar notas, a reunir ilustraciones e incluso a hacer un borrador de unos cuantos capítulos para un libro de Trabajo Social con familias. En él esperaba dar a la gente más joven que acudía al campo de las organizaciones de la caridad una explicación de los métodos que sus maestros habían encontrado útiles. Sin embargo, pronto se hizo evidente que ningún método ni aspiración estaban adaptados peculiar y únicamente al tratamiento de las familias que acudían a las organizaciones de caridad. Esencialmente, los métodos y aspiraciones del trabajo social de casos eran o deberían ser los mismos en cada tipo de servicio, sea el sujeto un paralítico sin hogar, un niño descuidado de padres alcohólicos o una madre viuda con niños pequeños. Algunos procedimientos, por supuesto, eran adecuados para un grupo de casos 
y no para otros, según el tipo de inhabilidad social tratada. Pero los aspectos que más necesitaban ser destacados acerca del trabajo de casos eran los comunes a todos. La división del trabajo social en departamentos y especialidades era una necesidad y una conveniencia, aunque existían semejanzas fundamentales.

Entre otros profesionales -como médicos y abogados, por ejemplosiempre hubo una base de conocimiento en común. Si un neurólogo tenía ocasión de tratar con un cirujano, cada uno podía asumir del otro un dominio de los elementos de todo un grupo de ciencias básicas, además de la experiencia formulada y transmitida de su propio gremio. Pero qué conocimiento común podían asumir los trabajadores sociales en semejante caso. Esta era mi pregunta en 1902. Me parecía entonces, y es todavía mi opinión, que los elementos del diagnóstico social, una vez formulados, deberían constituir parte del fundamento del cual todos los trabajadores sociales de casos podrían ocuparse en común. Debería ser posible con el tiempo dar por sentado en cada trabajador social un conocimiento y un dominio de los elementos y de las modificaciones que las décadas de práctica, seguramente, podrán aportar.

Esto estrechó el tema que me había propuesto en los primeros procesos del trabajo de casos, pero al mismo tiempo lo ensanchó enormemente porque demandaba para su tratamiento una experiencia de todos los diferentes tipos del mencionado trabajo de casos.

Como cabeza ejecutiva, en aquellos días, de una organización bastante grande, tenía poco tiempo para el estudio, de manera que la tarea fue pospuesta durante casi nueve años. Alrededor de 1909, después de convertirme en miembro del equipo de la Russell Sage Foundation, fue cuando lo retomé de nuevo.

Mientras tanto me había empezado a dar cuenta de la amplia utilidad de la evidencia social, del diagnóstico social y del tratamiento social, cada uno en sus campos determinados y en otras profesiones, incluso cuando estas últimas trataban con gente que no eran dependientes o delincuentes. Era evidente que el trabajo social de casos podía completar el trabajo de la justicia, de la enseñanza, de las terapias. Además, grupos de trabajadores estaban haciendo cosas notables en las organizaciones sociales ya existentes. Estaban desarrollando una capacidad de diagnóstico en cuanto a tratamiento de las dificultades de los seres humanos, capacidad de diagnóstico que debería tener una amplia oportunidad, especialmente en su período formativo, de conseguir el nivel de técnica social, sin estar acorralados por las antiguas tradiciones de los profesionales, ya fueran de tribunales, hospitales o colegios. 
Retomé esta tarea, por segunda vez, en el invierno de 1910, con un punto de vista bastante distinto al de entonces, y con la determinación de ir lo más allá posible de los límites de mi propia experiencia en mis investigaciones. Francis H. Mclean, mi compañero en la Fundación en estos momentos, me prestó una ayuda inestimable durante esta empresa. El había invitado a un grupo de trabajadores sociales de casos, a preparar artículos cortos que describieran de una manera informal los métodos y experiencias de su trabajo, cuando tomaban las medidas que precedían al desarrollo del plan del tratamiento. Más tarde, este grupo se incrementó, y algunos de sus artículos -sobre temas como, por ejemplo, las fuentes de información existentes en el barrio, las relaciones con los jefes en el estudio del historial de un empleado, los métodos de conducir la primera entrevista, etc.- fueron reproducidos por ellos mismos y distribuidos entre sus compañeros de las organizaciones de caridad. Esto se hizo en parte para poder sacar provecho de críticas o comentarios. Los artículos eran demasiado experimentales para su publicación. Sin embargo, contenían pasajes de gran valor, que he aprovechado en la segunda parte de mi libro «Diagnóstico Social», citando el autor cada vez que lo hago.

El paso siguiente fue contratar a dos trabajadores de casos con experiencia -uno en trabajo social de medicina y otro en trabajo social con familias- para estudiar historiales originales de casos durante un período de un año. Se leyeron los casos en cinco ciudades distintas. No se intentó llegar a una media de trabajo de casos en estas ciudades. Al contrario, nuestro objetivo era sacar a la luz la mejor práctica de trabajo social que se podía encontrar, con tal de que estuviera realmente en uso y no fuera una práctica excepcional. Además, estos lectores de casos hicieron muchas entrevistas a trabajadores de casos, transcribiéndolas cuidadosamente. Dado que mi propia experiencia había sido casi completamente en el campo de las organizaciones de caridad, se cuidó mucho centrar la mayoría de la lectura de casos y entrevistas en las organizaciones sociales médicas y de ayuda a niños. Una gran parte del material ilustrativo, utilizado tan libremente en la segunda parte del libro mencionado, está recogido de la colección mucho más grande de apuntes de casos y de las anotaciones de entrevistas preparadas por estos dos lectores de casos, aunque también he hecho uso de mis apuntes y de los recogidos sobre la marcha, de mis compañeros en el Departamento de Organizaciones de Caridad de la Fundación.

\section{¿Por qué continuar con tan arduo trabajo?}

Dado que desde su inicio le había interesado a este departamento la enseñanza del trabajo de casos en las distintas escuelas para trabajado- 
res sociales, se empezó a preparar una edición de un grupo de historiales originales, la mayoría de ellos casos actuales, para su uso en el aula. Estos se reprodujeron en su totalidad con sus defectos (un mal trabajo puede enseñarnos tanto como un buen trabajo) y fueron utilizados en conferencias por un pequeño grupo acreditado de profesores de trabajo de casos. También se recogieron de varios especialistas críticas y comentarios sobre algunos de estos historiales. Como se ha dicho en otra parte, el experimento de editar los historiales de casos no podía ser público, porque sus sujetos eran personas reales y había que respetar su intimidad. Incluso cuando todos los nombres habían sido cambiados, descubrimos que había pocas cosas más reconocibles que un historial completo de un caso social. El experimento, por limitado que fuera, sacó a la luz muchas sugerencias valiosas.

\section{¿Cómo fueron los comienzos del diagnóstico social?}

En la mayor parte, el tema del diagnóstico social se opone a un trato estadístico, aunque como un modo de empezar y de llegar a una medida cuantitativa aproximada de la frecuencia relativa de las consultas realizadas a las distintas fuentes exteriores de información y cooperación se hizo un breve estudio estadístico. Se convenció a cincuenta y seis organizaciones de trabajo social que nos dejaran hacer un listado de las fuentes exteriores consultadas por cada organización en cincuenta casos. Los resultados de este estudio están en la segunda parte y en uno de los apéndices del libro Diagnóstico Social.

Uno de las técnicas de estudio menos utilizadas fue cartearse o entrevistar a trabajadores de casos que habían cambiado de un tipo de trabajo de casos a otro -de trabajo con familias a protección de menores, de trabajo con extranjeros (asentamiento) a trabajo con personas que están en libertad condicional o al trabajo social médico (hospitales, enfermos) - para aprender los cambios de métodos y los cambios de énfasis necesitados al cambiar de tarea.

\section{¿Por qué el concepto "Diagnóstico Social"?}

Diagnóstico Social es el intento de llegar a una definición lo más exacta posible de la situación social y de la personalidad de un cliente en concreto. La recogida de evidencia o investigación empieza el proceso, lo sigue el examen crítico y la comparación de evidencia y, por último, se procede a su interpretación y a la definición de la dificultad social. Si una palabra debe describir el proceso entero, diagnóstico es más adecuada que investigación, aunque en su uso estricto la primera pertenece al final del proceso. 
Una condición propia del diagnóstico social es su limitación de tiempo relativamente inflexible -cuando se compara con otras formas de investigación social-. Esto no quiere decir que no se pueda revisar o corregir un diagnóstico social; a menudo debe ser revisado. Otra condición propia es la acción, siempre beneficiosa, dado que evalúa las capacidades de la persona.

\section{¿Qué procesos llevan al diagnóstico?}

La recogida de información en los siguientes ámbitos:

1. La primera entrevista

2. El grupo familiar

3. Fuentes exteriores en general

4. Los parientes como fuentes

5. Las fuentes médicas

6. Los colegios

7. Los jefes y otras fuentes en el trabajo

8. Las fuentes documentales

9. Las fuentes del barrio

10. Fuentes diversas

11. Las organizaciones sociales

12. Cartas, mensajes telefónicos, etc.

13. Comparación e interpretación

14. La filosofía básica

¿Qué papel cumple el estudio del grupo familiar?

Los buenos resultados del tratamiento individual se echan a perder a menudo porque el trabajador de casos ha ignorado la historia familiar de su cliente y no ha sido preparado para el repentino afloramiento de tendencias escondidas durante mucho tiempo.

La familia tiene una historia propia aparte de la historia de los miembros que la componen. Por lo tanto es muy necesario tener una idea de la evolución de la vida familiar para cualquier intento de discriminación entre lo importante y lo no importante entre los datos de un caso a tratar. Además es importante obtener de la familia :

- Una idea de la evolución de la vida familiar.

- Poder o capacidad de cohesión.

- Capacidad de afecto, para la admiración, para la formación adicional, para el esfuerzo energético, para el disfrute y para el desarrollo social. 
- Hay que conocer al marido y padre con la madre e hijos.

- La individuación de los niños en el hogar (con fecha exacta de nacimiento).

- Aspectos físicos de la casa:

- Ingresos y gastos

- Hábitos de alimentación y

- Vivienda

El diagnóstico debe, por lo tanto, establecer una base sólida para el tratamiento, mirando más allá de los «síntomas presentados» a las más profundas y complejas causas.

La diferencia entre síntomas presentados / causas profundas y complejas como pensamiento y contenido queda muy claro en este texto.

Otra cosa que ayuda al pensamiento claro es el hábito de clasificar a las familias en cuanto a su poder o capacidad de cohesión. La familia unida «es capaz de mandar a sus hijos a cualquier parte de la Tierra sin dañar en lo más mínimo los lazos que les unen». En la familia inestable «un traslado a la calle de al lado es suficiente para romper dichos lazos".

Esta capacidad de cohesión es sólo uno de los factores positivos para la reconstrucción en el trabajo de casos con familias.

¿Qué es necesario para la reconstrucción en el trabajo de casos con familias?

La habilidad para descubrir, notar y utilizar los factores positivos para la reconstrucción es un rasgo definitorio del verdadero trabajador social.

Otros son la capacidad para el afecto, para la admiración, para la formación adicional, para el esfuerzo más energético, para el disfrute y para el desarrollo social. Con niños, especialmente, merece la pena probar y desarrollar los indicios más pequeños de aptitud, ambición y éxito.

¿Por qué las fuentes exteriores?

Las relaciones sociales de un cliente no están limitadas a su familia inmediata, y tampoco nuestras fuentes de percepción deberían estarlo.

¿Existen variaciones en los procesos de diagnóstico social?

Sí, y quiero llamar la atención sobre los siguientes procesos: 
- Discapacidades sociales

- La familia del inmigrante

- La deserción y viudez

- El hijo abandonado

- La madre soltera

- Los ciegos

- El hombre sin techo - el borracho

- Los dementes - los deficientes

- Supervisión y revisión

¿Cuáles son los riesgos en el proceso de razonamiento del diagnóstico social?

Pueden suceder de cuatro maneras, se puede dar:

- una regla general equivocada,

- un caso concreto equivocado,

- una analogía equivocada o

- una relación causal equivocada.

La tendencia generalizada es buscar una sola causa. Sin embargo, cuando se buscan causas en la motivación humana tenemos que esperar que la causa no sea una y sencilla, sino que sean causas complejas y múltiples.

¿Cuáles son los mayores riesgos en cuanto al estado de ánimo del propio trabajador de casos?

Se encuentran en sus predisposiciones personales, profesionales y en sus suposiciones, es decir, en las reglas establecidas que son el producto de su experiencia.

La mejor defensa contra estos riegos es ser consciente de ellos. Una vez que, por ejemplo, se saca a la luz un prejuicio personal, se puede contrarrestar su influencia en el propio pensamiento.

Hay que prevenir a los trabajadores de casos contra otros hábitos de pensamiento: el uso habitual de pocas fuentes de percepción o de cooperación, el desuso continuado de una fuente que anteriormente no estaba disponible pero que en la actualidad sí lo está, el hábito de pensar en términos medios y el hábito de favorecer a la primera hipótesis o a una hipótesis ingeniosa.

Todas estas fuentes de experiencia -judicial, psicológica y médicaestán modificando el trabajo social profundamente y, como ya se ha mencionado, éstas también están siendo modificadas por él. Sin embargo, a veces se observa una tendencia a salirse de las normas eficaces 
en la asistencia social conectada con el ámbito judicial o clínico. La explicación de esto reside en que las profesiones establecidas hace mucho tiempo tienen unas raíces muy profundas. Tienen sus tradiciones, su rutina de procedimiento, su terminología, su sentido de solidaridad profesional. El Trabajo Social tiene algunas de estas cosas. Cuando el médico o el juez recibe a los asistentes sociales como un complemento a su clínica o su juzgado, puede tener una idea muy vaga de la distinta contribución e interpretación del hecho social que pueden aportar a su trabajo. En este caso, se tiende a encajarlos en las tradiciones de su propia profesión y se ignoran las características propias del Trabajo Social. El juez los usa como detectives; el médico, acostumbrado a la obediencia implícita de las enfermeras, puede usarlos para las tareas con los pacientes. Un resultado infortunado, aparte de la pérdida de oportunidades, es que, si se hace una observación social en un informe social, ellos aceptan como profesionales acostumbrados en su propio campo a aplicar pruebas rígidas, pero no reconocen la necesidad o la posibilidad de analizar la evidencia social.

\section{¿Pensó en alguna ocasión en otro método?}

Se eligió el plan de recoger sugerencias de muchos especialistas para una serie de cuestionarios de tipos no de preguntas para plantear al cliente del trabajador de casos, no de cuestionarios a rellenar, sino de listados de preguntas sugerentes, las cuales podrían ser útiles para el trabajador de casos a la hora de cuestionarse a sí mismo en algún momento de su investigación. Es seguro que tal descarga de preguntas, como se presenta en la tercera parte del libro mencionado, puede ser malentendida por alguien. Es efectivamente una estratagema bastante torpe, pero no se nos ha ocurrido, ni a mí ni a mis compañeros, ninguna otra manera de dar al trabajador de casos, en un espacio reducido, una visión general de las posibles implicaciones de una discapacidad concreta. Se verá que los cuestionarios no están preparados por la misma personas y que tendrían que ser actualizados.

\section{¿Cuál ha sido el problema más difícil?}

El más difícil de todos mis problemas ha sido hacer una presentación del tema de la evidencia en la primera parte, que sería de valor práctico para el trabajador de casos. Éste está manejando datos todo el tiempo. ¿Cómo puede aprender a manejarlos de tal manera que le ayude a lograr un resultado realmente social? Cuando el catedrático Hans Gross estaba preparando su gran manual para los oficiales investigadores de los tribunales europeos ${ }^{1}$, proyectó, al principio, tener cada parte 
escrita por un especialista -por un médico, un armero, un fotógrafo, etc.-. Pero decidió finalmente que estos especialistas no podían satisfacer las necesidades de los oficiales investigadores, al no tener en sus mentes las condiciones y objetivos de los propios oficiales. Por lo tanto, aunque Gross consideró necesario que los distintos capítulos de su libro « hubieran sido expuestos de una manera más científica» para alcanzar su objetivo, se vio obligado a adoptar un plan menos ambicioso. Con mucha menos capacidad que Gross, que tenía una mente enciclopédica, esto es lo que yo he tenido que hacer, y no podría haberlo hecho sin la ayuda muy generosa de críticas y revisiones de aquéllos que sabían de Derecho, Historia, Psicología y Lógica.

\section{¿En qué consiste el concepto de evidencia social?}

Se puede definir EVIDENCIA SOCIAL como todos los hechos o datos de la historia personal o familiar que, tomados juntos, indican la naturaleza de las dificultades sociales de un cliente en particular y los modos de solucionarlas.

Los procesos que llevan al diagnóstico social y por consiguiente a la creación de un plan de tratamiento social pueden dividirse en la recopilación de las evidencias y, a partir de ahí, la descripción de las inferencias. La recopilación de evidencias pasa por ser de las primeras relaciones del asistente social con su cliente, con la familia del cliente y con las fuentes externas.

La evidencia social, como la concibe el científico o historiador, incluye todos los aspectos que, aparentemente irrelevantes cuándo se toman como hechos aislados, pueden todos juntos aportar luz a la cuestión; en lo concerniente al trabajo social. Respondiendo a la pregunta ¿qué acciones pondrán a este cliente en una relación positiva con la sociedad?

\section{¿Quiénes colaboraron en el libro Diagnóstico Social?}

El Diagnóstico Social fue una labor de equipo. Entre las personas que lo hicieron posible están el catedrático J.H. Wigmore, decano del departamento de Derecho de la Universidad de Nortwestern, y la catedrática Lucy Salmon, jefa del departamento de Historia en Vassar; han sido muy bondadosos y han hecho sugerencias respecto a distintos capítulos. Una mención especial merece la Sra. Ada Eliot Sheffield, de Cambridge, Massachussetts, que no sólo ha leído y criticado la mayor 
parte del manuscrito, sino que al menos dos capítulos son de su creación.

No se pueden dar agradecimientos individuales a los varios de cientos de trabajadores de casos que han contestado cartas, examinado cuestionarios, prestado historiales de casos y ayudado de otras maneras. Tienen vidas llenas de requerimientos y están acostumbrados a trabajar hasta el agotamiento, así que todos respondieron a este pedido adicional con prontitud y buen humor.

En 1914, siendo «Kennedy lecture del New York School of Philanthropy», utilicé parte de estos datos que había recogido entonces en un ciclo de seis conferencias. Tuve que negar entonces, y también lo hago ahora, la idea de que la persona que «estudia» discursos técnicos de métodos puede hacerse de esta forma un «practicante eficiente».

Al mismo tiempo que el conocimientos de libros, se necesita la práctica supervisada y una personalidad atractiva y enérgica.

\section{¿Considera importante la relación de la teoría y la práctica?}

La enseñanza práctica en el diagnóstico social y tratamiento fue posible para los estudiantes gracias a las oportunidades que el trabajo social les ofreció desde el principio en las sociedades de organización de la caridad y después en otras agencias. El trabajo social no puede llegar a dominarse sólo a través de los libros o de la enseñanza en clase, aunque los dos tienen su papel en el conocimiento.

El método que pasa por alto o impide la individualidad del trabajador está condenado no sólo en el campo del Trabajo Social sino en la enseñanza, en el arte y en todas las formas de esfuerzo creativo. Pero en ninguna de estas disciplinas los practicantes se han negado a beneficiarse de estudios del proceso en su propio campo, y en ninguna han encontrado un conocimiento ordenado, el enemigo de la inspiración. Una vez, Phillips Brooks dijo de un cierto tipo de ministro: «cuanto más luce y quema la cabeza vacía, más hueca delgada y seca se hace». Tendría problemas en decir quién deja detrás un campo más quemado, el trabajador que funciona sólo con la inspiración o el trabajador que depende demasiado o únicamente de las reglas y fórmulas.

Para terminar, nadie me acusará de deslealtad al grupo con el que he estado identificada durante tanto tiempo porque no he dudado en indicar sus actuales puntos débiles en el aspecto del diagnóstico. Emprendí mi tarea porque había debilidades, pero no podía haber salido adelante sino fuera por muchos trabajadores sociales que han hecho un 
trabajo original y eficaz, y muchas veces en condiciones muy difíciles.

Si después de examinar estas páginas, el acusado y sobrecargado practicante está tentado a pensar que lós consejos contenidos en ellas son impracticables en las condiciones que necesariamente limitan su trabajo diario, que se pregunte si «necesariamente» no es una petición de principio, y si algunas de estas condiciones deberían y podrían ser cambiadas. Entonces, si todavía está seguro de que estoy equivocada, o si encuentra otros errores, que me escriba y me lo cuente. Tengo motivos para pedir sus críticas. Nadie sabe mejor que yo lo provisional que es este discurso. Como existe una posibilidad, aunque muy remota de que haya otra edición del Diagnóstico Social, me gustaría conseguir que fuera más útil de lo que ahora, con todos mis esfuerzos, soy capaz de conseguir.

Este es el texto de una entrevista imaginaria con Mary Richmond que ha buscado las respuestas a los interrogantes nacidos de la lectura de Social Diagnosis. Respuestas tomadas de los contenidos de su libro editado en 1917.

Gracias Mary Richmond.

\section{BIBLIOGRAFIA}

RICHMOND, M. (1917) «Social Diagnosis». Rusell Sage Foundation. New York. 



\title{
ACTUACIONES PREVENTIVAS EN CONTEXTOS COMUNITARIOS
}

\author{
Una oportunidad, ¿necesidad?, \\ para el trabajo social con enfoque comunitario
}

\section{FCO. JAVIER DOMÍNGUEZ ALONSO}

Departamento de Trabajo Social y Servicios Sociales. Universidad de Alicante.

\section{ABSTRACT}

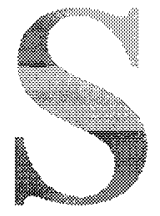

iempre que pensamos en tratar de actuar antes de que algo no deseado suceda, estamos pensando en clave preventiva. Pensar así, inevitablemente, nos conduce a un modelo de trabajo que tiene que ver con nuestro propio talante, nuestra formación y nuestra forma de concebir el ejercicio profesional. Pensar en actuar antes es pensar en clave comunitaria, actuando allí y desde allí, donde tienen lugar las situaciones y conflictos que afectan al conjunto de la población. La vuelta a la comunidad no es una moda, o un modo de proceder de un grupo de profesionales inquietos o "progres"; tampoco es una estrategia oportunista para momentos de crisis. Entender el Trabajo Social en su vertiente comunitaria es quizá la única manera de entender y hacer trabajo social. Es en el contexto comunitario donde se hacen necesarios y adquieren sentido propio los programas preventivos. Únicamente bajando al terreno de lo cotidiano, descubriendo y escuchando las distintas narrativas de personas y colectivos, sistematizando nuestra práctica, surge con coherencia la necesidad de las actuaciones preventivas.

Palabras clave: Prevención. Programas de intervención. Modelo ecológico. Redes Sociales. Trabajo Social con la Comunidad.

\section{INTRODUCCIÓN}

\subsection{Desde el Trabajo Social}

El trabajo social se institucionaliza en una coyuntura histórica (finales del s. XIX y principios del s. XX) marcada por la necesidad de constituirse en una profesión que amortiguie los problemas de los pobres, excluidos e inadaptados como consecuencia del éxodo rural hacia 
las ciudades, y de las condiciones que se crearon con el auge de la revolución industrial. Nace en un «terreno de nadie», en un espacio, el social, entre la economía y la política, sin posibilidad de influir y cambiar las situaciones que generaban la exclusión, pobreza y desigualdad de amplias capas de la población.

Esta situación de ambigüedad y ambivalencia, como afirma Alvarez de Uría ${ }^{1}$, «se ha perpetuado hasta la actualidad: era preciso promover el cambio pero sin alterar el orden; era necesario intervenir pero sin que los especialistas de la práctica llegasen nunca a poseer las claves últimas de su intervención», destinados a restaurar las fracturas sociales, preocupados más por desarrollar medidas de previsión y protección social, que por trabajar por la igualdad y la promoción de los derechos, tanto humanos como sociales, que más tarde refrendarían distintos Tratados internacionales.

¿Dónde se encuentra hoy el Trabajo Social? ¿Cómo desarrolla su labor? ¿Cuál es el sentir de los profesionales? ¿Hacia dónde debería dirigir su mirada, su reflexión y su actividad? ¿Cuál debería ser el papel de las Escuelas de Trabajo Social en el futuro de una profesión indisolublemente vinculada a un cuerpo de conocimientos, principios y valores que le son propios? Estas, y otras muchas preguntas, forman parte del sentir de un gran número de asistentes y diplomados en Trabajo Social que desde distintos ámbitos y organizaciones tratan de dar coherencia, vitalidad y credibilidad a una disciplina y a una profesión, que, en contacto directo con los hombres y mujeres de su tiempo, tiene en los derechos humanos y la justicia social sus principios fundamentales ${ }^{2}$.

\subsection{Por un nuevo modelo y perfil profesional en la práctica del Trabajo Social.}

Existe en la actualidad un cierto «malestar» generalizado en la profesión que tiene muy distintas causas, pero, para lo que aquí nos interesa, vendría concretado por los «corsés» en los que los profesionales desarrollan su trabajo, y que justifican muchas veces por la ineficacia de las acciones desarrolladas para resolver las situaciones problema en las que se encuentran personas, grupos, colectivos y colectividades. Esta insatisfacción viene acompañada de la necesidad de un cambio en el modelo profesional establecido vinculado, según manifiestan distintos profesionales 3 :

Alvarez de Uría, F., "En torno a la crisis de los modelos de intervención social", en Alvarez de Uría, F. et alt., Desigualdad y pobreza hoy, Talasa, Madrid, 1995, p.8.

2 Ver la última definición que la IFSW hace de Trabajo Social.

3 Respuestas realizadas dentro de un trabajo realizado centrado en el estudio de diferentes 
- "El trabajo de despacho es insuficiente" (Trámites y trabajo mayoritariamente burocrático); mientras que "el trabajo de calle permite un contacto directo, permite llegar a la gente, conocer de forma directa los problemas" (Interés/necesidad por un trabajo social de orientación comunitaria); "hacer una entrevista es una cosa muy fría», «el personal te cuenta películas», «es un trabajo de "parcheo"» (Perpetuación del modelo de casos individual); «dentro de una serie de problemas de fondo no se tiende a asumir cuáles son las causas (Prevención). Un modelo donde los «usuarios» identifican al trabajador social con la institución, y los empleadores no suelen tener muy claras las funciones de los trabajadores sociales (conflicto de identidad profesional y de rol: control-apoyo).

Este modelo, con el que pienso se identificarían muchos profesionales, es, por su ambigüedad y confusión, inoperante para ofrecer respuestas válidas a las situaciones y problemas actuales; es poco eficiente al generar unos gastos que no se rentabilizan, así como por unos programas que no se evalúan coherentemente; y es desmotivador para profesionales y ciudadanos que no encuentran satisfechas sus demandas. Por todo ello, se hace necesario un nuevo modelo de trabajo social y un nuevo perfil profesional, y hacia ellos deberían ir dirigidos muchos de los esfuerzos desde distintos campos y ámbitos de influencia de los trabajadores sociales, en una era de marcado individualismo al que no somos ajenos.

El nuevo modelo debería de ser más activo, interesándose más por el origen y las causas de los problemas sociales que originan desajustes y dramas, tanto individuales como familiares. Debería centrarse más en el territorio, interactuando con las personas y grupos de la colectividad, desarrollando una nueva manera de estar, de ver y escuchar, educando vista y oído para «oír lo inaudible y ver lo invisible» (J. Galtung), y planteando intervenciones desde las demandas expresadas y compartidas, trabajando por hacer aflorar muchas otras que no son sentidas como problema por los distintos grupos sociales. Debería también facilitar las redes sociales, la comunicación, los afectos compartidos, la vida hacia fuera de personas, grupos colectivos y colectividades. Un modelo, en definitiva de corte preventivo, superador del asistencialismo; reparador, educativo, promocional y participativo; creador y mantenedor de tejido social y en contacto e interrelación con otros servicios, organizaciones e instituciones presentes en su ámbito de referencia.

Un nuevo perfil de profesional, con un amplio bagaje y aprecio por el análisis teórico, capaz de interpretar y dar explicación del origen y 
causa de los problemas que afectan a individuos, grupos y colectivos; capaz de analizar la incidencia que tiene lo global en lo local, planificando y aplicando programas y proyectos innovadores que den respuesta a necesidades de grupos y colectivos de su ámbito de influencia, aunando el discurso teórico-técnico y el práctico, en coordinación y diálogo con otros servicios, profesionales y dirigentes sociales y políticos. Un profesional con capacidad de empatía y cercanía con la gente, impulsor y líder de propuestas que puedan ser compartidas. En definitiva un «tejedor de redes sociales», dinamizador de historias compartidas, facilitador de autonomía y desarrollo desde lo individual a lo grupal y colectivo. Un profesional capaz de prever y evaluar los programas que se llevan a cabo, convencido de que las necesidades son cambiantes y las respuestas deben adecuarse a los cambios y no tanto a la tradición de lo ya establecido.

\subsection{El interés por la prevención}

Siempre que pensamos en tratar de actuar antes de que algo no deseado suceda, estamos pensando en clave preventiva. Pensar así, inevitablemente, nos conduce a un modelo de trabajo que tiene que ver con nuestro propio talante, nuestra formación y nuestra forma de concebir el ejercicio profesional. Pensar en actuar antes implica pensar en clave comunitaria, actuando allí y desde allí, donde tienen lugar las situaciones y conflictos que afectan al conjunto de la población: una persona, un grupo, un colectivo o de la colectividad. Es desde el propio medio donde nacen las propuestas de mejora y las aspiraciones compartidas. La vuelta a la Comunidad no es una moda, o un modo de proceder de un grupo de profesionales inquietos o "progres"; tampoco es una estrategia oportunista para momentos de crisis. Entender el Trabajo Social en su vertiente comunitaria es quizá la única manera de entender y hacer trabajo social, a no ser que queramos seguir en esa situación confusa y ambigua, atendiendo a situaciones puntuales e individuales (mayoritariamente) sin entrar en la trama donde se operan tales situaciones.

Es en el contexto comunitario donde se hacen necesarios y adquieren sentido propio los programas preventivos. Sólo ampliando el «objetivo de nuestra cámara" conseguiremos tener el ángulo y la perspectiva adecuada para hacernos con una foto real de lo que pasa en nuestros contextos. Únicamente bajando al terreno de lo cotidiano, descubriendo y escuchando las distintas narrativas de personas y colectivos, sistematizando nuestra práctica, surge con coherencia la necesidad de las actuaciones preventivas.

Sin embargo, la prevención puede no ser más que un concepto de 
moda o un discurso oportunista carente de contenido. Prevenir no es sólo evitar que algo suceda para de este modo ahorrar recursos en momentos de crisis, o evitar gastos mayores. Prevención es apostar por un futuro mejor para muchas personas, para mejorar el bienestar y la calidad de vida de muchas otras. Prevención significa planificar «desde abajo», sin urgencias, manteniendo los programas a medio y largo plazo, independientemente de los distintos grupos en el poder. Significa también garantizar los fondos necesarios para el mantenimiento de los programas diseñados, estableciendo una coordinación horizontal y contando con la colaboración de todos aquéllos que tengan algo que ver con las actuaciones desarrolladas.

La prevención es una gran oportunidad para el Trabajo Social, que por su proximidad a los ciudadanos y a las situaciones carenciales cotidianas y/o estructurales, disponen de un conocimiento privilegiado para, con la participación de la trama social, de las personas, grupos y colectivos, construir nuevos escenarios de intervención, pasando de una atención residual (con los «efectos») y mayoritariamente individual-familiar, a otro tipo de acciones más colectivas, que busquen tanto la prevención de los riesgos, como la educación y promoción de las personas, grupos y colectivos dentro de una red de relaciones potenciadora de su propia autonomía y responsabilidad.

La historia del trabajo social es la historia por la lucha de la dignidad de las personas, por tratar de evitarles sufrimientos y facilitarles el ejercicio de sus derechos y un mayor bienestar. A lo largo de esa historia se han dado ambiguiedades y giros históricos, pero siempre ha estado presente la idea de que tales supuestos y situaciones que afectan negativamente a las personas pudieran ser evitados. Y ese esfuerzo se ha hecho con la gente, con las comunidades donde los trabajadores sociales desarrollaban su labor.

Pensar en la prevención desde la comunidad no está exento de utopía. Utopía que siempre ha caracterizado a esta profesión desde sus orígenes más remotos. Ojalá nunca perdamos esa capacidad para soñar escenarios distintos, animados por compañeros de camino capaces de inventar nuevos itinerarios, nuevas rutas y caminos, que nos conduzcan a todos a situaciones de una mejor y mayor calidad de vida, de relaciones interpersonales, de derechos compartidos, de justicia social desde nuestros propios contextos en los que se desarrolla nuestra vida cotidiana. Una utopía razonable, es decir, desde el realismo de lo cotidiano, y desde la realidad y los desafíos que el trabajo social tiene en la actualidad. 


\section{BREVE HISTORIA Y CONCEPTO DE LA PREVENCIÓN}

\subsection{Antecedentes históricos de la prevención ${ }^{4}$}

La historia de la prevención es la historia por evitar el sufrimiento humano, tratando de buscar, mediante mecanismos mágico-religiosos o racionales, el reducir la probabilidad de aparición de determinadas patologías o situaciones que se prevén dolorosas y causantes de malestar personal, familiar o social.

El concepto de prevención estuvo ligado durante mucho tiempo a la medicina. Las transformaciones producidas por la Revolución Industrial en el s. XIX y el proceso de urbanización, las míseras condiciones de vida de los trabajadores y de sus familias y los descubrimientos sobre el origen bacteriano de muchas enfermedades (Pasteur) y el desarrollo de las vacunas, orientó parte de la investigación hacia acciones preventivas de carácter comunitario. Progresivamente, las concepciones unicausales de los problemas se han transformado en modelos multicasuales y, al mismo tiempo, se han diferenciado distintos niveles en la prevención.

Erich Lindeman (1944), psiquiatra de orientación psicoanalista, es uno de los pioneros que centraron su atención en las intervenciones preventivas ante problemas psicosociales. Creó un programa de salud mental centrado en estrategias preventivas. Este programa ofrecía sus servicios a todos los que debían enfrentarse a crisis o situaciones difíciles: pérdida de personas significativas o cambios de estatus social. Caplan $(1964,1988)$ es quien más ha difundido la idea de la prevención, especialmente por su concepción de la prevención primaria, que debería contar, según él, con la disponibilidad de todo tipo de recursos (físicos, psicosociales, socioculturales, etc.) para impedir la aparición de cualquier tipo de problema en los individuos, grupos y comunidades, así como facilitando y potenciando la acción de la comunidad como sustentadora y aportadora de recursos para sus miembros.

A partir de la década de los sesenta, el concepto de prevención se ha ido aceptando como una de las características fundamentales de la intervención social y comunitaria. En este sentido, Cowen $(1972)^{5}$ define la Intervención Social Comunitaria como una acción de tipo preventivo, en contraste con las intervenciones tradicionales, cuyo objetivo es la curación y sólo reacciona cuando aparece el problema. Otros autores ${ }^{6}$ inciden en la prevención para reducir la desorganización social

4 Sigo en este punto a López Cabanas, M. y Chacón, F., Intervención psicosocial y servicios sociales. Un enfoque participativo, Síntesis, Madrid, 1997, pp. 114-115.

5 Citado por López Cabanas, M. y Chacón, F., o.c., p.114. 
y personal.

\subsection{Marco teórico de la prevención: definiciones}

Según Casas?: "la noción de prevención está relacionada con realidades conocidas, sobre las que se sabe o se tiene la experiencia acerca de sus efectos valorados negativamente; con la probabilidad de su aparición; y con su no deseabilidad social".

El mismo Casas hace en otro lugar ${ }^{8}$ la siguiente síntesis del concepto de prevención:

"Aquel proceso de intervención social que, con el objetivo último de mejorar el bienestar y la calidad de vida de las personas y sistemas humanos, y acorde con conocimientos rigurosos, manipula los factores asociados o implicados en la génesis de diferentes enfermedades, problemáticas o necesidades sociales, desarrollando actuaciones concretas a fin de evitar su aparición, reaparición o agravamientos".

Otra definición, un poco más sintética de prevención es la de E. Granaz (1986):

"Los esfuerzos desplegados para evitar la aparición o intensificación de unos problemas determinados".

\subsubsection{Tipologías y clasificaciones sobre la Prevención}

López Cabanas, M. y Chacón, F. (1997: 115-122), citando a Orford (1992), describen cuatro de las tipologías de actividades preventivas más difundidas. Me referiré a las dos que considero más importantes para el objeto de este trabajo:

\subsubsection{La clasificación de Caplan}

La clasificación de intervenciones preventivas más citada y conocida es, como ya se ha dicho, la presentada por Caplan en 1964 en el contexto de la Psiquiatría Preventiva. Cada una de las tres tipologías de Caplan dispone en la actualidad de interesantes revisiones recientes?.

" Martínez, M., et al., "Prevención y promoción en Psicología Comunitaria", en A: Martín, F. Chacón y M. Martínez (Eds.), Psicología Comunitaria, Visor, Madrid, 1988.

7 Casas, F., Infancia: perspectivas psicosociales, Paidós, Barcelona, 1998, p. 165.

8 Casas, F., Bienestar Social: una introducción pscosociológica, PPU, Barcelona, 1976 , p. 79 .

9 Fernández-Ríos, L., Manual de psicología preventiva: Teoría y práctica, Siglo XXI, Madrid, 1994. 
A medida que las ciencias de la salud se han ido haciendo más sociales, en el sentido de tener más en cuenta los contextos sociales en los que se da o promueve, sea la salud, sea la enfermedad, ha ido emergiendo el reto de intentar reencontrarse con las elaboraciones acerca de la prevención, no siempre coincidentes, que se han desarrollado independientemente en el ámbito de la intervención social. Por esta razón (siguiendo a Casas, 1998:166-67) las propuestas de definiciones presentadas a continuación intentan ser integrativas:

\section{- Prevención primaria}

Originalmente, según el propio Caplan, es un concepto comunitario. Implica la disminución de la incidencia de un enfermedad, y se focaliza en reducir el riesgo de toda la población. Al ofrecer el campo más vasto para la prevención, es esta modalidad la que ha concentrado mayor interés de los expertos como forma de atender tanto enfermedades como problemas sociales. Por eso es sobre la que más se ha debatido y teorizado.

Hoy en día se cuenta con un amplio consenso sobre algunas de sus características básicas: debe tener un enfoque comunitario, ser interdisciplinaria, ser proactiva, interconectar los diferentes aspectos de la vida de las personas (orientación bio-psico-social), utilizar técnicas educativas y sociales, orientarse a dotar a las personas de recursos ambientales y personales para que afronten sus problemas ellas mismas, y promover contextos sociales justos (Fernández Ríos, 1994).

La prevención primaria se entiende que va dirigida a grupos o poblaciones que no manifiestan signos evidentes de enfermedad o problema social; sólo existe la consideración de que algunos de sus miembros (o todos) pueden estar en situación de riesgo.

- Prevención secundaria

Es la que tiene como objetivo la reducción de los efectos de la enfermedad. Implica disminución de la prevalencia, y focaliza muchos esfuerzos en la detección precoz.

En el campo social se la ha asociado con la identificación de individuos portadores de factores de riesgo, es decir, vulnerables.

Las principales estrategias de Prevención Secundaria serían (según Cabanas, 1996:115):

- Desarrollo de pruebas de detección precoz.

- Puesta en marcha de programas de intervención efectivos para reducir o eliminar la frecuencia, duración, intensidad o incapacita- 
ción producida por el problema.

- Mejorar las instituciones encargadas de la intervención.

- Desarrollo de estrategias apropiadas para la intervención en crisis, al objeto de reducir los efectos negativos de ésta, y aumentar su competencia para enfrentarse a posteriores situaciones vitales estresantes.

\section{- Prevención terciaria}

En las ciencias de la salud a menudo se considera ya en desuso el concepto de prevención terciaria, que Caplan identificaba con el de rehabilitación, por lo que fue muy polemizado como concepto preventivo (Fernández-Ríos, 1994). Pero en el campo de las ciencias sociales algunos autores han venido asimilando prevención terciaria a seguimiento posterior a la intervención, que es una idea bien diferente ${ }^{10}$. Le llamemos como le llamemos, el seguimiento posterior a la intervención, gran reto pendiente de muchos sistemas de protección social, no es sólo trascendente para un trabajo preventivo riguroso, es también crucial para una correcta evaluación a medio y largo plazo de las consecuencias de nuestro trabajo preventivo.

Un procedimiento simple de diferenciar a las tres formas de prevención, es a través de la secuencia temporal del problema; las actividades preventivas realizadas antes del comienzo del problema son prevención primaria; las realizadas durante la afectación del problema, prevención secundaria; las realizadas después de la cesación del problema, prevención terciaria.

\subsubsection{Clasificación de Bronfenbrenner ${ }^{\prime \prime}$}

Esta clasificación, más aplicable para la prevención en temas sociales, utiliza conceptos procedentes del modelo ecológico, con una concepción teórica del ambiente "como algo que va más allá de la conducta de los individuos y que incluye sistemas funcionales tanto dentro como entre entornos":

- Microsistema, que haría referencia al complejo de interrelaciones dentro del entorno inmediato (familia, lugar de trabajo, etc.).

10 "El objetivo de la Prevención Terciaria es reducir las sccuelas y consecuencias negativas de los trastornos. Aunque no haya sido posible ni prevenir un nuevo caso, ni acortar su duración interviniendo en las primeras fases, aún es posible evitar que el problema produzca incapacidades o secuclas negativas sobre el desarrollo normal de la persona." Cfr.: López Cabanas M. y Chacón, F. (1998: 115).

$"$ Bronfenbrenner, U., La ecología del desarrollo humano, Paidós, Barcelona, 1987. 
- Mesosistema, entornos en los que la persona en desarrollo participa realmente, relaciones entre sistemas distintos con los que se entra en relación (colegio, centro de salud, etc.).

- Exosistema, ambientes con los que tal vez no entre nunca en relación, pero en los que se producen hechos que afectan a lo que ocurre en el entorno inmediato de las personas (políticas de empleo, sociales, de salud, etc.).

- Macrosistema, se trata de patrones generalizados, de las instituciones sociales comunes a una determinada cultura. "La política oficial es una parte del macrosistema que determina las propiedades del exo-, meso- y el microsistema, que ocurren a nivel de la vida diaria y dirigen el curso de la conducta y el desarrollo" (o.c., p.28-29).

Cada vez es mayor el número de investigadores y profesionales que tienen en cuenta esta distinción para señalar la necesidad de diseñar programas preventivos que no se centren sólo en el nivel individual o micronivel. Esto requeriría acciones sociales y políticas para influir en la toma de decisiones gubernamentales, legislativas y empresariales para brindar, entre otras cosas estabilidad en el empleo y de los ingresos. El origen del trabajo social estuvo marcado por la idea de ajustar el individuo a su ambiente, nivel individual, pero existe una tendencia creciente a reconocer la necesidad de que la prevención debe incluir proyectos que impliquen cambios en los sistemas.

\section{2.2. La prevención en los servicios sociales y en la práctica del trabajo social}

Esta perspectiva general estaría incompleta si no abordásemos uno de los principales problemas que se plantean los expertos de la intervención social y de los Servicios Sociales: las repercusiones y diferencias que en los programas preventivos produce la propia finalidad de la intervención.

Uno de estos aspectos es la etiología multifactorial de la mayoría de los problemas sociales que tienen un gran componente psicológico, y que hace que sean más difíciles de prevenir.

Una segunda dificultad es el largo período de tiempo que suele transcurrir entre el origen de esos factores y la manifestación del problema, y entre los intentos preventivos y la posible constatación de sus efectos.

Recientemente, algunos autores (Martínez et al., 1988: 59), por ejemplo, consideran que la prevención no conlleva una visión de hacer progresar el bienestar o la calidad de vida, sino que pretende mantener el nivel actual; que en la mayoría de los casos se dirige a grupos de riesgo, 
y que la responsabilidad de las acciones preventivas recae fundamentalmente sobre los profesionales, y sobre los recursos del Sistema de Salud y de los Servicios Sociales. Partiendo de estas críticas, estos autores proponen la promoción entendida como una estrategia mediadora entre la gente y sus ambientes, sintetizando la elección personal y la responsabilidad social, de manera que se cree un futuro mejor. Entre las características de las actividades de promoción estos autores citan:

- Tienen connotaciones positivas, no están orientadas al déficit.

- Implican necesariamente a la población en su conjunto, en vez de enfocarse a grupos de riesgo.

- Intentan, en especial, conseguir una efectiva y concreta participación de la comunidad, tanto en la definición de problemas, como en la toma de decisiones sobre las medidas que se deben adoptar.

- Se orientan hacia los estilos de vida, promoviendo habilidades personales para influir sobre los factores que determinan la salud y el bienestar, así como para el desarrollo de estrategias adecuadas para afrontar situaciones problemáticas.

- Procuran reforzar las redes y apoyos sociales, como determinantes de actitudes, valores y conductas significativas.

- Se relacionan muy directamente con las condiciones de vida (vivienda, trabajo, etc.), prerrequisitos de la salud y el bienestar social.

- Influyen sobre el entorno físico y social para fortalecer los factores favorables y modificar los que dificultan los estilos de vida saludables. Se trataría de conseguir que las opciones que mejoran la calidad de vida sean fáciles de elegir.

- Combinan enfoques y estrategias diversas, pero complementarias: comunicación, educación, cambios organizacionales, desarrollo comunitario, etc.

En resumen, la prevención se dirigiría, casi exclusivamente, a las necesidades de déficit, y la promoción intentaría alcanzar las necesidades de desarrollo, es decir, las aspiraciones. En prevención social tendría que hablarse, más que de «individuos en riesgo», de «contextos de riesgos», tratando de favorecer más los indicadores de protección, que la identificación de los indicadores de riesgo. Del mismo modo, no debería remarcarse solamente las dificultades, sino también las oportunidades que ofrece para la prevención-promoción cualquiera de los niveles del modelo ecológico. A pesar de todo, ambos enfoques no serían opuestos, sino complementarios, ya que puede ser prematuro abandonar las actividades preventivas dirigidas a los problemas. 


\section{LA PREVENCIÓN EN EL ÁMBITO DEL TRABAJO SOCIAL}

Con demasiada frecuencia, y a veces no sin razón, se ha dicho que el Trabajo Social ha estado más orientado a paliar situaciones carenciales de los individuos que ha favorecer el pleno desarrollo y bienestar de las personas, grupos y colectivos. Sin embargo, existe toda una tradición en la profesión y en la conceptualización del Trabajo social orientada a eliminar las causas que dan origen a los problemas, por no ser éstos una característica innata de ciertos individuos o grupos, sino que están originados por el contexto social en el que se encuentran inmersos los distintos grupos humanos. Esta función asistencial, preventiva y promocional del Trabajo Social, orientada a individuos y colectivos, ha ido evolucionando de modo distinto según el momento histórico concreto, el modelo profesional de cada tiempo y el perfil profesional que de él se ha deriva$\mathrm{do}^{12}$.

Actualmente, la orientación comunitaria del Trabajo Social concibe a éste como un proceso de ayuda psicosocial en el que es preciso tener en cuenta no sólo a las personas, sino también a su entorno y especialmente la interacción que se produce entre ambos. Las intervenciones comunitarias, en tanto que potenciadoras de las capacidades personales y sociales, cumplen una función preventiva en lo que se refiere a la aparición de situaciones de riesgo o problemas sociales, con resultados a medio y largo plazo.

Por otra parte, la atención a situaciones de necesidad o dificultad no será adecuada si no se consigue la implicación de la sociedad en las distintas fases de la intervención social. Sin la participación efectiva de la comunidad, o de los distintos grupos sociales que la forman, no será posible la integración comunitaria y la solución efectiva de los distintos

12 Esta tensión dialéctica tuvo un momento álgido en los albores de la profesión al desarrollarse, dentro de la C.O.S. (Chariry Organization Society) dos tendencias distintas: una que conducía a la individuación (O. Hill), y otra que llevaba a la socialización y a la Organización de la Comunidad (E. Denison). En la primera, el individuo era el "culpable" de su situación, y el objetivo "adaptarle" a la sociedad mediante el tratamiento individual (Trabajo Social de casos). En el segundo se consideraba al individuo "víctima" de la sociedad en la que estaba inmerso. A través de actuaciones comunitarias (Organización de la Comunidad) se buscaba el cambio en las situaciones ambientales mediante la mejora de las condiciones sociales y la búsqueda de recursos apropiados con la participación de la comunidad. Más adelante, M. Richmond insistirá en la importancia del ambiente para la comprensión de las personas según las distintas situaciones en las que puede encontrase. Ella proponía, como método de intervención, la acción directa con la persona e indirecta con el ambiente. Esta dialéctica entre individuo y sociedad persiste aún en nuestros días abarcando distintas dimensiones y prácticas, tanto profesionales como políticas. 
problemas, sean éstos individuales, familiares o sociales, que en ella estén presentes. En este sentido puede afirmarse que las intervenciones comunitarias suponen un instrumento que facilita la participación social, dotando de contenido real la democracia.

Cuando tratamos de entender la comunidad en sí misma, su funcionamiento, en la resolución de problemas y atención a las necesidades de sus miembros, parece haber un acuerdo generalizado para considerar la teoría de sistemas sociales y la teoría ecológica humana como las que mejor permiten comprender a la comunidad, global y parcialmente considerada.

La teoría del sistema ecológico ayuda a comprender los cambios poblacionales, las migraciones y el crecimiento dinámico de la comunidad. Refleja los aspectos más destacados de los grupos. La teoría de los sistemas sociales afecta a las instituciones del sistema comunitario, a su funcionamiento. Presta atención a la organización formal que afecta a la comunidad (economía, educación, etc.). Estudia las intervenciones de los subsistemas a nivel horizontal y vertical, entre sí y con otras comunidades.

Entre los principios de un enfoque ecológico en los que situar la práctica del Trabajo Social comunitario está el establecimiento de un marco de prevención y de promoción. Como señala Olza ${ }^{13}$ :

"La intervención comunitaria puede hacerse en un plano individual, grupal organizacional o institucional. Desde el punto de vista de los objetivos, va dirigido a la prestación de servicios, desarrollo de recursos, prevención, reconstrucción social, cambio social y modificación de los sistemas sociales existentes".

Este aspecto preventivo y promocional característico del Trabajo Social comunitario, concretado en acciones, actuaciones y programas de intervención dirigidos a grupos y colectivos sociales tratando de actuar antes, no después, atacando las causas y orígenes socio-ambientales de los problemas, no sus efectos o manifestaciones personales, es el que considero más adecuado para dar una respuesta adecuada y eficiente a las demandas y problemas del entramado social en la actualidad.

\subsection{La aportación de distintos autores}

La prevención, desde el Trabajo Social, ha sido considerada por dis-

13 Olza, M., "Trabajar en la comunidad", en J. Fco. Morales y M. Olza (Coord.), Psicología social y Trabajo social, Mc Grawhill, Madrid, 1996, p. 545. 
tintos autores desde ángulos y perspectivas diversas. Sin la pretensión de ser exhaustivo, recojo distintas aportaciones de algunos de ellos, tanto antiguos como contemporáneos.

\subsubsection{Función propia del Estado y de las Administraciones}

- LUIS VIVES

Sostiene la tesis de que la prevención y el socorro de los pobres constituye una de las funciones propias del Estado.

- INFORME BARCLEY:

En él se recomienda un cambio de orientación del Trabajo Social hacia un Trabajo Social Comunitario, haciéndolo unir a que las Administraciones locales adopten una estrategia preventiva.

\subsubsection{Como contenido y objetivo del Trabajo Social}

- LANE REPORT:

Es un hito en la literatura científica sobre la organización de la comunidad, donde se dice que ésta tiene por objeto la eliminación y la prevención de las necesidades.

- FRIEDLANDER:

Entre los objetivos de la organización de la comunidad está la ayuda a los ciudadanos para la prevención del sufrimiento.

- N. DE LA RED:

En referencia a las nuevas definiciones del Trabajo Social, N. de la Red, se refiere a que es en la interacción entre el hombre y el medio donde se produce y manifiesta la situación problema; y en cuanto que tal medio debe aportar los elementos necesarios para prevenir y superar estas situaciones.

- C. DE ROBERTIS:

La prevención es uno de los objetivos fundamentales del Trabajo Social, por lo que es lógico que los encontremos en las intervenciones dirigidas a una población.

\subsubsection{Como finalidad del Trabajo Social}

- SHEAFOR y COLS:

El Trabajo Social, a la vez que trabaja para prevenir problemas y mejorar las condiciones locales, también puede mejorar para lograr el cambio en los distintos planos, el local, regional o estatal. 


\section{- LOURDES GAITÁN:}

Ante el conflicto, el Trabajo Social propicia el cambio de las situaciones y capacita a los seres humanos para el mismo. Pero también actúa para prevenir el conflicto y restablecer el equilibrio.

\subsubsection{Como actividad del Trabajo Social}

- B. WERNER:

Las actividades del profesional pueden equipararse en: satisfacción de necesidades del individuo y de la sociedad, restaurar las capacidades disminuidas futuras y prevenir las eventuales disfunciones.

- ÁlVAREZ-URÍA:

La tendencia en la mayor parte de los países occidentales apunta a intervenir sobre el terreno con una concepción más ágil y eficaz de los servicios públicos animados por nuevos profesionales capaces de intervenir a la vez con medidas preventivas y reparadoras ante problemas específicos que han de ser neutralizados arbitrando programas también específicos.

- MARTÍNEZ, MIRA-PERCEVAL y REDERO:

Una actuación social preventiva, para que sea eficaz, nos lleva de nuevo a la necesidad de potenciar el trabajo de orientación comunitaria y, por consiguiente, a destacar el principio de descentralización. Implica un nuevo enfoque de las actuaciones superador de la microintervención centrada en el individuo y su familia, para centrarse más en la comunidad, con un planteamiento sistémico y sin olvidar los posibles dilemas éticos que se puedan plantear.

\subsubsection{Como función propia del Trabajo Social}

- G. HAMILTON:

El Trabajo Social también deberá preocuparse del mejoramiento de las condiciones sociales, estimulando una acción preventiva y esforzándose para conseguir una vida social constructiva para todos.

- N. DE LA RED:

Históricamente el Trabajo Social ha colaborado en las funciones asistenciales, de inserción, rehabilitación, prevención y promoción orientadas a la superación de determinados problemas sociales.

- ESCUELA DE T. S. DE ALICANTE:

Entre las funciones globales que el Trabajador Social tiene que desempeñar figuran: atención directa, prevención, planificación, inves- 
tigación, promoción, transformación y docencia.

\subsection{En las distintas legislaciones}

La mayoría de las leyes autonómicas de Servicios Sociales resaltan entre sus principios generales el concepto de prevención de los problemas sociales como fundamento de sus intervenciones. A modo de ejemplo:

La Ley de Servicios Sociales de la Comunidad Valenciana señala: "las actuaciones en el ámbito de los Servicios Sociales deben tender a superar una política social superadora de las condiciones que dan lugar a la pobreza y la desigualdad social, evitando y corrigiendo los mecanismos que originan la marginación y promoviendo mayores cotas de bienestar". Para ello, entre otros principios que se citan está: "la prevención, planificación y evaluación, a fin de hacer una gestión eficiente y eficaz". Al hablar de los Servicios Sociales (art. 11) y de las prestaciones integradas y polivalentes dirigidas a toda la población, mediante actuaciones "preventivas, asistenciales y rehabilitadoras".

La Ley Orgánica 1/1996, de 15 de enero, de Protección Jurídica del Menor y de Modificación parcial del Código Civil y de la Ley de Enjuiciamiento Civil, se cita, entre los principios rectores de la actuación de los poderes públicos: "la prevención de todas aquellas situaciones que pueden perjudicar su desarrollo familiar" (art. 11.2).

A pesar de la rotundidad y de la importancia concedida a la prevención, en el ámbito de los principios, objetivos y finalidades, de distintas legislaciones y disciplinas, comparto con Sánchez Vidal, A., (1991:337) que:

«La prevención no pasa de ser mucho más que un artículo de fe generalizado en el ideario de múltiples disciplinas científicas y programas políticos, pero apenas practicado en la realidad».

\section{ACTUACIONES Y PROGRAMAS PREVENTIVOS: ALGU- NOS PRINCIPIOS BÁSICOS A TENER EN CUENTA PARA EL DISEÑO DE PROGRAMAS}

La inmensa mayoría de los problemas o necesidades sociales corresponden a situaciones sociales complejas, en las que intervienen muchas variables, frecuentemente interrelacionadas y difíciles de con- 
trolar. De ahí la necesidad de establecer diseños precisos para la aplicación de los distintos programas de intervención.

\subsection{Componentes, niveles y estrategias de intervención}

Según Sánchez Vidal, A. (1991:351), todo programa preventivo (interventivo) consta de cuatro componentes básicos:

1. Objetivos del programa: qué se intenta conseguir. Los objetivos deben de ser claros y tan específicos como aconseje el nivel de trabajo en que se desarrolla el programa.

2. Población a la que se dirige y el nivel o niveles en que se desenvuelve. Cuanto mejor especificada o identificada esté la población o grupo diana, más específico podrá ser el programa y más eficiente la asignación de recursos. Bloom $(1984)^{14}$ ha sugerido tres estrategias generales para la identificación de grupos diana en programas preventivos:

a) Población total de un área geográfica dada. El criterio de identificación es aquí geográfico-demográfico. El blanco real de prevención será toda la población.

b) Transiciones o hitos vitales. El criterio de identificación aquí es evolutivo, basándose en los momentos cruciales de la historia vital de las personas que van ligadas a momentos evolutivos relevantes.

c) Grupos de riesgo. Identificados a través de la localización de factores o indicadores de riesgo estadísticamente asociados con el desarrollo de alguna situación problemática.

d) Los niveles en que se desarrolla el programa preventivo (que coincide con el grupo diana) suelen centrarse en: el individuo, la familia o grupo pequeño, la comunidad y la sociedad total. Cada uno requerirá una metodología y contenido interventivo diferenciados: en la persona, el desarrollo de competencias; en los sistemas sociales, la modificación de su funcionamiento, reducción de sus fuentes de estrés y el incremento del grupo social.

3. Estrategia y metodología. Cómo, de qué forma se va a realizar el programa y qué procedimientos se van a usar para conseguir los objetivos preventivos marcados. Hay que tener en cuenta que no existen fórmulas generales sino, más bien, pistas o indicadores más o menos válidos según el tipo de problema y blanco del programa. Por otra parte es casi imposible separar contenido y método (qué se hace y cómo se hace). 
Finalmente hay que tener en cuenta que estas metodologías preventivas son, o pueden ser, estrategias centralizadas, de intervención desde arriba. Es preciso compensar este enfoque con otro (correspondiente al polo comunitario de prevención) que recoja los intereses o aspiraciones desde abajo para conectar con ellos los contenidos y metodología de los del programa e implicar realmente a la comunidad en la solución de ellos. Una metodología que haya tenido en cuenta la población (la comunidad) sólo como objeto, y no como sujeto de la acción, será un montaje tecnocrático externo y con pocas probabilidades de éxito y técnicamente ineficiente y dispendioso (caro). En definitiva, un programa preventivo sin contacto con las necesidades de la comunidad gastará recursos y energía innecesarias para producir un resultado mediocre.

4. Contenido del programa preventivo: Aquellas acciones y componentes que forman, integradas en una estrategia coherente, el corpus del programa, estando dirigidas a alcanzar los objetivos preventivos planteados.

\subsection{Principios y procedimientos de acción preventiva}

Las actuaciones preventivas deben dirigirse, y alcanzar, a todo el universo en el que individuos, grupos y colectivos recrean su vivir cotidiano, por lo que es preciso actuar en todos esos ambientes. Los programas de intervención deben incluir acciones que impliquen cambios en los sistemas.

1. Por el cambio individual.

Cuando se habla de prevenir algo, se acostumbra a hacer a partir de la recopilación sistemática de datos que nos apuntan la existencia de factores de riesgo. Muchos de estos factores de riesgo lo son "multirriesgo" al estar presentes en el origen de muchas problemáticas diversas (p.e., el alcoholismo de un progenitor lo encontramos en niños/as desatendidos, infractores, fracaso escolar, etc.).

2. Para el cambio individual, cambiar el contexto.

Sin duda, puede ser mucho más importante que identificar a individuos en riesgo. Deberíamos centrarnos más en cambiar algo referido al entorno donde se mueven los individuos. Propiciar este cambio, con la participación de la comunidad, es uno de los objetivos del Trabajo Social Comunitario. Las interacciones entre los individuos y su medio suelen ser útiles para explicar, y diferenciar, la responsabilidad individual y social. Un individuo puede cambiar un determinado tipo de comportamiento, pero si su contex to no cambia es muy posible que tal comportamiento resurja. 
La mayoría de programas preventivos buscan la manera de desplegar intervenciones sociales que lleguen a repercutir indirectamente dentro de los grupos familiares de una comunidad. Este renacido interés por el nivel familiar (microsistémico) frente a los clásicos desarrollos en el individuo, no pueden hacernos perder la vista en la globalidad del problema, ni del hecho de que existen otros factores intervinientes a nivel de exosistema y macrosistema que, con frecuencia, son los más determinantes para conseguir la eliminación de los riesgos y la oportunidad y posibilidades de desarrollo de personas y de amplios sectores de la población.

3. De los individuos en riesgo a las poblaciones en riesgo.

Como se ha dicho, más que hablar de individuos en riesgo, hay que hablar de contextos de riesgo. Si no se actúa primaria y eficientemente en estos ambientes toda intervención está llamada al fracaso. Por ejemplo, para desarrollar programas preventivos altamente focalizados, como en el caso de los malos tratos y abandono en la infancia, dado que no existen instrumentos muy precisos para detectar posibles familias o padres maltratados, los programas preventivos que se proponen intervenir sobre perfiles individuales no resultan muy eficientes. El mejor procedimiento para prevenir los malos tratos, concluyen algunos autores ${ }^{15}$, es establecer y potenciar los servicios dirigidos a toda la población, a pesar de su dispersión y su alto coste y falta de eficiencia.

\section{Práctica integradora.}

Esta vía intermedia entre lo individual y lo poblacional, a niveles muy concretos: barrio, distrito, etc., puede facilitar la actuación sobre factores de riesgo social, en una tarea interventivo-preventiva cada vez más técnica y más específica para contextos distintos.

Suele darse un consenso generalizado (Sánchez Vidal, A., 1991:363) sobre los siguientes criterios de éxito de los programas preventivos:

a) Están dirigidos hacia un blanco o diana poblacional claro y su enfoque especificado en función de los riesgos y problemas (necesidades) del grupo.

b) Están diseñados para alterar la trayectoria vital de las personas, realizando cambios a largo plazo. Los cambios se suelen centrar en sistemas sociales (como la familia o la escuela) involucrando educativamente a mediadores relevantes (padres, educadores, etc.).

c) Además, proporcionan a las personas nuevas destrezas o habi- 
lidades para confrontar situaciones y apoyo social para enfrentarse a las transiciones vitales.

d) Fortalecen el apoyo social natural recibido desde la familia, comunidad o escuela, movilizando el apoyo de otras fuentes.

e) Recogen evidencia rigurosa para documentar su éxito y resultados en formas y dimensiones variadas y pertinentes en cada caso.

En esta misma línea se manifiestan López-Cabanas y Chacón (1996:120-121) que transcriben las características que (FernándezRíos, 1994) presentan los programas de prevención primaria que obtienen éxito, así como procedimientos básicos de la prevención (Albee y Gullota,1986): la educación; la promoción de la competencia; la consulta o asesoramiento; la capacidad o potenciación; la prevención en sistemas sociales y organizaciones comunitarias; la autoayuda y los paraprofesionales (grupos de apoyo informal, voluntariado).

\subsection{Dificultades, limitaciones y obstáculos de la prevención}

A pesar de la bondad y oportunidad de la prevención y de los distintos programas preventivos, esta línea de intervención no está exenta de problemas y posibles efectos contraproducentes y/o residuales:

Unas primeras críticas vienen determinadas a raíz de las siguientes preguntas:

- ¿Actuar cuando todavía no hay problema?

¿Quién determina que una situación o comportamiento son problemáticos $\mathrm{y}$, por tanto, no deseables?

- ¿Problemáticos para quién?

Un segundo bloque de críticas estarían dirigidas a los riesgos y límites éticos, técnicos, sociales y políticos de los programas preventivos.

- ¿Entrar en un programa de prevención es etiquetaje social? Parece que la estimagtización y el etiquetamiento que provoca la selección para la intervención de un sujeto supuestamente de alto riesgo puede provocar efectos perjudiciales para el desarrollo personal.

- Un problema técnico que plantea la prevención es lo relacionado con la dificultad de predecir con garantías.

En uno de los estudios mejor controlados (Farrington, 1975) ${ }^{16}$, los

16 Kazdin, A. E. y Buela-Casal, Conducta antisocial. Evaluacion, tratamiento y preven- 
resultados de factores de predicción, sólo un 50\% de los jóvenes delicuentes podía identificarse correctamente.

Al ser la prevención, por naturaleza, una actividad planificada, proactiva, diseñada para prevenir perjuicios futuros, más que algo que se realiza a petición de individuos a causa de su malestar actual, es posible que se produzcan abusos. Únicamente, a través de la participación en el diseño de programas preventivos por parte de la comunidad pueden minimizarse estos riesgos.

Cristina de Robertis (1996) al referirse a la prevención como objetivo del Trabajo Social Comunitario afirma que: "la prevención no debe estar dirigida, pues, a cambiar los comportamientos de una población, sino a cambiar la situación -factor de riesgo- en la que aquélla se encuentra (...). Debe cambiarse la imagen de la prevención, compuesta de prohibiciones y amenazas ".

"La prevención es un objetivo que alberga grandes esperanzas" (Kazdin y Buera-Casal, 1994), refiriéndose a la prevención de la conducta antisocial).

\section{CONTENIDO Y CARACTERÍSTICAS DE LOS PROGRAMAS PREVENTIVOS-PROMOCIONALES EN EL CONTEXTO DE LOS SERVICIOS SOCIALES DE ATENCIÓN PRIMARIA}

El campo que ofrece la Atención Primaria para la realización de programas preventivos está todavía por explorar y explotar, en el mejor sentido de la palabra. La proximidad que ofrece para mantener un contacto cercano y directo con la realidad social del territorio que abarque nuestro campo de acción, con un conjunto de personas, grupos y colectivos que lo pueblan, así como con las organizaciones formales e informales que en él desarrollan su labor, nutre de un potencial a nuestra práctica profesional que es difícil poderla encontrar en otros contextos. Estamos, como profesionales, dentro de ese conjunto de personas que configuran nuestro ámbito de intervención. Del modo como nos posicionemos dependerá, en gran medida, nuestro bien-hacer y nuestro bien-estar, y lo que es más importante el bienestar de un gran número de la comunidad.

\subsection{Proceso de elaboración: "una forma de ser y estar con".}

La intervención comunitaria es objeto de trabajo de distintas mate- 
rias, profesiones y profesionales: Trabajo Social, Psicología comunitaria, Sociología, Medicina, Salud pública, etc., lo cual lleva a relacionarse interdisciplinariamente y, también, a delimitar los objetivos y métodos de intervención para lo cual es necesario establecer claramente los límites y/o nexos de la práctica interventiva. Hoy parece aceptada la complementariedad entre distintas disciplinas, así como la necesaria colaboración interprofesional e interinstitucional, para llevar adelante programas de intervención comunitaria. Del mismo modo es necesario también establecer los límites precisos desde la especificidad, que también existe, de cada disciplina y de los profesionales de la intervención social comunitaria.

El papel que juega el profesional que interviene con la población es determinante para que la población acepte como suya cualquier tipo de intervención que pueda proponérsele. Si no consideramos a la comunidad como sujeto de su propio destino y como el mejor de los recursos con los que contamos para desarrollar nuestra labor profesional, muchos de nuestros esfuerzos serán inútiles. Esto exige pasar a un segundo plano, perder el protagonismo que con frecuencia nos impulsa, convirtiéndonos en compañeros de camino, aportando nuestro saber y nuestra práctica profesional con talante dialogante, estimulando, potenciando, sosteniendo y promoviendo procesos de cambio, donde el protagonista es la propia comunidad. Este actuar "desde abajo", compartiendo y colaborando con aquéllos con quienes queremos ayudar forma parte de la mejor tradición del Trabajo Social.

Payne $(1995)^{17}$ sostiene que los profesionales que mejor pueden desarrollar esos roles, y esta manera de trabajar, son los/as profesionales del Trabajo Social, por varias razones:

- Están en los servicios sociales: Son los principales profesionales en los departamentos de los servicios, y sus sistemas de valores y habilidades son capitales.

- La práctica social: Los/as trabajadores sociales ha sido educados/ as prioritariamente en las ciencias sociales y psicológicas para centrarse en las interacciones con los clientes en la vida normal más que para seguir un modelo médico identificado con la enfermedad.

- A nivel educativo han sido preparados en un amplio abanico de ciencias sociales más que en un limitado número de habilidades prácticas o de tipo particular de servicio.

- Formación práctica y centrada en la práctica. El carácter generalista de su formación les permite centrarse en sus problemas

17 Payne, M., Teorías contemporáneas del trabajo social, Paidós, Barcelona, 1995, p. 134-35. 
y en la relación de ayuda a los clientes de los servicios más que en mostrar su habilidad profesional.

- Centradas más en aquellas habilidades que les permiten manejarse en las relaciones interpersonales que en facilitar unos servicios técnicos.

- Habilidades para valorar las situaciones psicológicas complejas. Son cruciales en la atención de las necesidades comunitarias.

- Orientadas al riesgo. Por su propia formación e independencia tienden a animar al cliente para que asuma riesgos al seguir su propio camino y evite volverse dependiente de otros.

- Orientación a la participación. Históricamente están comprometidos con la abogacía social.

En la intervención del trabajador/a social prima lograr el desarrollo de los individuos y grupos en una perspectiva de integración en la comunidad, buscando como objetivo la mejora de las condiciones de vida, y de la vida de los ciudadanos. "La intervención comunitaria se legitima por la responsabilidad institucional, los planteamientos técnicos de los profesionales y la participación social de los ciudadanos", pero también por la forma de estar, de decir y de hacer junto con otros, favoreciendo y creando espacios de comunicación, participación y corresponsabilidad.

La verdadera misión del Trabajo Social es construir un significado, un propósito y un sentido de obligación hacia la comunidad, poniendo las bases para el compromiso y el apoyo social. Por ello, en palabras de Spetch (1990), "el Trabajo Social sólo encuentra su verdadera misión en la práctica comunitaria".

En la actualidad, en un contexto de sociedad y economía global, que produce fenómenos de precariedad, vulnerabilidad, marginalidad, pobreza y exclusión social en un buen número de sus ciudadanos, se hace más necesario que nunca este enfoque comunitario del Trabajo Social que ha de tener en cuenta todos estos procesos y ha de saber proponer programas y proyectos que den respuesta a las nuevas necesidades de la sociedad, de los grupos y comunidades, así como de los individuos particulares. Trabajar desde y con la comunidad unifica y da contenido a nuestra acción, así como a nuestra profesión, superando concepciones anquilosadas y compartimentalizadas del Trabajo Social, y por ello ineficaces, convirtiéndonos en ocasiones en profesionales en tierra de nadie, administradores de recursos escasos, con poder para decidir en situaciones y momentos vitales para muchas personas, pero habiendo perdido, quizá, la capacidad de escucha para compartir narrativas y la imaginación y creatividad para ofrecer otras respuestas. 


\subsection{Según los niveles de Prevención}

La clasificación que hace Caplan de la prevención: primaria, secundaria y terciaria, nos permite hablar de prevención estricta e intervención en una progresión dinámica que, como mínimo, trata de eliminar que los déficits imposibiliten a personas y colectivos su capacidad de integración en la sociedad de la que forman parte. Además, favorece el que podamos referirnos de manera más precisa al hablar de prevención gracias a las distintas modalidades que presenta.

Por otra parte, no es incompatible con la clasificación que ofrece Bronfenbrenner, al presentarnos la importancia decisiva que adquieren los distintos ambientes para el desarrollo de personas y grupos. Estos distintos ambientes son verdaderos sistemas que interactúan de modo directo en un contexto dado y que afectan directamente, positiva o negativamente según los casos, a las oportunidades vitales de personas y grupos, a la posibilidad, o no, de su desarrollo, y a la manifestación de comportamientos de distinto tipo que permitirán su integración o exclusión social. Desde esta visión ecológica, se hace necesario la intervención, principalmente, en los niveles del exo, meso y macro sistema. Algunos de estos sistemas quedan muy alejados de las posibilidades reales de influencia del/a trabajador social, por lo que será necesario ampliar nuestra mirada (en las distintas políticas, legislaciones, cultura, etc.), así como tratar de influir, por sí o por (y con) otros, en esos sistemas que tienen una influencia directa en el individuo y su entorno más próximo (en el microsistema).

Por tanto, los niveles de prevención que nos presenta Caplan, más claros quizá, pero también más asépticos, deberían interrelacionarse sistémicamente con lo que nos propone Bronfebrenner, lo que conduciría necesariamente a tomar partido, a situarnos comprometidamente en la construcción de lo social, así como en los movimientos y fuerzas que la van conformando. Tarea nada fácil pero necesaria para no ser simples espectadores de lo que sucede, relegados -como buenos samaritanos-a recoger a los caídos por el camino, repartiendo migajas de un pan que otros han cocinado y que reparten según conveniencias y distintos, y muchas veces ocultos, intereses.

Aterrizando a nuestros contextos comunitarios, desde esta visión clara y compleja que nos ofrecen los autores mencionados anteriormente, el realismo comprometido de nuestras actuaciones preventivas con la comunidad, debería incidir en la creación de marcos e itinerarios de oportunidades, favoreciendo estrategias de intervención favorecedoras de "capital humano", de fortalecimiento de aptitudes y actitudes personales, de redes de apoyo natural, informal y formal, a través de 
programas educativos, preventivos, promocionales, de participación e inserción social, de capacitación e inserción laboral, de desarrollo de un clima familiar y social que favorezca el diálogo, la aceptación positiva de las diferencias en la red comunitaria dentro de un contexto dado.

De modo ilustrativo, y desde mi experiencia en contextos de Atención Primaria, siguiendo la clasificación de Caplan $^{18}$, propongo distintos programas dirigidos a familias y grupos y población, en la comunidad local, desde una concepción ecológico-sistémica y de Redes Sociales.

a) Programas de prevención primaria:

Son programas de amplio espectro demográfico: dirigidos a grupos muy numerosos. Indiscriminados respecto a la población receptora de los mismos. Se realizan a través de los Mass media. Ideas pocas y claras. Reiterativos. Fundamentalmente de carácter informativo, más que motivador, o profundizador. Deben incidir especialmente en los agentes socializadores: escuela, familia. Se debe evaluar el impacto que producen.

En la práctica del Trabajo Social no son muy frecuentes los programas dirigidos a este nivel de prevención. Tampoco la profesión ha mostrado un excesivo interés por temas como la publicidad, el marketing, campañas informativas, etc., así como el uso que las nuevas tecnologías aportan a nuestra tarea. Últimamente se ven algunas a nivel nacional y local, aunque creo que no son suficientes. Deberíamos plantearnos en nuestro trabajo un mayor número de prácticas de este tipo que sensibilicen positivamente y ayuden a conocer, evitar y/o desarrollar buenas prácticas y comportamientos saludables. Creo que una parte del presupuesto, de un Ayuntamiento, y de un Centro Social Comunitario, debería dedicarse a este fin, con mensajes claros y bien focalizados. Dentro del ámbito de la Atención Primaria se dan distintas necesidades y problemas específicos de ciertas poblaciones que no se dan en otros barrios o distritos de una ciudad. A ese conjunto de población estarían indicados también este tipo de campañas.

Tratando de ser más concreto, cuando reflexionamos sobre nuestra práctica profesional descubrimos con frecuencia situaciones negativas que se están consolidando y cuyos efectos a medio y largo plazo sabemos que serán muy contraproducentes; por otra parte comprobamos que a través de nuestras intervenciones no se obtienen cambios y mejoras que favorezcan su eliminación, a pesar de los esfuerzos y gastos que tales intervenciones suponen.

${ }^{18}$ Casas, F., (1996:92-94; 123-26; 141-156). 
Es el caso, por ejemplo, de las situaciones de maltrato que sufren muchos niños y niñas dentro del domicilio familiar. Con los datos recogidos por las profesionales de un programa con familias ${ }^{19}$, en las que había un total de 173 niños y niñas menores de 18 años, 124 (el 72\%) presentaban algún tipo de maltrato; y, de ese total, 162 (el 94\%) tenía algún tipo de conducta inadaptada en su casa, colegio y/ o en la calle. Es indudable el buen trabajo de las profesionales y significativo, aunque no suficiente, el nivel de logro de logro conseguido en la erradicación de esas conductas. Dado que, en un alto porcentaje, la variable interviniente, aunque esté asociada a otras, es cultural, al considerar que es un modo legítimo de solucionar conflictos con los hijos, cabría preguntarse: ¿no sería preferible desarrollar una campaña de sensibilización para favorecer el buen trato hacia los niños y las niñas? Personalmente creo que sería muy efectivo, desde un planteamiento comunitario y desarrollando paralelamente otro tipo de estrategias y servicios que apoyen esa campaña. Del mismo modo, campañas sobre la tolerancia, sobre prácticas saludables de salud, romper con la soledad y el aislamiento social, etc.

b) Programas de Prevención secundaria:

Dirigidos a grupos de riesgo, con el problema de alguna manera ya manifiesto pero incipiente. Son propiamente intervención precoz, y también prevención de males mayores o retardadores de los mismos. Pretenden inducir al cambio de hábitos y actitudes. Facilitan información importante, sólida, a los sujetos y preferentemente de manera activa. Se dirigen a grupos pequeños. Se pretende de alguna manera ir creando redes sociales de apoyo. Se debe evaluar el proceso de cambio experimentado en los grupos de riesgo.

Es en este nivel de prevención donde se desarrollan gran parte de los programas en el ámbito de la Atención Primaria, en los cuales se tienen en cuenta las relaciones e influencias que ejercen los niveles exo y meso en el microsistema. El interés actual por las intervenciones en el microsistema ha ayudado a la superación de la intervención individual, aunque ésta todavía tiene numerosos adeptos.

Así, el desarrollo de programas preventivos dirigidos a madres en estado de gestación y/o en el periodo perinatal ${ }^{20}$, con dificultades manifiestas o potenciales, y con el objetivo de prevenir futuros ries-

19 Programa de Educación Familiar, Memoria del año 2000, Ayuntamiento de Alicante y Fundación Nazaret.

20 "Programa de actuación con familias de niños/as de alto riesgo social detectadas en el periodo perinatal", Memoria del año 2000, Fundación Nazaret, Alicante. (Programa subvencionado por la Conselleria de Bienestar Social de la Generalitat Valenciana). 
gos al niño/a que va a nacer, y garantizarle un nivel de bienestar y cuidado óptimo, tratando de asegurar el bienestar de la madre antes y después del parto, evitando, o reduciendo la posibilidad de la separación del niño/a de su ambiente natural. Son programas de detección precoz, de carácter socio-sanitario, donde se hace necesario la coordinación e implicación efectiva de, al menos, tres ámbitos-sistemas distintos: los servicios sanitarios, los servicios sociales y educativos. A través de las distintas acciones, se garantiza el seguimiento de los casos durante un periodo de tres años.

Este tipo de programas, todavía no demasiado extendidos, situados estratégicamente entre la prevención primaria y secundaria, o de "prevención secundaria temprana", constituyen, a mi modo de ver, una excelente oportunidad para la práctica profesional de los/as trabajadores sociales, al combinar la prevención-promoción en los distintos ambientes donde viven y con-viven estas personas, y desde la necesaria coordinación y complementariedad de distintos sistemas implicados en estos grupos de población muy vulnerable, y con importantes impedimentos y carencias para la crianza y cuidado del recién nacido.

Otro tipo de programas centrados en la familia son los denominados de Educación Familiar ${ }^{21}$. A partir de la demanda expresada, o de la implícita no manifestada pero detectada o intuida por el/la profesional, se inicia una intervención familiar que tiene en cuenta a todo el sistema familiar y al conjunto de sistemas con él relacionados (salud, educación, empleo, vivienda, etc.), y todo ello desde el propio contexto (barrio, asociaciones, grupos informales ) en el que viven las personas. Estos programas tienen un carácter claramente educativo-promocional, promoviendo el cambio de actitudes y la adquisición de habilidades y competencias que ayuden al equilibrio en el propio sistema familiar, a la creación, sostenimiento y ampliación de sus redes sociales, así como a la integración social y laboral de sus miembros.

Grupos de apoyo, y de expresión, constituidos preferentemente por madres con escasos recursos y habilidades personales, y jóvenes adultas que no terminaron su proceso formativo. El objetivo de este programa $^{22}$ se centra en crear un espacio de encuentro de desarro-

2. Domínguez Alonso, F. J., " El programa de eđucación familiar en el Ayuntamiento de Alicante", V Congreso Estatal de Inserción Social, Ministerio de Trabajo y Asuntos Sociales. Secretaría General de Asuntos Sociales. Instituto de Migraciones y Servicios Sociales, Madrid, 1999, Vol. I, pp. 459-468.

22 "Programa de Desarrollo y Organización Familiar", que está funcionando en cuatro distritos de la ciudad de Alicante en convenio entre el Ayuntamiento y la Fundación Nazaret. 
llo personal y de mutuo apoyo, que favorezca el crecimiento de la autoestima y la adquisición de hábitos y habilidades para el mantenimiento de sus núcleos familiares en su vida cotidiana. Se incluyen sesiones y talleres teórico-prácticos sobre cuidados de sí mismas, de organización y economía doméstica, salud: propia y de los suyos, convivencia y de habilidades para la búsqueda de empleo, además de los talleres de costura, patronaje, cocina y alfabetización. Estos grupos suponen para un buen número de ellas una plataforma para continuar con otros procesos e itinerarios de inserción y, para el conjunto, un estímulo importante para dignificar sus relaciones y su vida cotidiana.

Otro tipo de programas son los dirigidos a menores sujetos a una medida judicial en medio abierto ${ }^{23}$. Estos programas que empezaron a desarrollarse como consecuencia de la entrada en vigor de la Ley 4/1992, de 5 de junio, sobre reforma de la Ley Reguladora de la Competencia y el Procedimiento de los Juzgados de Menores ${ }^{24}$, adquiere mayor dimensión con la nueva Ley de 5/2000, de 12 de enero, Reguladora de la Responsabilidad Penal de los Menores ${ }^{25}$. Las posibilidades que se abren para la intervención con estos jóvenes desde el modelo ecológico, aunque no exentas de dificultades, son enormes y todavía muchas de ellas están por descubrir.

c) Programas de Prevención terciaria

Denominados de rehabilitación en el campo estricto de la salud. En el mundo de los Servicios Sociales o de la intervención en problemas de índole social, serían más bien los Programas de Seguimiento que constituyen un proceso de independización de los sujetos, respecto de la institución, o de los profesionales o del tratamiento más estricto seguido anteriormente. Se pretende en ellos la consolidación de hábitos, actitudes, estilos de vida, ya adquiridos. Se pretende también la generalización de conductas a ámbitos más abiertos, de mayor complejidad y/o de menor control. En ocasiones y campos esta fase supone la implicación de los sujetos en el trabajo directo o en la prevención de otros casos.

En toda intervención es importante preguntarse sobre los logros conseguidos y la durabilidad de los mismos. Sería iluso pensar, y pretender, que nuestra intervención, por muy eficaz que haya sido, vaya a tener efectos definitivos y perdurables. Lo lógico es prever que sur-

Domínguez Alonso, F.J. y Otros, "Análisis del programa de seguimiento de medidas judiciales de régimen abierto en la ciudad de Alicante durante 1996", en Alternativas. Cuademos de Trabajo Social, Escuela Universitaria de Trabajo Social, Universidad de Alicante, Alicante, 1997, $\mathrm{n}^{\circ}$ 5, pp. 97-118.

24 BOE $n^{\circ} 140$, de 11 de junio de 1992

25 BOE $n^{\circ} 1 \mathrm{l}$, de 13 de enero de 2001 . 
girán nuevas dificultades y momentos de crisis en las familias, grupos y sistemas, que requerirán de apoyos concretos. Los resultados de los programas ${ }^{26}$ presentados anteriormente ofrecen una respuesta muy satisfactoria a muchas de estas familias y jóvenes a la solución de sus problemáticas (en torno al 60\% de éxito). Por lo tanto sí se puede hacer algo siempre, y mucho en algunos casos. Quizá nunca todo lo que las situaciones requieren, y ello por varios motivos, entre ellos la carencia de programas de seguimiento de la intervención. Es lo que se llama la prevención terciaria, continuar con los casos para evitar regresiones y cronificación de situaciones que obligarán a nuevas intervenciones desde el sentimiento de fracaso de las anteriores y con un coste muy elevado.

Los programas post-intervención garantizarían o facilitarían la consistencia de los cambios producidos, a la vez que evitarían recaídas que, por una parte serían más costosas económicamente, pero, sobre todo, muy desanimantes a nivel personal y familiar, y también para el sistema profesional. Hay jóvenes, familias, que requieren de este tipo de apoyo desde el mismo momento de la despedida y terminación de la intervención.

Aquí adquiere una especial relevancia el Trabajo Social Comunitario que, en una de sus dimensiones principales, consistiría en el mantenimiento de las redes familiare ${ }^{27}$ y sociales de estos grupos, así como en su capacidad para potenciar y facilitar el contacto con otros recursos y servicios sin necesidad de una intervención directa e intensiva. Al igual que en los programas de intervención preventiva a nivel primario, éstos, los de nivel de prevención terciaria, tampoco cuentan con la voluntad política, técnica y presupuestaría que a todas luces es necesaria y deseable. Este tipo de intervención es más eficaz y eficiente a medio y largo plazo.

Podemos asegurar la viabilidad, la conveniencia y el éxito de este tipo de programas. Sus efectos positivos se evidencian en el crecimiento personal y familiar, el incremento de sus capacidades y habi-

Domínguez Alonso, F. J., "Programas preventivos de intervención familiar en el ámbito de los Servicios Sociales Comunitarios", en I Jornadas sobre intervencion familiar en el siglo $X X I$, (documentos de las ponencias), Villajoyosa (Alicante), 25,26 y $27 \mathrm{de}$ octubre, 2001.

27 "Las redes de atención informal son vulnerables y frágiles y, precisamente cuando ya no pueden dar más de sí, comienzan a llegar a las áreas de Servicios sociales (...). Si la política y la práctica del Trabajo Social se orientara más al apoyo y refuerzo de las redes informales, para ayudar a los cuidadores, y menos para ocuparse de los problemas cuando esas redes ya no pueden más, es probable que se redujera la necesidad de aquellas solicitudes".

National Institutc for Social Work, Trabajadores Sociales. Su papel y cometidos. Narcea, Madrid, 1992, p. 283. 
lidades, su mayor autoestima y el fortalecimiento de su red social, producen efectos y habilidades para desarrollar su papel y mantener su sistema en situaciones de mayor equilibrio y capacidad para afrontar las situaciones de crisis y cambios futuros.

\section{EPÍLOGO}

Más que una conclusión, se trataría de una invitación a seguir en el camino $^{28}$, redescubriendo, imaginando, y re-creando nuevos itinerarios, nuevos modos de ser y de estar con las personas, grupos y colectivos que forman parte de la comunidad de la que también nosotros, y otros muchos profesionales y sistemas, formamos parte. Se trata de "estarestando" en el entramado social del que formamos parte, en diálogo permanente con los otros, cuantos más mejor, abiertos y conscientes a los rápidos cambios sociales que se producen en nuestro mundo, a nivel global, y que tienen repercusiones evidentes en nuestros contextos locales.

Es época de "rupturas" múltiples, familiares, laborales, nacionales e internacionales. Como dice Kisnerman en un bello libro" 29 : "Estamos en una sociedad en crisis, en una sociedad donde las rupturas configuran parte de la cotidianidad", y en esa cotidianidad es donde el Trabajo Social desarrolla su tarea, junto con las personas, que constituyen el recurso más valioso con el que podemos contar, y con sus narrativas particulares que nos abren los ojos a la verdad de su existencia y a la búsqueda de su identidad que nos obliga a repensar y reformular la nuestra, la del Trabajo Social.

Existen distintos campos que se abren para el Trabajo Social en la actualidad, que demandan una respuesta de éste, y que obligan a "repensar lo social". Uno de ellos surge a partir de las políticas y las prácticas contra la pobreza y exclusión social. La pobreza, además de ser una "vergüenza social", crea desigualdad y sitúa a grandes grupos sociales en zonas de vulnerabilidad y exclusión social. (R. Castel). En este contexto de desigualdad, adquiere un papel relevante la tenencia o no de un empleo estable. La carencia de éste, provoca situaciones de

Silvia Navarro, con ese lenguaje poético del que hace gala, tiene muchos escritos en esta línea, donde sugiere bellos itinerarios y formas renovadas de intervención en la red social, con individuos, grupos y colectivos, desde y con la comunidad: Navarro, S., Desde la Red Social: Nuevos itinerarios y geografias en la intervención familiar, en I Jornadas sobre intervención familiar en el siglo XXI, (documentos de las ponencias), Villajoyosa (Alicante), 25,26 y 27 de octubre, 2001.

29 Kisnerman, N, Pensar el Trabajo Social. Una introducción desde el construccionismo, Lumen humanitas, Buenos Aires, 1998, pp. 156-158. 
desintegración social y aparición de numerosas patologías, además de la imposibilidad de acceder a los servicios que la sociedad ofrece al conjunto de los ciudadanos, y la no satisfacción de sus derechos cívicos y sociales.

Pero también es época de oportunidades, tanto a nivel global como local. El llamado fenómeno de la globalización, con tantas caras oscuras, permite abrir los ojos y ampliar nuestras posibilidades de acción a nivel local a partir del desarrollo de la información, la tecnología y la comunicación intercultural. Este es el convencimiento de un hombre que ha conseguido, a través de los microcréditos concedidos a las mujeres, sacar de la pobreza a un buen número de la población de la India. Para él "la globalización es algo grandioso para la gente pobre. Ahora los menesterosos son ciudadanos del mundo". Con una gran dosis de utopía afirma que "las nuevas tecnologías pueden cambiar radicalmente la sociedad mundial. Si nos proponemos unos objetivos sociales y empezamos a trabajar en ellos ahora mismo, creo que la erradicación de la pobreza mundial es perfectamente posible. No podemos perder esta oportunidad de oro, esta facilidad. Sería una vergüenza" ${ }^{30}$ ".

A un nivel más local, y favoreciéndonos de la integración de España como Estado miembro de la Unión Europea, existen toda una serie de iniciativas y programas sociales de enormes posibilidades para la acción social y el trabajo con nuestras comunidades y colectivos, tanto en el ámbito de la formación como en el del empleo, los equipamientos, intercambios y otros muchos. (Cfr.: las iniciativas comunitarias, proyectos como IGLOO que comprende aquellos proyectos que constituyen una respuesta global a favor de los colectivos sometidos a situaciones de exclusión social. Las actuaciones incluyen acciones globales e integradoras en formación, empleo, vivienda, acompañamiento social. Está integrado dentro de la iniciativa comunitaria EQUAL. Etc.).

Las llamadas empresas de inserción laboral son una interesante iniciativa para la integración social de estos colectivos vulnerables que buscan la integración laboral a través de programas de capacitación, preparación, formación, apoyo-seguimiento e incorporación al trabajo productivo. Las posibilidades que ofrecen estas iniciativas abren un nuevo frente de intervención para los trabajadores sociales, apoyando a las personas y a las empresas, colaborando y participando activamente en programas de actuación global en la lucha contra la pobreza y exclusión social (Cfr. Documentación Social, $\mathrm{n}^{\circ}$ 117-118).

Estas iniciativas ofrecen una posibilidad y un campo de acción para los trabajadores sociales. Como afirma López-Aranguren" ${ }^{31}$ " Nos si- 
tuamos en un contexto social nuevo con nuevas claves para su interpretación y que está suponiendo la consolidación de la fractura social y territorial. El Trabajo Social ha de dar respuesta a estos nuevos y complejos problemas sociales. Es necesario, afirma, 'repensar lo social'. Hará falta renovar nuestras políticas públicas, que deben prevenir tanto como curar".

Desde este "repensar lo social", en un momento de crisis, incertidumbres, inseguridades y espacios desconocidos, es desde donde se abren para el Trabajo Social las oportunidades para preguntarse cuál es su espacio y su papel, cuáles son sus roles y funciones, cómo debe de situarse en el dominio de lo cotidiano, en lo local desde lo global, desde el despacho y la calle, entre lo económico y lo político, para ofrecer respuestas, itinerarios y caminos renovados, re-construyendo una disciplina y una profesión que busca, con prácticas preventivo-educativaspromocionales, transformar situaciones y realidades desde el con-vivir con personas, grupos y comunidades.

\section{BIBLIOGRAFÍA}

ALVAREZ URÍA, F.: «En torno a la crisis de los modelos de intervención social», en F. Alvarez Uría y otros, Desigualdad y pobreza hoy, Talasa, Madrid, 1995.

BRONFENBRENNER, U.: La ecología del desarrollo humano, Paidós, Barcelona, 1987.

CASTELLS, R.: Les métamorphoses de la question sociale, Fayard, París, 1995.

DE LA RED, N.: Aproximaciones al Trabajo Social, Siglo XXI. Madrid, 1993.

DE ROBERTIS, C. y PASCAL, H.: La intervención colectiva en trabajo social. La acción con grupos y comunidades, Ateno, Buenos Aires, 1994.

DOMÍNGUEZ ALONSO, F. J.: «Programas preventivos de intervención familiar en el ámbito de los Servicios Sociales Comunitarios», I Jornadas sobre intervención familiar en el siglo XXI, (documentos de las ponencias), Villajoyosa (Alicante), 25, 26 y 27 de octubre, 2001.

DOMÍNGUEZ ALONSO, F. J., y otros: «Análisis del programa de seguimiento de medidas judiciales de régimen abierto en la ciudad de Alicante durante 1996», Alternativas. Cuadernos de Trabajo Social, Escuela Universitaria de Trabajo Social, Universidad de Alicante, Alicante, 1997, n 5, pp. 97-118.

DOMÍNGUEZ ALONSO, F. J.: «El programa de educación familiar en el Ayuntamiento de Alicante», V Congreso Estatal de Inserción Social, Ministerio

31 López-Aranguren, L.M" "Nuevos problemas, nuevas preguntas, nuevas respuestas". En Documentación Social $\mathrm{n}^{\circ} 117-118,1999-2000$, pp. 5i y 52. 
de Trabajo y Asuntos Sociales. Secretaría General de Asuntos Sociales. Instituto de Migraciones y Servicios Sociales, Madrid, 1999, Vol. I, pp. 459468.

ELKAIM, M.: Las prácticas de la terapia de red, Gedisa, Barcelona, 1989.

ESTEVE I ORTEGA, E.: «De los Servicios Sociales a las redes comunitarias como instrumento para integración social», IV Congreso Nacional de Servicios Sociales. Gijón. 1998.

FERNÁDEZ RÍOS, L.: Manual de Psicología Preventiva: teoría y práctica, Siglo XXI, Madrid, 1994.

GRACIA FUSTER, E.: El apoyo social en la intervención comunitaria. Paidós. Barcelona, 1997.

HAMILTON, G.: Teoría y práctica Trabajo Social de Casos. Prensa Médica Mexicana. México, 1987.

HILL, R.: Nuevos paradigmas en Trabajo Social. Siglo XXI. Madrid, 1992.

KISNERMAN, N.: Pensar el Trabajo Social. Una introducción desde el construccionismo, Lumen humanitas, Buenos Aires, 1998.

LÓPEZ CABANAS, M. y CHACÓN, F.: Intervención psicosocial y Servicios Sociales. Un enfoque operativo. Síntesis, Madrid, 1997.

MARTÍNEZ ROMAN, Ma . A.: «Política social, pobreza y exclusión social», en C. Aleman, C. y J. Garcés, Política Social, McGraw-Hill, Madrid, 1997.

MARTÍnEZ, M., y otros (1988): “Prevención y promoción en Psicología Comunitaria, en A. Martín, F. Chacón y M. Martínez (Eds.), Visor, Madrid, 1988.

MOIX, M.: Introducción al Trabajo Social, Trivium, Madrid, 1991.

MUSITU, A.: Intervención psicosocial: programas y experiencias, Popular, Madrid, 1993.

NATIONAL INSTITUTE FOR SOCIAL WORK: Trabajadores Sociales. Su papel y cometidos, Narcea, Madrid, 1992 (conocido como «Informe Barclay»).

NAVARRO, S.: «Un salto con red a la comunidad», Revista de Servicios Sociales y Política Social, Consejo General de Colegios oficiales de Diplomados en Trabajo Social, n 40, Madrid, 1997.

NAVARRO, S.: «Desde la Red Social: Nuevos itinerarios y geografías en la intervención familiar», en I Jornadas sobre intervención familiar en el siglo XXI, (documentos de las ponencias), Villajoyosa (Alicante), 25, $26 \mathrm{y}$ 27 de octubre, 2001.

NORA DABAS, E.: Red de redes. Las prácticas de intervención de redes sociales, Buenos Aires, Paidós, 1993.

OLZA, M.: «Trabajar en la Comunidad», J.F. MORALES, J., y M. Olza (Coord.), Psicología Social y Trabajo Social, Mc Graw Hill, Madrid, 1996. 
PAYNE, M.: Teorías Contemporáneas del trabajo social, Paidós, Barcelona, 1995.

SÁNCHEZ VIDAL, A.: Programas de prevención e intervención comunitaria, PPU, Barcelona, 1993.

TAYLOR, S. J.: Introducción a los métodos cualitativos de investigación, Paidós, Barcelona, 1994.

VARIOS: «Empresas de Inserción», Documentación Social, n 117-118, Caritas Española, Madrid, 1999-2000.

VILLALBA, C.: «Intervención en redes». Documentación social, $\mathrm{n}^{\circ} 98$, Caritas Española, Madrid, 1995.

ZAMANILLO, T., y GAITÁN, L.: Para comprender el trabajo social, Verbo Divino, Navarra, 1991. 


\title{
INICIATIVA SOCIAL Y TRABAJO SOCIAL COMUNITARIO
}

\author{
ENRIQUE PASTOR SELLER
}

Escuela Universitaria de Trabajo Social. Universidad de Murcia.

\section{ABSTRACT}

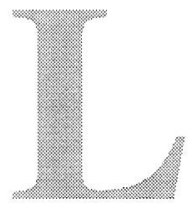

a contribución de la iniciativa social al Trabajo Social Comunitario no supone, a pesar de su relevancia en la actualidad, una novedad. El Trabajo Social se ha encontrado desde siempre vinculado y comprometido con las actuaciones emprendidas por personas, grupos e instituciones sociales.

Sin embargo, en la actualidad, las entidades de iniciativa social se han convertido en uno de los fenómenos sociales más importantes en la configuración de la Sociedad del Bienestar. Las corrientes teóricas y las prácticas sociales muestran una clara reconfiguración de las relaciones entre los distintos sectores en los que se dimensiona la sociedad: Estado, mercado, entidades de iniciativa social o tercer sector y redes primarias o solidarias.

Las entidades de iniciativa social adquieren un papel de vital importancia en la definición, gestión e implementación de las políticas sociales, en la configuración relacional de los sistemas sociales, en los nuevos escenarios de participación ciudadana, en la descentralización de la gestión social, en definitiva, en la vertebración del tejido social. En este sentido, el Trabajo Social, tiene el reto de fomentar y movilizar el fenómeno asociativo, mejorar y apoyar a las entidades de iniciativa social e incorporarlas en los procesos de intervención en, para y con la comunidad.

Palabras clave: sociedad del bienestar, gestión compartida, participación integral, relaciones en red, redistribución de posibilidades, identidades comunitarias, partenariado local, permeabilidad social, estrategia relacional comunitaria. 


\section{LOS CAMBIOS SOCIALES}

Como señala Hobsbawn (1995) vivimos en un mundo en el que no sabemos a dónde nos dirigimos, ni tampoco a dónde deberíamos de dirigirnos. Es la dificultad en definir el modelo de sociedad que desearíamos, más allá de la cotidianeidad y de los problemas y necesidades que van apareciendo.

El intenso ritmo de los cambios internacionales, políticos, sociales, demográficos, urbanísticos, económicos y científico-tecnológicos de nuestro tiempo está dando lugar a una transformación muy profunda del modelo de sociedad, en la que aparecen nuevas formas de experiencia social y relación interinstitucional, que van a modificar nuestros modos de vida, de trabajo, de ocio, así como las costumbres y las formas de pensar, actuar y relacionarnos con el entorno social. Así, la comprensión de las estrategias del Trabajo Social Comunitario requiere de la identificación y análisis de los principales cambios sociales que acontecen en nuestras sociedades y con los que se interrelaciona.

Asistimos a una intensificación de las relaciones sociales y económicas en todo el mundo por las que se enlazan y se relacionan de manera interdependiente los acontecimientos locales de "aquí" y los que ocurren en lugares lejanos; en una amalgama de relaciones en red, en la que todos los acontecimientos se relacionan entre sí sin existir espacio ni tiempo que amortigüen esta interdependencia. De esta forma, en el Trabajo Social Comunitario debemos considerar que lo que sucede en un barrio de una determinada localidad, posiblemente ha sido influido por factores, decisiones o sucesos que operan a una distancia lejana de la zona en cuestión; lo que implica una complejidad en el análisis y resolución de las problemáticas. La globalización conlleva a la acción concertada de Estados, de territorios, así como de las organizaciones sociales, las cuales diseñan redes transnacionales capaces de intercambiar estrategias, medidas, personas, presupuestos, conocimientos, etc., e influir en acciones gubernativas. Se trata de un fenómeno multifactorial que afecta a todos, aunque no de forma equitativa, tanto a los grandes sistemas como a los aspectos más íntimos y personales de nuestra cotidianeidad. Los argumentos referidos a los efectos de la globalización son divergentes, existiendo estudios comparados que muestran la favorable incidencia de la globalización en el Sistema de Protección Social Español (Sarasa, 2001). En cualquier caso, y en coincidencia con Gaitán (2001), el concepto de globalización sirve tanto para definir procesos, como para legitimar actuaciones, siendo un fenómeno que unifica y fragmenta sociedades.

La globalización nos conduce a la cuestión de la sostenibilidad del 
"modelo" de desarrollo en el que nos encontramos inmersos. El desarrollo es sinónimo de igualdad y justicia social, y por tanto, debe estar orientado a satisfacer las necesidades de la generación presente sin comprometer la capacidad de las generaciones futuras para satisfacer sus propias carencias. En cualquier caso el desarrollo es desigual, tanto en el ámbito internacional (Norte-Sur) como en cada país, región o localidad (cuarto mundo).

Es de suma relevancia destacar los cambios en las estructuras de la población (aumento de la esperanza de vida, creciente envejecimiento de la población, caída de la natalidad) y los que se producen en la estructura y roles de la familia tradicional: familias unipersonales, monoparentales, monomarentales (Camacho y Trabada, 2000: 217-220) $y$ en los hogares: hogares compartidos, hogares unipersonales, etc., que en cualquier caso son cada vez más reducidos, implicando menores mecanismos de apoyo personal ante situaciones de dificultad social. Según datos de la encuesta de población activa referidos al tercer trimestre del 2000 (INE, 2000), existen en España alrededor de 13 millones de hogares, de los que el $15 \%$ está compuesto por una sola persona, proceso que desde una perspectiva longitudinal nos ofrece un fenómeno en aumento, tanto en términos absolutos como relativos. En relación a las personas mayores de 65 y más años, cabe destacar que el $16 \%$ vive solo, siendo significativamente mayor en el caso de las mujeres que asciende al 22\% (Ministerio de Trabajo y Asuntos Sociales, 2001a). Las relaciones de parentesco son de gran importancia en la mayor parte de la población, pero con la postmodernidad han dejado de ser las portadoras de los vínculos sociales, debido al declive de la familia (Giddens, 2000). La separación espacio-temporal de sus miembros está produciendo un distanciamiento entre sus componentes.

Cabe resaltar la relevancia del factor migratorio en todos los aspectos de la vida social (demográficos, educativos, sanitarios, convivenciales, laborales, asociativos, hábitat, etc.), produciendo una sociedad abierta, repleta de flujos, mestiza, pero también con múltiples conflictos. Una sociedad multicultural, que precisa responder al fenómeno de la inmigración desde una perspectiva global, con un especial énfasis en la integración sociolaboral y la atención a menores inmigrantes sin núcleo convivencial o familiar.

Nuestras sociedades postmodernas se caracterizan por su nomadismo, por su enorme movilidad, en un triple sentido: física de las personas (se "acortan" distancias), social (una sociedad abierta) y psíquica (capacidad del hombre de adaptarse a las continuas demandas de la vida y al conocimiento práctico -asimilación- de un gran repertorio de roles). La movilidad social ha contribuido a la psíquica, que unido a los 
medios de comunicación de masas (con efectos cognitivos) hace que las personas puedan conocer y experimentar nuevas situaciones. Este nomadismo produce cambios en los estilos de vida, afectando al territorio, emergiendo multitud de transformaciones en los procesos de urbanización y revitalización del medio rural.

Nos hallamos en la sociedad del saber: la necesaria especialización y la creciente racionalidad de la sociedad produce la generalización de los procesos educativos formalizados que tienden a abarcar de forma continua a todas las personas en todos los lugares.

La crisis del modelo fordista de organización del trabajo y de las relaciones laborales conduce a un modelo de especialización flexible, cuyas características organizacionales y de proyección externa afectan a las organizaciones e intervenciones públicas y privadas en el ámbito comunitario. Las nuevas tecnologías de la información y la comunicación favorecen nuevas formas de organización e intervención, siendo preciso adaptar las modalidades de introducción tecnológica para evitar disfunciones, situaciones conflictivas graves y procesos de exclusión social. Así, la irrupción de las nuevas tecnologías de la información y la comunicación es un fenómeno global, que genera nuevas desigualdades en función del diferencial bagaje educativo y cultural que disponen los ciudadanos

Las pautas de consumo actuales son las de la "diferenciación dentro de la homogeneidad", donde el tiempo libre aparece como un área generadora de empleo y con enormes potencialidades empresariales. El mayor tiempo libre requiere de la socialización de las actividades de ocio, cultura y deporte, en la que deben incorporarse las entidades sociales, con el fin de favorecer el acceso, uso y disfrute por aquellas personas y grupos que presenten dificultades sociales. En este sentido emergen con fuerza en los últimos años, organizaciones voluntarias con fines medioambientales, culturales y deportivos (Medina, 2001; Ruiz 2001).

Otro fenómeno de importancia es la masiva incorporación de la mujer a los mercados de trabajo. Esta inclusión al mundo laboral presenta rasgos evidentes de desigualdad de género, en cantidad y calidad, en el acceso y promoción a puestos de responsabilidad y relevancia pública y privada. En este sentido, en la encuesta de población activa del último trimestre del 2000 (INE, op.c.), podemos observar que el $69 \%$ de los subempleos son ocupados por mujeres en los distintos grupos de edad.

Todos estos fenómenos representan una muestra de la dinámica social actual, estando íntimamente relacionados entre sí. De esta for- 
ma, no se pueden entender unos sin referencias a los otros.

En el contexto de estos procesos sociales de la postmodernidad emergen nuevas formas de pobreza y exclusión social, un conjunto de ciudadanos vulnerables que requieren de nuevas respuestas: son las personas desempleadas de larga duración o en paro recurrente y las ocupadas en subempleos; los jubilados anticipados, los jóvenes que abandonan el sistema educativo sin una cualificación reglada mínima que les permita un acceso digno al mercado laboral; las personas dependientes sin recursos; las personas mayores solas; las madres con cargas familiares; los agricultores sin acceso a la propiedad de la tierra; los analfabetos, los inmigrantes -especialmente no regularizados-; las minorías étnicas y culturales; los trabajadores con baja cualificación; los discapacitados; las personas sin hogar; las personas drogodependientes; los reclusos y exreclusos; los residentes en barrios degradados socialmente y las habitantes de núcleos de población aislada y sin recursos. Un colectivo vulnerable caracterizado por la desafiliación social (Castel, 1997), en una sociedad exclusógena (Camacho y Trabada, op.c.; Laparra y Corera, 2001), que requiere de respuestas integradoras (Ministerio de Trabajo y Asuntos Sociales, 2001b.; Porras, 2001), en el marco de una nueva configuración relacional de los sistemas de producción del bienestar.

\section{EL PLURALISMO DEL BIENESTAR SOCIAL}

Estamos pasando del Estado de Bienestar a la Sociedad del Bienestar, basada en el pensamiento de Welfare Mix; lo que implica pasar de concebir las ayudas e impulsos vinculados al Welfare (bienestar) como un modo de vida (expectativas crecientes) a entenderlos como una nueva oportunidad (oferta).

En los primeros años de los sesenta se producen los síntomas iniciales del agotamiento del modelo de crecimiento keynesiano que dio origen al modelo de Estado de Bienestar. Con la crisis económica general iniciada en 1973 y la inviabilidad del planteamiento fiscal (O'Connor, 1981) del Estado de Bienestar se cierra paulatinamente la época de este modelo, caracterizado por la expansión de la demanda, el gasto público, el fordismo, el endeudamiento y el consenso social; sin conllevar un verdadero avance en los mecanismos de decisión y participación ciudadana (Wenger, 1998: 83-84).

La situación de crisis viene provocada por las limitaciones de la intervención estatal desde una triple perspectiva. La primera, ideológica, al cuestionarse la legitimidad del Estado ante la ineficacia del siste- 
ma en satisfacer las necesidades sociales. La segunda, económica, ante el incremento galopante del gasto público que conduce a un endeudamiento público estructural. La tercera, política, ante una incesante e inacabable extensión de los derechos sociales ante cualquier riesgo.

Emergen así, diferentes modelos de Estado de Bienestar con relación al voluntariado: conservador, liberal, socialdemócrata y nueva izquierda (García R., 2001). En el debate pragmático del Bienestar Social surgen distintas posturas, aunque todas ellas parecen coincidir en la conveniencia de redimensionar el Estado de Bienestar, dando una mayor presencia a la sociedad civil, mediante modelos plurales en los que se conceda una importancia fundamental al denominado tercer sector e, incluso, al mercado.

El pluralismo del Bienestar conlleva la redefinición del papel del Estado, la incorporación activa de los agentes públicos y privados en la resolución de las necesidades sociales (Montoro, 1997; 1998), la complementariedad y corresponsabilidad pública y privada (Giddens, 1996), un papel relevante de la sociedad civil en asociación con el Estado en orden a fomentar la renovación y el desarrollo de la comunidad desde una nueva economía mixta (Giddens, 1999). Se trata de una reorientación en los modos de intervención pública, menos productor, más subvencionador y financiador; una gestión pluralista del bienestar (Rodríguez, 1996; Rimbau i Andrea, 2001; Gaitán, op.c., Fantova, 2001, García R., op.c.), que conlleva la relación complementaria de los agentes sociales existentes, la búsqueda de la efectividad de las políticas y la implicación social en su gestión.

La nueva configuración relacional se produce en nuestro país en un proceso inacabado de consolidación del Estado de Bienestar, lo que conlleva una situación de riesgo en el proceso de expansión de los derechos sociales. El nuevo pacto entre los distintos sectores de nuestra sociedad no debe suponer la deslegitimación y retirada de las instituciones del Estado de Bienestar, ni un proceso que desrresponsabilice a las Administraciones Públicas de los derechos ciudadanos y tienda a privatizar, mediante la gestión indirecta, los servicios y prestaciones públicas.

\section{EL TERCER SECTOR EN EL NUEVO CONTEXTO RELACIONAL DEL BIENESTAR}

La estructura institucional de nuestras sociedades avanzadas se caracteriza por la existencia de cuatro grandes sectores o subsistemas del sistema social: el sector público, el sector privado mercantil, el sec- 
tor privado no lucrativo o tercer sector y el sector informal o redes primarias de solidaridad o comunidad. Desde esta perspectiva sistémica, el dinamismo del sistema social conlleva la permanente interacción y conflicto de los subsistemas que lo conforman. Así, la modificación de uno de ellos supone el cambio del resto, que a su vez, se transforman a sí mismos. De esta forma, los papeles de cada sector o subsistema se construyen y reconstruyen de manera continua por sí mismos y por la misma sociedad.

El tercer sector es complejo y heterogéneo, como muestra la diversidad de términos utilizados para su denominación, hasta diecisiete según Salinas (2001), los cuales enfatizan un aspecto concreto de la realidad que representan. Las dificultades metodológicas suponen un segundo aspecto de análisis.

En relación a la diversidad terminológica, los enfoques y términos más comúnmente utilizados son: economía social (preponderancia de una forma de gestionar social y democráticamente la empresa) ${ }^{1}$, sector caritativo (énfasis en el apoyo que estas entidades reciben del sector público para el fomento de las donaciones privadas caritativas ${ }^{2}$; organizaciones sin ánimo de lucro (ONL) -"Non-profit Organizations"(especial atención al principio de no-distribución de beneficios) ${ }^{3}$, sector independiente (preponderancia del papel que las entidades no lucrativas juegan como grupo de fuerza independiente tanto frente a las acciones del sector público como respecto del privado lucrativo), sector voluntario (acento en el aspecto de la voluntariedad, especialmente en

1 Son organizaciones empresariales con unas características peculiares, siendo las más significativas las siguientes: prestar servicios a sus miembros y al entorno social, la autonomía de la gestión, los procesos de decisión democrática por los que se rige y la primacía de las personas y del trabajo sobre el capital en el reparto de las rentas. Destacar que en España, con la promulgación de la Ley 27/1.999, de 16 de julio, de Cooperativas, se incorporan a éstas las cooperativas de iniciativa social, que pueden ser calificadas como entidades "sin ánimo de lucro". Así, las entidades de economía social y las entidades sin ánimo de lucro se diferencian con claridad al precisar las primeras ser calificadas como "sin ánimo de lucro" para su consideración y efectos. De esta forma el término "sin ánimo de lucro" tiende a ser el más definitorio en lo que respecta al denominado tercer sector.

2 No obstante, las investigaciones al respecto nos muestran que las donaciones privadas no son la únicas, ni incluso la mayor fuente de renta de estas entidades. Así, los recientes estudios dirigidos por Álvarez de Mon indican la fuerte dependencia pública del Tercer Sector, alcanzando hasta un $70 \%$ del conjunto de la financiación (Álvarez de Mon, 1998).

3 Este principio supone la imposibilidad de distribuir sus eventuales beneficios a los individuos que las controlan, así como a los empleados, siendo su principal diferenciación con el sector privado. Ello no quiere decir que no existan beneficios, sino que los supucstos excedentes se han de reinvertir en el seno de la entidad y nunca a los socios, partícipes o personas que ejercen funciones de dirección y control. 
el uso de trabajo voluntario); sector de organizaciones no gubernamentales (recalca el aspecto de independencia de estas entidades respecto del sector público) ${ }^{4}$ y tercer sector (definidas a partir del orden que ocupan en relación a los otros subsistemas).

La segunda cuestión es la referida a las dificultades metodológicas, basada fundamentalmente en dos aspectos, el primero en cuanto a la distinción entre las acciones propias del sector privado no lucrativo centrado en la prestación de servicios y las acciones filantrópicas o de donación y, en segundo lugar, el diferente grado de estructura formallegal requerida en cada país para la constitución-legalización y gestión de estas entidades. Así, como indica Ruiz (op.c.:81), el ámbito no lucrativo ha recibido un tratamiento administrativo y legal tardío, fragmentado y marginal, por lo que no existe un control estadístico de su tamaño, estructura y funcionamiento.

En la realidad, observamos una complementariedad de los enfoques anteriormente citados, dado que muchas entidades sin ánimo de lucro obtienen recursos humanos y económicos tanto de las Administraciones Públicas como de personas y empresas privadas. En este sentido cabe realizar la siguiente reflexión crítica: la obtención de fondos públicos reduce la independencia de estas organizaciones con respecto a las Administraciones, al ser éstas las que determinan los criterios y prioridades de los servicios, programas y actividades a subvencionar. En cierta forma, supone una "debilitación" del principio de independencia que se le supone con la consideración de no gubernamental.

De los enfoques y clasificaciones existentes respecto del Tercer Sector $^{5}$, y más concretamente como ONG, las características básicas

4 Su uso procede de las organizaciones dedicadas a los países en vías de desarrollo, no vinculadas con el gobierno. En España, este término se ha extendido al conjunto de organizaciones no gubernamentales, diferenciándose de las orientadas a la cooperación internacional, adquiriendo estas últimas la denominación de organizaciones no gubernamentales de desarrollo. Es un enfoque que enfatiza lo no-gubernamental; tratando de ser una alternativa ágil y eficaz a la burocracia estatal, lo que permite movilizar capacidades y recursos de manera más integral y rápida.

5 La primera clasificación la encontramos en el Informe de Beveridge (1948) que distingue entre: entidades mutualistas, o dedicadas a la satisfacción de necesidades de sus miembros; y entidades altruistas u orientadas a la satisfacción de las necesidades de los grupos más desfavorecidos. Hansmann (1980) diferencia a las entidades en función de los sistemas de financiación y de gestión. Ascoli (1987), nos ofrece una clasificación combinada (ámbito de actividadies, organización y dependencia), estructurando el tercer sector en once organizaciones. Casado (1989) distingue las iglesias, las asociaciones de vecinos y afectados, las obras sociales de patrocinio público o privado, las coordinadoras y colectivos de acción cívica y las fundaciones culturales, educativas y asistenciales, mencionando además otras cuatro clases de entidades no gubernamentales: colegios profesionales, sindicatos, asociaciones empresariales y partidos políticos. GUI (1991) utiliza dos variables o categorias: una la dominante o colectivo que 
que reúnen estas entidades son: organización formal, privada (independiente de las Administraciones y sujeta a derecho privado), imposibilidad de distribución de beneficios, gestionadas autónomamente y con participación de voluntariado. Así, el tercer sector estaría formado por: entidades de carácter voluntario (surgidas de la libre iniciativa ciudadana), organizadas y dirigidas de manera autónoma, con el objeto de conseguir un incremento de los niveles de calidad de vida, a través de la intervención en la política social y sin fines lucrativos.

En el contexto de la emergencia del tercer sector en la prestación directa de servicios públicos, desearía destacar el olvido que se ha producido respecto de las redes primarias informales o comunitarias (familia, grupos fraternales o amistosos, agrupaciones vecinales). Se trata de un sector que proporciona elementos clave para la detección de las carencias personales y comunitarias, así como de estrategias psicosociales y afectivas de resolución de las mismas. El pluralismo del bienestar, al que antes aludíamos, configura una oferta mixta de bienestar social, que en ocasiones ha hecho invisible al sector informal o de redes primarias. En la actualidad, observamos un cambio de tendencia en este sentido mediante la incorporación de la familia y las redes comunitarias en las políticas sociales; muestra de ello es el Plan Nacional de Acción Social para la Inclusión Social de España 2001-2003, que los considera soportes fundamentales para situaciones de riesgo o exclusión social.

Los cambios sociales enunciados y la nueva configuración relacional de los sectores de la sociedad demandan nuevos espacios y servicios, orientados a cubrir las necesidades como ciudadanos, con capacidad de tomar decisiones e intervenir en su entorno próximo, colaborando en su transformación. Se hace preciso un nuevo modelo que permita romper los clichés de clientelismo y asistencialismo que han generado personas dependientes de los sistemas de protección social, generando modelos no burocráticos en el acceso, uso y disfrute de los recursos y

dirige la actividad de la entidad y otra la beneficiaria o colectivo que obtiene explícita o implícitamente el beneficio de la organización. Así distingue tres tipos de entidades: de beneficio mutuo o introvertidas, de interés público o extrovertidas y de interés o proyección mixta. Salomón y Antheier (1993) realizan la clasificación internacional de entidades no lucrativas (ICNPO), fundamentada a partir del tipo de actividad económica que realizan. De esta forma se clasifican las entidades no lucrativas en doce grandes grupos de actividad: cultura y ocio, educación e investigación, salud, servicios sociales, medio ambiente, desarrollo y vivienda, servicios legales y políticos, promoción del voluntariado, actividades internacionales, actividades religiosas, asociaciones profesionales y sindicales y no clasificados (Álvarez de Mon Pan de Soraluce (Dir.) y otros, op.c.. Esta clasificación presenta entre sus ventajas la riqueza asociativa que contempla, permitiendo identificar e integrar el amplio abanico y criterios de entidades no lucrativas existentes y es utilizada por múltiples autores (Ruiz, 2001). 
fundamentalmente en un proceso de toma de decisiones que aglutine la máxima audición e integración de actores y organizaciones En este nuevo contexto emergen con fuerza las acciones e iniciativas sociales, que pueden jugar un papel importante en su contribución.

\section{APORTACIONES DEL TERCER SECTOR AL TRABAJO SO- CIAL COMUNITARIO}

El tercer sector lo conforman un conjunto heterogéneo de entidades no lucrativas, las cuales pasan a desempeñar un papel crucial en el tránsito a una sociedad civil, no sólo en la atención integrada de colectivos en dificultad social, sino como organizaciones generadoras de riqueza y empleo en sí mismas. La importancia de este sector para el Trabajo Social Comunitario en el ámbito local se encuentra determinada por el volumen de recursos económicos, materiales y humanos que gestionan cada vez con mayor intensidad; así como por el papel de participación y acción colectiva. Las principales contribuciones de la iniciativa social al Trabajo Social Comunitario son las siguientes:

En primer lugar, los valores y principios sobre los que se rigen dichas entidades y su intrínseca relación con la acción colectiva que sustenta el Trabajo Social Comunitario, concretamente la cooperación, la solidaridad social, la participación asociativa y ciudadana y la ayuda mutua.

En segundo lugar, en razón de su potencialidad humana y diversidad/pluralidad asociativa. En este sentido cabe recordar que los estudios realizados con respecto al tercer sector por diferentes organismos públicos y privados, como, por ejemplo, el IMSERSO, BBV (Ruiz, 2000), CIS, IESE, Plataforma para la Promoción del Voluntariado (Medina, 1999), Fundación Tomillo, entre otros, nos indican el aumento de personas y entidades voluntarias. Así, respecto al primer aspecto, como nos indica Ruiz (2001), el número de voluntarios en sentido amplio se encuentra alrededor de tres millones de personas. En relación a la distribución desagregada por subsectores ICNPO, los servicios sociales, la salud y el medio ambiente, aparecen por este orden como los ámbitos que mayor dedicación se les presta por parte de los voluntarios. Así, la incorporación a la acción voluntaria y a las entidades voluntarias son aspectos más atractivos y valorados que los partidos políticos (Funes, 1997). Respecto a las entidades voluntarias, son once mil entidades las que se encuentran registradas en el Directorio de ONG (Ministerio de Trabajo y Asuntos Sociales, 2001c).

La diversidad y pluralidad asociativa, orientada a diferentes secto- 
res de población y ámbitos de actuación es muy notable: personas mayores, personas con minusvalía, jóvenes, drogodependencia, personas afectadas por el SIDA, mujeres, infancia y familia, inmigrantes, refugiados, desplazados, reclusas y exreclusas, pueblo gitano, programas integrales, entidades de promoción del voluntariado, sin techo, etc. Por último, resaltar la importante aportación de las ONG al PIB, siendo alrededor del $0.58 \%$ (Ministerio de Trabajo y Asuntos Sociales, 2001 b), lo que supone un gasto total cercano a los cuatrocientos cincuenta mil millones de pesetas, es decir alrededor de 11.000 pesetas por habitante al año.

En tercer lugar, por su carácter innovador. Resaltar su aportación respecto al empleo generado, como nuevo "yacimiento de empleo" (Chacón, 1998; Martínez Martín y González, 2001), en sentido cuantitativo y cualitativo. En referencia a la primera dimensión, el empleo remunerado generado a jornada completa en las ONG de acción social se cifra aproximadamente en 80.000 empleos, es decir, un $0.98 \%$, del empleo del sector servicios (Ministerio de Trabajo y Asuntos Sociales, 2001b). Según Ruiz (op.c.), el empleo remunerado equivalente del sector no lucrativo asciende al $4.10 \%$ del empleo equivalente total.. En referencia a la segunda dimensión, destacar las características de las personas que emplean y las estructuras de inserción laboral que emergen en su seno, convirtiéndose en importantes elementos de las nuevas políticas activas de empleo. En este sentido nos referimos a las empresas de inserción, entendidas, conforme a la FEEDEI (2000), como estructuras productivas de bienes o servicios con personalidad jurídica, cuyo fin es la incorporación al mercado laboral normalizado de colectivos en situación de desventaja social o exclusión, que llevan a cabo un proyecto personal de inserción mediante un proceso de aprendizaje adecuado que contempla la consecución de habilidades sociales, laborales, formación básica, cualificación laboral y conocimientos de mercado, que les permitan mejorar sus condiciones de empleabilidad (Laparra y Aguilar, 2001: 47). Así las entidades no lucrativas son un yacimiento de empleo como organización y al mismo tiempo por los centros y programas sociales, sanitarios y de formación-empleo que desarrollan.

La innovación no sólo queda en ser promotores de creación en su seno de iniciativas de inserción laboral (empresas solidarias y de inserción social, centros especiales de empleo, etc.), sino por un conjunto de "buenas prácticas" en la prevención, tratamiento e inserción social de colectivos con especiales dificultades (diseño de itinerarios de reinserción social de personas exreclusas, medidas personalizadas de acompañamiento para la incorporación laboral, realojamientos en viviendas normalizadas, ejecución de medidas judiciales para jóvenes infractores en medio abierto, programas integrales dirigidos a poblaciones rurales, ac- 
tuaciones a favor de personas drogodependientes, comunidades gitanas, etc.)

En cuarto lugar, destacaría su cercanía a la problemática social, permitiéndoles una interacción fluida con las redes personales y comunitarias de las personas y de los grupos existentes en el entorno social próximo. Son agentes favorecedores de la comunicación y acción entre sectores e instituciones de un territorio (intermediarios), con capacidad para canalizar las preocupaciones ciudadanas. Cabe recordar que muchas entidades se constituyen por los mismos afectados, siendo soportes, en sí mismas, para la estabilidad emocional y psicosocial de personas y grupos concretos.

En quinto lugar, sus estructuras organizacionales flexibles y abiertas ofrecen enormes oportunidades para afrontar las problemáticas y prestar servicios adecuados a ellas.

En sexto lugar, destacar su capacidad de integrarse en redes transnacionales y nacionales, a la vez que intervenir en lo próximo, en lo local. Las entidades de iniciativa social se agrupan en redes que les permiten influir en procesos de toma de decisiones en el ámbito internacional, nacional, regional y local.

En séptimo y último lugar, muy relacionado con el aspecto anterior, resaltar la experiencia como colaboradores de las Administraciones en la gestión e implantación de políticas y programas socio-sanitarios y en iniciativas de patrocinio privado. Hasta la década de los noventa no aparece en nuestro país una regulación específica acerca de las relaciones entre la iniciativa social y el sector público. Son las leyes autonómicas ${ }^{6}$ y nacional ${ }^{7}$ de voluntariado, así como las leyes autonómicas de Servicios Sociales de "segunda generación", las primeras que intentan normativizar estas entidades, al tiempo que diseñar los mecanismos de colaboración con las entidades públicas. Esta regulación surge desde la pluralidad de los marcos jurídicos de las distintas Comunidades y ciudades autónomas. Cabe resaltar la reciente crea-

- Por orden, la primera es de 1991 referida al Instituto Catalán del Voluntariado, en 1992 se promulga la Ley del Voluntariado Social de Aragón, en 1993 el Decreto del Voluntariado Social de Andalucía, en 1994, la Ley de Voluntariado Social de Madrid y el Decreto del Voluntariado Social de la Rioja, en 1995, se promulga la Ley de Voluntariado Social de Castilla-La Mancha y el Decreto de Castilla y León. Es en 1998, -en 1996 se había promulgado la ley de ámbito estatal-cuando se promulgan el mayor número de leyes de voluntariado, concretamente Extremadura, Navarra, La Rioja, Canarias, Baleares, País Vasco. En el año 2000, se promulga la Ley de Voluntariado de Galicia.

7 Ley 6/1996, de 15 de enero, del Voluntariado, publicado en el BOE de 17 de enero de 1996. 
ción del Consejo Estatal de ONG de Acción Social ${ }^{8}$ y el Consejo Estatal de Voluntariado.

Después de describir las principales aportaciones de la iniciativa social para el Trabajo Social Comunitario, es necesario realizar una reflexión crítica en torno al proceso de estructuración e interacción social e institucional de estas entidades. Las instituciones europeas y los gobiernos nacional, autonómico y local inician a partir de los 80 un proceso de respuesta a las demandas y reivindicaciones de los movimientos sociales (feministas, ecologistas y demás), a través de la implantación de políticas, organismos y programas de diverso signo (igualdad de oportunidades, etc.), desarrollados en gran parte a través del modelo de gestión indirecta (mediante subvenciones a las organizaciones sociales). Estas entidades inician un proceso de estructuración organizativa que responde a los requerimientos legales y administrativos, para prestar los servicios que requieren y demandan las Administraciones. Esta situación influye progresivamente no sólo en su proyección externa (relaciones, objetivos, actividades...), sino también en su proyección interna (las organizaciones difuminan su identidad para poder integrar nuevos miembros).

Las entidades de iniciativa social tienden así a una prestación de servicios, dejando en ocasiones, en un segundo lugar, el desarrollo de una identidad común. Se inicia la mirada al exterior. Esta situación ha conducido a la reducción de la impronta reivindicativa de las organizaciones sociales; así sus demandas se han desvitalizado, se han burocratizado, se dejan en espera de ser canalizadas a través de subvenciones $\mathrm{u}$ otros medios indirectos. Las organizaciones sociales necesitan influir en actores sociales y políticos que favorezcan su integración en las redes que determinan las agendas/prioridades políticas. Estos esfuerzos minimizan las actuaciones centradas en la construcción social de identidades colectivas. El ámbito político, una vez introduce en su agenda política asuntos demandados por los movimientos y entidades sociales, influye de manera directa en la estructura, objetivos, actividades y proyección interna de estas organizaciones. Sus discursos se canalizan por trayectorias definidas administrativamente, sus esfuerzos se dedican a crear una red de actores sociales en torno suyo que favorezcan influir en la red de asuntos políticos. Una vez incorporadas las entidades, la Administración es la que diseña los mecanismos de participación (seguimiento, control, limitaciones y fronteras...).

En la actualidad nos encontramos en un momento de disolución creciente de la política organizada y de politización de la vida organizada, 
todo ello en un contexto de especialización de las políticas y de complejización del tejido de responsabilidades de intermediarios. Los múltiples compromisos de los gobiernos propician un juego de influencias cada vez más extendido y difuso. Las políticas sociales, enmarcadas en planes plurianuales, intersectoriales e interinstitucionales, recogen las demandas, pero también las posibilidades y trayectorias administrativas que domestican su expresión; sus discursos se administran.

\section{DIMENSIONES ESTRATÉGICAS DEL TRABAJO SOCIAL COMUNITARIO}

Del análisis de las experiencias de intervención comunitaria en el ámbito local podemos destacar marcos reales que permitan visualizar las dimensiones estratégicas que son necesarias emprender para la consecución de un Trabajo Social Comunitario eficaz. Entre otros, cabe destacar los siguientes déficits:

- Insuficiente coordinación de los programas y actuaciones de los distintos sistemas e instituciones de protección social de una misma localidad o zona.

- Solapamiento de actuaciones de profesionales, asociaciones, grupos y personas y, por tanto, una reducción de la eficacia de todas ellas.

- La ruptura del ritmo natural de los procesos de intervención al encontrarse en ocasiones sujetos a procedimientos de acceso y obtención efectiva de subvenciones públicas.

- Falta de reconocimiento y apoyo de acciones voluntarias personales, familiares o de grupos no constituidos formalmente.

- Escasos o insuficientes mecanismos de participación ciudadana en los procesos de toma de decisiones en el ámbito local, a la vez que una reducida motivación y participación ciudadana en las actuaciones comunitarias, especialmente en aquellas cuestiones que consideran no les afecta directamente.

La necesaria actuación global de la intervención comunitaria en el ámbito local requiere de una coordinación de las instituciones y grupos que intervienen en el ámbito local. Esta gestión coordinada en el contexto local debe permitir rentabilizar los recursos existentes, evitando duplicidades en la actividad de las diferentes entidades y grupos que intervienen y el consiguiente derroche de recursos y facilitar una mayor y mejor atención de la población. Así, las dimensiones estratégicas del Trabajo Social Comunitario se encuentran basadas en dos líneas de gestión y promoción. La primera, centrada en la creación y fortalecimiento de una red de relaciones inclusivas de ámbito comunitario, y la 
segunda, orientada a la promoción y organización de una participación descentralizada.

\subsection{Creación y fortalecimiento de una red de relaciones inclusivas}

Los procesos sociales anteriormente descritos, y, especialmente, el desarrollo de las comunicaciones, han conllevado una profunda transformación de las relaciones personales e institucionales en la vida comunitaria. La deslocalización del tiempo y del espacio que procuran las nuevas tecnologías facilitan la emergencia de redes personales, organizacionales y comunitarias de origen disperso y desconocido para los actores que la protagonizan (redes virtuales). En el lado opuesto, los estudios realizados (Molina, 2001; Ministerio de Trabajo y Asuntos Sociales, op.c.) muestran una reducción de la densidad media de las redes personales y la pérdida de los lazos íntimos (no persistencia en el tiempo). De esta forma se contrasta que la proximidad y cercanía dejan de ser atributos que confieran una densidad interaccional y, por consiguiente, elementos de apoyo comunitario por sí mismos.

El estudio de las organizaciones, los recursos y su marco normativo nos proporciona un conocimiento sesgado de la dinámica existente en una determinada comunidad. La comprensión de la complejidad del tejido social e interrelacional requiere de un acercamiento y de una mirada comunitaria integradora de los tres ámbitos que proporcionan la coherencia integradora que requiere el análisis e implementación de las estrategias comunitarias. Nos referimos a la identificación, análisis, intervención y evaluación multidimensional, interdisciplinar e interinstitucional de las redes sociales existentes en el ámbito comunitario de referencia (inmediato e indirecto).

En relación a la multidimensionalidad, las estrategias de análisis e intervención a nivel individual, familiar, grupal y comunitaria, se interconectan entre sí generando un sistema de apoyo comunitario intermedio entre lo formal y lo informal. Se trata de analizar y gestionar con los actores y sectores sociales, las interacciones específicas que se dan entre las personas, las familias, los grupos, las organizaciones y Administraciones.

La interdisciplinariedad facilita la comprensión integradora y el desarrollo de programas y actuaciones conjuntas de los distintos profesionales que intervenienen de forma directa e indirecta en el ámbito comunitario.

Por último, la dimensión interinstitucional se refiere a la necesidad de integrar políticas y estrategias de análisis e intervención de los servicios, centros y programas de los sistemas de protección social (sanita- 
rios, servicios sociales, educación, trabajo, vivienda), buscando los mismos y de las instituciones (públicas y privadas) de las que dependen.

Se trata de innovar y trazar líneas de conexión entre las diferentes redes existentes en el ámbito comunitario, que permitan integrar políticas y ofertas de los distintos sistemas de protección social, coordinar e integrar las acciones profesionales de un mismo equipo y de los pertenecientes a otros sistemas e instituciones. Supone incorporar a las personas implicadas (profesionales, familia, personas de apoyo, voluntarios, líderes comunitarios, representantes de organizaciones) en el análisis, proceso de toma de decisiones, intervención y evaluación de las actuaciones; así como a las entidades públicas, organizaciones comunitarias y empresariales en la resolución de las problemáticas que les afectan.

Así, el Trabajo Social Comunitario se caracteriza, entre otros aspectos, en su intermediación en las redes sociales, en el complejo tejido interaccional de una comunidad, en las capacidades y habilidades que facilitan la conexión e interacción positiva entre personas y personas, personas y familias, personas y grupos, grupos y grupos, entidades y comunidad, etc. Son, por tanto, las relaciones y sus efectos el aspecto a enfatizar en la aproximación, análisis e intervención en el ámbito comunitario.

Por lo tanto, identificar y analizar las redes sociales existentes (profesionales, institucionales, personales y comunitarias) es el aspecto preliminar para ayudar a ampliarlas, fortalecerlas, resolver conflictos y colaborar con y entre ellas. La dinámica de las relaciones que emanan de ellas y el patrón de sus interacciones (pautas de disposición a colaborar y significado de las relaciones) permite explicar los aspectos conductuales, discursivos y relacionales de los actores y organizaciones implicadas. El análisis de las interacciones interorganizacionales o externas y las intraorganizaciones o internas (en el seno de la misma organización) permite detectar sectores, colectivos de población y situaciones de necesidad que disponen de estructuras y redes de apoyo (infancia, personas mayores, mujeres con cargas familiares, etc.) y aquéllos que no se encuentran incorporados a ninguna estructura y red, nivel de integración existente entre los diferentes sistemas, instituciones y organizaciones de una localidad, grado de coordinación de la red de profesionales que actúan en un mismo ámbito comunitario, programas y acciones que se implementan en una determinada comunidad, adecuación de las acciones comunitarias a los grupos y organizaciones existentes, tipos de apoyo existente y potencial entre las organizaciones, percepción valorativa de las organizaciones respecto de la red de apoyo social existente (evaluación entre apoyo social recibido y percibido). 
Como observamos, el análisis de las redes de relaciones formales e informales existentes en una determinada comunidad proporcionará elementos estratégicos de intervención, basados en el fortalecimiento de las redes sociales existentes, la potenciación de los recursos internos de las personas, grupos y entidades, con la intención de ayudarles a fortalecer sus capacidades y habilidades para favorecer y mejorar la interacción social, la generación de redes flexibles que permitan la integración y cooperación interinstitucional y profesional y la adhesión de nuevos actores y organizaciones. De ahí que el Trabajo Social Comunitario se caracterice por su capacidad en analizar y gestionar redes y, por tanto, por su estrecha vinculación con la iniciativa social.

En este sentido es de enorme interés destacar las aportaciones que desde el Trabajo Social Comunitario podemos ofrecer a las entidades de iniciativa social para mejorar su proyección interna y externa, mediante el desarrollo de capacidades y habilidades que les permitan una adecuada jerarquización de problemáticas, el diseño y presentación de programas y proyectos a diferentes entidades públicas y privadas, la implantación de actuaciones y el seguimiento y la evaluación de las mismas, la mejora de las habilidades de interacción con el entorno social e institucional, ofrecerles estrategias, técnicas y habilidades que les permitan gestionar la participación y los recursos humanos en el seno de su organización, apoyar a las personas que desarrollan tareas de responsabilidad en las organizaciones para mantener comportamientos y actitudes adecuadas a la complejidad de las situaciones con las que se encuentran, innovar en la captación de fondos como mecanismo de reducir la dependencia del sector público, lo que implica acciones orientadas a una gestión financiera transparente. Se trata de apoyarles para que adquieran las capacidades y habilidades necesarias para saber trabajar en red (Pastor, 2001), lo que supone confiar en los otros, sustituir la competencia por la cooperación, aprender de los demás, negociar, adquirir competencias sociales, todo ello sin perder el compromiso social que promovió su origen y evolución.

\subsection{Promoción y organización de una participación descentrali- zada.}

La participación, en el Trabajo Social Comunitario, es un mecanismo que debe permitir ofrecer y obtener información, captar sugerencias y alternativas, discutir sobre opciones, gestionar centros, programas y servicios; pero sobre todo es un proceso social protagonizado por los actores sociales y orientado a la toma de decisiones. Es la consideración de proceso y no de producto o resultado de acciones predeterminadas lo que marca un estilo y nivel de participación de calidad cer- 
cana a la verdadera toma de decisiones. Se trata de una relación dialéctica, recíproca y bidireccional que permita una influencia mixta entre los distintos sectores de nuestra sociedad. Así no es sólo la Administración la que influye en la cantidad, naturaleza, fines y funcionamiento de las entidades y grupos, sino que éstos también influirán en el diseño de las políticas sociales. La participación se convierte así en un mecanismo de permeabilidad social.

Es necesario que la participación se aleje de mecanismos estandarizados, extrapolados sin un análisis y adaptación a la realidad concreta a la que pretende servir. Cada lugar y momento tiene su identidad y requiere una gestión de la participación acorde a ella. De esta forma, los mecanismos de participación se deberán adaptar al medio, a las personas y grupos que allí conviven, y no viceversa.

El concepto y la gestión de los mecanismos de participación están, en ocasiones, estructurados desde la dependencia del que la impulsa. La gestión burocrática de la participación se refleja posteriormente en su implementación y resultados. La reglamentación como fin de la consecución de la participación constituye el mayor determinismo de la acción colectiva. Así los mecanismos diseñados para fomentar la participación ciudadana se convierten en instrumentos que determinan y limitan la sustantividad de la participación colectiva. De esta forma, en ocasiones, las entidades y mecanismos diseñados para la participación, son en realidad instrumentos de desmovilización colectiva.

La gestión e implementación de estrategias de Trabajo Social Comunitario se basan en la innovación de mecanismos de participación complementarios que permitan la integración en el proceso a la red de relaciones institucionales o formales e informales existentes, favoreciendo la inclusión de personas, grupos, entidades y discursos. Para ello, en la intervención comunitaria en el ámbito local, es preciso seguir dos líneas básicas de promoción y organización de la participación: la primera, centrada en la construcción de diversos canales de participación, favoreciendo la máxima incorporación al proceso de personas, grupos y entidades; y la segunda, estableciendo "caminos" de interrelación entre los distintos mecanismos de participación creados, al objeto de aunar, enriquecer e integrar discursos, mejorar el análisis de la realidad y focalizar en cada espacio y tiempo la intervención que realmente se precisa.

Cabe destacar, en cuanto a prácticas de participación local, la importancia de la implantación de los núcleos de intervención participativa aplicados a lo social en el ámbito de lo social, la creación de centros de interés (Alberich,1999) y las redes estratégicas de desarrollo local (estructura de participación contemplada en la iniciativa comunitaria 


\section{EQUAL).}

Por tanto, el Trabajo Social Comunitario se enfrenta al reto de implementar modelos de gestión caracterizados por la integración de los sectores implicados, que rompa esquematismos y promueva estímulos de cambio y participación social efectiva, siendo necesaria la creación de fórmulas, o iniciar un proceso de modificación de las existentes que permitan la máxima representatividad social, especialmente de los colectivos con menor representación. Supone el fomento de mecanismos de participación generados desde la óptica de la diversidad y la complementariedad.

\section{CONCLUSIONES}

El Trabajo Social Comunitario en el ámbito local camina hacia un modelo de gestión, implementación y financiación basado en el paternariado local, es decir, en la colaboración y concurrencia de las Administraciones públicas, privadas (lucrativas y no lucrativas) y los ciudadanos con fórmulas flexibles y adaptadas que permitan superar la reglamentación burocrática de la participación ciudadana, con la intención de incorporar el máximo de iniciativas locales en el análisis, planificación y evaluación.

Las iniciativas sociales proporcionan marcos organizacionales dinámicos capaces de apoyar, contribuir y hacer efectiva esta participación. La multidimensionalidad del Trabajo Social Comunitario precisa incorporar los procesos de intervención en, para y con la comunidad en el conjunto de servicios y programas que se gestionan desde el ámbito local. Se trata de enfatizar la proximidad en la detección de carencias, la focalización de las actuaciones y la participación ciudadana en el proceso.

Las organizaciones de iniciativa social y el Trabajo Social Comunitario están llamados a entenderse, a caminar juntos en los procesos de promoción social con las comunidades locales.

\section{BIBLIOGRAFÍA}

ALBERICH NISTAL, T.: "Modelos de gestión en la iniciativa social sin ánimo de lucro" en I Seminario Nacional de Iniciativa Social sin ánimo de lucro en los Servicios Sociales Municipales. Cartagena. Mayo. 1999.

ALGUACIL GÓMEZ, J.:"Ciudad, ciudadanía y democracia urbana", en Revista de Documentación Social, núm.: 119, abril-junio. Cáritas. Madrid, 2000, 
págs.: 157-177.

ASCOLI, U.: "Estado de Bienestar y Acción Voluntaria", en Revista Española de Investigaciones Sociológicas, núm. 38. Centro de Investigaciones Sociológicas. Madrid, 1987, págs. 119 -162.

CAMACHO GUITIÉRREZ, J, y TRABADA CRENDE, E.: "La infraclase urbana: algunos perfiles de la exclusión social", en Revista de Documentación Social, núm.: 119, abril-junio. Cáritas. Madrid, 2000, págs.: 213-238.

CASADO, D.: Las organizaciones sociovoluntarias. Organizaciones voluntarias e intervención social. Edit. Acebo. Madrid. 1989

CASTELLS, M.: "El futuro del Estado de Bienestar en la Sociedad Informacional" en S. GINER y S. SARASA (eds.) Buen gobierno y política social. Ariel. Madrid. 1997, págs.. 173-189.

CASTEL, R.: La metamorfosis de la cuestión social. Una crónica del asalariado. Paidós. Barcelona. 1997.

CHACÓN RODRÍGUEZ, L.: Los yacimientos de empleo en España. Potencial de crecimiento y desarrollo futuro. Ministerio de Trabajo y Seguridad Social. Madrid. 1998.

FANTOVA AZCOAGA, F.: La gestión de organizaciones no lucrativas. Herramientas para la intervención social. Colección Intervención Social. Editorial CCS. Madrid. 2001.

FUNDACIÓN TOMILLO: El empleo de la ONGs de acción social. Madrid. 2000.

FUNES RIVAS, M. J.: "Evolución y tendencias de las asociaciones voluntarias en España: las Organizaciones No Gubernamentales como nuevo fenómeno en el panorama asociativo", en F. Tezanos, J ; Montero, J. M.; y Díaz, J. A. (eds.): Tendencias de futuro en la sociedad española. Primer foro sobre tendencias sociales. Edit. Sistema. Fundación Sistema. Colección de Ciencias Sociales, Madrid, 1997.; págs. 511-531.

GARCÍA CAMPA, S.: "La participación del voluntariado en las decisiones públicas: el Consejo de Voluntariado", en Revista del Ministerio de Trabajo y Asuntos Sociales, núm.: 30. Madrid, 2001, págs. 93-110.

GARCÍA ROCA, X.: "El voluntariado en la sociedad de Bienestar" en Revista de Documentación Social, núm.: 122, enero-marzo. Cáritas. Madrid, 2001, págs.: 15-40.

GAITÁN, L.: "Nuevos ámbitos para la intervención social"en PALLARÉS, J., PELEGRINN, X y AMEZAGA, J. (Coord.) Yacimientos profesionales para el Trabajo Social. Nuevas perspectivas de intervención. Colección Trabajo Social Hoy. Edit. Mira. Zaragoza, 2001, págs.: 17-33.

GIDDENS, A: Más allá de la izquierda y de la derecha. Edit. Cátedra. Madrid. 1996. 
La tercera vía. La renovación de la Socialdemocracia. Edit. Taurus. Madrid. 1999.

Un mundo desbocado. Los efectos de la globalización en nuestras vidas Edit. Taurus. Madrid. 2000.

GUTIÉRREZ RESA, A.: Acción Social no Gubernamental. Edit. Tirant lo blanch. Valencia. 1997.

"Los rostros de la solidaridad". Conferencia presentada en el $1^{\circ}$ Congreso de Voluntariado. Murcia. Noviembre. 2001.

HERNÁNDEZ AJA, A.:"Barrios y equipamientos públicos, esencia del proyecto democrático de la ciudad", en Revista de Documentación Social, núm.: 119, abril-junio. Cáritas. Madrid, 2000, págs.: 79-113.

HERRERA GÓMEZ, M.: El Tercer Sector en los sistemas de Bienestar Social. Edit. Tirant lo blanch. Valencia. 1998.

HOBSBAW, E: Historia del siglo XX. Crítica. Barcelona. 1995.

LAPARRA NAVARRO, M. y AGUILAR, M.: "Las empresas de inserción: algunas reflexiones para seguir avanzando" en PALLARÉS, J., PELEGRÍN, X y AMEZAGA, J. (Coord.) Yacimientos profesionales para el Trabajo Social. Nuevas perspectivas de intervención. Colección Trabajo Social Hoy. Edit. Mira. Zaragoza, 2.001, págs.: 35 a 63.

LAPARRA NAVARRO, M. y CORERA OROZ, C.: "Los Servicios Sociales de Atención Primaria ante la Desigualdad y los Nuevos Procesos de Exclusión". Ponencia presentada en el Congreso de Servicios Sociales de Atención Primaria. Murcia. Noviembre 2001.

MARTÍNEZ MARTÍN, Ma. I. y GONZÁLEZ GAGO, E. "Coexistencia de voluntariado y trabajo asalariado en las ONG de Acción Social" en Revista de Documentación Social, núm.: 122, enero-marzo. Cáritas. Madrid, 2001, págs.: 85-104.

MARTÍNEZ ROMÁN, M. A.: "Política Social, pobreza y exclusión social” en ALEMÁN BRACHO, C. Y GARCÉS FERRER, J. (Coord.) Política Social. Edit. McGraw-Hill. Madrid 1998. págs: 479-504.

MEDINA TORNERO, M.E. (Dir.): Perfil del voluntariado en la Comunidad Autónoma de Murcia. Plataforma para la Promoción del Voluntariado en la Región de Murcia. 1999.

"El voluntariado en Murcia: una visión crítica y estratégica para el futuro". Conferencia presentada en el $1^{\circ}$ Congreso de Voluntariado. Murcia. Noviembre. 2001.

MINISTERIO DE TRABAJO Y ASUNTOS SOCIALES: Las personas mayores en España. Informe 2000. Madrid. 2001a.

Plan Nacional de Acción para la Inclusión Social del Reino de España. Junio 2001 - Julio 2003. Consejo de Ministros del 25 de mayo de 2001. 
www.mtas.es. Madrid. 2001b.

II Plan Estatal de Voluntariado, 2.001-2.004. Consejo de Ministro del 22 de junio de 2001. www.mtas.es. Madrid. 2001c.

MOLINA, J.L.: El análisis de redes sociales. Una introducción. Editorial Bellaterra. Barcelona. 2001.

MONTORO, R.: "La reforma del Estado de Bienestar: derechos, deberes e igualdad de oportunidades", en Revista Española de Investigaciones Sociológicas, núm. 79, Centro de Investigaciones Sociológicas.Madrid. 1997, págs:9-41.

"Fundamentos teóricos de la Política Social" en ALEMÁN BRACHO, C. Y GARCÉS FERRER, J. (Coords.) Política Social. Edit. McGraw-Hill. Madrid 1998, págs.: 33-50.

MORA ROSADO, S.: "Movimientos sociales y voluntariado. Hacia un nuevo marco de complicidades", en Revista de Documentación Social, núm.: 122, enero-marzo. Cáritas. Madrid, 2001, págs.: 105-124.

NAREDO, J. M.: "Ciudades y crisis de civilización", en Revista de Documentación Social, núm.: 119, abril-junio. Cáritas. Madrid, 2000, págs.: 13-38.

O'CONNOR, J.: La crisis fiscal del Estado. Barcelona. 1981. Edit. Península.

PASTOR SELLER, E.:"La iniciativa social y los nuevos procesos de intervención comunitaria". Comunicación presentada en el $1^{\circ}$ Congreso de Voluntariado. Murcia. Noviembre. 2001.

PORRAS MUÑOZ, M.:"La gestión pública de los Servicios Sociales de Atención Primaria. Situación actual y perspectivas".Ponencia presentada en el Congreso de Servicios Sociales de Atención Primaria. Murcia. Noviembre 2001 .

RIMBAU I ANDREA, C.:"Nuevos planteamientos en los servicios sociales" en Revista de Servicios Sociales y Política Social, núm.: 54, julio. Consejo General de Colegios Oficiales de Diplomados en Trabajo Social. Madrid. 2001, págs.: 9-25.

RODRÍGUEZ CABRERO, G.: Las entidades voluntarias en España, Institucionalización, estructura económica y desarrollo. Ministerio de Asuntos Sociales. Madrid. 1996.

RUIZ OLABUENAGA, J. I. (Dir.): El sector no lucrativo en España. Bilbao. Fundación BBV. 2000.

"El voluntariado en España" " en Revista de Documentación Social, núm.: 122, enero-marzo. Cáritas. Madrid, 2.001, págs.: 67-83.

SALINAS RAMOS, F.: "El voluntariado y las organizaciones no lucrativas ante el nuevo milenio". Conferencia presentada en el $1^{\circ}$ Congreso de Voluntariado. Murcia. Noviembre. 2001.

SARASA URBIOLA, S.: "El Modelo Social Español. Análisis comparado", 
Ponencia presentada en el Congreso de Servicios Sociales de Atención Primaria. Murcia. Noviembre 2001.

URRUTIA V. Y AREÍLZA, G.:"El poder local y las nuevas políticas urbanas", en Revista de Documentación Social, núm.: 119, abril-junio. Cáritas. Madrid, 2000, págs.: 239-257.

WENGER DE LA TORRE, D.: "Estado de Bienestar, políticas económicas actuales y vías alternativas", en ALEMÁN BRACHO, C. Y GARCÉS FERRER, J.(Coords.) Política Social. Edit. McGraw-Hill. Madrid 1998. Págs.: 79-94. 



\title{
MEDIACIÓN SOCIAL CON GITANOS EN VILLENA (ALICANTE)'
}

\author{
JOSÉ CABANES HERNÁNDEZ
}

Sociólogo. Servicios Sociales del Ayuntamiento de Villena (Alicante)

\section{DESCRIPCIÓN DE LA UBICACIÓN DE LAS FAMILIAS GI- TANAS DE VILLENA}

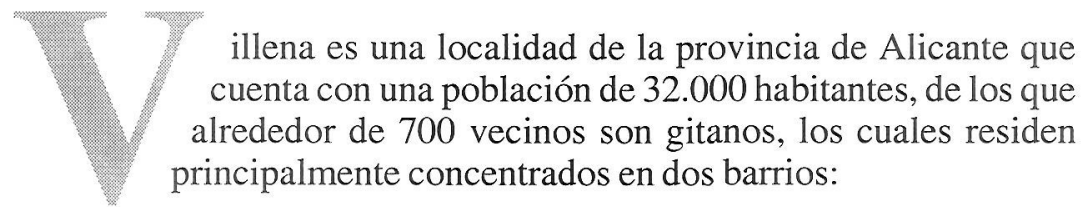

- Barrio del Rabal: es el casco histórico del municipio, donde se encuentra situado el castillo, en cuya parte alta existía un gran número de cuevas excavadas en el monte donde residían muchas familias gitanas, aunque no sólo gitanas. Actualmente nadie vive en cuevas propiamente dichas, aunque muchas de las casas tienen alguna habitación excavada en la roca. Muchas de las viviendas se encuentran deterioradas, y no todas reúnen unas mínimas condiciones de habitabilidad. Las relaciones vecinales son bastante tensas, tanto interétnicas como intraétnicas, en lo cual influye tanto el alto índice de heroinómanos residentes en el barrio, como el hecho de que se concentre allí todo el tráfico de heroína del municipio. La situación laboral es precaria, con empleos temporales y poco cualificados, lo que supone una economía de subsistencia. Todos los niños de este barrio se encuentran escolarizados en el C.P. Ruperto Chapí (un colegio donde el $12 \%$ de los alumnos son gitanos).

- Barrio San Francisco: se construyó en los años 60 en el extrarradio del municipio (se encuentra a $1,5 \mathrm{~km}$. del mismo, sin que exista continuo urbano) para reubicar a la población que vivía en las cuevas. En el barrio hay viviendas en altura y casas unifamiliares, siendo alrededor del $50 \%$ de los vecinos gitanos. Las relaciones

Ponencia en el IV SEMINARIO DE FORMACIÓN: MEDIACIÓN Y EDUCACIÓN INTERCULTURAL, organizado por la Federación de Asociaciones Gitanas Extremeñas y el Instituto Municipal de Servicios Sociales del Ayuntamiento de Badajoz. Badajoz, 24 al 27 de julio de 2000. 
interétnicas no son malas. Existen problemas de desempleo y trabajos precarios, así como mucha economía sumergida del sector zapatero y juguetero. La mayoría de los niños gitanos están escolarizados en el C.P. Sta. Teresa, situado en dicho barrio, si bien la mayoría de los niños no gitanos están escolarizados en otros centros escolares del municipio (el C.P. Sta. Teresa cuenta con un $80 \%$ de alumnos gitanos).

\section{LA PLAZA DE MONITOR PARA LA POBLACIÓN GITANA}

Mi trabajo depende del departamento de Servicios Sociales, con el que me coordino, pero que no se encuentra situado físicamente dentro de ninguno de los dos barrios con población gitana, por lo que sólo estoy en Servicios Sociales las últimas horas de la mañana y en las reuniones de equipo.

Cuando yo comencé a trabajar como monitor hace dos años y medio, el trabajo que tenía que desarrollar no estaba diseñado, dado que yo era la tercera persona que pasaba por esa plaza en dos años, y cada una de las dos anteriores había hecho cosas distintas. Me planteé dos cosas, lo que quería hacer y lo que no estaba dispuesto a hacer:

- Lo que quería hacer: centrar mi trabajo en el aspecto escolar, rechazando por tanto el convertirme en un cajón desastre que llevase temas de vivienda, empleo, etc.

- Lo que no estaba dispuesto: a ser el "informante clave" de las trabajadoras sociales sobre asuntos de familias gitanas (lo que no quiere decir que no me coordine con los Servicios Sociales).

No quería tener nada que ver en el tema de ayudas económicas a familias. En el sentido que las familias no me tomasen como la puerta de entrada para obtener ayudas de las trabajadoras sociales, ya que en ese caso se establece una relación viciada. De esta forma, las familias tienen claro que aunque trabajo para los Servicios Sociales, no depende de mí el que les den una ayuda económica, o les cedan una vivienda, sino que "el Pepe" sólo lleva el tema de "los nenes" (colegio, actividades extraescolares, etc.). Eso hace que la relación sea más sincera, que no exista esa relación de poder entre quien te puede dar algo, y quien ha de conseguirlo.

\section{OBJETIVO DEL TRABAJO}

El objetivo general que yo me marco es conseguir la escolari- 
zación "normalizada" de todos los alumnos gitanos, entendiendo por normalizada el que tengan las mismas probabilidades de éxito o fracaso escolar que el resto de compañeros.

Evidentemente, es un objetivo a muy largo plazo, pero tiene una diferencia fundamental frente al típico objetivo del absentismo escolar, que tanto preocupa a la Administración. Es que no basta con que los niños vayan al colegio, sino que además hay que trabajar para que esa escolaridad sea fructífera. Eso supone que no sólo hay que trabajar con las familias de los niños absentistas, sino también con las de los que acuden con normalidad, con los profesores de estos niños, y con cualquier persona o institución que pueda favorecer dicho éxito escolar.

\section{LÍNEAS DE TRABAJO A PARTIR DE ESE OBJETIVO}

Para potenciar esa "escolarización normalizada", yo me he marcado distintos objetivos, o líneas de trabajo, que me sirven para no perder el norte en el día a día, e ir consiguiendo pequeños logros que vayan en esa dirección. Estas líneas son:

1. Conseguir la escolarización temprana, a ser posible desde la guardería, pero en cualquier caso, desde la educación infantil de 3 años. Aunque en infantil la enseñanza no es obligatoria, es muy importante trabajar con las familias y las maestras el absentismo en esos primeros años, pues está demostrado que los niños que faltan mucho a estas edades tienen muchas más posibilidades de fracaso escolar.

2. Reducir el absentismo escolar. Digo reducir porque considero que es imposible su erradicación, dado que la situación de precariedad económica de muchas familias hace inevitable cierto tipo de faltas, al tiempo que la visión de las familias gitanas con respecto al absentismo no es la misma que la de la institución escolar. En este sentido, me comentaba una madre gitana hace un par de veranos: "Pepico, tanto venir a verme porque la nena faltaba algunos días, y ahora los payos qué, todo el verano sin dar clase".

3. Retrasar el abandono escolar. Intentar que los niños y niñas gitanas dejen la escuela lo más tarde posible. Hasta hace pocos años, era normal que la mayoría de los menores gitanos dejasen la escuela entre $5^{\circ}$ y $6^{\circ}$ de primaria, pero afortunadamente eso está cambiando. En Villena el primer ciclo de la ESO ( $1^{\circ}$ y $2^{\circ}$ de ESO ) sigue impartiéndose en los colegios de primaria, y en $3^{\circ}$ de ESO pasan al Instituto. Mi objetivo, por ahora, es que nadie deje el colegio antes de terminar $2^{\circ}$ de ESO y que, como mínimo, haga la matrícula en el 
Instituto. Esto puede parecer un objetivo muy alto o muy bajo, según se mire:

- Puede parecer alto porque en $1^{\circ}$ y $2^{\circ}$ de ESO algunos alumnos gitanos tienen un desfase escolar muy grande y apenas hacen ya nada en el colegio y además algunos colegios prefieren que dejen de ir para que no les den problemas, y en ocasiones las familias los necesitan para que les ayuden laboralmente.

- Y puede parecer bajo porque la Ley marca como obligatoria la escolarización hasta los 16 años. Y este objetivo supone dar por hecho que pueden dejar el colegio antes.

Desde mi punto de vista, creo que los chavales, si quieren dejar el colegio lo van a dejar por muchas leyes que hayan, y si el listón está bajo es más fácil convencerlos para que aguanten uno o dos años ( $2^{\circ}$ de ESO). El que nadie lo deje antes de $2^{\circ}$ de ESO permite que los alumnos que van bien no se contagien del abandono escolar de los que tienen un desfase escolar muy fuerte, y hace que los que vienen detrás no se hagan planteamientos del tipo: "yo en $6^{\circ}$ me lo dejo, porque mi hermano también se lo dejó en $6^{\circ}$ ", sino que tengan claro que hay una edad mínima. El conseguir que todos ellos se matriculen, como mínimo, en el Instituto es una forma de forzar a que se familiaricen con el centro, y que vayan unos días, y confiar en que les resulte agradable y que aguanten allí. Creo que la tradición de gitanos en el Instituto es todavía anecdótica, y que hay que ir sentando bases para que los niños y las familias lo vean con normalidad.

4. Diversificar a los alumnos gitanos en el mayor número de colegios posible (tanto públicos como concertados). Considero que la concentración de muchos alumnos gitanos en un mismo centro conlleva la ghetización del mismo, y ello tiene una repercusión directa en el menor rendimiento académico. Problemas de la concentración:

- Los alumnos gitanos se relacionan casi exclusivamente entre gitanos, con lo que no tienen la oportunidad de conocer a otros niños, y mejorar sus relaciones sociales.

- Los alumnos payos optan por colegios donde no haya gitanos, con lo que nunca pierden el miedo a lo desconocido, y no tienen ocasión de superar sus prejuicios sobre los gitanos.

- Los profesores, si pueden, optan por colegios donde no haya muchos gitanos, con lo que los colegios con concentración de alumnos gitanos cambian mucho de profesorado, siendo en muchos casos profesores sin experiencia laboral (en el colegio Sta. Teresa de Villena, este curso puede darse el caso de que cambie el 
90\% del profesorado).

- Es más fácil convencer a los maestros para que se vuelquen en el objetivo de conseguir buenos resultados académicos de los niños gitanos cuando el número de éstos es bajo. Mientras que en lugares donde hay muchos alumnos, los profesores suelen desmoralizarse o relajarse, y marcar objetivos académicos muy bajos.

El objetivo de diversificar a los alumnos gitanos en el mayor número de colegios posible es algo que se debe favorecer, pero que necesariamente pasa por que sea la familia la que tome esa decisión. La mayoría de las familias gitanas prefieren llevar a sus hijos al colegio más cercano a su casa, pero algunas familias piden expresamente conseguir plaza en un colegio donde sus hijos vayan a aprender más, o donde no haya tantos gitanos (normalmente para evitar conflictos con otras familias), y es en esos casos donde hay que conseguir matrícula en otro colegio, cosa que no suele ser fácil.

5. Reducir el fracaso escolar. El fracaso escolar está motivado en muchos casos por el absentismo, y en ese sentido, cuanto menos absentismo haya menos fracaso escolar. Pero también se produce a la inversa, que niños que nunca han sido absentistas fracasan escolarmente, y a partir de ahí se aburren y faltan al colegio. En este aspecto influyen muchas variables, desde la motivación del alumno, la importancia que la familia dé a la escuela, las tareas escolares en casa, la motivación de los profesores, etc. Lo cierto es que muchos alumnos gitanos empiezan a quedarse descolgados en $3^{\circ} \circ 4^{\circ}$ de primaria, y que si no se puede conseguir el que hagan toda su escolaridad con buenas notas, al menos sí se debe intentar que el descuelgue sea lo más tarde posible. En este sentido, me he planteado en este último curso, que si bien tengo que trabajar con todos los niños gitanos, el prestar una mayor atención en aquéllos que potencialmente pueden obtener buenos resultados, con el fin de que no pierdan el ritmo, y al tiempo sirvan de referente para otros compañeros gitanos, y para los profesores (que no siempre es fácil hacerles ver que los niños gitanos también pueden aprobar). En cualquier caso, el concepto de fracaso escolar es muchas veces diferente entre familias y colegios, porque lo que muchos padres gitanos esperan de la escuela (que aprendan a leer, escribir, y las cuatro reglas matemáticas), suele llegar a conseguirse, con lo que cuando dejan el colegio el profesor puede pensar que ha fracasado escolarmente, y la familia todo lo contrario.

6. Fomentar la relación entre familias y colegios, con el fin de que colaboren en la marcha escolar de los niños gitanos. La escuela y las familias siguen siendo dos mundos demasiado alejados, y en 
ocasiones contrapuestos, lo que no favorece la escolarización de los niños gitanos. Muchas familias desconocen el funcionamiento del colegio, e incluso desconfían del trabajo de los maestros, y lo mismo suele pasar a la inversa, y la relación se perpetúa en el tiempo sin que nadie dé el primer paso.

7. Mejorar la formación del profesorado con respecto al conocimiento cultural del pueblo gitano, de la realidad social de éste en Villena, y de las posibles estrategias escolares para mejorar su rendimiento académico. Esto se puede hacer de dos formas:

- Cursos o seminarios específicos sobre el tema.

- La formación continua, basada en el día a día, hablando con los distintos profesores y explicándoles cuestiones puntuales.

Yo confiaba mucho en la primera opción, pero la experiencia del curso pasado, en el que organicé un seminario con ponencias muy interesantes (desde mi punto de vista, y así lo comentaron también muchos profesores), donde participaron 140 profesores, me hacía pensar que éste sería un curso mucho más fácil en el trabajo cotidiano con los maestros. Sin embargo, el resultado no ha sido tan positivo, y lo cierto es que la gente llega a los cursos con unas ideas ya adquiridas, que no se pueden cambiar con 4 ó 5 charlas. Aún así, creo que hay que aplicar las dos opciones, charlas específicas, y un trabajo cotidiano de reeducación.

En el colegio Sta. Teresa, que, como he comentado, cambia el profesorado todos los años, el director me ha pedido que el primer día que lleguen los nuevos maestros tenga una sesión con ellos para explicarles la realidad social del colegio, y acompañarles a conocer el batrio. El que se den cuenta de que eso es necesario desde un primer momento, creo que es ya un logro.

\section{V. ¿CÓMO SE TRABAJA ESTO?}

Digo cómo se trabaja, y no cómo se consigue, porque éste es un trabajo de largo plazo, donde se van cosechando pequeños éxitos y fracasos todos los días, en el que siempre se está aprendiendo y experimentando, y en el que el reto es no quemarte en los problemas diarios, sino tener un visión de largo plazo para poder valorar lo que se va consiguiendo, y al tiempo, ser capaz de transmitir esa visión optimista al resto de profesionales.

Hay que ser consciente desde un principio que los objetivos que te marcas en este trabajo no dependen exclusivamente de ti, sino que influyen otras muchas personas e instituciones y que, por tanto, tienes 
que ganarte la confianza y la colaboración de todas ellas para poder obtener resultados.

Yo lo tomo como un trabajo de comerciante, donde uno está siempre en contacto con la gente, y a cada uno ha de venderle un producto (a esto me ayuda el haber vendido en el mercado con mi padre):

- A las familias, la importancia que tiene para sus hijos el que saquen los estudios.

- A los colegios, el que son alumnos como cualquier otro, con los que se puede trabajar y obtener resultados, y que vale la pena apostar por ellos y contar con sus familias.

- A los alumnos el que ellos valen mucho, a nivel individual, y que pueden aprobar si se lo proponen, y que el colegio es mejor que estar en la calle.

Pero, para poder "vender estos productos" hay que tener en cuenta que la única arma con que se cuenta es con la credibilidad personal. El que lo respeten a uno, y que lo que esté proponiendo sea percibido como algo positivo para el interesado, ya que el monitor no tiene ninguna autoridad para imponerle nada a nadie. Uno debe de ganarse la confianza de cada uno de los sectores con los que trabaja (colegios, gabinete psicopedagógico, cada una de las familias extensas, alumnos, etc.), porque si no estableces previamente una situación de respeto mutuo, y de saber ponerte en la situación del otro, cuando quieras conseguir cosas no te van a hacer caso.

Cuando yo comencé a trabajar, me di cuenta que no podía llegar exigiendo cosas, ni a las familias, ni a los colegios. La estrategia fue el ganarme su confianza, y la forma que he utilizado es la de que antes de pedirle un favor a alguien ( $\mathrm{y}$ se puede entender por un favor, el que no saquen a la niña del colegio con 12 años), tenías que haberle hecho tu varios favores a la familia. En este sentido, y teniendo en cuenta que mi trabajo no está definido por nadie, sino que lo diseño yo, suelo plantearlo no como una obligación por el sueldo que me pagan, sino como algo que podría no hacer pero que hago porque considero que es mejor para ellos.

Así, por ejemplo, cuando ayudo a las familias a rellenar las becas escolares, se lo planteo como algo que no tengo por qué hacer si no quiero, y las familias lo agradecen. Pero de la misma forma se lo planteo también al colegio, ya que si no les ayudo yo a rellenarlas tienen una avalancha de madres para que se las rellenen en el colegio, y si algún niño se queda sin echar la beca, cuando empieza el curso el tutor tiene problemas para que la familia pueda comprar los libros. No se trata de una cuestión de "me debes un favor", pero sí de "yo te ayudo 
cuando lo necesitas".

Muchas veces el ganarte la confianza es sencillamente saber escuchar a la gente, y que vean que eres capaz de entenderlo y de ponerte en su situación. Tanto en la situación de las familias gitanas, como en la situación de los profesores. Muchas veces los maestros se sienten frustrados como profesionales por no conseguir mejores resultados con los alumnos gitanos, y te cuentan sus problemas y necesitan que los entiendas, y después ellos están más predispuestos a aceptar tus consejos en el trato con los chavales o con las familias. Y lo mismo pasa con las familias.

Por tanto hay dos cuestiones fundamentales en este trabajo:

1. Tienes que ganarte a la gente con la que trabajas, ayudándoles en aquéllo que esté en tu mano, con el fin de que cuando tú pidas cosas haya cierta obligación moral de mirar por ti.

2. No puedes quedar mal con ninguna de las partes. Por mucho que te enfades no debes cerrarte puertas, porque en este trabajo vas a tener que relacionarte antes o después con la misma gente, aunque en ocasiones puedan entrarte ganas de "mandar a paseo" a una familia, o a un profesor, etc. Y esto no es siempre fácil, porque se dan situaciones complicadas, y encuentras profesores racistas o familias que te engañan..., pero es preferible evitar el enfrentamiento y buscar otras vías de solución, a quedar mal con un director y que se dificulte el trabajo con ese colegio.

\section{ESTRATEGIAS DE MEDIACIÓN}

$1^{\circ}$. Es fundamental ganarse la confianza de los directores de los colegios.

Ellos son la puerta de entrada para poder trabajar con los tutores. En este sentido hay que tener en cuenta: cómo se suele ver, de entrada, al monitor: "el defiende gitanos". La figura del monitor se percibe como un intruso que viene a vigilar los derechos de los gitanos frente a la actividad de los profesores, y a decirle al colegio lo que tiene que hacer. Como si no fuese suficiente con la desconfianza que de por sí les suponen los alumnos gitanos.

Mi estrategia fue intentar no responder a ese prejuicio, sino ofrecerme como alguien que viene a ayudar. Y ayudar suele suponer (desde la visión del colegio) solucionar problemas de comportamiento. En este sentido la forma fue echar una mano en la mediación con algunos chavales con los que tenían problemas, de la siguiente forma: por un 
lado, hablar con cada uno de los críos (la mayoría de los niños me respetan bastante, porque yo también los respeto a ellos, y porque tenemos una relación de mucho tiempo), e intentar marcarles objetivos de comportamiento asequibles (no el que se portasen bien, sino, pedirles como un favor personal el que durante un plazo limitado de tiempo no hiciesen cosas concretas de las que se quejaban los profesores). $\mathrm{Y}$ por otro lado, concerté una entrevista entre el director y el jefe de estudios y los padres de cada uno de estos críos. La actitud del director fue: "si quieres quedamos, pero no vendrán, llevamos dos años mandándoles citaciones y no han venido nunca". Pero, como a los padres fui a su casa a pedirles personalmente que fuesen a la reunión, y además yo me ofrecía a acompañarlos; pues sí que fueron. Las entrevistas fueron un tanto frías en el primer momento, pero cuando iban hablando la relación se estrechaba, y ambas partes (dirección y padres) se daban cuenta que "el otro" también estaba preocupado por el bien del chaval. El resultado fue una disminución (temporal, evidentemente) de los problemas diarios con esos niños, y un cambio de actitud del colegio hacia mi trabajo, ya que no había reaccionado justificando el comportamiento de los niños gitanos, y además, gracias a la mediación se había mejorado la situación escolar (para los directores, la mejora de la situación escolar de los niños gitanos, suele entenderse como la mejora del comportamiento. La mejora del aprendizaje es otra categoría, más cercana a los tutores).

Actualmente, en uno de los colegios tengo llave para entrar y salir cuando quiero, y en el otro, aunque no llego a tanto, lo cierto es que la relación es muy estrecha.

\section{$2^{\circ}$. Hay que ganarse la confianza de las familias gitanas.}

Me refiero a cada una de las familias gitanas extensas que residan en el municipio. Porque no sirve de nada tener una excelente relación con una familia, si no puedes acceder a otras.

Cuando comencé a trabajar, ya conocía a muchas de las familias gitanas, pero con algunas no tenía ningún trato. Además, cuando trabajas para los Servicios Sociales, te haces más "payo", aunque seas gitano (que no es mi caso). Quiero decir, que las familias te ven con cierto recelo, un poco como el espía de las asistentas sociales. Hay que decir que a mí me valieron mucho mis amistades previas con muchas familias gitanas, y también el haber trabajado con la mayoría de los niños, con los que tenía buena relación, algo que las familias valoran. Después el trato diario, el escuchar sus problemas y saber ponerte en su lugar, sin juzgarlos, y el ir haciendo distintos favores que no están directamente relacionados con mi trabajo (gestiones de papeles, dar la cara 
en alguna empresa para conseguir algún trabajo, etc.), ha hecho que la relación sea cada vez más cercana, y ha ido rompiendo los prejuicios que sé que algunas familias tenían sobre mí, tanto por ser "payo" como por trabajar para Servicios Sociales.

A la hora de trabajar con las familias, tengo claro que no pueden haber excepciones. Por un lado, es importante ganarse el respeto de aquellos miembros de las familias extensas que tienen un mayor peso dentro de la misma (independientemente de que tengan hijos en edad escolar o no), y por otro lado, también trabajo con las dos o tres familias que se dedican al tráfico de droga, ya que los objetivos escolares para sus hijos son los mismos que para el resto de niños y niñas.

\section{3․ Ganarse la confianza y el respeto de los menores.}

Muchas veces, tanto el absentismo como el rendimiento escolar, dependen de la motivación que el niño o la niña tenga, y la posibilidad de motivarles para que apuesten por los estudios está en cierta medida condicionada por el cómo te vean a ti. El hecho de haber trabajado varios años como monitor de tiempo libre en los veranos con los niños y niñas gitanas, así como el haber sido monitor de comedor durante cinco cursos, hacía que los niños me conociesen, y existía una buena relación previa. Aún así, teniendo en cuenta que el trabajo de seguimiento escolar supone estar exigiéndoles cosas constantemente, he intentado compensarlo con actividades de ocio en fines de semana y en verano. Por ejemplo: llevarme a los niños a jugar al fútbol al polideportivo los sábados por la tarde; conseguirles entradas para el cine de la Casa de la Cultura cuando hay películas infantiles; llevármelos de excursión con la bici; ir a la piscina; etc. Estas actividades las voy condicionando en base a que se lo ganen. Por ejemplo, les digo: "el que no falte ningún día al colegio esta semana se viene el sábado al cine". Aunque en ocasiones tenga que bajar el listón con alguno para que se venga de vez en cuando.

Creo que el tener buena relación con los chavales facilita también la relación con los padres, ya que las familias valoran el trabajo que se hace con sus hijos.

\section{EL TRABAJO DÍA A DÍA}

\subsection{Protocolo municipal de absentismo escolar}

Hay que decir que el Ayuntamiento de Villena cuenta con un protocolo de absentismo, según el cual el orden de actuación en los casos de 
absentismo es el siguiente:

a) Cuando un tutor detecta que un niño falta a clase mucho (más de 5 días al mes), lo pone en conocimiento de la dirección del centro, que envía una citación a la familia recordándole que es obligatoria la asistencia, y que deben acudir al colegio para explicar la causa del absentismo, advirtiéndole que en caso de no acudir se dará parte a los Servicios Sociales.

b) En caso de que esa carta no surta efecto, se comunica a los Servicios Sociales, y éstos envían citación a la familia para que acuda a una entrevista con la trabajadora social, y explique el motivo del absentismo, recordándole en la misma su obligación como padres de responsabilizarse de que sus hijos acudan al colegio. Se le advierte que, en caso de que persista el absentismo, se hará un informe a la Comisión de Absentismo Escolar Municipal, y que ésta puede denunciar el caso a la Fiscalía de Menores para que tome las medidas oportunas.

c) Si la familia no acude a la cita, se la vuelve a citar, pero en esta segunda ocasión se envía a través de la policía municipal, que es quien la entrega en mano con acuse de recibo.

d) Si, a pesar de todo esto, el absentismo persiste, la Comisión de Absentismo decide si se tramita una denuncia ante la Fiscalía de Menores (extremo al que nunca se ha llegado).

\subsection{La recogida de faltas en los colegios}

Si bien ésta es la forma teórica de actuar, considero que es una manera demasiado rígida, y además muy lenta, pues cuando el absentismo se ha consolidado es mucho más difícil motivar al menor para que acuda a gusto al colegio. Por ello, en el caso de los menores gitanos, que son con los que yo trabajo, el sistema es el siguiente:

Cuando comencé a trabajar, lo primero que hice fue presentarme a los directores de los colegios (acompañado por la trabajadora social que tuviese mejor relación con el centro), expresarle al director mi predisposición a colaborar con ellos para mejorar la escolaridad de los alumnos gitanos (no pedirles que ellos colaborasen con mi trabajo, para que no me viesen como un intruso, aunque en la práctica la colaboración es mutua), y solicitarles si podía ir al siguiente claustro del colegio para presentarme a todos los profesores, y explicarles cómo iba a plantear mi trabajo, y ponerme a su disposición para cualquier problema que tuviesen.

A partir de ahí, un día por semana acudo a cada uno de los colegios donde hay menores gitanos. Tengo un listado por cursos de todos los 
alumnos del colegio (gitanos y no gitanos), dividido por cuadrículas mensuales de faltas (cada tutor tiene también esas faltas). Previamente, he negociado con los directores de los colegios (y no ha sido fácil), el que cada tutor anote diariamente las faltas de los alumnos, diferenciando entre mañana y tarde. Es importante saber si las faltas son de mañana o tarde, porque un niño que suele faltar por las mañanas, es muy posible que tenga problemas en casa para despertarse y por tanto la solución hay que buscarla por ese camino, mientras que si las faltas suelen ser de tarde, la solución puede pasar por una beca de comedor escolar (si es porque los padres vienen tarde del mercado, o porque se queda durmiendo después de comer).

Como las faltas las recojo semanalmente, la relación con cada tutor es muy fluida, y al tiempo que recojo las faltas pregunto cómo le ha ido la semana con los distintos alumnos gitanos. Puedo hablar unos 5 minutos de media con cada tutor, pero es un tiempo suficiente para hacerme una idea de cómo le va a los chavales, y poder detectar problemas del tipo:

- Absentismo (obvio).

- Mal comportamiento (esto es algo que agobia mucho a los profesores, y en muchos casos es la función casi exclusiva para la que te quieren).

- Problemas de falta de material.

- Carencias relacionadas con los deberes.

- Necesidad de que estudie más en casa.

- O, a veces, la grata sorpresa de decirte que va bien o ha mejorado.

Recuerdo que al principio de comenzar a trabajar, un profesor que daba clases en $4^{\circ}$ de Primaria, no me facilitaba nada el trabajo y todo lo que hacía eran comentarios derrotistas y peyorativos sobre las posibilidades de estudio de los niños gitanos. Todo esto, poniéndome como prueba a un alumno gitano que tenía, y que en todo el curso no había conseguido que trajese (aunque fuesen sin hacer) las hojas de deberes que le mandaba, ni que trabajase en el aula. Estuve hablando con la madre, y quedamos en tratar, como mínimo, que bajase todos los días la cartera, y reforzarle los dos para que hiciese algo de deberes. En una semana el niño se acostumbró a subirse y bajarse la cartera de casa, y con parte de ayuda mía y el refuerzo de la madre comenzó a llevar los deberes hechos todos los días. A partir de ahí, en la entrevista con el tutor, éste me estuvo contando asombrado los progresos que había hecho en clase (a nivel de esfuerzo), y cambió su actitud con respecto a mi trabajo. Al mismo tiempo, los comentarios positivos sobre mi trabajo, que este profesor hizo con sus compañeros, sirvieron para mejorar 
la relación con otros profesores que en un principio eran escépticos ante la figura del monitor.

En estas entrevistas semanales, muchas veces me siento el psiquiatra de algunas maestras, porque muchas veces tienen problemas con alumnos gitanos y no entienden lo que pasa, o no saben cómo actuar, y necesitan comentarlo con alguien y que les entiendan. En este sentido, y a pesar de que muchas veces tienes que aguantar comentarios un tanto fuertes, el planteamiento que suelo tener es el de:

$1^{\circ}$ Decir que entiendo que es difícil en ocasiones, pero que está haciendo un gran trabajo.

$2^{\circ}$ Recordarles los logros que se han ido consiguiendo con los alumnos gitanos en los últimos años, y que no hay que quemarse en el día a día, sino tener una visión de largo plazo.

$3^{\text {o }}$ En algunos casos concretos, y confiando en su discreción, explicar los problemas de la familia, y el cómo pueden afectar a la situación que el niño vive en clase (esto suele servir para que se sitúen en la realidad que no ven, porque algunos profesores realmente desconocen que hay gente que vive en situaciones tercermundistas, o que tienen padres toxicómanos, etc.).

El día que estoy en cada colegio, aprovecho para tomar café en la sala de profesores a la hora del recreo, y en cierto modo, llegas a ser visto casi como un compañero por parte de muchos maestros, lo que facilita el trabajo.

\subsection{El trabajo con las familias}

Una vez que conozco las faltas de asistencia, me paso por las casas a hablar con las familias. Intento ir entre lunes y miércoles, porque el efecto de la negociación con las familias suele tener una duración limitada en el tiempo (depende de casos), y si voy un jueves o un viernes, cabe la posibilidad de que acudan a clase un día, llegue el fin de semana, y dejen de ir el lunes. Mi experiencia me dice que en muchos casos el acudir a clase es una cuestión de inercia, cuando se coge el hábito de ir todos los días no se falta, y cuando faltan (por cualquier cuestión) varios días, se acostumbran a no ir. Así, que prefiero hablar con la familia a primeros de semana, y que cojan la inercia de ir toda la semana.

Cuando voy a las casas nunca planteo la cuestión de las faltas directamente, sino que suelo comentar que he estado en el colegio y que me han dicho como iba el niño, y que era una lástima porque siendo tan listo (o tan bueno, o cualquier cosa positiva) que al faltar pues se está quedando descolgado de sus compañeros (suelo buscar comparacio- 
nes con algún otro niño gitano que vaya bien, a fin de que sirva de referente para la familia, y no lo vean como una cosa de payos). Intento que lo vean como que estoy allí, no para exigirles que lleven más a su hijo al colegio, sino porque me preocupo por el chaval y quiero lo mejor para el.

Las visitas pueden ser por el tema de absentismo, pero también por cuestiones relacionadas con los deberes, con que se acerque al colegio a las 12 para que el maestro le explique como va el nene, etc.

Cuando se trata de una familia con la que creo que la negociación puede ser más dura, o que pueden estar menos predispuestos con el tema escolar, en ocasiones utilizo la siguiente estrategia: Unos días antes me paso por la casa con alguna excusa que suponga un favor por mi parte (algún favor que me hayan pedido que les mire, o llevarles una foto que tenía del hijo, o de una boda, etc.), y charlo un poco con ellos sin hacer ninguna referencia al tema escolar. De esta forma, cuando voy unos días más tarde a hablarles del tema del colegio (como algo que me acaban de comentar), la predisposición de la familia es mucho mejor.

Si una familia, a pesar de hablar con ellos, no consigo que vaya el niño al colegio, analizo quién es la persona de su familia que pueda tener más influencia sobre ellos. En ocasiones es el marido (porque en algunas casas el marido se va a trabajar todo el día, y no sabe que sus hijos faltan al colegio), y vas por la noche y todo se soluciona. En otros casos (la mayoría), es el abuelo paterno (de ahí mi hincapié en ganarme a los gitanos viejos), otras el hermano mayor, o incluso una hermana de la madre, (el tener claras las relaciones familiares existentes, es fundamental para desarrollar el trabajo). En este caso me acerco a la casa de esta persona, y le explico que tengo un problema, que no es un favor para mí, pero que es una lástima que los niños no vayan al colegio, y que los padres no se preocupan. En resultado suele ser que te digan: "no te preocupes que yo hablaré con el padre", y suele tener efecto.

En caso de que nada de esto funcione, les explico que a mí me pagan lo mismo vayan o no, que es por el niño, y que mi trabajo es recoger las faltas de los niños en los colegios y entregarlas en Servicios Sociales. Que les he estado tapando durante un tiempo, pero que no me puedo jugar mi trabajo porque es el pan de mi hijo, y que si no lo llevan al colegio yo tengo que dar parte, que no lo tomen a mal, y que lo que pase después ya no es responsabilidad mía.

El año pasado tuve dificultades con una familia en la que uno de sus hijos de 10 años, no iba nunca al colegio. El niño se negaba, y su padre 
que es toxicómano no se imponía. La familia cobraba una ayuda social, con la que comían, y si yo lo comunicaba a Servicios Sociales la iban a perder. Los intentos con los padres habían sido infructuosos, así que fui a hablar con el abuelo (el hombre me estima mucho, entre otras cosas porque ve que me mareo por sus nietos). Le expliqué la situación, y el hombre me pidió como un favor que le dejase unos días para que él hablase con su hijo, y que si a la semana siguiente seguía faltando su nieto, que lo comunicase a donde hiciese falta, que él lo entendía.

En algunos casos, una familia me comenta que necesitan que el niño o la niña falte al colegio algunos días por cualquier motivo (normalmente por cuestiones laborales). En estos casos negocio con ellos una fecha concreta para que vuelvan al colegio, y durante esos días yo no comunico a nadie las faltas. Esto tiene normalmente buenos resultados, ya que si no fuese negociado, faltarían de igual forma, y seguramente no volverían a ir al colegio.

\subsection{El programa despertador}

Al poco tiempo de estar trabajando como monitor, tuve un caso de un niño de 9 años que faltaba al colegio porque vivía sólo con su padre (en el barrio del Rabal), y cuando el padre se iba a trabajar el niño se quedaba durmiendo. El padre me pidió como un favor el que fuese por la mañana a despertar al niño como única forma de que no faltase al colegio.

A partir de subir todas las mañanas al barrio, cuando tenía algún caso de un niño que faltaba porque la madre no podía bajarlo por las mañanas (en un primer momento fueron dos madres que tenían un niño recién nacido y otro de 4 ó 5 años), le ofrecía el favor de llevármelos también al colegio, ya que de todas formas tenía que ir con el otro niño. Las madres accedieron contentas y muy agradecidas de mi preocupación por los críos. (Hay que decir que los llevo al colegio, pero que nunca los recojo).

El ir al barrio por las mañanas supuso que muchos niños que antes bajaban solos, me esperaban y se venían conmigo. De manera que hay días que bajo rodeado de 15 ó 20 niños. Esto me ha servido de excusa para acercarme a las casas de algunos de esos niños (concretamente a las casas donde se suelen quedar durmiendo los padres y faltan al colegio), y llamar para preguntarles si se viene el hijo conmigo.

El efecto que ha tenido este programa sobre el absentismo ha sido importantísimo, ya que niños que faltaban casi todas las mañanas, ahora casi no faltan. Pero además de la reducción del absentismo escolar, tiene otras ventajas: 
- Me permite una relación diaria con las familias, de manera que al tiempo que voy a las casas a despertar o recoger a los niños, me informan de cosas o bien yo les doy recados de los maestros, o sencillamente hablamos de cualquier cosa que puede no tener nada que ver con la escolaridad pero que sirve para mantener una buena relación personal.

- La imagen del monitor por parte de las familias es una imagen positiva. Ven que no sólo les exiges que vayan al colegio sus hijos, sino que te molestas en subir a las casas a levantarlos si hace falta, o llevarlos en tu coche si llueve, y por tanto que no es un trabajo que haces sencillamente por que te pagan, sino porque aprecias a sus hijos. (Dejo siempre claro a las familias que el subir a por los niños lo hago porque quiero, que no es algo que me mande el Ayuntamiento).

- Me permite preguntarles a los niños por la mañana si han hecho los deberes (algunos me los enseñan), y si llevan todo el material que necesitan para ese día. Así, algunos profesores que se quejaban de niños concretos que nunca llevaban el material que tocaba, ahora están sorprendidos del cambio en los niños, y hay algún crío que hace los deberes casi con la ilusión de enseñármelos a mí por la mañana.

Como contraposición, este programa tiene el riesgo de que algunas familias se acomoden a que les despierten y les lleven los niños al colegio, y por tanto que suponga una menor implicación en sus obligaciones hacia la escolaridad de sus hijos (esto siempre me lo están echando en cara los profesores). Creo que hay alguna familia que sí le pueda estar pasando esto (en estos casos lo que hago es no pasar de vez en cuando por su casa, para que sepan que no se pueden confiar totalmente conmigo, porque si no puedo ir no tengo por qué hacerlo), pero también considero que hay algunos niños que por sus circunstancias familiares, no irían ninguna mañana al colegio si no los recogiese.

\section{A MODO DE CONCLUSIÓN}

Lo que he expuesto aquí son simplemente los objetivos que en mi trabajo como mediador (en Villena se le llama monitor, aunque las funciones sean las mismas) me marco, y a grandes rasgos cómo desarrollo ese trabajo en el día a día. No quiero decir con esto que sea la mejor forma de trabajar, ni que sea extrapolable a cualquier sitio. Sencillamente es una experiencia concreta en un municipio concreto.

No he hablado de resultados, pero no quisiera dar la imagen de que 
todo es perfecto, ni de que todos los objetivos que me marco los consigo al $100 \%$. El día a día va dejando pequeños éxitos y pequeños fracasos, y mucho desgaste personal. Se trata de un trabajo a largo plazo, como una carrera de fondo, y la única forma que tengo de no quemarme es ir agarrándome a los pequeños logros que se van consiguiendo (por ejemplo, que un chaval llegue a la Universidad), y analizar los resultados comparativamente con años anteriores, para poder apreciar que se va progresando, y que el esfuerzo diario vale la pena. 



\title{
SERVICIOS SOCIALES E INMIGRACIÓN: LÍMITES Y RETOS PARA UNA NUEVA POLÍTICA SOCIAL
}

\author{
ENCARNA GUILLÉN* \\ FERNANDO DE LUCAS \\ DARÍO PÉREZ \\ ANDRÉS ARIAS \\ Escuela Universitaria de Trabajo Social. Universidad Complutense de Madrid.
}

\section{RESUMEN}

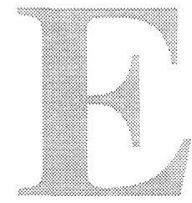

n este artículo se realiza una reflexión crítica sobre nuestro sistema de Servicios Sociales tomando como punto de partida las nuevas demandas, dificultades y contradicciones que ha generado el reciente y significativo crecimiento de la población extranjera en España. Se afirma, entre otras cosas, que el principio de intervención de los Servicios Sociales ha de identificarse con su objeto material, esto es, las carencias, y no con la condición de extranjería, no necesariamente vinculada con aquellas. Se defiende, asimismo, que parte de la solución a los problemas que afectan a los Servicios Sociales, pasa por una mayor coordinación con el resto de los subsistemas de Bienestar y, sobre todo, porque éstos últimos amplíen su cobertura para responder a aquellas necesidades que, como ocurre con alguna de las que manifiestan los extranjeros, están más vinculadas a su campo concreto de actuación.

\section{ABSTRACT}

The new problems, demands and contradictions that the recent and significative growth of immigrantion has generated in Spain are used to develop a critical examination of our Social Services 
System. Two main conclusions are derived from that examination: Social Services should continue to hold their material object, the users demands, instead of pointing their interventions on the fact of being a foreigner citizen. Part of solution to the main problems of the Social Services System requires a better coordination with and a greater aid of the others Welfare sub-systems.

\section{INTRODUCCIÓN}

El reciente incremento del número de extranjeros en España ha situado a nuestra sociedad frente a nuevos retos y problemas para los que en algunos casos no parece del todo preparada. Asimismo, ha contribuido a subrayar ciertas contradicciones preexistentes de nuestro Sistema de Bienestar Social aún no superadas.

De entre ellas, se piensa que una especialmente relevante tiene que ver con la integración social de los ciudadanos y con el papel que en este sentido ha de representar el subsistema de Servicios Sociales. Buena parte de las dificultades que éste manifiesta a la hora de ofrecer respuestas técnicas adecuadas a los inmigrantes tiene su origen en las mismas causas que subyacen a los problemas de atención al resto de la población.

Es por ello que el objetivo fundamental de este artículo consiste en ofrecer una serie de reflexiones sobre las limitaciones que actualmente presentan nuestros Servicios Sociales tomando como punto de partida el desafío que para nuestra sociedad está suponiendo la atención de un creciente número de personas en situaciones de necesidad: los inmigrantes extranjeros.

Para ello, en primer lugar, nos ocuparemos del sempiterno problema que supone la denominación adecuada de los fenómenos en el ámbito de los Servicios Sociales. En concreto, analizaremos el problema del lenguaje relativo a la inmigración y su papel como constructor de procesos de inclusión y exclusión.

En segundo lugar, nos centraremos en uno de los objetivos tácticos que persiguen los Servicios Sociales: la integración. Para ello caracterizaremos los diferentes modelos de integración de extranjeros que pueden guiar el trabajo de los Servicios Sociales, indicando cuando sea el caso, las dificultades que plantea cada uno.

En tercer lugar repasaremos someramente las cifras relativas a la inmigración en España, haciendo énfasis en las principales necesidades que presentan los inmigrantes extranjeros no comunitarios. 
En cuarto lugar, atenderemos al asunto, siempre controvertido, de los Servicios Sociales como derecho. En este caso veremos cómo la legislación relativa a la inmigración ha vuelto a reiterar alguno de los problemas que ya encontramos en los fundamentos legales de los Servicios Sociales.

Finalmente, plantearemos una nueva forma de concebir los Servicios Sociales, más restrictiva pero más intensiva en su cobertura, limitada esencialmente a la prevención y asistencia en los procesos de exclusión derivados del fracaso en la atención del resto de los Sistemas del Bienestar.

\section{EL PROBLEMA CONCEPTUAL Y LA REIFICACIÓN DE CIERTOS ÓRDENES MORALES}

Como estudiantes, profesores y estudiosos de los Servicios Sociales sabemos del babelismo conceptual que sufre nuestra materia. Así, mientras que en ciertos ámbitos un mismo significante se utiliza para referirse a diversos significados, en otros, en cambio, son varios los significantes que sirven a un mismo significado. La cuestión carecería de importancia y tendría fácil solución si sólo se tratara de la construcción de taxonomías bajo los principios de exclusión y exhaustividad. Pero el problema es más complejo de lo que en un principio podría parecer. No en vano, no tenemos más que recordar cómo los pragmatistas norteamericanos, desde Mead hasta los etnometodólogos, nos advirtieron que somos las personas quienes creamos y recreamos la sociedad y todo lo que en ella se comprende; o cómo el gran filósofo nos reconvino al indicar que en la búsqueda del significado no podemos movernos más allá de nuestras peculiares "formas de vida" y de nuestros particulares "juegos del lenguaje".

Por ello, debemos ser conscientes de que los Servicios Sociales no sólo inciden sobre la realidad inmediata de los ciudadanos a partir de sus intervenciones, sino que también contribuyen a reificar ciertos órdenes morales y no otros a partir de las ideas de persona y sociedad que su propia concepción sustenta.

Un buen ejemplo en tal sentido lo constituye la decisión de ofrecer Servicios Sociales especializados para inmigrantes. Pensemos, para empezar, en las implicaciones que tiene el hecho de que sean concebidos como servicios especializados y no como generales y, a continuación, las que conlleva el uso del término inmigrantes en vez del de extranjeros.

Si un servicio especializado se ofrece en función de las caracterís- 
ticas o necesidades especiales del colectivo que debe ser atendido, habrá que entender, y así se transmitirá, que los inmigrantes manifiestan necesidades y/o características sustancialmente diferentes de las que muestran el resto de los ciudadanos, más allá de las que son evidentes y que, en un principio, no tendrían por que provocar tal especialización. Así se corre el riesgo de que se desarrollase una red de dispositivos específicos y/o monográficos con la denominación "Centro Social de Atención a Inmigrantes". Lo que podría conllevar estigmatización y favorecer procesos de segregación.

Si por otra parte el servicio se le ofrece a inmigrantes en vez de a extranjeros, habrá que tener en cuenta que estas palabras tienen en nuestro lenguaje común acepciones en algunos casos diferentes. Sobre todo, cuando comprobamos que al menos en España, "inmigrante" es asociado a la imagen de "moro", "marroquî", "árabe", etc., y en absoluto con "francés", "alemán" o "norteamericano" (éstos, en todo caso, serían extranjeros que vienen a "dar", frente a los otros que vienen a "quitar")'. La carga estigmatizante se incrementa con locuciones que no son castellano repetidas hasta la saciedad en medios de comunicación, declaraciones institucionales, aulas y conversaciones. Hablamos entonces de los "inmigrantes irregulares", "ilegales" o "económicos", cuando en el idioma español la condición de "irregular" o "ilegal" no puede aplicarse a una persona o cosa, sino a situaciones. En cambio, pocas veces se escucha "extranjeros en situación de irregularidad", que sería lo correcto.

Este uso del lenguaje no es siempre caprichoso y, a fuerza de repetirse, adquiere, como indica Bourdieu (1999), visos de realidad. El lenguaje vuelve a descubrirse como un sistema que esconde, pero también transmite, un cierto orden social y determinados intereses ${ }^{2}$. Así se consolidan nuevas formas de estratificar la inmigración (o cualquiera que pertenezca a un ellos desde el nosotros socialmente reconocido) desde el status y la etnia ${ }^{3}$.

t Como podemos comprobar en las encuestas del CIS. A la pregunta de los grupos que se asocian con la palabra «inmigrante», más del $72 \%$ de encuestados encuadra a éstos con los provenientes del Norte y África subsahariana además de los ciudadanos hispanoamericanos (véase Blanco, Cristina, 2000: 183).

2 Incluso se puede afirmar sobre la construcción interesada y dirigida por personas, organizaciones, instituciones y medios de comunicación que imponen un discurso basado en «colectivos de riesgo», "situaciones de emergencia» etc., que contribuyen a la culpabilización de los afectados y al desarrollo de políticas más punitivas y restrictivas que de verdaderos Servicios Sociales.

3 Esta cuestión no ha dejado de estar presente en los Servicios Sociales al plantearse, desde los mismos, la definición del "otro". Caso de las implicaciones que se derivan, y el modo en el que se define, a las personas y a su medio cuando se hace referencia a ex-reclusos, exprostitutas, ex-toxicómanos, etc. 


\section{MODELOS DE INTEGRACIÓN}

Por este camino, podemos extender tales problemas a lo que serán los mecanismos empleados para elaborar políticas de integración y acogida de inmigrantes. De esas políticas, inevitablemente, dependen los Servicios Sociales. Decimos que el problema se extiende porque ninguna política ni servicio social puede ser razonable si no se conoce el problema sobre el que se trabaja. Esto ocurre cuando se identifica la integración como política a seguir con uno de sus modelos, por ejemplo, la asimilación (muchos no saben que la segunda busca la primera y que ésta puede emplear la asimilación, como también otros modelos de integración como el melting-pot o el pluralismo. Aquí pretendemos aclarar estos conceptos).

En primer lugar, cuando hablamos de integración, lo hacemos sobre una base según la cual, una vez establecidas en una sociedad determinada (suponemos de forma permanente), personas que son - digámoslo-, extrañas para su cultura, se plantea un problema de repuesta en forma de elaboración de nuevos modos de convivencia. Decimos tal cosa bajo la certeza que las diferencias étnicas, culturales y de costumbres de los nuevos grupos con respecto a la sociedad receptora (habitualmente mayoritaria y, más o menos, homogénea culturalmente) modifican la situación originaria de los autóctonos. Partiendo de la idea de que éste es un hecho consumado en las sociedades occidentales ${ }^{4}$ frente al cuál no se acepta el recurso a la persecución ni a la violencia (aunque pueda producirse), pues hablamos de sociedades sujetas al Estado de Derecho, se plantea entonces el problema de integración de extranjeros en la sociedad acogedora.

\subsection{Asimilación}

En este orden de cosas, el más antiguo de los modelos de integración es el conocido como asimilación. La asimilación es propia, por naturaleza, de situaciones en las que el flujo de extranjeros es pequeño, y por lo tanto, prácticamente inapreciable. Estaríamos ante una situación en la que el esfuerzo, individual, debe realizarlo el extranjero recién llegado adaptándose a la comunidad receptora.

Las primeras propuestas surgen de los trabajos pioneros de la Es-

+ No olvidemos que el fenómeno de la inmigración no sucede sólo en Europa y Norteamérica. El tradicional efnocentrismo occidental olvida que el fenómeno de la inmigración es incluso mucho más preocupante en los países subdesarrollados y en vías de desarrollo (otra conceptualización etnocéntrica) que soportan fuertes flujos de inmigrantes, sean éstos por razones económicas -pobreza-, guerra o persecución, hacia sociedades política, social y económicamente en crisis. 
cuela de Chicago, aunque por entonces no se aplicaban sobre pequeños grupos de inmigrantes, sino sobre flujos bien importantes de los mismos, lo que contradecía la utilidad de este modelo como respuesta a casos individuales. La inmigración poseía dimensiones estructurales y su respuesta debería ser social y política, no sólo particular.

En realidad, la asimilación (como ya se vio en los años cuarenta, cuando el modelo entró en desuso tras fuertes críticas) respondía a los intereses de los grupos étnica y políticamente dominantes de la sociedad norteamericana. Es decir, los que se ubicaban en lo que sería el perfil WASP5. Por lo tanto, "asimilación" equivaldría a "waspización" o "americanización", expresión de una ideología conservadora ${ }^{6}$.

Como nos indica la profesora Blanco (2000:114), existen otras interpretaciones del modelo asimilatorio que relativizan la carga conservadora y "americanizadora" supuestamente derivada de las propuestas de la Escuela de Chicago. La asimilación, según esta otra perspectiva, sería la respuesta más realista a la situación racial y étnica norteamericana. Serviría para "igualar" a los extranjeros con los nativos en vistas a la supresión de las barreras sociales y culturales generadoras de prejuicio y discriminación. A pesar de estas buenas intenciones, la asimilación cayó en desgracia pues se comprobó que si la aculturación se producía, la asimilación social no, perpetuándose la discriminación. Además, nadie se había planteado si los extranjeros deseaban asimilarse perdiendo su cultura.

El problema es que este modelo, demostrado ineficaz en las primeras décadas del siglo pasado, recobra fuerza en la actualidad y, como hemos dicho, se amolda en nuestras conversaciones, literatura y prensa, como una forma de respuesta al problema de la inmigración. La asimilación se acepta como única solución, sin que se establezca un debate sobre sus verdaderas implicaciones. Lo que pone en evidencia la persistencia o revitalización de un discurso, si no conservador, paternalista sobre los extranjeros.

\subsection{Melting pot}

Este es un anglicismo no muy extendido en España que identifica el segundo modelo genérico de integración. Melting pot en inglés vendría a representar una especie de marmita donde se mezclan y funden alimentos, en nuestro caso, un crisol de culturas.

5 Como saben ustedes, White Anglosaxon-Protestant.

6 Como pudo verse a través de las cuotas o restricciones que la nación norteamericana (en concreto la Comisión Dillingham) elaboró durante las primeras décadas del siglo XX para con italianos, griegos o, sobre todo, chinos 
Por lo tanto, se trata de una locución y modelo también procedente de Estados Unidos, elaborado de forma más definitiva a partir de los años treinta del siglo XX. A pesar de venir inspirado por la idea de una fusión de la diversidad cultural en una nación común (la norteamericana), el melting pot no deja de ser una versión, edulcorada, de la asimilación. Decimos esto porque incluso los defensores del melting pot eran conscientes de la extrema dificultad -o imposibilidad, caso de los negros- de incorporar a la comunidad a aquéllos que no respondían, por etnia, raza, religión y/o cultura, al modelo wasp. Es más, en el melting pot la aceptación de la pluralidad de los grupos interactuantes no era más que un eslabón entre la diversidad y la asimilación final.

La crisis de este modelo fue patente desde que se pusieron de manifiesto las enormes dificultades para sortear las barreras religiosas y raciales. En la práctica, la discriminación hacia determinadas razas y culturas permanecía, a pesar de la aceptación y representación de los rasgos y valores culturales norteamericanos por parte de los nuevos ciudadanos (como así ocurrió con muchos norteamericanos de origen mejicano). Así, el crisol ansiado, no se producía.

\subsection{Pluralismo}

Este modelo tomó cuerpo (aunque ya existían precedentes) en la década de los años setenta, heredera de la conflictividad social de finales de los cincuenta y años sesenta. En aquel tiempo, como nos recuerda Cristina Blanco (2000: 119), se vivió lo que vino a llamarse un ethnic revival.

El pluralismo, fuese "débil" o "fuerte", era contrario a los modelos anteriores, pues éstos negaban el derecho a mantener la propia identidad étnica, aunque conviene hacer distinciones:

El pluralismo recorrió una trayectoria que va desde el reconocimiento a la pervivencia de ciertos vestigios culturales (folklorismo) ${ }^{7}$, es decir, pluralismo débil; hasta el pluralismo fuerte, que otorga protagonismo a los grupos minoritarios y, por lo tanto, orilla discursos tolerantes enmascaradores de un paternalismo contrario a la dialéctica de los derechos.

Si nos fijamos bien, el primer pluralismo-débil-, en el fondo busca la asimilación. Sólo el incremento de la conciencia y conflictividad interétnica, así como la incorporación al debate ideológico y científico de consideraciones de carácter ético (que toman, por primera vez, la

Siempre y cuando éstos se encontrasen dentro del respeto y fidelidad a los principios y deberes democráticos y no supusieran agresión ninguna a los mismos. 
perspectiva de los extranjeros), provocarán un pluralismo fuerte (una de sus versiones de hoy es el multiculturalismo que defiende Charles Taylor, y que ataca ferozmente Giovanni Sartori -Sartori, 2001-).

El pluralismo más elaborado defiende la pervivencia de las diferencias culturales, pero dentro de la esfera privada, mientras que aboga por la construcción de un referente social común a respetar por todos. Es decir, el pluralismo defiende la diversidad, pero considerando, a su vez, las reglas del juego democrático.

Aquí es donde se desarrolla el debate más serio. Steinberg (1981), hace tiempo, y más recientemente Sartori (2001) relativizan o rechazan las identidades étnicas y la posibilidad de combinar el substrato cultural occidental (universalismo) con el pluralismo particularista.

Se afirma, contra el pluralismo, que la etnicidad es más mito que realidad y que las nuevas generaciones hijas de emigrantes pierden (incluso rechazan) sus rasgos originarios y la sustancia de su etnicidad. Ésta quedará transformada en una especie de etnicidad simbólica, estética.

También la defensa de la diversidad, para el propio Steinberg, puede suponer el mantenimiento de las desigualdades (cosa que ya se planteó en la Escuela de Chicago), tanto por arriba (colocando los grupos barreras tras ellos), como por debajo, es decir, reproduciendo el conflicto de clases ${ }^{8}$.

Otros, como Sartori, indican que la lucha por lo diferente atenta contra el espíritu universalista, pues, en muchos casos, esa diversidad es contraria -culturalmente- al discurso de los derechos. La pregunta es interesante: ¿cómo es posible luchar por la igualdad de condiciones promoviendo la desigualdad? Así, el autor italiano llega a una conclusión similar a la de Steinberg, aunque por otro camino. Sartori afirma que el objetivo del multiculturalismo de Taylor y sus seguidores, en el fondo, es la desigualdad, pues sólo así podría sobrevivir la diversidad que, obligatoriamente, supone diferencia.

Es cierto que el pluralismo sacraliza la etnicidad, pero lo mismo ocurre con sus contrarios, que defienden la cultura receptora (lo que, por supuesto, es legítimo). Pero esto es como combatir el nacionalismo con nacionalismo (bien lo sabemos en España). Por otro lado, la etnicidad, si es simbólica, es etnicidad, pues basta que los miembros que la viven crean en ella para que exista. La etnicidad es resultado de un proceso

8 Además, si el pluralismo pugna por la igualdad, condena a la propia etnicidad a desaparecer, pues el derrocamiento de las barreras de clase, por fuerza, debe acelerar la desaparición de las diferencias étnicas. Sólo preservando la desigualdad (y el conflicto) se perpetuaría la diversidad cultural (que Steinberg asume como de clase). 
de construcción social y simbólico, poco importa si está basada en condiciones sociales objetivas o no, pues los mitos que fundamentan las culturas no lo son por haber sucedido, sino por constituirse en el referente desde el que se construye y ordena una comunidad su Welstanschauung. Otra cosa sería si la etnicidad fuese meramente estética, lo que la condenaría a su desaparición.

A su vez, cabría decir que últimamente, cuando se plantea este debate, se asume por todos que el universalismo es una contribución europea (esencialmente ilustrada, francesa). Como es lógico, corroboramos tal afirmación, pero no podemos estar de acuerdo con que tal universalismo (discurso de los derechos) se constituya en El Signo Cultural Europeo y occidental. En absoluto podemos secundar tal cosa, aunque lo deseásemos, pues el particularismo, desde el que se construye la idea romántica de nación con todo su andamiaje (caso del concepto germano de volkgeist o genio nacional), también nos pertenece. Ahora bien, creemos en el universalismo como meta, pero no podemos obviar los hechos. Y éstos dicen que los mismos europeos y, en concreto, los españoles, son bien reacios a perder sus signos culturales. Existan o no nuevas culturas y comunidades en sus territorios. Además, el propio pluralismo se afirma en la teoría, pero no existe suficiente aplicación práctica del mismo que nos sirva para alcanzar a ver su viabilidad 9 .

Cabe preguntarse en qué lugar se posiciona el Sistema de Servicios Sociales en materia de integración (sí es que así lo ha hecho). Lo que nosotros apreciamos -salvo determinadas iniciativas pioneras aisladas-, en lo que podríamos llamar "modelo de Servicios Sociales español", es la develación de un Modelo de Sorpresa de Servicios Sociales, en el sentido de que los Servicios Sociales no han sido preparados ni diseñados para afrontar nuevos y más tipos de demandas. De esta manera, los Servicios Sociales reaccionan a posteriori pero, sobre todo, mediante respuestas improvisadas y urgentes, ni siquiera cotejadas con otras experiencias muy positivas como las elaboradas en otros países europeos ${ }^{10}$. El resultado es que una vez paridos los planes estratégicos, lo hacen sobre un entramado socioasistencial disperso en iniciativas y no ideado para ello. Y lo que es más, sobre una base de

9 En este sentido, defendemos la idca de una sociedad regida por los principios universalistas que, por definición, deben respetar a los individuos. Combinar universalismo con particularismo, no agrediendo los derechos de las personas es bien difícil y la asimilación, que es lo que ahora se propone (camuflada de una u otra manera) no parece la mejor solución.

to Por ejemplo, los modelos de acogida y atención en dispositivos de alojamiento que ya se encuentran bastante desarrollados en países como Alemania. Del mismo modo, sistemas de campamentos para colectivos itinerantes que se han implantado desde hace tiempo en Francia. 
recursos y medios muy vulnerables.

No nos debe extrañar tal cosa, el propio gobierno español, hasta la fecha, apenas ha planteado políticas de integración (a no ser que incluyamos en las mismas los procesos de regularización que sirven para sacar de situaciones de ilegalidad a la población extranjera). No se han dado pasos más allá, lo que supone que el Estado español espera que la integración sea espontánea, lo que es tanto como no establecer estrategias contra otros resultados, también espontáneos, de una inmigración abandonada a sí misma, es decir, conflicto, prejuicio, discriminación y xenofobia, cuando no racismo. Así, pues, el problema no es de los Servicios Sociales (aunque también lo sea de hecho) sino de toda la Política Social.

\section{LA INMIGRACIÓN EN CIFRAS}

Hemos convenido, como una verdad incontestable, que la inmigración en España es un hecho consumado y de importantes dimensiones. También se acepta que, desde 1985, España pasa de ser un país emisor a ser receptor de trabajadore ${ }^{11}$. Este hecho afecta tanto a nuestra convivencia como a nuestro sistema de Servicios Sociales. Pero, como profesionales, debemos apoyar empíricamente tales afirmaciones. De lo contrario, estaríamos contribuyendo a poco más que a una simple creación de opinión y, a su vez, provocar mayor confusión gracias al empleo de verdades a medias y nuevos estereotipos. Además, no olvidemos que tal fenómeno dista mucho de ser homogéneo y de afectar por igual a todo el territorio estatal. Así, pues, recojamos brevemente las principales cifras sobre el número, proporción y distribución de los extranjeros en España.

\subsection{Datos generales}

En primer lugar, en lo que respecta al stock (volumen total en una fecha determinada) de extranjeros en España convenimos en que éstos ascienden a 1.600.000. Cuatrocientos mil corresponden a extranjeros comunitarios (pertenecientes a la UE) y el resto proviene de fuera de las fronteras de la Unión ${ }^{12}$. Esto supone que, en España, aproximadamente un $4 \%$ de la población registrada es extranjera.

1 Sería conveniente recordar que, a pesar de las cifras, por cada extranjero que trabaja en España, hay 2,2 españoles trabajando en el extranjero, dato que no se tiene en cuenta cuando se afirma que los extranjeros -inmigrantes- vienen a «quitarnos el trabajo» (Lavié, 2001: 105).

: Cabría añadir los nacionalizados, no porque se les considere extranjeros, pues ya son 
Podemos extraer dos conclusiones de estos primeros datos. Por un lado, el peso relativo de la población extranjera en España dista mucho de ser abrumador (más aún si comprobamos que Alemania, a finales de la década pasada, mostraba un $8,5 \%$ de población extranjera dentro de sus fronteras) aunque sí es reseñable. Por otro, comprobamos que se ha producido un cambio significativo en los últimos años: en 1989 la mayoría de los extranjeros eran de procedencia comunitaria (según los datos consultados en el INE), suponiendo el 61,3\% del total. Aún así, ya por entonces, los españoles creían que la presencia extranjera era mayoritaria y procedente, sobre todo, del Norte de África, Centro y Sudamérica. Lo que muestra que tales opiniones no se basaban en la experiencia personal, es decir, la relación directa -cara a cara-con los extranjeros. En este sentido, el español tiende a identificar la extranjería o, más concretamente la inmigración (con su carga valorativa) en los grupos que, como hemos dicho antes, se identifican con los ciudadanos africanos, centro y sudamericanos y, en definitiva, lo que los medios han llamado eufemísticamente "emigrantes económicos".

Pero para 1998 se había producido un cambio significativo situándose el número de extranjeros comunitarios en España en un porcentaje del $41,03 \%$ sobre el total de inmigrantes ${ }^{13}$. A pesar de ello, sería conveniente indicar que, siendo la población extranjera en España no tan cuantiosa como el estereotipo indica, su distribución es bastante irregular (aunque tiende a repartirse cada vez más), encontrándose destinos que aglutinan a buena cantidad de estos flujos, como es el caso de Cataluña y Madrid ${ }^{14}$.

Pues bien, encaminándonos hacia el impacto de los extranjeros sobre el sistema de Bienestar Social español, podemos comprobar cómo, en el período que va desde diciembre de 1998 a abril del 2001, 500.000 nuevas personas se afiliaron a la Seguridad Social, siendo el $71 \%$ de éstas personas extranjeros extracomunitarios, lo que ratifica las cifras anteriores ${ }^{15}$.

españoles a todos los efectos, sino porque su situación primigenia era diferente. En los últimos doce años han alcanzado Ios $130.000,100.000$ de ellos no comunitarios.

13 El resto de ciudadanos de la Europa no comunitaria sumaban un $4,9 \%$, por un $20,45 \%$ de extranjeros provenientes del continente americano (Ios estadounidenses alcanzaban un $2,16 \%$ que sólo era superado por los dominicanos $-3,37 \%$ y peruanos $-3,46 \%-$ ). Los ciudadanos asiáticos Ilegaban al $8,44 \%$ y los africanos componían un $24,94 \%$ (aunque sólo los marroquíes suponían un 19,58\%).

14 Ambas Comunidades Autónomas poseen, respectivamente, un $23 \%$ del total, sumando casi la mitad de todos los extranjeros en España. Habría que añadir Andalucía, todo el arco mediterráneo y las islas Canarias como las Baleares como otros focos primordiales de afluencia de extranjeros.

15 Pero es más, estos trabajadores, en el año 1998 aportaron 274.667 millones de pesetas a la Seguridad Social y obtuvieron prestaciones de desempleo y asistencia sanitaria por valor 
Por otro lado, con respecto a la natalidad, después de los famosos crecimientos vegetativos en la década de los noventa, podemos decir que, por segundo año consecutivo, crece la natalidad ${ }^{16}$.

El impacto en la Escuela también ha sido notable, pues se han incorporado más de 100.000 nuevos alumnos extranjeros en las escuelas españolas. De ellos, unos 57.000 sólo en Madrid, lo que supone un $60 \%$ más que el año pasado en la misma Comunidad Autónoma. Por lo tanto, estamos ante un incremento rapidísimo que desborda la capacidad de respuesta, más aún de los Servicios Sociales educativos. En este sentido, conviene indicar que el Sistema Educativo como consecuencia de la falta de una Política Social ante el fenómeno de la inmigración, viene sufriendo a lo largo de los tres últimos años importantes dificultades a la hora de asumir su papel como instrumento de integración de la población inmigrante. En algunas zonas de España se están creando "guetos educativos"17. La falta de preparación de este Sistema de Protección ante el nuevo perfil de la población y su déficit de recursos de apoyo, agrava la situación del propio sistema en aquellos lugares en los que existen grupos importantes de población inmigrante $\operatorname{asentada}^{18}$.

de 90.000 millones. Del IRPF se obtuvieron unos ingresos de 49.000 millones de pesetas. Como nos dice el profesor Lavié (ibid.), en el capítulo del gasto social, los gastos realizados fueron de 74.000 millones de pesetas en sanidad; 40.000 millones en educación; 14.000 en desempleo y 3.079 en programas del IMSERSO. Tales cifras descubren, a pesar de que prácticamente el 95\% de los extranjeros regularizados en España han entrado o permanecido en nuestro país de forma clandestina por la falta de procesos formales de emigración (salvo alguna excepción como es el caso de la República Dominicana), que los inmigrantes se han convertido en una fuente de riqueza para el país pagando más de lo que reciben como prestaciones sociales.

16 En el año 98 el promedio de hijos por mujer fértil llegó a I,15, mientras que en el año 2000 alcanzaba ya el 1,23, garantizándose, después de bastante tiempo, el reemplazo de la población. En cifras absolutas, podemos decir que el año pasado nacieron 18.000 niños más que en 1999, fundamentalmente como resultado de una política de reagrupación familiar que pretende garantizar la generación de repuesto que se educará en España (lo que resulta paradójico ante la permanente cerrazón de las leyes de extranjería).

17 Es decir, centros escolares donde la proporción de niños inmigrantes es muy supcrior. Esto provoca que los niños autóctonos abandonen dichos colegios para dirigirse, en la mayoría de los casos, a la red privada de centros docentes.

is Parece claro que nuestros Sistemas de Protección Social no estaban preparados para un tipo de inmigración de asentamiento, es decir, aquélla que plantea su permanencia en nuestro país por períodos largos de tiempo. Incluso, muchos inmigrantes son conscientes de la dificultad de retorno. La inmigración clásica que venía produciéndose en cl conjunto de Europa tenía un sentido de itinerancia y de temporalidad, es decir, el objetivo del asentamiento no se planteaba. Por este motivo, apenas se producía la inmigración de las unidades familiares, sólo se contaba con el/la inmigrante como sujeto aislado que venía a trabajar. Ante este perfil de inmigrante, los Sistemas de Protección Social tenían una función meramente paliativa y asistencial. No se planteaban la integración como objetivo, o más bien, como exigencia ante los cambios en los modelos de inmigración. 


\subsection{El problema laboral}

Con respecto al ámbito laboral, comprobamos que los extranjeros trabajan fundamentalmente en el servicio doméstico y de hogar, seguido por la agricultura, construcción, hostelería y restauración. La mayoría lo hacen por cuenta ajena. Una vez preguntadas estas personas por si tenían empleo en su país de origen, el $65 \%{ }^{19}$ responde que sí lo tenía, pero que la baja remuneración y discontinuidad del mismo les obligó a salir.

En este sentido asistimos al desarrollo de una Economía Dual ${ }^{20}$ en la que los inmigrantes ocupan los empleos más precarios, transitorios y peligrosos. La renta media mensual de estos trabajadores se sitúa entre las 100.000 y 140.000 pesetas (cuando la mediana de ingresos de un madrileño ronda las 210.000-250.000 pesetas ${ }^{21}$ ). Ciertamente, los españoles rechazan una serie de trabajos que sí son atractivos para los extranjeros por su remuneración .

El paro también afecta a los extranjeros y, de forma preocupante. Vemos que un 50\% de los hombres marroquíes están en el paro. En cambio, las mujeres reflejan una mayor inserción laboral. De hecho, las "reglas" migratorias indican que la mujer soporta y se adapta mejor al fenómeno migratorio.

19 Estos datos y los siguientes debemos pertenecen al Banco de Datos del sociólogo Ramón de Marcos, al que agradecemos su facilitación así como las sugerencias y orientaciones que sobre este artículo ha hecho.

20 La Teoría del mercado dual, como recoje Blanco (2000: 66) de su fundador, Piore, supone una perspectiva macro para explicar las causas del fenómeno migratorio. Según este autor, los mercados laborales nacionales expresan una desigualdad que se concreta en un doble mercado laboraI: nativo/foráneo. Así, pues, la inmigración responde al requerimiento estructural de las sociedades receptoras. Las economías más desarrolladas necesitan de mano de obra, necesidad que se explica por cuatro razones estructurales de estas economías: Inflación estructural de los países que reciben mano de obra. Ya que los trabajadores nacionales disfrutan de la proteccion de una legislación sociolaboral que limita la modificación salarial, se contrata al extranjero, que acepta los trabajos de bajo salario y prestigio que no admiten los autóctonos. Las motivaciones de los trabajadores nacionales remiten al salario y el status, mientras que el inmigrante sólo buscaría salario (que le confiere status en comparación con su situación de origen). El dualismo económico se establece en las sociedades desarrolladas ya que el capitalista procura rentabilizar el capital fijo, apenas invirtiendo en el variable. Así se divide el mercado de trabajo en un sector primario (producción estable dirigica a rentabilizar el capital: trabajos rentables, cualificados, bien remunerados y propios de nativos) y otro secundario caracterizado por trabajos de baja cualificación, salario y status. Trabajos inestables y propios de extranjeros que son los que soportan las fluctuaciones de los ciclos económicos, amortiguando el conflicto en el sector compuesto por trabajadores autóctonos. Piore concluye indicando que este mercado expresa una demografia de la fuerza de trabajo al ocupar los trabajadores inmigrantes el segmento que antes ocupaban mujeres y niños.

21 De todas mancras, no se nos escapa que la distribución de la Renta en España, como en Madrid, es muy desigual. 


\subsection{Otras novedades}

A la tradicional emigración masculina en edad laboral, se han sumado categorías antes residuales como son los menores, mujeres y familias desestructuradas. También se ha incorporado el mundo de la delincuencia (caso de mafias organizadas), lo que incide sobre la violencia. El fenómeno migratorio sufre, como bien sabemos, del problema de la marginación y exclusión sociales. De hecho, de las 49.295 personas en cárceles españolas, $8.668(17,6 \%)$ son extranjeros (no incluimos los datos de la Comunidad Autónoma de Cataluña por no disponer de ellos).

Por otra parte se observa una recuperación del nomadismo, que puede comprobarse por la llegada de personas de etnia gitana procedentes fundamentalmente del Este de Europa. Las razones de este hecho parecen explicarse por la caída de los países del socialismo real y de las economías que lo sustentaban, liberando a estos individuos de los férreos controles que tenían en sus países ${ }^{22}$.

\subsection{Procesos de regularización (¿o una política asimilacionista no declarada?).}

Como antes hemos argumentado, el gobierno español no se ha decidido por una política de integración de los extranjeros. En todo caso, los medios dedicados al fenómeno de extranjería (salvo iniciativas locales aisladas), se han dirigido hacia los procesos de regularización "extraordinarios", sistema de cupos y procesos por causas humanitarias o "de arraigo" de los inmigrantes. De esta especie de política de inmigración parece desprenderse una intención de asimilación de extranjeros no expresada, pero que se ha enquistado en el debate sobre la inmigración. Algo que consideramos insuficiente y anacrónico con respecto a la realidad de la extranjería debido a la cantidad y diversidad (étnica, cultural y de procedencia) de los inmigrantes. Estos procesos se iniciaron en el año 1985 y continuaron en 1991, 1996, 2000 (con 200.000 personas regularizadas) y 2001 (se han pedido 322.000 solicitudes de las cuales 75.000 se han acogido a la fórmula "de arraigo").

El sistema de cupos se ha dirigido, sobre todo, a personas que ya residían en España ${ }^{23}$. De todas maneras, este sistema es muy conser-

22 Se observan, a su vez, diferencias importantes entre la minoría étnica gitana española, asentada desde hace tiempo, frente a la nueva. De hecho, se reproduce otra forma de estratificación entre gitanos españoles y extranjeros, a los que no reconocen los primeros.

23 El primero se produjo en el año 1993, seguido de los acaecidos en el 94, 95, 97, 98 y 99 
vador y complejo, pues se establece una pugna en torno a quién decide sobre el cupo: ¿Estado?, ¿empresarios?, ¿sindicatos?, ¿Comunidades Autónomas?. Además, este sistema se ideó para flujos migratorios cualitativamente homogéneos (caso de las migraciones producidas por los españoles en los años sesenta y setenta), que se dirigían a un sector muy concreto de la economía. El cambio en el mercado laboral y su gran diversificación imposibilita la gestión homogénea de los cupos. En el momento en el que esto se escribe, el gobierno estudia suspender el contingente de trabajadores extranjeros para el año 2002 por la falta de ofertas presentadas por los empresarios españoles. Si añadimos a este problema que el proceso de fijación del número de extranjeros precisos para el mercado laboral es muy complicado y lento ${ }^{24}$, podemos apreciar las limitaciones del establecimiento de cupos que, probablemente, incrementarán su dificultad y carácter conservador.

Por último, se incluye la forma de regularización por causas humanitarias o de "arraigo". En el caso de los cupos, se solicita la presentación de datos de trabajo, pero en lo que a estas causas se refiere, el proceso es bastante diverso. Tal figura fue puesta en marcha a través de la Comisión encargada para este asunto creada en el Foro de Inmigrantes de 1998. Derivada de tal propuesta se constituyó la figura del "Defensor del pueblo extranjero".

En verdad, al no existir procesos formales de emigración se condena a la gran mayoría de la población extranjera a vivir en la clandestinidad y, por consiguiente, se contribuye a la marginación y a la exclusión. Éstos serían los mal denominados "extranjeros ilegales" o "irregulares", condición a la que les destina la política de extranjería española.

En este orden de cosas, los Servicios Sociales deben afrontar problemas derivados de la extranjería (en el campo educativo, laboral, de la delincuencia y violencia, de infancia y tantos otros) sin apoyo certero del resto de herramientas que un Estado de Derecho orientado por un principio de justicia social (esto es, el Estado Social) debe poner en marcha. Por lo tanto, no sólo hablamos de unos Servicios Sociales de

El proceso sería el siguiente: cada provincia forma una comisión ejecutiva con miembros del Ministerio del Trabajo, INEM, de la Comunidad Autónoma, sindicatos y patronal que determinarán el número de trabajadores extranjeros necesarios para su provincia. El INEM, a continuación, examina las necesidades y demandas del mercado nacional para que, más tarde, se elabore una propuesta donde se especifica el número de trabajadores por sector laboral. Tal propuesta deberá ser elevada al delegado o subdelegado del Gobierno que debe remitirla, a su vez, a Madrid. Posteriormente el gobierno aprueba un contingente y a las comisiones ejecutivas provinciales les corresponde, en este paso, distribuir sus propios cupos y elaborar sus informes. El Ejecutivo deberá aprobar el mismo no más tarde del 31 de diciembre. 
"sorpresa" sino una Política Social de "sorpresa". Algo que, como veremos a continuación, se confirma a la luz del entramado legislativo.

\section{ATENCIÓN SOCIAL A INMIGRANTES: VERTIENTE JURÍ- DICA DE LOS DERECHOS SOCIALES.}

Si estamos hablando sobre el fenómeno social de la inmigración, más aún cuando lo abordamos desde su relación con los Servicios Sociales, debemos obligatoriamente referir los elementos normativos que definen las respuestas asistenciales para el sector de los extranjeros. A la luz de estos textos, comprobamos cómo se reproducen vacíos y huecos que obstaculizan la garantía y el disfrute de los derechos sociales (sin los cuales, en un Estado Social, no pueden asegurarse los derechos ciudadanos) de los extranjeros en España. Así, se incrementa el número y carácter de las carencias de los extranjeros, que ni siquiera podrán satisfacer los Servicios Sociales, por incapacidad y falta de apoyo legal.

Así, pues, y por orden de jerarquía normativa, partimos de la actual Ley sobre Extranjería ("Ley orgánica 4/2000 de 11 de enero, sobre derechos y libertades de los extranjeros en España y su integración social"). El título de esta Ley plantea dos de los requisitos a cumplir en ella: reconocimiento de los derechos de los extranjeros -entre los que se encuentran los denominados "sociales"- y la integración de los mismos (objetivo de la Ley). Comprobamos que estos elementos se relacionan directamente con lo que planteamos sobre la atención social en materia de extranjería.

La Ley 4/2000, en su artículo 14 del Capítulo I ("Derechos y libertades de los extranjeros"), establece los derechos de los extranjeros a la Seguridad Social y a los Servicios Sociales, afirmando explícitamente lo siguiente:

"1. Los extranjeros residentes tendrán derecho a acceder a las prestaciones y servicios de la Seguridad Social en las mismas condiciones que los españoles.

2. Los extranjeros residentes tendrán derecho a acceder a los servicios y prestaciones sociales, tanto a los generales y básicos como a los específicos, en las mismas condiciones que los españoles ${ }^{25}$.

3. Los extranjeros, cualquiera que sea su situación administrativa, tienen derecho a los servicios y prestaciones básicas". 
Como se observa, parece que se reconoce el derecho y la posibilidad de acceso a los Servicios Sociales de los extranjeros. Sin embargo, con la lectura de dicho artículo, surgen algunas preguntas a las que la actual estructura normativa de Servicios Sociales no responde. ¿Cuáles son las prestaciones generales o básicas a las que se refiere la Ley?. ¿Dónde y quién las ha definido normativamente?. Desde nuestro punto de vista, la Ley 4/2000 establece peculiares juegos de magia al reconocer el derecho a algo que no está definido en ningún marco normativo previo. Se hace referencia a unos derechos sociales que en la actualidad se concretan en prestaciones y servicios de carácter graciable, además de dispersas en el conjunto del territorio nacional ${ }^{26}$. Ello, en la práctica, supondrá que un inmigrante, en el marco de la Ley $4 / 2000$, recibirá un tipo de prestaciones "básicas" según la localidad en la que se encuentre.

Por el contrario, hay que señalar otros derechos sociales reconocidos en la Ley 4/2000 (Derecho a la educación; artículo 9. Derecho a la atención sanitaria; artículo 12) que cuentan con un marco normativo estatal que define de forma homogénea y general las prestaciones básicas de cada uno de los Sub-sistemas de Protección Social. Pero, en nuestro caso, carecemos de una Ley Estatal donde se defina lo que podríamos denominar como prestaciones básicas del Sistema de Servicios Sociales, lo que va a favorecer, como sucede con la población autóctona, una situación de desigualdad territorial en la atención al colectivo social de inmigrantes. Así se puede afirmar que el criterio de igualdad (sin quererlo la ley) es reconocido en la medida que ubica a la población inmigrante en la misma situación de subjetividad y vulnerabilidad que la población autóctona con relación al Sistema de Servicios Sociales. Pero, además, resulta paradójico que una Ley de carácter sectorial (Ley de Extranjería) pretenda que se reconozcan unos derechos sociales referentes al Sistema de Servicios Sociales, que no se recogen en ningún tipo de Ley General.

Según nuestro punto de vista, esta Ley coloca en un importante compromiso al Sistema de Servicios Sociales, ya que desde una Ley de rango superior a las actuales Leyes Autonómicas del sector (recordémoslo, lugar en el que se definen los Servicios y prestaciones básicas), se plantean unos derechos a los que no se puede responder con la actual configuración normativa y, en consecuencia, organizacional y funcional de los diferentes Sistemas Autonómicos de Servicios Sociales. Más aún cuando, como hemos señalado, nuestro Sistema de Protección Social es graciable de facto y está sujeto a múltiples limitacio-

26 Por supuesto, sin olvidar la compleja y heterogénea red autonómica y local que hoy existe en materia de Servicios Sociales. 
nes y restricciones.

Esta compleja situación jurídica podría generar la interposición de algún tipo de recurso/reclamación, por el que se llegase a "obligar" a las Administraciones a definir con más precisión y rigor jurídico los servicios y las correspondientes prestaciones básicas del Sistema de Servicios Sociales, las cuales, en la actualidad, son definidas en el conocido como "Plan Concertado" (instrumento no jurídico) que ha sido desarrollado con el objetivo de posibilitar una Red Pública de Servicios Sociales en las Corporaciones Locales. Sin duda, hay que reconocer su importante valor como instrumento operativo para la organización y funcionamiento de los actuales Servicios Sociales, sobre todo como un impulsor técnico y económico de las actuales Redes Públicas Municipales. Sin embargo, carece de valor jurídico y normativo para garantizar y estabilizar los derechos sociales propios de nuestro Sistema de Protección Social, careciendo, asimismo, de capacidad para legitimar el actual Sistema Institucional de Servicios Sociales.

En esta misma línea de indefinición de servicios y prestaciones para el colectivo de inmigrantes extranjeros, se encuentra el reglamento de ejecución de la Ley Orgánica 4/2000, de 11 de enero, sobre derechos y libertades de los extranjeros en España y su integración social, reformada por la Ley Orgánica 8/2000, de 22 de diciembre. Este nuevo instrumento jurídico Real Decreto 864/2001, de 20 de julio, supone un paso más en la concreción de los derechos y deberes de los extranjeros, en su sección $2^{\mathrm{a}}$, artículos 145 y siguientes, hacen referencia a la "red pública de centros de inmigración", los cuales, desarrollarán funciones de atención, acogida e intervención social, para ciertas situaciones específicas (solicitantes de asilo, refugiados, apátridas...). En este sentido, también hacen referencia a los inmigrantes que "se hallen en situación de vulnerabilidad o corran riesgo de exclusión social". Esta amplia "tipología" de ciudadanos extranjeros en situación de necesidad es equiparable a las situaciones de vulnerabilidad de la población autóctona. Sin duda, nos volvemos a encontrar en la idea de crear dispositivos especializados para el colectivo de inmigrantes extranjeros, cuando nuestra propuesta se sitúa en la integración de éstos en la red de Servicios Sociales Generales.

Por otra parte, se puede afirmar, desde nuestro punto de vista, que el Ministerio de Trabajo y Asuntos Sociales asume competencias que no le corresponden, ya que desde dicho nivel institucional, se propone asumir la creación y desarrollo de dispositivos de atención propios de la Red de Servicios Sociales. En ningún momento se hace referencia a las competencias de las Comunidades Autónomas y de las Corporaciones Locales para la creación, desde dichos niveles institucionales, 
de la "red pública de centros de inmigración". En este sentido, la disposición adicional novena del Reglamento, hace una referencia genérica a la intragación social, señalando que las Administraciones competentes "desarrollen sus competencias en todas aquellas materias relacionadas con la integración social...". Se vuelve a la imprecisión y ambigüedad en lo referente a servicios y prestaciones que recibirán los ciudadanos extranjeros.

Del mismo modo, donde también se definen los Servicios Sociales es en la Ley de Bases del Régimen Local de 1985. Comprobamos que en ella sólo se plantea la obligatoriedad de las Corporaciones Locales a desarrollar Servicios Sociales ${ }^{27}$, sin precisarse ni detallarse en ningún momento lo que podríamos definir como "prestaciones básicas". De esta manera se extiende al marco de las Corporaciones Locales la ambigüedad y la escasa objetivación de estos derechos sociales ${ }^{28}$.

Si pasamos al marco normativo de la Comunidad de Madrid, vemos cómo la Ley actual de Servicios Sociales (Ley 11/1984, de 6 de junio), simplemente por su fecha de promulgación, se encontraba bien lejana de atender y sospechar la aparición del reciente fenómeno social de la inmigración. En aquellos momentos los extranjeros constituían un sector poblacional reducido, concentrado de forma mayoritaria en extranjeros comunitarios, en aquéllos que acudían por razones de intercambio cultural, o a ocupar puestos en empresas multinacionales o a hacer turismo.

Esta Ley, de todas maneras, se refería de forma genérica al colectivo de extranjeros, señalando algunas situaciones específicas que ya en ese momento comenzaban a atenderse desde el incipiente Sistema de Servicios Sociales. En este caso nos referimos a las situaciones de solicitante de asilo y refugio, así como los reducidos casos de apátridas que acudían a nuestro país. Ambas circunstancias constituían objeto de intervención, ya que generaban múltiples estados de necesidad en los sujetos que las padecían. No se recoge ningún otro tipo de situación que planteara la exigencia de intervención y/o mención al sector de extranjeros.

La Ley madrileña señala, en su artículo segundo ("Titulares de derechos"), lo siguiente:

"Los extranjeros, refugiados y apátridas podrán beneficiarse de

${ }^{27}$ Como puede verse en el artículo 25.2.k sobre la prestación de Servicios Sociales y de la promoción de inserción social y en el 26.1c, donde se indica la obligatoriedad de prestar Servicios Sociales en los municipios de más de 20.000 habitantes.

28 Y en definitiva, se perpetúa el problema de los derechos sociales propio de la Constitución española y de todas las normas programáticas o promotoras que de ella se extraen. 
los servicios sociales de acuerdo con lo dispuesto en los vigentes Tratados Internacionales, en la Ley reguladora del derecho de asilo y de la condición de refugiado y, en su defecto, según la práctica de la justa reciprocidad, o conforme se establezca reglamentariamente para los que se encuentren en reconocido estado de necesidad".

Parece clara la profunda ambigüedad sobre la conceptualización que sobre los derechos sociales de los extranjeros efectúa la Ley, pues, como ella misma establece, serán los correspondientes reglamentos quienes definan cómo y quiénes son los extranjeros que podrán acceder a los Servicios Sociales. Es cierto, sin embargo, que reconoce la situación de necesidad como objeto de intervención desde el Sistema de Servicios Sociales. Por lo tanto, esta Ley viene a reforzar nuestro principio de intervención, es decir, las necesidades y no la condición de extranjero. Es importante indicar que en la referida redacción de la Ley no se establece la condición de residencia como criterio para prestar los Servicios Sociales (más adelante se observará cómo se plantea dicho requisito).

Hay que señalar que la única modificación que ha tenido esta Ley hasta la fecha tiene que ver con el reconocimiento de la población extranjera como sujeto de derecho de los Servicios Sociales de la Comunidad de Madrid. En este sentido, en el año 1994 fue promulgada la Ley 7/1994 del 6 de julio, de reforma del artículo 2 de la Ley 11/1984, de 6 de junio de Servicios Sociales. Con ella se pretende extender los derechos a los que pueden acogerse los extranjeros residentes en la Comunidad de Madrid. Este artículo queda así redactado:

"Artículo 2. Titulares de Derecho.

1. Tendrán derecho a los servicios sociales regulados en la presente ley todos los residentes en el territorio de la Comunidad de Madrid, y los transeúntes, sean españoles o extranjeros, residentes en cualquier territorio de la Unión Europea, que se encuentren en evidente estado de necesidad de asistencia y protección social siempre que se cumplan los requisitos que el Consejo de Gobierno de la Comunidad de Madrid determine.

2. Los extranjeros no residentes en la Unión Europea podrán beneficiarse de los servicios sociales de acuerdo con los vigentes tratados internacionales, en la reguladora del Derecho de Asilo y en la Condición de Refugiado conforme se establezca reglamentariamente para los que se encuentren en reconocido estado de necesidad".

Se aprecia cómo la Ley queda modificada con el fin de adecuar el texto autonómico a las nuevas condiciones sociales. En concreto, que- 
da planteado el criterio de residencia como exigible para recibir prestaciones del Sistema de Servicios Sociales. Ello significa que, con una lectura y aplicación estricta de la Ley, quedarán fuera de dicho Sistema de Protección Social muchos extranjeros que se encuentran "ocultos" o "invisibles" para la sociedad y sus instituciones, siendo los que más necesitan de Protección Social, especialmente prestaciones básicas: alojamiento, manutención, acompañamiento social, etc.

Hay que indicar, además, que en el Pleno celebrado el día 8 de noviembre de 1989 en la Asamblea de Madrid, fue aprobada la Proposición no de Ley 25/1989, en la que se proponía la extensión de los Servicios Sociales de titularidad de la Comunidad de Madrid a los extranjeros. Sin lugar a dudas, se trataba de una mera declaración de buenas intenciones, fruto de la presión social y, sobre todo, de la percepción de la situación por venir con relación al cada vez mayor incremento de la población extranjera en Madrid. Es probable que esta declaración tuviera como objetivo superar la contradicción presentada sobre la exigencia de solicitud del requisito de residencia. Planteándose así lo que podríamos denominar como la "universalización" de los Servicios Sociales al conjunto de extranjeros con independencia de su situación jurídico-administrativa. Esta buena declaración de intenciones, hasta la fecha, ha carecido de concreción. Han tenido que pasar más de diez años para que la Comunidad Autónoma se planteará el fenómeno social de la inmigración como objeto de actuación ${ }^{29}$.

Desde la promulgación de la referida Ley de Servicios Sociales que, como todos sabemos, se encuentra en proceso de sustitución por otra normativa más acorde a los nuevos tiempos, se han desarrollado diferentes leyes y decretos legislativos en los que, en algunos casos, se deja clara la imposibilidad de acceder a prestaciones y servicios (Decreto 73/1990, de 19 de julio por el que se aprueba el Ingreso Madrileño de Integración) y en otros, por el contrario, se reconoce la posibilidad de acceso al sistema de Servicios Sociales ${ }^{30}$. Probablemente, la puesta en marcha del denominado "Plan Regional para la Inmigración"

29 En este caso hay que indicar que a lo largo del pasado verano (2001) fue aprobado por la Asamblea de Madrid el denominado "Plan Regional para la Inmigración (2001/2003)", instrumento institucional en el que se definen objetivos y recursos para la atención de los inmigrantes extranjeros que se encuentran en nuestra Comunidad.

30 Tal es el caso de los menores extranjeros, que en virtud a la Ley 6/1995, de 28 de marzo, "De garantías de los derechos de la infancia y la adolescencia de la Comunidad de Madrid", se establece el reconocimiento de los derechos de los menores recogidos en la Constitución y en la Convención sobre del niño. En este sentido, se reconoce el derecho de acceso a los servicios de atención a la infancia sin discriminación alguna. Incluso se hace mención expresa (art. 26) a este sector; "los menores extranjeros que se encuentren en la Comunidad de Madrid, deberán recibir ayudas públicas siempre que lo requieran como fomento de su integración social, linguiística, cultural...". 
suponga la modificación en la práctica de diversas normativas que limitan el acceso de los extranjeros a ciertas prestaciones del Sistema de Servicios Sociales.

Así, pues, el fenómeno de la extranjería ha descubierto el modelo de intervención que hemos denominado por "sorpresa", es decir, la actuación que se desarrolla después de producidos los acontecimientos $y$, por lo tanto, la improvisación y urgencia subsiguientes en los recursos y medidas a aplicar en cada caso, ya que como se ha observado, ha tenido que pasar cierto tiempo para diseñar estrategias de actuación enmarcadas en planes más globales e interrelacionados con el resto de Sistemas de Protección Social. Los límites y deficiencias del sistema de Bienestar Social y de la política social española han quedado desvelados.

Los Servicios Sociales, diseñados para una población estándar, que ni siquiera garantiza por ley su diseño en lo que al nivel secundario se refiere, reciben una "lluvia" de demandas no satisfechas por la política social española. Ni fueron creados para solventar tales problemas ni es ese su cometido.

\section{EL SISTEMA DE SERVICIOS SOCIALES ESPAÑOL COMO SISTEMA "ESTÁNDAR"}

Hemos dicho que nuestro sistema de Servicios Sociales expresa una serie de defectos y dificultades consustanciales a su formación y diseño. A pesar de la voluntad de creación de unos Servicios Sociales modernos acaecida, sobre todo, en la década de los años ochenta, los hartamente repetidos problemas de competencias entre la Administración Central y la Autonómica, la diversidad regional, así como la diferente sensibilidad municipal, han impedido la consolidación de unos Servicios Sociales para todos, en igualdad de condiciones y que, en verdad, pudiesen cumplir con efectividad sus cometidos.

La doctrina indica que, si bien el nivel primario de los Servicios Sociales fue relativamente garantizado (recordemos las objeciones que Demetrio Casado -2001- ha hecho a esta afirmación) no ha ocurrido lo mismo con el nivel secundario o el especializado que, además, ha ido dirigiéndose cada vez más hacia la iniciativa privada y social, con lo que esto supone de incremento de su vulnerabilidad, al depender, en gran medida, de subvenciones y convenios que se establezcan en cada momento.

Esto ha llevado a que las críticas sobre nuestro sistema ${ }^{31}$ de Servicios Sociales sean especialmente duras: sistema puramente benéfico, 
enmascarador de desigualdades, generador a su vez de nuevas desigualdades, etc.

Así, pues, si los Servicios Sociales, como actividades técnicas de alcance estructural moderado, han tenido importantes dificultades para afrontar sus retos de manera procedente, ¿qué cabe esperar de los mismos, diseñados para una población española relativamente homogénea culturalmente? Si las demandas diferenciales de los españoles eran complejas, ahora se les suman las de los extranjeros que, inevitablemente, recorren todo el entramado sectorial de los Servicios Sociales, demandando soluciones en familia, infancia, juventud, condición sexual, delincuencia y reclusión, etc. Por este motivo, el Sistema de Servicios Sociales (principalmente en las grandes ciudades y en las zonas agrícolas en las que se ha producido una gran afluencia de población extranjera), se encuentra sometido a un proceso de tensiones internas (redefinición de estructuras organizativas y funcionales) y externas (incremento de la demanda). Ello favorece que sea aún más ostensible y manifiesta su vulnerabilidad ${ }^{32}$.

La respuesta que hoy procura el Sistema de Servicios Sociales a la población extranjera es el resultado de un proceso dinámico de cambio en sus perfiles y necesidades, así como de la progresiva adaptación de la red a esta nueva situación. En un principio, el Sistema de Servicios Sociales comenzó atendiendo principalmente a la población extranjera a través de la Red de atención a Personas Sin Hogar: Albergues, Centros de Acogida, Comedores, etc. ${ }^{33}$ También es cierto que en las localidades en las que se produjo un cierto asentamiento de colectivos que obligó a sus autoridades a desarrollar actuaciones específicas desde la red básica (Bohadilla del Monte, Distrito de Fuencarral), pero por su

31 Cabría preguntarse si los Servicios Sociales en España pueden responder a la idea de Sistema, pues no pudo establecerse jamás un campo normativo que garantizase la creación de una red homogénea de Servicios Sociales en sus dos niveles para todo el Estado. Más aún si entendemos que dicha red debería garantizar el disfrute de los derechos sociales y ciudadanos que los Servicios Sociales, como derecho subjetivo que son, deberían coadyuvar.

32 En otras palabras: "atendemos a los más vulnerables, desde el Sistema de Protección Social más vulnerable". Hay que reconocer, a pesar de todo, que la flexibilidad y agilidad del Sistema, así como la voluntad y cualificación de sus técnicos, está favoreciendo una adecuación del mismo para procurar respuestas a los nuevos colectivos y sus necesidades a pesar de que se mantienen muchos déficits y limitaciones, tanto en recursos humanos como en medios técnicos y materiales.

33 Resulta interesante observar los datos que reflejan las memorias de los Centros de la Red de Personas sin Hogar. Por ejemplo, en el Albergue de San Martín de Porres en 1991, de la poblacion atendida el $38 \%$ eran extranjeros y el $31 \%$ en 1992 . Del mismo modo, el Centro Municipal de Acogida San Isidro reflejaba en esos mismos años unos porcentajes del $17 \%$ y el $16 \%$ respectivamente. El conjunto de la Red se ha situado siempre en un porcentaje superior al $25 \%$ de extranjeros en relacion con la totalidad de usuarios de los distintos Centros. 
localización y su valor cuantitativo apenas tuvo reflejo en el conjunto de la Red de Servicios Sociales. Del mismo modo, no podemos olvidar la reducida red de centros de atención a la población solicitante de asilo y refugio (CEAR-Centro de Atención a Refugiados), cuya dependencia institucional ha correspondido siempre a la Administración Central y a la propia Cruz Roja, como entidad social independiente encargada de la atención de las personas extranjeras perseguidas por razones de religión, cultura, política, etc.

En la década de los años ochenta y principios de los noventa, los extranjeros mostraban un perfil diferente al actual. Se trataba de personas que estaban de paso hacia otros países (por ejemplo, los polacos con destino a Canadá o EEUU); o bien planteaban su estancia en nuestro país de forma transitoria en vistas a un retorno a su lugar de origen con la mayor cantidad de ingresos económicos en el menor tiempo posible. Eran, casi en su totalidad, adultos, hombres (más estos primeros) y mujeres sin ningún tipo de carga familiar en el país de origen. La familia quedaba en su país con otros familiares. Esta situación de independencia familiar permitía una mayor autonomía para poder acceder al mercado de trabajo y, a su vez, una mayor facilidad de movimientos en el país o países a los que emigraban. Por consiguiente, su contacto con la red de Servicios Sociales Generales era muy escasa. Bien por desconocimiento de la misma o bien porque sus necesidades básicas eran cubiertas de forma autónoma por los propios interesados o bien, por los recursos señalados con anterioridad (comedores, albergues, etc.).

Desde mediados de los años noventa se comienza a producir una afluencia mucho mayor de extranjeros acompañada de un cambio en el perfil de esta población que había modificado su actitud con relación a su permanencia en el país receptor. Ahora se plantea su estabilización en el país de llegada, dejando (u olvidando) para más tarde el retorno a su origen. Por lo tanto, las demandas de asentamiento e integración van a ir apareciendo en lo que denominaríamos como el "imaginario de la inmigración extranjera". Ello supondrá que muchos extranjeros comiencen a acudir a los Servicios Sociales Generales demandando prestaciones cuyo objetivo, más o menos explícito, es la integración y normalización en nuestra sociedad (ayudas de libros para menores, ayudas de comedor en colegios, ayudas para alquiler de vivienda, etc.). Los extranjeros que vinieron a nuestro país en los primeros años de la década de los noventa comenzaron a reagrupar la familia, ya que su situación personal se estabilizaba. Así, pues, los miembros familiares que estaban en los países de origen comenzaron a reencontrarse en el nuevo país. Al mismo tiempo, se produce una emigración con el conjunto de la unidad familiar. 
El resultado de esta nueva situación es evidente, comenzando a producirse un progresivo incremento de extranjeros en la Red de Servicios Sociales Generales ${ }^{34}$. Ello, a su vez, está obligando a las distintas instituciones y administraciones a poner en marcha Planes y Programas específicos de atención a la población extranjera. En definitiva, se ha tomado "conciencia político-institucional" ante el fenómeno social de la inmigración extranjera. De esta forma, será posible superar el modelo de "sorpresa" y pasar al modelo de "planificación estratégica", el cual permitirá definir y movilizar más recursos y nuevas estrategias de actuación.

No podemos finalizar este apartado sin hacer una especial referencia a las ONGs centradas en la atención a inmigrantes. Su papel ha sido muy importante en su doble vertiente. En primer lugar, como organizaciones prestadoras de servicios ante la ausencia de la iniciativa pública-institucional. En este sentido, en los últimos seis años hemos asistido a la creación de múltiples experiencias asistenciales, regidas por las Organizaciones Solidarias que han prestado servicios básicos y sobre todo, programas de apoyo a la integración (clases de idiomas, apoyo en las gestiones de regularización, etc.). En segundo lugar, hay que reconocer a las ONGs el papel que desempeñan como agentes de sensibilización social y sobre todo, de reivindicación y de protesta ante las diferentes situaciones de desigualdad e injusticia que se producen con la población extranjera ${ }^{35}$.

Cabe indicar que el crecimiento del movimiento de ONGs ha estado unido al propio crecimiento y desarrollo de la población extranjera en nuestro país. En la actualidad se puede afirmar que se cuenta con una Organización Solidaria según zona geográfica de origen de la población extranjera e incluso país. Sin olvidar, por supuesto, otras muchas organizaciones con un sentido más generalista y de un mayor capital social e histórico (Médicos del Mundo, Cruz Roja, Asociación Solidaridad Trabajadores Inmigrantes-ASTI), las cuales han desempeñado un importantísimo papel a la hora de configurar el actual Sistema

34 A modo de ejemplo podemos tomar los datos de la ciudad de Madrid. En los Servicios Sociales Generales de esta ciudad a lo largo de 1999 han pasado 3.576 extranjeros. En el año 2000 la cifra casi se ha duplicado, atendiendo a unas 6.475 personas extranjeras (Memoria de los Servicios Sociales Municipales 2000).

35 Otros debates a plantear en referencia al tercer sector, sobre los que aquí no tenemos espacio, se encontrarían en el fomento de la inhibición de la iniciativa pública; la creación de un mercado asistencial con profesionales en precario (cuando no un mercado negro de mano de obra); la dispersión, heterogeneidad y solapamiento del tercer sector y, lo que es más importante, la sedimentacionn de un substrato cultural sobre el que se construye su discurso y forma de intervención, lo que puede suponer, como decimos, una forma de acción benéfica o filantrópica en vez de una política decidida en la defensa de los derechos de los más débiles. Sobre este asunto tratan Santanera y Gallo (1999). 
de Servicios Sociales, entendido éste como la estructura de Protección Social formada por la iniciativa pública y social. En este caso, aún no ha entrado el tercer agente: el mercado.

El resultado hoy es la asunción por parte del subsistema de protección social que denominamos como Servicios Sociales, de los diferentes retos, internos y externos, que han supuesto para éstos el importante crecimiento de población inmigrante en nuestro país.

Sin embargo, conviene recordar que el éxito de la integración no es responsabilidad única de dicho sistema de protección, por el contrario, constituye una tarea a compartir y a desarrollar por el conjunto de lo que definimos como Sistema de Bienestar. Es decir, resulta imprescindible la participación de los otros sistemas: Sanidad, Educación, Empleo, etc. con los Servicios Sociales para que éstos puedan jugar su papel específico, es decir, desde la respuesta ante las necesidades sociales. Incluso podríamos entender que los Servicios Sociales asumiesen un papel como sistema mediador (Sarasa, 1993), entre los diferentes Sistemas de Protección Social para favorecer y acompañar los procesos individuales de integración de la población extranjera. Así se podrían suprimir ciertas barreras culturales y se posibilitaría la incorporación en las diferentes redes de protección social a la población en general. Es decir, evitar en la medida de lo posible la reproducción de procesos de exclusión.

\section{CONCLUSIONES}

Visto lo anterior, caben las siguientes conclusiones:

1. La afluencia de extranjeros en España ha puesto de manifiesto las contradicciones y debilidades del Sistema de Bienestar Social y a su vez, del propio subsistema de Servicios Sociales.

2. El Sistema de Bienestar precipita hacia los Servicios Sociales con requerimientos de intervención que no le son propios (desde lo que entendemos como objeto material del mismo, es decir las necesidades sociales). Ello favorece la indefinicion de nuestro subsistema de Protección Social y sobre todo, incrementa su grado de frustración, ya que no es capaz de responder a muchos de los requerimientos "no adecuados" hechos por el resto de Sistemas de Protección Social. Se busca que legitime su papel como sistema de actuación residual, es decir, que actúe sobre lo que nadie quiere.

3. Así, pues, se corre el riesgo de que el principio orientador de intervención de los Servicios Sociales -las necesidades- pueda reem- 
plazarse por una condición en concreto -extranjería- lo que supondría una alteración del objeto material de los Servicios Sociales con el riesgo añadido de estigmatización y trato desigual a los usuarios. Los Servicios Sociales no solventan la condición de extranjería -lo que sería un absurdo- sino necesidades (sean éstas de extranjeros o no). Por este motivo, parece más oportuno no generar respuestas asistenciales en forma de dispositivos específicos en la lógica de la "extranjería" como problema. Por el contrario, resultará más adecuado comenzar por reforzar la red general de Servicios Sociales para que ésta, desde la lógica de las "necesidades" desarrolle sus capacidades y potencialidades de intervención.

4. Estos problemas descubren que no sólo los Servicios Sociales, sino la Política Social, se dilucida como una política de "sorpresa" y "emergencia" ante situaciones no previstas. De esta forma, un sistema de Servicios Sociales, no concluido y con fallas, dirigido hacia una población más o menos homogénea culturalmente, tiene que adaptarse a las necesidades de una población que tiende hacia una mayor heterogeneidad cultural. Pero esa adaptación queda imposibilitada cuando el Sistema madre, el de Bienestar Social, es el primero que no cumple sus objetivos y delega sus funciones en uno de sus subsistemas, el que además es más débil y vulnerable, recibiendo así las demandas más diferenciales.

5. Por otra parte, el marco conceptual se convierte en una especie de laguna de confusión y fuente de prejuicios, lo que incrementa los problemas a la hora de poder elaborar y definir políticas de integración ajustadas y, por otra parte, genera corrientes de opinión basadas en falsedades y verdades a medias.

6. En al ámbito jurídico se observa cómo la Ley sigue caminando tras los hechos, pero no pretende adaptarse a ellos, pues deja en suspenso la satisfacción de los derechos sociales, infraestructura del Bienestar Social. Como sucede con la población autóctona, el marco normativo actual no garantiza los derechos sociales, referidos al Sistema de Servicios Sociales, a la población inmigrante extranjera.

7. Así, pues, urge un cambio de orientación a varias alturas para que los Servicios Sociales puedan afrontar sus cometidos. En primer lugar debería consolidarse el Sistema de Servicios Sociales en sus dos niveles (más aún el secundario, y si fuese posible mediante ley y garantía pública del mismo, cosa harto difícil). Debería crecer, asimismo, el compromiso del resto de subsistemas de Bienestar Social y sobre todo, la necesaria coordinación entre ellos, cosa que hasta la fecha se ha mostrado imposible. 
8. A su vez, sería menester implantar, de una vez por todas, un discurso de derechos más que de graciabilidades y punición. Realmente, hasta que no se logren tales objetivos, será difícil plantear uno u otro modelo de integración, quedando aplazados los mismos hasta que la política de extranjería sea algo más que una política policial y de suministro de mano de obra barata. No se han afrontado los modelos de integración hasta la fecha salvo las iniciativas dispersas de colectivos y asociaciones particulares, con lo que las propuestas no irán más allá de la mera asimilación. Además queda por revisar el papel de la Universidad y sus diseños curriculares, ya que será difícil plantear Servicios Sociales cuando los actuales y futuros profesionales no han sido preparados con las herramientas necesarias para trabajar con grupos tan heterogéneos (por ejemplo, linguísticamente) como son los que componen el cuerpo de extranjeros en España.

De esta manera, podremos seguir creyendo, quizás un poco ilusoriamente, en la posibilidad de una sociedad más integradora que excluyente, una ciudadanía que se autodefina por el ejercicio de sus derechos y deberes y no por el consumo, atomización y planicie cultural (germen de miedos y prejuicios), una política social más acorde con los principios igualitarios y unos Servicios Sociales más como garantía de tales derechos que como mera acción benéfica o de urgencia del Sistema general.

\section{BIBLIOGRAFÍA}

AYUNTAMIENTO DE MADRID. Área de Servicios Sociales (2000): Memoria de los Servicios Sociales Municipales. Madrid.

BLANCO, C. (2000): Las migraciones contemporáneas. Alianza Editorial, Madrid.

BOURDIEU, P. (1999): Contrafuegos (trad. Joaquín Jordá). Anagrama, Barcelona.

CASADO, D. y GUILLÉN, E. (2001): Manual de Servicios Sociales. CCS, Madrid.

CIS http://www.cis.es (el CIS publica periódicamente encuestas relacionadas con las actitudes hacia la inmigración).

COMUNIDAD DE MADRID. Consejería de Servicios Sociales (2001): Plan Regional para inmigración 2001/2003. Madrid.

INE http://www.ine.es (los informes del INE sobre migraciones son anuales, así como las encuestas de migraciones). 
LAVIÉ, A.H.(2001): Retos de la Inmigración en España. Reflexiones, sugerencias, sensibilidades. Biblioteca de Estudios Sociales y Económicos, Diputación de Cádiz. Cádiz.

SANTANERA, F. y GALLO, A.M. (1999): Volontariato. Trent'anni di esperienze: della solidarietà ai diritti. Utet Libreria, Torino.

SARASA URDIOLA, S. (1993): El servicio de lo social. Ministerio de Asuntos Sociales. Madrid.

SARTORI, G. (2001): La sociedad multiétnica. Pluralismo, multiculturalismo y extranjeros (trad. Miguel Ángel Ruiz de Azúa), Taurus, Madrid.

STEINBERG, S. (1981): The ethnic myth: race, ethnicity and class in America. Beacon Press, Boston. 



\title{
TERRITORIO, HÁBITAT Y VIVIENDA FRENTE A LA EXCLUSIÓN SOCIAL
}

\author{
FCO. JAVIER MIRA GRAU
}

Patronato Municipal de la Vivienda de Alicante.

Departamento de Trabajo Social y Servicios Sociales. Universidad de Alicante.

RESUMEN

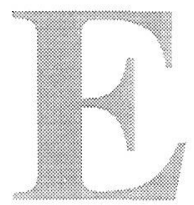

1 objetivo de este artículo es intentar reflejar la estrecha relación condicionante entre territorio, hábitat y vivienda en los procesos de exclusión social.

El trabajo hace un recorrido desde los efectos de la era de la globalización sobre el territorio urbano, los conflictos que surgen en un hábitat y ciudad con determinadas características, donde se plantean unos retos de intervención tendentes a la lucha contra la exclusión social y, a la par, a la sostenibilidad.

Para la revisión de esa radiografía del territorio, se repasan las principales problemáticas de los barrios desfavorecidos españoles, características que delimitan los instrumentos de intervención tendentes a un hábitat social e integrador. De forma operativa, se ofrecen algunos rasgos característicos del Concurso de Buenas Prácticas Urbanas de Naciones Unidas.

Palabras clave: Territorio; Hábitat; Ciudad; Vivienda; Globalización; Barrios Desfavorecidos; Buenas Prácticas Urbanas Innovadoras.

\section{INTRODUCCIÓN}

El crecimiento económico produce una, cada vez mayor, deuda social y una ampliación de la dualización social, incluso podríamos hablar de fragmentación social. La pobreza y la exclusión social es un fenómeno cada vez más urbano, cuyas consecuencias negativas son, entre otras, segregación espacial, estigmatización social, y barrios periféricos deteriorados constructiva y socialmente.

La desigualdad urbana y su reflejo en barrios desfavorecidos o en colectivos que presentan indicios de vulnerabilidad, constituye una rea- 
lidad que reclama día a día la necesidad de dedicar análisis e intervenciones para poder establecer acciones específicas. Es necesario plantear un enfoque tanto desde el punto de vista social como urbano y económico, y prever la necesidad de establecer protocolos de alerta que permitan la adopción de estrategias y medidas preventivas.

El alojamiento y el hábitat son aspectos que necesitan ser integrados en una política más amplia de integración social. La pobreza se urbaniza en cuanto a la exclusión social provocada por el incumplimiento efectivo del derecho a la vivienda.

Los barrios provocan, en algunas ocasiones, exclusión, segregaciones espaciales y estigmatización social. Por esto, la planificación urbana debe dirigirse al desarrollo sostenible del medio ambiente urbano, potenciando la diversidad de la vida urbana y la heterogeneidad, evitando la diferenciación. Por el contrario, la ciudad segregada pasa a constituirse en unidad fragmentada con barrios deteriorados y periféricos, en muy mal estado constructiva y socialmente. De este análisis se desprende que una respuesta eficaz pasaría por la intervención de los poderes públicos, no pudiendo dejarse en manos sólo de la iniciativa privada.

Igualmente, se debe potenciar y profundizar en las prácticas ya realizadas y conocer, sobre todo, los problemas surgidos y las posibles alternativas, permitiendo sensibilizar a la opinión pública, a las Administraciones y a los diferentes agentes económicos y sociales sobre la necesidad de afrontar este reto de un modo serio y eficaz.

\section{LOS EFECTOS DE LA GLOBALIZACIÓN SOBRE EL TERRI- TORIO.}

De manera especial durante la década de los noventa en el contexto europeo, si bien podríamos hablar a escala mundial, se ha ido produciendo una fase de rápidos cambios en el desarrollo de las ciudades, en base, fundamentalmente debido a la creación del Mercado Único en 1992, la apertura de las fronteras orientales y los procesos de convergencia que se han generado en ese entorno.

Estos factores se producen en un marco de internacionalización de la economía, junto a otros procesos propios de la sociedad postindustrial, como son los efectos derivados de la revolución tecnológica, la entrada en un nuevo ciclo de transición demográfica, las nuevas tendencias en el estilo de vida, en el uso del tiempo y del espacio, y en los hábitos de consumo, relacionados todos ellos con los cambios en la movilidad de las personas, de los bienes y de la información. 
Este contexto ha conllevado una precariedad laboral donde han sido determinantes las influyentes «demandas» del Fondo Monetario Internacional para toda la Unión y para España en particular, donde se han presentado exigencias para la Europa del euro, y donde se está dando una desregulación social que promueve la globalización económica. En este sentido, se avanza, pues, hacia un entorno laboral cada día más precario, donde la inestabilidad se está convirtiendo en una norma, y donde la protección social al desempleo tenderá a reducirse como vía también para garantizar la máxima empleabilidad.

Las actividades económicas son cada vez más interdependientes y la forma de integrarse en los mercados regionales, nacionales y mundiales, van a ser determinantes para la cohesión social y la sostenibilidad de cada ciudad. Esta tendencia aventura un marco social caracterizado por unos porcentajes cada vez más amplios de población vulnerable, en especial en los ámbitos urbanos, especialmente en las metrópolis.

Aunque lo analizaremos con profundidad más adelante, estos fenómenos se están reflejando hoy día en los espacios urbanizados llamados barrios desfavorecidos. En estos barrios se van acumulando progresivamente los procesos de exclusión. Esta vulnerabilidad tenderá a extenderse y a cronificarse en determinadas zonas, donde las variables se reflejan especialmente en el incremento del paro (en especial de larga duración), la generalización de la precariedad en el trabajo, la reducción de los niveles salariales, la disminución de la protección social, y por la creciente desintegración social donde es difícil encontrar redes de apoyo social.

Por otro lado, el progresivo envejecimiento de las poblaciones metropolitanas hará también que un factor adicional de creciente vulneralibilidad sea la edad. Ya es una realidad la existencia de barrios enteros donde se «almacena» la población más envejecida y que configuran probablemente barrios en crisis. Igualmente, la vulnerabilidad se acrecentará para la mujer. Los mayores niveles de paro que se ve obligada a soportar, el carácter más precario (trabajo a tiempo parcial) de los empleos a los que accede normalmente, los aún más reducidos niveles salariales, las cargas familiares a las que normalmente se ve obligada a hacer frente, su absoluta preponderancia al frente de hogares monoparentales, su menor movilidad (debido también a su protagonismo en las tareas de cuidado familiar), hará que sea un sector social especialmente afectado por la desintegración social creciente que se va instalando en las metrópolis.

En definitiva, podríamos hablar de que el espacio urbano se endurece y la pobreza se urbaniza. Esto ha provocado que las grandes ciudades hayan realizado grandes esfuerzos para abordar estos problemas 
mediante operaciones estratégicas de modernización, actuaciones de descentralización equilibradora y de rehabilitación de su edificación e infraestructura urbana, renovando las áreas obsoletas y abandonadas; pero la actuación en las áreas congestionadas está resultando inadecuada y las estrategias no contemplan, en general, suficientemente los problemas de sostenibilidad y de cohesión social.

La evolución ocupacional y la de la distribución de ingresos derivada de la reestructuración económica y social a escala global provocan una creciente diferenciación dentro de las sociedades urbanas. Igualmente, la tendencia a la polarización socioeconómica (creciente división entre ricos y pobres) y a la pluralización cultural (derivada de la diferencia de ingresos, pero también de la multiplicación de los grupos étnicos) generan esquemas de segregación y la posibilidad de que se produzca una fragmentación irreversible del espacio urbano.

En cuanto a la estructura de la ciudad, conviven diversos modelos de estructura (centros históricos, ensanches, polígonos, urbanizaciones y áreas de edificación dispersa) junto a nuevas tendencias de extensión y renovación. Esto ha fomentado una separación extrema de funciones por barrios, la urbanización discontinua y la ocupación extensiva del territorio. Estos cambios están creando problemas nuevos y más graves de habitabilidad y sostenibilidad, junto al despilfarro de suelo e infraestructura y la elevación de los costes de mantenimiento de servicios.

El mercado de suelo no está siendo capaz de responder con solares adecuados a las necesidades económicas, sociales y de infraestructuras. Las tendencias desrreguladoras de los usos del suelo agravaron el problema al no establecerse un liderazgo público de la construcción del modelo de ciudad, a través de mecanismos de gestión más dinámicos, que utilicen el propio mercado y la iniciativa pública, orientando la renovación de la ciudad.

Precisamente debido a los rasgos que definen el papel de la globalización sobre el territorio, es el pluralismo y la dinámica de la sociedad urbana la que debe transformarse en un mecanismo de integración significativo en la era de la globalización. Los desafíos que tiene que enfrentar la sociedad urbana globalizada requieren nuevos mecanismos de regulación, nuevas formas de gestión y un nuevo tipo de estado local. En contra de la opinión corriente de que la globalización determina que los Estados sean corrompidos y condicionados desde arriba, se levanta la idea de que la necesidad de autoregulación de los conflictos de la sociedad civil local contribuye a producir estructuras municipales diferenciadas (Lefebvre, 1991). 
Borja y Castells (1997) abundan en esta idea con un marco más concreto de actuación: "Los programas de vivienda y de carácter social (...) corresponden a los gobiernos locales y estatales. El gobierno federal se limita a establecer marcos legales y financieros con el fin de promover la igualdad de la ciudadanía. Sin embargo, las situaciones críticas o los déficits estructurales requieren políticas públicas concertadas (excepcionales o permanentes) que pueden ser impulsadas por el gobierno nacional (...). En algunos casos estos programas pueden contar con una colaboración concertada que vaya de organismos internacionales hasta ONGs y asociaciones vecinales".

\section{HÁBITAT Y CIUDAD: LOS CONFLICTOS QUE SURGEN}

La competencia creciente entre los centros económicos profundiza los problemas sociales en las ciudades. Las viejas y nuevas diferencias sociales y económicas se manifiestan fundamentalmente en el territorio y con toda claridad en las ciudades. Es en ellas donde se concentra la pobreza fundamentalmente.

Tras el panorama apuntado anteriormente, el reto de las ciudades pasa por articular sus necesidades de competitividad, cohesión social y sostenibilidad. Para ello tienen que resolver algunos conflictos importantes que intentaremos exponer a continuación.

En materia de economía urbana, ya comprobamos que las economías locales de cada ciudad son cada vez más interdependientes del resto. Sin embargo se carece, en general, de planes para orientar el desarrollo de las ciudades y regiones.

Muchas decisiones sobre infraestructuras que fomentan la competitividad y la localización de actividad económica se toman, en las ciudades (o sus barrios), como acciones sectoriales para la atracción de inversiones, sin analizar los impactos que se producen sobre la estructura económica, social y urbana, y sobre la sostenibilidad ambiental, creando problemas encadenados a corto y largo plazo.

Las nuevas dinámicas económicas no afectan tampoco por igual a todo el territorio de las áreas urbanas. La nueva inversión empresarial se concentra en ciertas zonas de la ciudad, mientras otros barrios pierden su actividad económica y, poco a poco, van concentrando todas las consecuencias negativas de los procesos de globalización. Las políticas de desarrollo de la competitividad no consiguen conectar la dinámica de las áreas de oportunidad con las zonas que quedan descolgadas del proceso. Las políticas específicas para las zonas retrasadas se 
estructuran más como actuaciones reactivas a problemas sociales crecientes que como planteamientos globales de desarrollo.

El crecimiento económico de las ciudades va acompañado en la actualidad de un aumento de la exclusión social, al quedar una parte importante de la población fuera del sistema económico. La exclusión se da no sólo en determinados grupos sociales (pobreza, raza, edad, mujeres con cargas, etc.) sino que se hace especialmente visible en muchos barrios.

Existen amplias zonas de vulnerabilidad, en barrios con falta de oportunidades, accesibilidad y habitabilidad degradada, que recogen población en situación precaria de empleo, con formación inadecuada, en un medio social desmotivador, etc.

Las economías urbanas son parte integrante del proceso de transformación y desarrollo económicos. Son condición previa para la creación de una base económica diversificada que genere oportunidades de empleo. Será necesario crear muchos empleos nuevos en las zonas urbanas. Las ciudades generan actualmente más de la mitad de la actividad económica nacional en todo el mundo. Si se hiciera frente en forma efectiva a otros factores, como el crecimiento demográfico de las ciudades y la inmigración urbana, entre otras cosas, mediante la planificación urbana y el control de los efectos negativos de la urbanización, las ciudades podrían desarrollar la capacidad necesaria para mantener su productividad, mejorar las condiciones de vida de sus habitantes y proceder a la ordenación de los recursos naturales en forma ecológicamente sostenible.

Este modelo de crecimiento no hace sino agravar los desequilibrios ambientales, a pesar de ciertas declaraciones oficiales al respecto. Como la que se recogía en el documento que el gobierno español presentó ante la Cumbre de Hábitat II, de las Naciones Unidas: «A partir de 1992, las bases de la política económica española se asientan en el principio de desarrollo compatible con el medio ambiente («desarrollo sostenible»), de acuerdo con las ideas emanadas de la Cumbre de Río».

Cada vez más se está configurando un modelo productivo y territorial que consume más recursos de todo tipo (agua, energía, suelo, etc.), que induce un creciente impacto ambiental (mayor contaminación y residuos, reforzamiento del cambio climático, etc.), que cada día es capaz de generar menos empleo asalariado o dependiente, que incentiva una profundización en los desequilibrios regionales y en las desigualdades sociales de todo tipo, y que agudiza la dependencia del exterior.

Todo esto apunta a que el modelo que se está plasmando, con un componente urbano-metropolitano en proceso de intensificación, tenga 
un carácter crecientemente insostenible. Poco a poco los costes del presente modelo de desarrollo se están convirtiendo en «necesarios».

A su vez, está provocando un progresivo endeudamiento de las distintas estructuras político-administrativas (Estado, Comunidades Autónomas y Ayuntamientos), a pesar de la reestructuración del gasto público que se acomete, acorde con las estrategias de globalización, y que inciden especialmente en el recorte del gasto social que llegó a caracterizar al Estado de Bienestar. Este endeudamiento público se está convirtiendo, también, en un instrumento adicional de generación de desigualdad.

En suma, el presente modelo de desarrollo urbano induce unos desequilibrios económicos, sociales, territoriales y ecológicos, que hacen difícil su viabilidad o gobernabilidad, a medio y, sobre todo, a largo plazo. La presión ejercida sobre el medio urbano, y los ecosistemas que lo sustentan, por los procesos de urbanización, es cada vez mayor, sin que se establezcan controles adecuados respecto a la proporción de actividades que deben asentarse en distintos lugares, ni límites de capacidad de carga en determinadas áreas.

En materia de habitabilidad y vivienda también habría aspectos importantes a destacar. A pesar del gran esfuerzo realizado por muchas ciudades, para crear o reacondicionar espacios públicos, se detectan grandes deficiencias que se concentran fundamentalmente en los cascos antiguos y en los barrios residenciales populares. La habitabilidad de estos barrios presenta condiciones bastante generalizadas de degradación del espacio, que conducen al desarraigo y falta de identificación con sus barrios por parte de los vecinos y usuarios. Las causas fundamentales son los defectos de diseño y falta de complejidad de usos, la escasa integración de los barrios en áreas más extensas y la intrusión del vehículo motorizado, estacionado o en circulación, así como la escasa cooperación vecinal en su diseño y gestión.

Un factor importante de calidad de vida es la habitabilidad del parque edificado. Las condiciones de los edificios, y en particular de las viviendas, son inadecuadas en muchas ocasiones debido a diferentes causas, destacando, entre otras, la existencia aún de edificios sin condiciones mínimas de habitabilidad, los edificios en malas condiciones de mantenimiento o deteriorados, y los edificios con diseños y materiales escasamente reciclables y reutilizables.

Además, una vivienda adecuada significa algo más que tener un techo bajo el que guarecerse. Significa también disponer de un lugar privado, espacio suficiente, accesibilidad física, seguridad adecuada, seguridad de tenencia, estabilidad y durabilidad estructurales, ilumina- 
ción, calefacción y ventilación suficientes, una infraestructura básica adecuada que incluya servicios de abastecimiento de agua, saneamiento y eliminación de desechos, factores apropiados de calidad del medio ambiente y relacionados con la salud, y un emplazamiento adecuado y con acceso al trabajo y a los servicios básicos, todo ello a un costo razonable.

Desde que se aprobó la Declaración Universal de Derechos Humanos en 1948, el derecho a una vivienda adecuada se ha reconocido como uno de los componentes importantes del derecho a un nivel de vida adecuado. Todos los gobiernos sin excepción tienen algún tipo de responsabilidad en el sector de la vivienda, como demuestran la creación de ministerios de la vivienda u organismos estatales análogos, la asignación de fondos al sector de la vivienda y las políticas, programas y proyectos de todos los países. El suministro de vivienda adecuada a todas las personas no sólo exige medidas por parte de los gobiernos sino de todos los sectores de la sociedad, incluido el sector privado, las organizaciones no gubernamentales, las comunidades y las autoridades locales, así como las organizaciones y entidades asociadas de la comunidad internacional. En un contexto global de creación de condiciones propicias, los gobiernos deben adoptar medidas apropiadas a fin de promover, proteger y velar por el logro pleno y gradual del derecho a una vivienda adecuada.

En aras a asumir dicha responsabilidad que entiendo debe ser mayoritariamente de carácter público, la política, pues, de vivienda debe propiciar la formulación, la evaluación periódica y la revisión de un marco que garantizara la oferta de vivienda como base para el suministro de una vivienda adecuada para todos. Uno de los principios fundamentales para formular una política realista en materia de vivienda es su integración con las políticas generales de desarrollo macroeconómico, ambiental y social. En las políticas de vivienda, centradas en la creciente demanda de vivienda e infraestructura, también se debe insistir en aumentar la utilización y en el mantenimiento del patrimonio de viviendas existente mediante la propiedad, el alquiler y otros regímenes de tenencia, a fin de satisfacer las diversas necesidades. Las políticas deben responder especialmente a las diversas necesidades de las personas pertenecientes a grupos desfavorecidos y vulnerables.

El aumento de los precios de la vivienda y el predominio del régimen de tenencia de propiedad hacen que difícilmente se puedan cubrir las necesidades de jóvenes y sectores populares en el mercado. Los altos precios y las diferencias entre distintos núcleos urbanos y distintos barrios han dado lugar a unos procesos de migraciones internas en las áreas metropolitanas en busca de las mejores condiciones de vi- 
vienda en términos de calidad y coste.

Por lo que respecta al protagonismo de los diferentes actores, públicos y privados, que deben llevar adelante las estrategias de intervención en las ciudades, cabe destacar lo siguiente. Las políticas para las ciudades y el territorio suelen carecer de un enfoque global que permita plantear estrategias consensuadas e integrar objetivos y decisiones sectoriales. Faltan a todos los niveles planes directores y estratégicos, de carácter continuo y con observatorios y seguimiento de los procesos, y de algunos espacios y temas específicos.

Un factor a destacar es la insuficiente coordinación entre niveles de la Administración y dentro de ellos. Es necesario aumentar la capacidad técnica y organizativa de las Administraciones, y en particular de los Ayuntamientos que por proximidad tienen una mayor carga de actuación y gestión en el territorio urbano.

Aunque las causas estructurales de los problemas deben abordarse a menudo a nivel nacional y a veces a nivel internacional, los progresos dependerán en gran medida de las autoridades locales como instancia más cercana y conocedora de la problemática del hábitat en su entorno, del establecimiento de asociaciones a todos los niveles de la Administración pública con el sector privado, del sector de las cooperativas, de las organizaciones no gubernamentales y comunitarias, los trabajadores y empresarios, y la sociedad civil en general.

En este sentido, Borja y Castells consideran que una de las tareas fundamentales de las instancias políticas municipales en el futuro consiste en armonizar la realización de los objetivos económicos con las funciones de integración social. Al mismo tiempo que las ciudades se sitúan en la economía global, deben también integrar y estructurar a su sociedad local. En este sentido, lo local y lo global son complementarios y no antagónicos. Esa integración social requiere mecanismos políticos democratizados, basados en la descentralización administrativa y en la participación ciudadana en la gestión municipal. Pero también exige una política económica local, como por ejemplo la de mantener un sector de empleo en torno a servicios públicos independientes de la competencia global (Borja/Castells, 1997).

Con todo, las Administraciones no son los únicos agentes productores y gestores de la gobernabilidad de la ciudad. El papel del mercado en la creación y gestión de la infraestructura de la ciudad es insuficiente. La concertación con el sector privado en operaciones de riesgo y actuaciones sociales, como la rehabilitación de barrios excluidos, no se produce, o su participación es meramente testimonial.

En algunas ocasiones, la impulsión de empresas públicas para la 
promoción de infraestructura urbana y para la gestión de servicios públicos, es una forma de flexibilización y de aumento de la incidencia en la organización de la ciudad. Algunas experiencias de consorcios y empresas mixtas con incorporación de sector financiero o industrial podrían facilitar la mejora de la ciudad.

Otro elemento a tener presente es el hecho que la participación ciudadana en la vida municipal es muy escasa siendo necesario un mayor acercamiento al ciudadano. Es necesario replantear los mecanismos de participación ciudadana que en muchas ocasiones se limitan a ser meros instrumentos de información y comunicación sin capacidad real de incidencia sobre la decisión final. Algunas experiencias de descentralización municipal han sido positivas pero el camino de la democratización de la vida municipal y la participación de los barrios apenas se ha iniciado.

Lo que parece evidente es que para encarar de forma óptima los aspectos sociales de la cuestión urbana es vital una planificación social estratégica que genere consensos y bajo la premisa de la coordinación de acciones.

A modo de alternativas al modelo de desarrollo urbano que prevalece y sensibilizados por los valores de la sostenibilidad, se deben articular medidas y movimientos de reivindicación que reclamen una forma de actuar diferente. En muchos casos son las asociaciones vecinales las que vuelven a ser el motor de proyectos alternativos para la mejora del hábitat. Los planes de desarrollo comunitario y local son un ejemplo de experiencias que nacen desde abajo para frenar las dinámicas de desigualdad.

Planes comunitarios, $\mathrm{u}$ otras iniciativas interdisciplinares abiertas al conjunto de la ciudadanía, abren una vía para recuperar una visión compleja y plural de la ciudad. Ejemplos como éstos devuelven protagonismo a las ciencias sociales en el ámbito de la vivienda y el urbanismo. Son una oportunidad para demostrar que la planificación urbanística y la cuestión urbana no son cotos cerrados de investigación y propuestas sólo técnicas. Al contrario, la ciudad es todavía un laboratorio excepcional de experiencias humanas en busca del bienestar colectivo. 


\section{LAS CIUDADES EN UN CONTEXTO DE CAMBIO: RETOS PLANTEADOS}

Precisamente a partir de los conflictos que anteriormente hemos visto que se están dando progresivamente en los contextos urbanos de las ciudades del mundo occidental, éstas tienen ante sí unos retos que pueden posibilitar un cambio en diferentes parcelas donde destacaremos a continuación las que entendemos que suponen una mayor apuesta por el bienestar colectivo.

El panorama urbano del entorno europeo viene caracterizado por el hecho de que aproximadamente un $80 \%$ de la población europea vive en ciudades, característica que hace de Europa el continente más urbanizado del mundo. Los datos demográficos confirman que la urbanización de la sociedad europea es un proceso en marcha, aunque a un ritmo más pausado que en las décadas anteriores. El crecimiento demográfico de las ciudades es una consecuencia directa de la tasa de crecimiento natural, los movimientos de población de las zonas rurales o menos prósperas y la emigración, especialmente la procedente de terceros países.

Como ya vimos, el medio ambiente y las condiciones que determinan la calidad de vida en general están adquiriendo una creciente relevancia como factores capaces de influir en la ubicación de las nuevas actividades. Las ciudades se enfrentan por lo tanto al desafío de adaptarse continuamente a los rápidos cambios de la economía y otros sectores.

La actual aparición de nuevas oportunidades económicas está contribuyendo en muchas ciudades a agrandar las disparidades sociales y económicas. Sumamente importante a este respecto es el hecho de que la mitad de los desempleados de la Unión Europea se encuentran en situación de paro prolongado. La situación de penuria de las ciudades se refleja, entre otras variables, en el aumento de la pobreza, el incremento de las personas sin techo, el aislamiento social, las ínfimas condiciones de alojamiento, el abuso de estupefacientes y las conductas delictivas.

En muchas ciudades europeas, el fenómeno de exclusión ha conducido a la segregación física de determinados grupos sociales a los barrios peor equipados. Cada vez se encuentra más extendida la opinión de que la segregación territorial no sólo constituye un problema en términos de empleo, educación y mala calidad de la vivienda, sino que además, los comportamientos excluyentes que de ella se derivan resultan perjudiciales para el interés y el atractivo económico de la ciudad 
La globalización y la pérdida de preponderancia del sector industrial en favor del sector de servicios no han disminuido la importancia del espacio urbano para el desarrollo económico. Un elemento crucial para el equilibrio territorial del desarrollo urbano es el equipamiento de las ciudades con servicios que les permitan atraer actividades comerciales modernas, y especialmente aquellas ciudades de tamaño medio bien conectadas con zonas de economía más saneada.

Precisamente en la línea del desarrollo de estrategias locales de empleo, la Unión Europea considera a este nivel de la Administración como instancia significativa para la consecución de objetivos comunitarios de carácter general, como el pleno empleo, el crecimiento económico sostenible y la cohesión social. El objetivo de las estrategias locales de empleo debería consistir en desarrollar el empleo en un territorio urbano mediante un conjunto integrado de medidas y un plan de acción.

También hemos podido comprobar anteriormente la enorme preocupación que los habitantes de las zonas urbanas tienen cada vez mayor por la calidad de su medio ambiente natural y físico. Según un estudio realizado por la Agencia Europea del Medio Ambiente, entre un $70 \%$ y un $80 \%$ de las ciudades europeas de más de 500.000 habitantes no reúnen los niveles mínimos de calidad de la atmósfera requeridos por la Organización Mundial de la Salud. El medio ambiente urbano sufre problemas graves como el transporte urbano y su capacidad de contaminación, el tratamiento de los residuos sólidos o las aguas residuales urbanas.

Partiendo de un concepto más amplio de medio ambiente, la planificación urbana de épocas anteriores no siempre ha contribuido a desarrollar el potencial de las ciudades y los barrios, y consiguientemente el desempeño simultáneo de diversas funciones. Ello ha provocado la aparición de zonas monofuncionales relacionadas con parcelas específicas de la actividad humana (trabajo, compras, ocio, residencia). La existencia de estas zonas reduce las posibilidades de que las ciudades se conviertan en espacios en los que los habitantes puedan desarrollar plenamente su existencia. Es necesario introducir cambios en las políticas de planificación urbana para obtener una mayor sostenibilidad, mezcla y diversidad, devolviendo a la ciudad su papel de animado lugar de encuentro para todo tipo de actividades a todas horas del día.

Precisamente sobre estos asuntos trataron los temas de la Conferencia Hábitat II que se llevó a cabo en Estambul en junio de 1996 y fue la segunda de las conferencias mundiales convocadas por la Asamblea General de las Naciones Unidas donde estuvieron presentes 20.000 participantes de 150 Estados. Sus objetivos fundamentales versaron 
sobre el análisis de la problemática relacionada con los distintos aspectos del asentamiento humano. A su término se llegó a la conclusión de que para asegurar las bases naturales de la vida humana es necesaria una estrategia mundial de crecimiento económico, justicia social y equilibrio ecológico.

Hábitat II fue la primera conferencia de Naciones Unidas en la que las ciudades tuvieron una participación importante y se mencionó la necesidad de una cooperación global. Los Estados participantes se pronunciaron por la autonomía municipal, la descentralización de las responsabilidades y la adjudicación de los recursos financieros necesarios a los municipios.

Hábitat II produjo dos documentos importantes: en primer lugar, la Agenda Hábitat, que incluye una nómina de principios y obligaciones y un plan de acción promulgados unánimemente por los participantes; y en segundo lugar, la «Declaración de Estambul» que fue discutida y aprobada por los jefes de Estado y de gobierno, o sus ministros, que se encontraron allí en ocasión del cierre de la conferencia.

Siguiendo este criterio y las propias estrategias marcadas desde la Cumbre Hábitat II, la labor de los gobiernos se debería basar en el establecimiento de marcos legislativos, institucionales y financieros, gracias a los cuales el sector privado, las organizaciones no gubernamentales y los grupos comunitarios pudieran contribuir plenamente al logro de vivienda adecuada para todos y un desarrollo sostenible del hábitat y el entorno, y conseguir determinar colectivamente su futuro, decidir cuáles son las esferas de acción prioritarias, encontrar y asignar cursos equitativamente y establecer asociaciones para lograr metas comunes.

El último de los retos que entendemos como vital parte de la necesaria integración y participación ciudadana en la sociedad urbana. En las ciudades se vive actualmente un debilitamiento del nivel de participación en el proceso democrático local. Esta participación es particularmente escasa en las zonas más marginalizadas de las ciudades.

Ahora bien, también hay que contemplar que la instancia de la Administración que se debiera emplear a fondo en estas cuestiones (los Ayuntamientos) se tiene que enfrentar a la dificultad de asumir su responsabilidad en la resolución de los problemas urbanos sin contar para ello con la capacidad institucional y financiera necesaria. Debido a las restricciones generales que se han impuesto al gasto público, los ingresos reales de las autoridades municipales han disminuido en el curso de la última década, con el resultado de que también la inversión local se ha contraído en la mayoría de los casos y, muy especialmente, en aqué- 
llos donde ha tenido lugar un aumento del gasto social de esas autoridades.

La Administración de las ciudades se ve complicada aún más por el hecho de que en ellas ejerce competencias una multiplicidad de autoridades públicas de ámbito tanto local como regional, nacional y hasta europeo. Este hecho puede no sólo crear dificultades para que las políticas se apliquen con éxito sobre el terreno, sino también impedir que los ciudadanos conozcan con claridad las instancias a las que corresponde la responsabilidad real en los problemas de su ciudad.

Para que la aplicación de la legislación y de los programas responda realmente a sus necesidades, es cada vez más importante formalizar la participación de los agentes locales en el proceso de toma de decisiones.

\section{PROBLEMÁTICA Y NECESIDADES DE ACTUACIÓN EN LOS BARRIOS DESFAVORECIDOS ESPAÑOLES}

Tras la revisión de cómo se encuentra el panorama global del entorno urbano y sus implicaciones directas sobre el hábitat social, es momento de profundizar en el contexto español, y más concretamente, en los llamados barrios desfavorecidos. Para ello, es imprescindible el análisis de las conclusiones que emanan del estudio realizado desde el Ministerio de Fomento con motivo de la participación en un grupo de trabajo de la OCDE (Arias, 1998).

El estudio parte de la constatación de que existen barrios desfavorecidos en las ciudades y de que en ellos se concentra una parte significativa de la población desfavorecida. Esta orientación del estudio proviene de dos hipótesis correlacionadas:

- La concentración de la desigualdad en determinadas áreas de la ciudad y su permanencia a lo largo del tiempo, en ciertos barrios consolidados dentro de la urbe, se debe a condiciones estructurales socioeconómicas y urbanas.

- Como consecuencia de su situación, en los barrios desfavorecidos interactúan procesos multidimensionales que combinan factores sociales, económicos y espaciales, dificultando el desarrollo de la población residente.

Debido a ello en distintos países se están poniendo en práctica políticas de barrio, como complemento de las políticas sectoriales de seguridad social, salud, educación, asistencia, vivienda, etc., que pretenden integrar medidas en actuaciones locales que contemplen los problemas 
específicos de la población. Programas de actuación que, partiendo de la necesaria colaboración de la sociedad civil y del sector privado, promuevan políticas de desarrollo socioeconómico en los barrios, recuperando el concepto de barrio y/o ciudad en sus dimensiones social, económica, urbanística e institucional.

A partir de esa filosofía de intervención y realizando una inmersión en la metodología y resultados del citado estudio, destacamos a continuación las distintas problemáticas detectadas según distintas variables, así como las líneas generales de actuación que se proponen.

\subsection{Tipología urbanística de barrios desfavorecidos.}

Las bolsas de pobreza se localizan en los barrios en los que se sitúa la oferta de viviendas más baratas del mercado, en alquiler o venta, y en las áreas en las que se alojan mediante autoconstrucción los nuevos hogares, en general por población inmigrante, que no pueden acceder ni siquiera a dicha oferta. Se trata de barrios que nunca reunieron las condiciones mínimas de habitabilidad, barrios que fueron creados, desde sus orígenes, para la población de menos recursos, o terrenos que se ocuparon al margen del planeamiento e incluso de la urbanización.

Esta permanencia, en el espacio social de la ciudad, de los barrios desfavorecidos se mantiene incluso cuando se producen operaciones de realojo dando viviendas de calidad a los habitantes antes mal alojados, ya que la población sigue teniendo los mismos problemas sociales y económicos, eso sí, en una vivienda habitable.

\subsection{Factores de vulnerabilidad en los barrios desfavorecidos.}

Los factores de vulnerabilidad que operan en los barrios desfavorecidos españoles se van encadenando entre sí normalmente. De ese modo, se concentra en ellos población que acumula factores de vulnerabilidad, como un bajo nivel educativo, formación profesional obsoleta para el mercado laboral, y paro, o empleo precario, población que tiene por lo tanto escasos recursos económicos y una alta dependencia de las prestaciones sociales.

En muchos casos las viviendas son inadecuadas cuando no se trata directamente de infravivienda, especialmente en cascos antiguos y áreas periurbanas o de ocupación de suelos no urbanizados. La vulnerabilidad se agrava también con las familias desestructruradas y monoparentales (especialmente encabezadas por mujeres), así como con la existencia en el hogar de personas discapacitadas. La falta de expectativas y estímulos para la juventud facilita el fracaso escolar y en ciertos 
casos la vinculación posterior a la droga y/o a algún tipo de marginalidad. Igualmente, se concentra población inmigrante con cultura y lengua, incluso de etnias distintas, que les dificulta su integración en la sociedad local.

Normalmente estos barrios suelen estar poco cuidados por las Administraciones, con degradación ambiental, servicios deficientes, mala accesibilidad, y desde luego sin apenas iniciativa económica local, abandono de los comercios y talleres, etc. Es decir, adquiriendo una imagen colectiva exterior e interior de abandono a su suerte, que realimenta la situación de marginalización, sólo superada por las reivindicaciones vecinales, cuando se organiza la parte más activa de la población.

Esta radiografía de la situación de vulnerabilidad evidencia que estamos hablando de un problema multidimensional, que requiere una actuación integrada para que las personas afectadas puedan superarlo, pero en los barrios desfavorecidos la actuación debe contemplar una intervención que, además, tenga en cuenta sus factores específicos: urbanísticos, ambientales, sociales, económicos y culturales.

Parece evidente que las actuaciones sectoriales apenas han conseguido aliviar alguna dimensión del problema, sin dar una alternativa a estas áreas en las que la población sigue estando formada por grupos vulnerables y los barrios en sí siguen siendo desfavorecidos; los mismos barrios, incluso, después de ser remodelados con nuevas viviendas y equipamientos.

\subsection{La dimensión espacial como factor de vulnerabilidad (escala barrio).}

Una aplicación reduccionista de la escala ciudad ha ido creando polígonos de vivienda de poca calidad y escaso equipamiento, y una estructura de actividades de la ciudad muy segregada, donde los responsables técnicos y políticos del urbanismo han olvidado la necesaria diversidad funcional y social.

Esta lógica de producir ciudad ha permitido, y permite, procesos que alteraron los barrios, reforzando, en los más vulnerables, las situaciones de declive que se han materializado en:

- Intervenciones públicas que aíslan y bloquean el barrio impidiendo su difícil regeneración.

- Acumulación progresiva de vivienda pública para grupos vulnerables.

- Concentración progresiva de grupos muy vulnerables en infravivienda. 
- Desaparición de empresas locales (talleres, comercios, etc.) y rechazo de nuevas inversiones por cuestiones de entorno social, ambiente físico, inseguridad, etc.

- Falta de recursos en el ambiente familiar y en redes sociales.

- Dificultad de los residentes para el acceso a una nueva formación profesional y a los empleos.

- Falta de apoyo a la vida cultural y asociativa de los barrios, así como de atención a los afectados en la toma de decisiones.

La interacción de estos factores crea procesos acumulativos. Aparece un efecto de «barrio en crisis» que comporta nuevas desventajas a los vecinos, a través de complejos procesos culturales, sociales y familiares.

\subsection{El declive de los barrios desfavorecidos en el momento actual}

Las tendencias parecen evolucionar hacia un mayor declive de los barrios desfavorecidos, agravándose muchas situaciones de precariedad laboral y paro duradero que se concentran más en estos barrios.

La situación de inestabilidad económica y pobreza que se genera, unida a condicionantes sociales como la desestructuración familiar y el entorno social del barrio, crean a veces círculos viciosos de declive y marginalización que pueden llegar a situaciones de exclusión. Estas situaciones son especialmente graves cuando las personas o familias están afectadas además por otros factores de vulnerabilidad derivados de alguna discriminación por motivo de edad, género, etnia, discapacidad, etc.

Por otro lado, el crecimiento difuso de las ciudades parece estar polarizando la ciudad más, si cabe, en barrios favorecidos y desfavorecidos, mostrando las desigualdades sociales y económicas en barrios muy definidos.

Ante este panorama, hay defensores de las teorías neoliberales que consideran que el propio mercado acaba regulando estos desequilibrios. Pero estos mecanismos, independientemente de su ineficiencia social e injusticia personal, no funcionan en los segmentos desfavorecidos de la sociedad, que tienen formación obsoleta, información insuficiente, dificultades para acceder a las nuevas viviendas inasequibles en precio y/o que se siguen produciendo en un espacio social muy segregado, y que, además, tienen escasa accesibilidad al empleo. 


\section{5. ¿Qué políticas necesitan los barrios desfavorecidos?}

Si no se promueven actuaciones específicas que permitan mejorar las estructuras sociales y económicas de los barrios desfavorecidos, se corre el riesgo de que la degradación de las áreas vulnerables llegue a límites a partir de los cuales resultan más difíciles de resolver, ya que alcanzado un cierto umbral de declive la regeneración es mucho más difícil, larga y costosa.

Como venimos destacando a lo largo de todo el artículo, los ejes de una política de barrios pasan porque el territorio, la ciudad y sus barrios sean lugar en el que potenciar el desarrollo económico y social, dentro de los límites de la sostenibilidad local y global. Para esto es necesario dar relevancia a las iniciativas locales para la creación de empleo y la mejora de la calidad de vida.

Otro de los elementos definitorios pasa por reforzar la democracia representativa con mecanismos de acción participativa a nivel de barrio y ciudad, desarrollando una política de mayor corresponsabilidad cívica para abordar los problemas de creación de empleo, cohesión social y sostenibilidad. Para ello hay que instrumentar muchas políticas desde abajo, desde programas de barrios, con participación de los afectados, priorizando actuaciones queridas por la población, que impliquen a la ciudadanía y faciliten su efectividad.

De la misma forma, los problemas de cohesión y de sostenibilidad ambiental sólo tendrán solución cuando se impliquen las personas y organizaciones, y para ello tienen que ponerse en marcha políticas con las que la sociedad civil se sienta cómplice, porque no considere ajenas, sino proyectos propios en los que puede intervenir y tiene responsabilidad.

\section{EL CAMINO HACIA UN HÁBITAT SOCIAL E INTEGRADOR}

En este apartado nos parece muy destacable las aportaciones del profesor Corraliza en un reciente artículo sobre esta estrecha relación entre hábitat y exclusión social (Corraliza, 2001).

Desde luego para la consecución de ese objetivo tan ambicioso, una premisa que debe caracterizar el conjunto de actuaciones a promover es el hecho de poner el énfasis en la innovación. Esto plantea dos necesidades básicas: la creación de laboratorios de ideas sobre las necesidades de la gestión local, y el establecimiento de redes y sistemas de intercambio de experiencias de gestión y actuaciones urbanas. La innovación, pues, podría ser definida a partir de tres rasgos comunes a 
la mayor parte de las propuestas presentadas.

En primer lugar, el principio de que toda intervención urbana es a la vez una intervención sobre el entorno físico, y sobre el entorno social. Parte del supuesto de que el espacio urbano es un entramado de parámetros que se influyen entre sí. Supone que muchos problemas de la estructura espacial urbana sólo tienen solución si, al mismo tiempo, se modifican las condiciones de existencia de la red social. Y, a la inversa, problemas que se detectan en una red social, sólo tienen cabal solución si, al mismo tiempo, se interviene sobre las condiciones físicas y espaciales del entorno sobre el que se aloja esa comunidad. Las condiciones de partida desiguales, la dinámica social que reproduce situaciones injustas se plasman en la morfología urbana, y conforma una estructura espacial de la desigualdad. Desde esta perspectiva, no cabe, pues, imaginar acciones contra la exclusión social que no se basen en acciones contra la exclusión espacial.

En segundo lugar, resulta innovador el principio de la participación misma en la acción local. El problema central de la participación en la planificación de actuaciones urbanas reside fundamentalmente en la definición de los escenarios de participación (tanto formal como informal), así como en la relación entre los escenarios de participación y el proceso de toma de decisiones sobre la intervención social y ambiental en el entorno urbano. Con frecuencia, la participación pública se remite a las fases de consulta o información pública de los distintos proyectos.

Por último, debe contemplarse la creación de un centro u observatorio permanente de detección de factores de riesgo en el desarrollo urbano. Este centro estaría dedicado al registro, estudio, análisis y prospectiva del desarrollo urbano, y actuaría como central de reflexión inter y transdisciplinar sobre los problemas de las ciudades, así como central de alarma de los factores de riesgo y promoviendo procesos innovadores de toma de decisiones.

Cabe mencionar en este sentido que la Unión Europea está dedicando fondos a proyectos de reequilibrio social y urbanístico en diferentes ciudades. Un ejemplo es el programa URBAN destinado a barrios especialmente afectados por el impacto de la crisis del mercado laboral y por deficiencias estructurales a nivel del hábitat. De hecho, el reglamento de fomento del Programa URBAN de la Unión Europea constata que: «las tensiones crecientes de la sociedad europea se manifiestan sobre todo en un alto grado de segregación social, que se expande en el centro de las ciudades y sus periferias».

El objetivo de la iniciativa comunitaria URBAN es la regeneración 
social y económica de las ciudades y barrios en crisis con el fin de promover un desarrollo urbano sostenible. El segundo ciclo de URBAN («URBAN II») cubrirá el período 2000/2006, y abarca 70 zonas urbanas desfavorecidas en toda la UE. La financiación total de la UE ascenderá a 728,3 millones de euros, y atraerá al menos una cantidad similar de financiación procedente de los sectores público y privado.

Una característica específica de URBAN II es el desarrollo de modelos innovadores de regeneración urbana. Otra de sus características es el fuerte énfasis concedido al proceso de cooperación y a la participación de los agentes locales. También habrá un intercambio de información y experiencia sobre desarrollo urbano sostenible dentro de la Unión Europea. URBAN II está financiado por el Fondo Europeo de Desarrollo Regional (FEDER).

La financiación se destina a la renovación de edificios y espacios públicos, iniciativas locales en favor del empleo, mejora de los sistemas de educación y formación en beneficio de las personas desfavorecidas, desarrollo de sistemas de transporte público más ecológicos, fomento de sistemas más eficaces de gestión de los recursos energéticos y del uso de energías renovables y aprovechamiento del potencial que ofrecen las tecnologías de la sociedad de la información.

Llegados'a este punto y bajo el prisma de potenciar fórmulas con carácter innovador como se planteaba anteriormente, lo que parece realmente difícil es la consecución del binomio calidad de vida y la lucha contra la exclusión social. La pregunta clave consiste en definir hasta qué punto un espacio urbano facilita o dificulta la satisfacción de las necesidades psicosociales básicas. La mejora en la calidad de vida urbana vendría dada, fundamentalmente, por el grado en que un espacio, por su forma, su estructura o su ubicación en la trama urbana, facilita o dificulta la satisfacción de estas necesidades.

Y precisamente como colofón a esta reflexión y como intento de plantear propuestas de actuación tendentes a ese recorrido desde un hábitat social como mecanismo integrador, queremos plantear los criterios generales, por lo interesante de la propuesta, que se plasman en la Convocatoria del IV Concurso de Buenas Prácticas. Las Naciones Unidas han considerado que el interés despertado y los resultados obtenidos en las tres convocatorias anteriores (1996, 1998 y 2000) confirman la eficacia del Concurso de Buenas Prácticas para fortalecer las políticas dirigidas a la mejora de las condiciones de vida de los ciudadanos, desde la perspectiva del desarrollo sostenible, de acuerdo con los principios establecidos en la Segunda Conferencia de las Naciones Unidas sobre Asentamientos Humanos (Hábitat II). 
Las propuestas deben tener una especial relevancia, tanto en relación con los problemas específicos que abordan, como desde el punto de vista de su contribución al discurso conceptual sobre la intervención en la ciudad para la mejora de la calidad de vida. En su conjunto, las prácticas que se presenten deben cumplir algunos rasgos característicos:

- Voluntad de considerar los problemas relacionados con la exclusión social o por razones de diversidad social (género, minorías, diversidad de procedencia, etc.) desde un enfoque integrado. El enfoque integrado quiere decir que se subraya la importancia de un esquema de actuación que, partiendo de un análisis de las causas de exclusión social, incida sobre el proceso social de la exclusión en su conjunto.

- Movilización de los recursos de la propia comunidad y, de esta forma, beneficiar a la comunidad en su conjunto y no sólo a los grupos de riesgo afectados.

- Incremento del asociacionismo y del partenariado, ampliando la base de los agentes sociales sobre los que se apoya.

- Propósito de convertir a los destinatarios en protagonistas del programa propuesto, y no en meros clientes.

En definitiva, se debe combinar la capacidad para movilizar recursos de las instituciones públicas y de los agentes sociales para abordar los problemas. Los efectos de estos recursos serían mucho menores si no fueran acompañados por los recursos (sociales, morales y de participación) de la propia comunidad. Se destaca de esta forma el importante papel que las asociaciones, los grupos informales, los líderes comunitarios y las redes de vecinos tienen en la eficiencia de estos programas. La participación y la implicación social es una garantía solvente de sostenibilidad de las experiencias.

\section{BIBLIOGRAFÍA}

AA.VV.: Políticas sociales urbanas. Convocatoria al debate, Red N.5. Políticas sociales urbanas. Programa URB-AL, Intendencia Municipal de Montevideo, Comunidad Europea, Montevideo, 1998.

AMIN, S.: El capitalismo en la era de la globalización. Paídos, Barcelona, 1999.

ARIAS GOYTRE, F.: La Desigualdad Urbana en España. Ministerio de Fomento. Madrid, 1998.

ASOCIACIÓN ESPAÑOLA DE PROMOTORES PÚBLICOS DE VIVIENDAS Y SUELO-PATRONATO MUNICIPAL DE LA VIVIENDA DE ALICANTE: 
Seminario Técnico: La vivienda y su aspecto social. Alicante, 1994. AYUNTAMIENTO DE BARCELONA-EUROCIUDADES: Las ciudades y las Políticas sociales en Europa. Congreso Europeo de Bienestar Social, Barcelona, 1991.

BANCO MUNDIAL: Los países en desarrollo y el sistema financiero mundial. Informe sobre desarrollo mundial. 2000.

BORJA, J. y CASTELLS, M.: Local y Global: la gestión de las ciudades en la era de la información. United Nations for Human Settlements (UNCHS), ed. Taurus, Madrid, España, 1997.

COMISIÓN DE LAS COMUNIDADES EUROPEAS: Fortalecimiento de la dimensión local de la estrategia europea de empleo. Bruselas, 2001.

CORAGGIO, J.L.:La Política Urbana Metropolitana frente a la Globalización. EURE, Vol. XXIII, N 69, Santiago, 1997.

CORRALIZA RODRÍGUEZ, J.A.: Hábitat: innovación, calidad y lucha contra la exclusión social. Instituto Juan de Herrera. Madrid, 2001.

CORTÉS ALCALÁ, L.: La cuestión residencial: bases para una sociología del habitar. Madrid, 1995.

CORTÉS, R.: La vulnerabilidad social. Marco teórico: antecedentes históricos del concepto. Dimensiones de análisis, de focalización y de intervención. Secretaría de Desarrollo Social, Subsecretaría de proyectos Sociales (SIEMPRO), 1996.

GAVIRIA, Mario y otros. Vivienda social y trabajo social. Editorial popular, Madrid, 1990.

HARVEY, D.: Urbanismo y Desigualdad Social. Siglo XXI. Madrid, 1973.

ONU: Informe sobre la situación social en el mundo, 1997. Departamento de Información Económica y Social y de Análisis de Políticas; Naciones Unidas, Nueva York, 1997.

PNUD: Informe sobre Desarrollo Humano. 2000.

UNITED NATIONS 1996: Report of the United Nations Conference on Human Settlements (Habitat II), Istanbul 3-14 June 1996, New York.

UNITED NATIONS: Agenda 21: Programme of Action for Sustainable Development. New York, 1992.

Recursos Internet en http://habitat.aq.upm.es. 
D O C U M E N T A C I ON 



\section{PLAN ESTATAL DE VOLUNTARIADO 2001/2004}

\section{TÍTULO I: DECLARACIÓN PRELIMINAR}

El voluntariado es una pieza fundamental para la construcción de la sociedad civil. Da vida a las aspiraciones más nobles de la humanidad: la búsqueda de la paz, la libertad, la oportunidad, la seguridad y la justicia para todas las personas.

- En esta época de globalización y de cambio continuo, el mundo se está haciendo cada vez más pequeño, más interdependiente y más complejo. El voluntariado, tanto a través de la acción individual como de la grupal, es una forma de:

- Poder sostener y fortalecer los valores humanos de comunidad, atención y servicio.

- Permitir a los individuos que ejerzan sus derechos y responsabilidades como miembros de sus comunidades, aprendiendo y creciendo a lo largo de toda la vida, desarrollando todo su potencial humano.

- Así como establecer contactos, dejando a un lado las diferencias que nos separan, de modo que podamos convivir en comunidades saludables y sostenibles, trabajando juntos para proporcionar soluciones innovadoras a nuestros desafíos comunes y para compartir nuestro destino colectivo.

- En el despertar del nuevo milenio, el voluntariado es un elemento esencial de todas las sociedades. Convierte en acción práctica y efectiva la declaración de Naciones Unidas de que «Nosotros, Los Pueblos» tenemos el poder de cambiar el mundo.

(Sección 1 de la Declaración Universal del Voluntariado adoptada por 14VE, Países Bajos, enero 2001)

\section{TÍTULO II: PRESENTACIÓN DEL PLAN ESTATAL 2001/2004}

- La conclusión del Plan Estatal del Voluntariado 1997/2000, así como la aceptación que ha tenido su desarrollo, principalmente entre Comunidades Autónomas y ONG de acción social, han dado lugar a la oportunidad de elaborar un nuevo Plan, en cuya redacción se han considerado varios aspectos.

- Por una parte, se ha de tener en cuenta el hecho de que es difícil incidir en un movimiento social, como es el movimiento voluntario, y conocer cuál es su situación en cada momento, debido a su complejidad, en cuanto que afecta a sectores muy diversos de la vida en comunidad, y debido a que, en general, toda evolución social requiere una plazo de tiempo bastante amplio para mostrar claramente sus frutos. Ello supone la necesidad de actuar estratégicamente, es decir, priorizando ciertos sectores de la realidad y con objetivos a corto plazo. Para trazar las líneas que alcancen estos objetivos, se ha de partir de cuál es el entorno en que se ha de implementar este Plan, y cuáles han sido sus logros y debilidades, con el fin de recoger aquellas actuaciones que permitan a los sectores implicados adaptarse a las oportunidades y desafíos de dicho entorno, aquéllas que profundicen en los logros del Plan anterior y las que aporten nuevas sugerencias en los ámbitos en que los resultados han sido más pobres.

- Además, se ha de llevar cabo una valoración periódica de cómo se está ejecutando el Plan y una final sobre el grado de su desarrollo y sobre la incidencia que pueda tener 
a su conclusión, determinando la consecución o no de los objetivos operativos propuestos y dando a conocer qué proyectos y experiencias se han realizado en virtud de las sugerencias y actuaciones contenidas en el Plan. Por ello, se incluye un último capítulo en que se esboza la metodología y los plazos en que se han de llevar a cabo el seguimiento y la evaluación del Plan 2001/2004.

\section{TÍTULO III: MARCO SOCIAL Y ADMINISTRATIVO DEL PLAN}

Marco Social

- A la luz de este planteamiento, cabe hacer mención, en primer lugar, de cuáles son las principales tendencias que han de influir necesariamente sobre la configuración del entramado social en estos próximos cuatro años y su posterior evolución, tendencias en que se ven implicados diversos factores de tipo político, sociocultural o económico. Estos factores de cambio tendrán, sin duda, una importante incidencia sobre aspectos diversos de las ONG (las demandas sociales, los servicios con que respondan a ellas, sus formas de organización o captación de fondos), lo que reviste una importancia esencial.

- Entre los factores políticos cabe señalar tres aspectos: la crisis de las ideologías, la fragmentación del poder del Estado, redefinición del papel que las Administraciones Públicas han de desempeñar y, por ende, el de los demás actores sociales.

- Uno de los fenómenos políticos más significativos en la actualidad es lo que se ha dado en llamar el fin de las ideologías, la difuminación de fronteras entre ideas, métodos o políticas que tradicionalmente se identificaban como de derechas o de izquierdas, y, en consecuencia, la intensificación de las relaciones entre grupos y organizaciones de diferente signo.

- Ello puede hacer pensar en una desvinculación de la labor de las ONG con el mundo religioso (de acuerdo con el documento «Las organizaciones de Voluntariado en España» de la Plataforma para la Promoción del Voluntariado en España, 1997, aún entonces en nuestro país el 23 '7\% de las entidades eran de carácter confesional), así como en un claro acercamiento de perspectivas desde las que actuar y de necesidad sociales atendidas por las ONG, y en consecuencia, una mayor cooperación entre ONG para solucionar de forma integral los problemas sociales, proceso que no está consolidado en nuestro país (según datos del mismo documento sólo el 52 '5\% de las ONG se encuentra integrado en otra, en una federación o en una coordinadora).

- Otro factor significativo es la fragmentación del poder del Estado, de un lado, dado por la internacionalización de la política, fenómeno que tiene una importancia mayor, si cabe, en el caso español, ya que España pertenece a la Unión Europea, una organización supranacional que ejerce una parcela de soberanía cedida por los Estados miembros, y, de otro lado, dado por el proceso de descentralización política que se vive en muchos países, origen en el nuestro de las Comunidades Autónomas. Paralelamente, han nacido nuevas instancias revestidas asimismo de poder, de tipo económico o comunicacional, lo que viene significando una paulatina pérdida del poder estatal, de su autonomía, de su prestigio y de su capacidad de actuación.

- Esta fragmentación puede verse, paradójicamente, como una multiplicación del poder y con él, una importante ampliación de la labor administrativa, de su producción jurídica, de las fuentes de financiación para las entidades, y de todas aquellas actuaciones o servicios prestados por las instancias públicas que pueden beneficiar, en gran medida, la labor de la iniciativa social. Ello supone una importante intensi- 
ficación de las relaciones entre ONG y Administraciones Públicas y, no sólo Administraciones nacionales, sino también diferentes organismos administrativos de carácter internacional.

- La terecra tendencia citada es la redefinición del papel del Estado, ya que del Estado de Bienestar, responsable exclusivo de la provisión de servicios sociales a los ciudadanos, se ha pasado a un nuevo esquema de relaciones entre el Estado y la Sociedad Civil, Io que los expertos han dado en llamar el Estado Relacional o Sociedad del Bienestar, que se ha traducido en una mayor corresponsabilidad en la satisfacción de las necesidades sociales de todos los sectores, creando nuevas sinergias y recreando las formas tradicionales de participación ciudadana.

- Ello supone que tanto las entidades empresariales como las organizaciones no lucrativas son también responsables de esa cobertura social, por sí o conjuntamente, lo que principalmente se encauza por diversos medios, entre los que destaca el marketing social, ya que se estima que en España está moviendo unos 20.000 millones anuales, aunque, como las otras formas de relación, tropieza con la polémica planteada en torno a los verdaderos motivos de una empresa (si son éticos o únicamente comerciales) y el hecho de que en esa polémica se vean también involucradas $O N G$, polémica cuya resolución pasa a ser de especial importancia para lograr una máxima colaboración entre entidades y un importante apoyo a las ONG por las empresas.

- Desde la perspectiva sociocultural, cabe destacar los cambios demográficos, culturales y educativos, también esenciales en la configuración de la sociedad.

- La población es uno de los factores clave en la definición de los distintos ámbitos de atención pública, dado que gran parte de las necesidades y las demandas de una sociedad vienen determinadas por ella. En España y en el conjunto internacional se vienen produciendo importantes cambios demográficos: la progresiva disminución de nacimientos (según datos del Atlas del Banco Mundial / Informe sobre Desarro1lo Mundial 2000-2001 la tasa de crecimiento anual en España cs de 0'2\%), una mayor esperanza de vida (78 años, de acuerdo con esa misma fuente), el envcjecimiento de la población (el Anuario Social de España 2000, de la Fundación La Caixa, recoge que el 16’3\% de la población española tiene más de 65 años) o la entrada de inmigrantes desde países menos desarrollados, hoy habitualmente varones en edad de trabajar.

- La problemática que estos cambios conllevan, de atención social a las personas mayores, cobertura de su tiempo de ocio o de ayuda a la integración cultural de los inmigrantes, se va a agravar en los próximos años, e incluso puede dar lugar a consccuencias inesperadas, y las ONG están también llamadas a responder a esa nueva problemática por su propio carácter, porque son más flexibles y creativas en sus modos de actuar, y porque atienden cada situación desde una perspectiva global e integradora.

- En segundo lugar, es un factor muy favorable para la vigorización de la cultura de solidaridad la difusión de una serie de nuevos valores promovidos por diferentes hechos sociales, como la urbanización (según el citado Atlas el 76\% de la población española es urbana) y la imposición de la comunicación social y las nuevas tecnologías.

- Aquellos valores van desde el mayor respeto hacia el medio ambiente (según el documento de la citada Plataforma, el 2'8\% de las ONG trabaja en este campo), 
hasta la vuelta a los principios liberales clásicos de fraternidad, igualdad, la justicia social, o la participación de los ciudadanos en todos los temas de interés general, la concienciación sobre las diferencias Norte-Sur, o la apreciación del ocio.

- Estos valores no sólo ayudan a legitimar la labor de las ONG, sino que también abren nuevos campos de demanda social y de acción para cllas, bien por una carencia objetiva, como la cooperación al desarrollo, bien por el deseo de mejorar la calidad de vida de los ciudadanos, como el uso del tiempo libre. Para cllo, es cspecialmente significativa la realización de campañas de sensibilización, principalmente a través de los medios de comunicación social, sobre necesidades. que apenas quedan cubiertas, como la atención a ciertas áreas o colectivos marginados.

- Por último, no se ha de olvidar la importancia de la elevación de los niveles educativos y de especialización profesional, que se viene dando en todas las sociedades que está producida tanto por consideraciones de tipo político y humanitario, como por exigencias del sistema productivo, que cada vez más requiere trabajadores con una mayor formación general y específica.

- Ésta es quizá una de las grandes desventajas de las ONU en comparación con el Sector Público o Privado, porque, en términos generales, no pueden ofrecer grandes compensaciones retributivas o laborales a sus colaboradores. Por ello, se han de esforzar por mantener el atractivo de un trabajo desinteresado para continuar captando a personas cualificadas tanto en áreas sociales tradicionales, como en nuevas áreas de gestión y dirección de organizaciones, de modo que no se abra una brecha infranqueable entre la calidad de los servicios que ellas prestan y la de los servicios ofrecidos por los otros dos sectores. Además, no se ha de olvidar que los recursos humanos de las entidades no lucrativas y, en particular, el voluntariado, constituyen, precisamente, la esencia misma de las ONG y son los que dan sentido a su forma de trabajar y a los proyectos que llevan a cabo.

- En cuanto a las tendencias económicas, destacan cuatro: la internacionalización de la economía, la agudización de la competencia, el creciente protagonismo dentro del sistema productivo de los servicios y diversas transformaciones en el mercado laboral.

- Uno de los cambios, no sólo económico, sino también político y cultural que se viene dando en los últimos años y que se acrecentará en los venideros, es la internacionalización de la economía, la intensificación de las relaciones comerciales, financieras o monetarias en el conjunto mundial, influida por los avances tecnológicos, los transportes y las comunicaciones, como muestra el hecho de que el comercio mundial mueve en torno a 5.500.000.000 de millones de dólares, de acuerdo con cl Informe Anual 2000 de la Organización Mundial de Comercio.

- En este entorno complejo y global, la coordinación entre ONG, a nivel nacional e internacional, no sólo ayudará a una mejora de la gestión de cada una, sino que además puede ser la única vía de solucionar problemas mundiales, como la cooperación con los países menos desarrollados (35 países tienen un desarrollo humano bajo, según el Informe sobre Desarrollo Humano 2000 del PNUD), la conservación del medio ambiente, con toda la problemática que supone el cambio climático (desertización, deforestación, emisión de gases nocivos a la atmósfera) o los flujos humanos de inmigrantes o refugiados (hay en la actualidad más de 22 millones de personas bajo el amparo del ACNUR). De este modo, la internacionalización pasa a ser tanto una oportunidad de intercambio y aprendizaje para las $O N G$, como un ingente campo de trabajo. 
- En segundo lugar, se ha de mencionar la imposición de la competencia entre las entidades por los recursos y por la demanda, tanto a nivel internacional como nacional, que hace que las organizaciones se esfuercen por ser más eficaces y eficientes en todos sus procesos.

- Si bien el principio de la competitividad, llevado hasta sus últimas consecuencias, no debe ser aplicado al Tercer Sector, sí lo son muchos de los principios y medios que emplean las empresas para ser competitivas. Las ONG deben también ser eficaces y eficientes y, para ello, se han de esforzar por diversificar sus vías de financiación, por dar a conocer a la comunidad su contribución al bienestar y sus logros, han de crear estructuras de coordinación para hacer presión sobre los gobiernos, para plantear sus problemas y conocer las experiencias de otras ONG en la resolución de problemas semejantes.

- En cuanto a la terciarización, sin duda es el sector servicios el que tiene una mayor aportación al Producto Interior Bruto y a la creación de riqueza en las sociedades occidentales, Producto que, según las Perspectiva Económicas de la OCDE, 2000, creccrá un 2'6\% en los años 2002-2006.

- Ésta es una gran oportunidad para el Tercer Sector (de acuerdo con los datos del estudio de la Fundación BBV, aporta en torno al 6 '5\% del Producto español) y, en particular, para las ONG, ya que en la actualidad se consideran como uno de los sectores con más potencial futuro en la creación de riqueza, y precisamente en el sector servicios, y como uno de los principales yacimientos de empleo.

- En cuanto al mercado de trabajo, se están produciendo importantes cambios cuantitativos, referidos a la reducción de la vida laboral de las personas y la disposición de un mayor tiempo libre, y cualitativos, por la necesidad de perfiles profesionales diferentes y la creación de puestos en nuevos sectores o ámbitos.

- En la actualidad, los colectivos que en mayor medida colaboran como voluntarios son, precisamente, aquéllos que quedan fuera del mercado de trabajo, desempleados, estudiantes o jubilados. Paralelamente, el gran reto es el de saber dar a conocer a los trabajadores la posibilidad de emplear su tiempo libre de forma útil y solidaria. Por otra parte, de acuerdo con el estudio «Empleo y trabajo voluntario en las ONG de acción social», de la Fundación Tomillo, 2000, las ONG constituyen un elemento esencial de creación de empleo, principalmente las organizaciones más recientes y las de mayor tamaño. Se calcula que las ONG contratarán, en los años 2000-2001, a casi 50.000 asalariados, principalmente en las áreas de servicios de restauración, personales, protección social y comercio. Esto permitirá a dichas entidades contar con una dotación humana adecuada a las funciones y proyectos que tengan en marcha.

- En resumen, se pueden señalar las siguientes conclusiones consideradas en la claboración del Plan:

- Una vía esencial para lograr un máximo acercamiento y entendimiento entre las ONG de diferente signo consiste en la intensificación de las relaciones en el marco del propio Tercer Sector.

- Las Administraciones Públicas han de ofrecer todo su apoyo a las ONG y al voluntariado para que desempeñen adecuadamente el papel social que les correspondc.

- Empresas privadas y entidades sin ánimo de lucro han de corresponsabilizarse, junto a los poderes públicos, de la resolución de los problemas sociales. 
- Las ONG han de dar cabida a todos aquellos ciudadanos que acudan a ellas bien en busca de atención para sus necesidades específicas, como beneficiarios, bien con el fin de participar en el trabajo social que las entidades realizan, como voluntarios.

- En ese sentido, se ha de dar la información precisa a la sociedad, de la forma más amplia y completa posible, para que los ciudadanos puedan optar por esta forma de participación, en pos de la consecución de valores como los de solidaridad, justicia o fraternidad.

- Se ha de seguir avanzando en los diversos aspectos vinculados con la educación en valores de la infancia y la juventud, y en la formación de los trabajadores de las ONG, sean profesionales, sean voluntarios.

- La información e integración en redes y organismos internacionales puede ser la única vía de solucionar muchos de los problemas mundiales.

- La aplicación de sistemas o principios propios de la empresa constituye una vía muy válida para la mejora y la modernización de las ONG.

- Se ha de apoyar a las organizaciones de voluntariado para que refuercen sus estructuras y cuenten con los recursos precisos para desarrollar al máximo sus potencialidades en la prestación de los servicios que les son propios, dando respuestas innovadoras a los problemas sociales y afianzando el compromiso ciudadano, en la creación de riqueza y para explotar todas sus posibilidades como yacimientos de empleo.

\section{Marco Administrativo}

- La elaboración del Plan Estatal del Voluntariado 2001/2004 exige, junto a la consideración de las actuales tendencias sociales, políticas y económicas, y de cómo han de incidir éstas en la configuración del Tercer Sector, la inclusión de datos y consideraciones provenientes del Balance del anterior Plan así como de las aportaciones e ideas de cuantas instancias se hayan implicadas en esta materia.

- En primer lugar, se ha tratado de reunir en la redacción del Balance del Plan 1997/ 2000 dos facetas distintas de igual importancia: la referida a la ejecución de las medidas del Plan y la relativa a su impacto.

- Por una parte, de las 127 actuaciones del Plan, se han desarrollado 92 (72'44\%) con 797 proyectos. En particular, cabe destacar la importancia de lo realizado en materia de sensibilización, pues el 92'3\% de las actuaciones propuestas inicialmente tuvicron desarrollo, y, por el contrario, la escasa significación del número de proyectos acometidos en materia de coordinación, dado que sólo el $50 \%$ de las actuaciones se han ejecutado. En cuanto al aspecto financiero, no es fácil dar unas cifras definitivas, pero considerando sólo la que ha sido aportada por las entidades promotoras de los proyectos, el presupuesto destinado en esos años al voluntariado asciende, al menos, a 5.100 millones de pesetas (5.100.061.239).

- Por otra parte, la valoración cualitativa sobre el verdadero impacto del Plan, junto a otros factores, sobre el movimiento voluntario los últimos años, se recoge básicamente en el apartado del Balance dedicado a los puntos fuertes y las debilidades de la ejecución del Plan 1997/2000.

- Los logros o puntos fuertes que se señalan en el Balance son los siguientes:

- Su propia existencia y singularidad, la redacción de sus objetivos y áreas, y la puesta en marcha de sus actuaciones o proyectos.

- La metodología seguida en su elaboración y ejecución, ya que siempre se ha 
buscado el consenso y el protagonismo de las ONG y los voluntarios que colaboran en cllas, dando al sector un documento de sugerencias y propuestas que le facilite la realización de una labor autónoma y actuando bajo el signo de la participación, que reúna perspectivas diferentes pero complementarias.

- Ha sido útil para vigorizar el voluntariado como forma de participación y compromiso social de los ciudadanos, ayudando a aplicar plenamente los contenidos de la Ley 6/1996 del Voluntariado.

- En materia de sensibilización, área que, como queda dicho, es la que se ha desarrollado en mayor medida, destacan varios logros:

- El crecimiento del número de voluntarios, de programas de voluntariado y de ONG que se ha producido en los últimos años, aunque, por supuesto, se debe también a otros muchos factores.

- Cambios en el perfil del voluntario, ya que cada vez son más los mayores y las personas ajenas al entorno familiar del beneficiario, quienes se interesan en las labores de acción social, se trabaja más en ámbitos territoriales sin una tradición asociativa significativa, y la responsabilidad voluntaria y su compromiso son cada vez más fuertes.

- En cuanto a la promoción, destacan una serie de hechos:

- El Plan ha ayudado a las entidades menores o más jóvenes a gestionar programas de voluntariado (de información a la sociedad, de coordinación entre entidades que trabajan en los mismos ámbitos, consolidación de recursos...) y a la vigorización de valores y principios eminentemente participativos en sus estructuras y en su actuación.

- En relación con ese tema, se ha conseguido una mayor consideración de los propios voluntarios en la jerarquía de la ONG, creando departamentos de gestión global de recursos humanos, y definiendo los roles de cada tipo de personal (voluntarios y profesionales, objetores o cooperantes).

- Se ha dado importancia al reconocimiento individual de los voluntarios, con la promoción del voluntario en el marco de cada una de las organizaciones.

- En muchas instituciones y servicios públicos, se han abierto nuevos espacios para la participación ciudadana y de las $O N G$ en la gestión y dirección.

- Ha supuesto el aumento del interés político y, por consiguiente, de la acción administrativa hacia el fomento del voluntariado y de la participación social.

- En materia de apoyo y dotación a las entidades no lucrativas, el Plan Estatal 1997/ 2000 ha significado diversas mejoras:

- Incremento del crédito destinado a programas de voluntariado en las últimas convocatorias con cargo a la asignación tributaria del Impuesto sobre la Renta de las Personas Físicas gestionada por el Ministerio de Trabajo y Asuntos Sociales, de los 491 millones de pesetas distribuidas en 1996 o los casi 588 del año 1997, hasta los 777 millones de pesetas ( 777.825 .029 pesetas) para el año 2000 ; incremento que, necesariamente, ha supuesto una mejora significativa en la prestación de servicios y en la realización de programas para el voluntariado en las ONG.

- Importancia concedida a los proyectos de formación de los voluntarios, gestores de voluntariado y miembros de las $\mathrm{ONG}$ en general.

- Finalmente, los logros del Plan anterior en materia de coordinación han sido los siguientes:

- Diálogo inicial entre ONG y Administración centrado en aspectos económicoadministrativos y legislativos, uno de cuyos principales resultados ha sido la 
creación del Consejo Estatal de ONG de Acción Social.

- Creación de estructuras y movilización de recursos en el marco de las Administraciones Públicas, y en particular, creación de un crédito en el presupuesto del Ministerio de Trabajo y Asuntos Sociales que se transfiere a las Comunidades Autónomas y las Ciudades de Ceuta y Melilla para la ejecución de proyectos en desarrollo del Plan, crédito que en el año 2000 alcanzó los 400 millones, y al que se ha de sumar lo aportado por las Administraciones Territoriales, dado que existe el compromiso de cofinanciación, al menos con una cantidad similar, de los proyectos ejecutados en el marco de dichas transferencias.

- El cxamen de la ejecución del Plan Estatal del Voluntariado ha puesto de manifiesto, junto a los logros anteriormente mencionados, una serie de debilidades o aspectos que, siendo esenciales para la concienciación de la sociedad y la vigorización del voluntariado, apenas han sido desarrollados, $y$, en consecuencia, no se ha dado un cambio real en esos sectores. Entre éstos cabe destacar los siguientes:

- Redacción excesivamente genérica del Plan, sin mecanismos, sugerencias o instrumentos que permitan a las instancias implicadas llevar a cabo sus objetivos, y sin medios concretos de seguimiento y evaluación de su ejecución y resultados.

- En materia de sensibilización, el Balance recoge los puntos débiles que a continuación se mencionan:

- Escasa visibilidad y difusión de la filosofía, contenidos y proyectos del Plan.

- Acceso muy reducido de las ONG y de las otras instancias implicadas en el fomento del voluntariado, a los medios de comunicación social de carácter general.

- Falta de estudios e investigaciones sobre aspectos cualitativos o cuantitativos del voluntariado y el Tercer Sector

- Escasa incidencia en la concepción del voluntariado como movimiento reivindicativo y transformador de la sociedad.

- El desarrollo del área de promoción, que pretendía crear una cultura de la solidaridad, también adolece de ciertas deficiencias:

- Falta de información sobre la implicación de distintas instancias en la promoción del voluntariado y en el apoyo de las ONG, en particular, de las Corporaciones Locales, a pesar de que éste es el ámbito natural de colaboración, dada la cercanía de los problemas y la orden constitucional a todas las Administraciones de promover la participación de los ciudadanos en el ámbito social, económico, político, etc.

- Escasa implicación de las estructuras y unidades públicas responsables del fomento del voluntariado en materias distintas a la acción social, y, en particular, en la educativa.

- Escasa implicación social de las empresas, dado que no existe aún una cultura de la colaboración no sólo entre el empresariado español, sino también frecuentemente entre las propias ONG.

- Mayor valoración y, en consecuencia, preferencia por los voluntarios, jóvenes en su mayoría, de las ONG de desarrollo y cooperación.

- En relación con el apoyo a las ONG son significativas las siguientes debilidades:

- Falta de adecuación entre las actividades formativas realizadas y las necesidades y demandas de las entidades no lucrativas.

- Pobreza en la oferta formativa para gestores o coordinadores de voluntariado, y para directivos y profesionales de las ONG. 
- Insuficiencia en la financiación pública, que está, además, apenas diversificada por sectores (sólo se conceden para algunas áreas como acción social o cultura) y, en particular, insuficiencia de información sobre las vías y las convocatorias, y sobre los procesos de concesión de numerosas ayudas.

- Escaso desarrollo de las diferentes medidas referidas al apoyo material o a los espacios físicos que las Administraciones Públicas se habían comprometido a ceder a las ONG.

- Debilidad de las estructuras públicas competentes en materia de voluntariado.

- Finalmente en el área de coordinación, que, como queda dicho, es la que se ha desarrollado en menor medida, el Balance apunta los siguientes aspectos:

- Apenas se han formado redes de trabajo que permitan el intercambio de información, la adecuación de las acciones a las verdaderas necesidades de las organizaciones, así como la maximización de los recursos disponibles y de los resultados obtenidos.

- Falta de contacto entre las organizaciones de menor tamaño y las Administraciones, en particular, la Administración General del Estado.

- Escasa coordinación entre ONG y Administraciones Autonómicas, y, cn ocasiones, entre éstas y Corporaciones Locales (Diputaciones, Cabildos, Ayuntamientos, Entidades Locales).

- No ha habido suficiente información, ni comunicación por ambas partes (Administración y ONG) sobre la ejecución de proyectos en desarrollo del Plan.

-- Junto a las consideraciones y datos derivados del Balance del Plan 1997/2000, sc ha de considerar, en segundo lugar, las ideas aportadas durante el proceso de elaboración del nuevo Plan.

- A finales del año 2000, y en paralelo al proceso de redacción del Balance, se comenzó a establecer diversos contactos y reuniones con entidades significativas (ONG de acción social que estaban participando en la valoración del Plan 1997 / 2000, Departamentos Ministeriales, Comunidades Autónomas, Universidades, y la Federación Española de Municipios y Provincias), y les fue enviado un pequeño cucstionario sobre las principales líneas estratégicas que habían de guiar la redacción del Plan 2001/2004, y en que se les solicitaban sugerencias y aportaciones para la elaboración de las nuevas actuaciones y áreas. Además, se recurrió al asesoramiento de algunas figuras expertas en cuestiones sociológicas con el fin de que pudieran dar ideas y propuestas novedosas que enriquecieran y dieran actualidad al texto del Plan.

- Con todo cl material rcunido, la Dirección General de Acción Social, del Menor y de la Familia, del Ministerio de Trabajo y Asuntos Sociales, que ha actuado como coordinadora en la redacción, ejecución y evaluación del Plan Estatal, comenzó a trabajar en el nuevo Plan a principios del año 2001, cuyo borrador fue presentado a lo largo de mes de mayo a las ONG de acción social convocadas inicialmente para su valoración, a la Comisión Técnica Interministerial (compuesta por los departamentos que, en virtud de sus competencias, se encuentran implicados en la materia, como son el Ministerio de Interior, el Ministerio de Justicia, el de Asuntos Exteriores, el Ministerio de Sanidad y Consumo, el Ministerio de Educación, Cultura y Deporte, el de Medio Ambiente y el propio Ministerio de Trabajo y Asuntos Sociales), la Federación Española de Municipios y Provincias, y la Comisión de Seguimiento del Plan (compuesta por los responsables técnicos del voluntariado en las Comunidades Autónomas y las ciudades de Ceuta y Melilla). 
- Posteriormente, en el mes de junio, fue presentado el Plan Estatal del Voluntariado $2001 / 2004$ a la Conferencia Sectorial de Asuntos Sociales y finalmente, se aprobó, como en el caso del anterior Plan, por Acuerdo de Consejo de Ministros el 3 de julio del año 2001.

\section{TÍTULO IV: ÁREAS}

- El Plan Estatal del Voluntariado 2001/2004 pretende dar continuidad a los objetivos y las acciones acometidas en el marco del Plan 1997/2000, pero no como un plan diferente o como un segundo plan, sino como un mismo documento aunque adaptado, por una parte, a una nueva etapa en que nuestras sociedades se harán, paulatinamente, más globalizadas, interdependientes y complejas, y, por otra, a la necesidad de reforzar los aspectos menos desarrollados por el anterior Plan y profundizar en sus logros. De este modo, se posibilita la consecución de objetivos fijados a largo plazo.

- Este carácter continuista ha determinado que se mantuviera, en términos generales, la estructura de áreas, medidas y actuaciones en que se organizaba cl Plan 1997/ 2000 , aunque con algunos cambios: en primer lugar, se sustituye el área de promoción, dado que sus contenidos no quedaban delimitados claramente, dando lugar a ciertas confusiones; en segundo lugar, se introduce el concepto de línea estratégica en sustitución de la denominación de medida, ya que la imposibilidad de actuar en todo lo relativo al movimiento voluntario aconseja dar al Plan un enfoque sectorial que priorice una serie de ámbitos y de acciones orientadas hacia objetivos concretos y a corto plazo; por último, se reduce el número total de actuaciones y se señala, en el caso de que ello sea posible, a qué instancia corresponde su rcalización, con el fin de hacer el Plan más operativo.

- Con estos cambios, se busca configurar un documento más idóneo para hacer frente a las debilidades del anterior Plan y a los desafíos, y para profundizar en los aspectos positivos de lo realizado y en las oportunidades del entorno, con el objetivo de desarrollar el voluntariado en nuestro país, haciendo de él una verdadera forma de participación social y un ejercicio esencial de responsabilidad para los ciudadanos.

\section{SENSIBILIZACIÓN}

- Objetivo: Proporcionar información a toda la sociedad acerca del valor, las oportunidades y la necesidad de participación voluntaria, de acuerdo con las características de cada grupo de edad y con los intereses de cada ciudadano.

- La consecución de este objetivo supone el recurso preferente a una scrie de medios y ámbitos esenciales para el fortalecimiento del movimiento voluntario en España.

- De esos medios destaca, en primer lugar, la difusión de informaciones y conocimientos no sólo sobre qué es el voluntariado, sino también sobre cuáles son los derechos y deberes de los voluntarios, en qué campos trabajan las ONG o qué objetivos y materias aborda el Plan Estatal del Voluntariado 2001 / 2004. En csta misma línea, y de acuerdo con lo señalado por numerosas entidades no lucrativas a lo largo del proceso de elaboración de este documento, la difusión no ha de buscar un mero incremento del número de voluntarios, sino principalmente un voluntariado de calidad, responsable, y plenamente comprometido con la sociedad y con los 
beneficiarios de su trabajo, lo que se puede lograr, entre otros medios, por el reconocimiento de la labor voluntaria y de la figura del voluntario en el seno de cada una de las entidades y en el conjunto de la sociedad.

- Asimismo, es muy importante para la sensibilización fomentar la investigación y el debate en esta materia, ya que se trata de un movimiento particularmente cambiante y heterogéneo que es difícil de delimitar y caracterizar, y en el cual ciertos acuerdos conceptuales y prácticos son fundamentales para su propia pervivencia y para $\mathrm{cl}$ desplicgue de todas las posibilidades que encierra.

- La difusión de informaciones a toda la sociedad implica, necesariamente, un completo desarrollo de las posibilidades de comunicación externa del Tercer Sector, concediendo, en el seno de cada una de las entidades no lucrativas, una atención especial a la profesionalización de estos departamentos y a la realización de acciones significativas para su conocimiento e identificación por el conjunto de la población, ya que, en la actualidad, esta identificación se limita, casi exclusivamente, a grandes organizaciones dedicadas a la cooperación.

- Paralelamente, no cabe duda de que la mayor presencia de las ONG en los medios de comunicación social de carácter general, como radio, prensa y televisión, constituye un elemento imprescindible en la configuración de una nueva imagen social de las ONG, pues también ha de contribuir a su conocimiento e identificación, así como al refuerzo de sus notas críticas y reivindicativas, que en la actualidad están particularmente asociadas con las ONG de cooperación al desarrollo y con las organizaciones medioambientales. Esta presencia en los medios de comunicación ha de difundir los valores y las acciones del voluntariado y las ONG, dando ejemplos y testimonios de cómo encauzar y afianzar los compromisos indjviduales con la socicdad.

- No obstante, existen algunos colectivos y algunos grupos de edad cuya scnsibilización reviste una importancia de primer orden como los niños y los jóvenes, ya que únicamente la impartición generalizada de una educación en valores puede garantizar un futuro solidario y más justo. Y en este contexto, la Universidad desempeña un papel destacado, ya que se trata de una de las instituciones pedagógicas por excelencia, no sólo debido al hecho de que contribuye extraordinariamente a la formación integral de la persona, sino también por su aportación fundamental a la creación de una conciencia crítica en las sociedades mediante la investigación y el estudio, la formulación de nuevas concepciones en materia social y el ofrecimiento de su bagaje intelectual al debate global que temáticas como las del voluntariado y las ONG pueden suscitar.

- Las personas mayores son otro de los grupos de edad que merece una especial mención, pues se trata de un colectivo cuya participación ciudadana, dado su ticmpo libre, sus experiencias personales, su interés y dedicación, y sus conocimientos profesionales, cs de inestimable valor. Asimismo, esa colaboración social puede suponer para los mayores una gran satisfacción personal, un profundo sentimiento de autoestima y la posibilidad de establecer nuevas relaciones.

- Pero la implicación social de las personas mayores, de los universitarios, de los jóvenes y los niños, y de todos los ciudadanos en general, no es necesaria en todos los ámbitos por igual, sino que resulta especialmente interesante en cl trabajo con colectivos en los que, hasta ahora, la colaboración voluntaria ha sido menor como el de enfermos de SIDA, pueblo gitano o personas reclusas y ex reclusas. En esta misma línea, cabe citar también al colectivo de las personas inmigrantes ya que su 
problemática específica y la difusión que de ella han hecho los medios de comunicación social, han dado un importancia capital tanto a la lucha contra la xenofobia y el racismo, como a los esfuerzos de numerosas ONG y entidades públicas por su integración social y laboral. Finalmente, no se ha de dejar de citar la existencia de otros ámbitos en que esta forma de participación social reviste una especial significación como la protección civil, la cultura o la sanidad, y, en particular, el voluntariado medioambiental, rural o local.

\section{I'linea estratégica:}

- Fomento y apoyo de todas aquellas iniciativas que supongan la difusión de las actividades voluntarias, el reconocimiento de los voluntarios y el debate sobre su concepto y papel social.

\section{Actuaciones:}

1.1. Realización de campañas de concienciación e información a la sociedad sobre la labor desarrollada por ONG y voluntarios, y sobre los valores de solidaridad, justicia y participación en que dicha labor se sustenta.

1.2. Difusión de acciones concretas llevadas a cabo por ONG o por voluntarios que ayuden a un mayor conocimiento y comprensión por la ciudadanía del papel social desempeñado por el Tercer Sector.

1.3. Organización de eventos atrayentes para el conjunto de la sociedad, como exposiciones de fotografía o pósters y carteles, conciertos, festivales de cine, etc., en los que el altruismo y la cooperación sean temáticas centrales.

1.4. Promoción del voluntariado en el ámbito de actuación o con el colectivo específico al que la Organización de Naciones Unidas dedica cada año.

1.5. Celebración del Día Internacional del Voluntariado y de otros Días Internacionales o Mundiales con el fin de dar a conocer diferentes oportunidades de participación voluntaria.

1.6. A poyo, por parte de las entidades públicas y de las entidades privadas lucrativas, a la organización por las ONG de jornadas, seminarios y conferencias para la reflexión y el debate de temas relacionados con el voluntariado.

1.7. Celebración anual de un Congreso Estatal concebido como espacio de encuentro para ONG y voluntarios, y como foro de conocimiento de nuevas expericncias e ideas para el voluntariado.

I.8. Difusión, por parte de la Administración General del Estado, de los contenidos y los logros del Plan Estatal del Voluntariado recurriendo para ello a medios como la elaboración de materiales divulgativos de diverso tipo, la difusión de información por Internet o la celebración de reuniones y jornadas informativas.

1.9. Establecimiento, por parte de las $\mathrm{ONG}$ o de entidades empresariales, de formas de reconocimiento individual y social de los voluntarios, como la difusión de testimonios personales o la concesión de premios.

1.10. Desarrollo de trabajos de investigación generales que profundicen en el conocimiento de los rasgos actuales del Tercer Sector en sus diferentes ámbitos y en sus tendencias de futuro.

1.11. Realización de estudios sociológicos sobre actitudes y opiniones de la sociedad hacia las ONU, y sobre la motivación y el compromiso de los voluntarios.

1.12. Realización de estudios económicos sobre el valor real de la aportación del voluntariado y sobre el coste que su gestión supone a las organizaciones en que 
colabora.

1.13. Realización de un estudio estadístico y psicosocial para conocer el censo real del voluntariado en tareas de Protección Civil, su distribución territorial, incidencia en la población, perfil y filiación social, motivaciones, expectativas y realidad de este ámbito de colaboración.

1.14. Fomento, por parte de las ONG y las entidades públicas, de un debate abierto y plural acerca del concepto y la práctica del voluntariado, que permita deslindar claramente la figura del voluntario de otras figuras próximas, dando cabida a nuevas experiencias de participación ciudadana, y que permita asimismo determinar el papel social que corresponde a cada sector.

1.15. Fomento de la reflexión, en el marco del Tercer Sector, sobre criterios éticos comunes a considerar en actuaciones externas, como las de tipo comunicacional o de captación de fondos.

1.16. Debate, entre ONG y Administraciones Públicas, acerca de la consolidación de un voluntariado de calidad, responsable y plenamente comprometido con la sociedad y con los beneficiarios de su trabajo.

\section{2"línea estratégica:}

- Sensibilización y compromiso de los medios de comunicación social hacia las temáticas relativas a las $O N G$ y el voluntariado, y a los valores que representan.

\section{Actuaciones:}

2.1. Fortalecimiento, por parte de las $\mathrm{ONG}$, de sus departamentos de comunicación, por la formación y la profesionalización de los responsables.

2.2. Impulso de la comunicación externa de las ONG mediante diversos medios como la edición de publicaciones periódicas, el diseño de una imagen corporativa o el lanzamiento de campañas de difusión y publicidad.

2.3. Consolidación de medios escritos, audiovisuales y electrónicos especializados en el voluntariado y en el Tercer Sector.

2.4. Apoyo, por parte de las Administraciones Públicas, a la presencia del Tercer Sector en los medios de comunicación social con el fin de difundir una imagen positiva y realista de las $\mathrm{ONG}$, dar a conocer su labor y sus logros, y proporcionar información a la ciudadanía sobre la posible colaboración en ONG de diverso tamaño y ámbito de actuación.

2.5. Colaboración de los profesionales de la comunicación para que se familiaricen con los temas relativos al voluntariado y la solidaridad, y los aborden en su trabajo, mediante $\mathrm{cl}$ acceso de estos profesionales a información especializada, cursos universitarios de formación y debate, o el contacto personal con profesionales de las ONG y las Administraciones Públicas implicadas en esta materia.

2.6. Promoción del tratamiento, por los medios de comunicación social, de aspectos vinculados con las ONG en el marco de los debates y programas en los medios audiovisuales, o artículos y reportajes en prensa e Internet.

2.7. Difusión permanente de informaciones referidas al Tercer Sector por las diversas cadenas de televisión existentes, consolidando canales espccializados, creando cspacios televisivos permanentes o por la cesión de espacios para ONG en las cadenas públicas. 


\section{$3^{a}$ línea estratégica:}

- Consolidación de la acción voluntaria en el ámbito educativo.

\section{Actuaciones:}

3.1. Desarrollo, en centros de enseñanza obligatoria, especialmente en los de secundaria y bachillerato, de campañas de sensibilización e implicación de profesores y de otros sectores de la comunidad educativa en acciones de voluntariado y de otras formas de contribución social, por medio de la organización de actos singulares, el acceso a la información existente en Internet, la elaboración de agendas escolares de voluntariado, etc.

3.2. Impulso a la creación, en el marco del Tercer Sector, de fondos documentales e informáticos en materia de voluntariado y educación.

3.3. Edición de material didáctico sobre educación en valores, libros de texto y materiales curriculares, útiles para la formación del profesorado y la enseñanza de los alumnos.

3.4. Realización de proyectos de formación en centros transferidos a Comunidades Autónomas y en los situados en el territorio de gestión del Ministerio de Educación, Cultura y Deporte.

3.5. Desarrollo de proyectos relacionados con el voluntariado y su acción social en los centros escolares, con el fin de que lleguen a formar parte de los proyectos educativos de dichos centros.

3.6. Impulso de la incorporación de los valores y contenidos relativos a las posibilidades de participación y compromiso como materia transversal en la enseñanza reglada.

3.7. Apoyo, por parte de la Administración General del Estado, a la participación de profesores y alumnos en acciones llevadas a cabo en el marco de los programas promovidos desde la agencias europeas, como los programas Sócrates y Leonardo.

3.8. Apoyo a la formación, desde las entidades del Tercer Sector, de agentes educativos voluntarios, como monitores y directores de tiempo libre.

3.9. Realización en los centros de enseñanza de actividades extraescolares cuyos contenidos preparen a los alumnos para futuros compromisos sociales, preferiblemente mediante la intensificación de las relaciones entre ONG y centros.

3.10. Promoción del diseño y lanzamiento de juegos, principalmente electrónicos, basados en la temática social y el voluntariado.

3.11. Creación, en las Universidades, de programas específicos, oficinas o agencias de promoción del voluntariado dedicadas a la sensibilización de la comunidad universitaria, al apoyo de las ONG que desarrollan su trabajo en los campus, y a la coordinación con aquellas instancias que, por su cercanía geográfica o similitud de intereses, puedan ofrecer recursos, experiencias o modelos enriquecedores para los proyectos de la propia Universidad.

3.12. Desarrollo de campañas de sensibilización de la comunidad universitaria hacia la participación social, la colaboración ciudadana y la construcción, en los alumnos, de un espíritu crítico y solidario que contribuya, en el futuro, a un ejercicio profesional más responsable y justo.

3.13. Impulso a la creación, en el marco universitario, de fondos documentales, bases de datos, hemerotecas, repertorios de investigaciones, y, en general, de cualquier tipo de documento de carácter nacional e internacional que pueda contener 
información significativa para profundizar en la reflexión y el conocimiento del voluntariado en sus diferentes campos de acción.

3. 14. Apoyo a la realización de investigaciones, estadísticas, tesis doctorales, trabajos tutelados o tesinas en materia de ONG y voluntariado.

3.15. Consolidación de los estudios universitarios sobre aspectos económicos, sociales o jurídicos del Tercer Sector, sean asignaturas y materias comprendidas en las titulaciones relacionadas con la salud, la educación o el trabajo social, sean estudios de postgrado y masters, sean seminarios y cursos de verano.

3.16. Apoyo, desde la Universidades, a la plena incorporación de las ONG al ámbito universitario, mediante la facilitación de recursos económicos, materiales o humanos, el asesoramiento por parte del profesorado a las ONG en cuestiones técnicas relacionadas con su práctica docente, la ejecución de proyectos sociales en el campus universitario o proyectos de voluntariado y cooperación en otros ámbitos, o bien mediante la difusión de las necesidades de voluntarios en las ONG.

3.17. Intensificación de las relaciones entre los diferentes campus universitarios, de la cooperación con los Ayuntamientos de las localidades en que se encuentran o de las ONG que trabajan en esos municipios, y la colaboración con Administraciones Públicas y cntidades privadas con el fin de favorecer la realización de proyectos conjuntos y el intercambio de conocimientos y prácticas en materia de voluntariado universitario.

\section{4'línea estratégica:}

- Consolidación de la acción voluntaria en diferentes grupos de edad y con diferentes colectivos.

\section{Actuaciones:}

4.1. Difusión, por parte de las ONG y de las Administraciones Públicas, de informaciones adecuadas a cada grupo de edad sobre todos los campos, opciones y oportunidades que existen para la colaboración voluntaria.

4.2. Impulso de la participación como voluntarios de colectivos que, por su disponibilidad de tiempo y por su experiencia, pueden hacer una significativa aportación a la actuación de las ONG, como es el caso de las propias personas beneficiarias en los programas, de personas dedicadas a labores domésticas o personas mayores ya jubiladas.

4.3. Incorporación, por parte de las $\mathrm{ONG}$, de jubilados y prejubilados expertos que puedan asesorar a profesionales y voluntarios en materias referidas al funcionamiento de la entidad o a la planificación, ejecución y evaluación de proyectos y programas.

4.4. Fomento de la participación de voluntarios en programas desarrollados por las ONG en materia de acción social, en particular, con aquellos colectivos en los que esta forma de colaboración ha sido menor, como personas afectadas por el VIH/SIDA, minorías étnicas y pueblo gitano y personas reclusas y exreclusas.

4.5. Promoción del voluntariado con personas inmigrantes o pertenecientes a otras culturas, mediante el lanzamiento de campañas o la edición de materiales en que se difunda una información realista acerca de su perfil humano y problemática, con el fin de crear en la sociedad española una imagen positiva de este colectivo.

4.6. Creación, en el marco del Tercer Sector, de fondos documentales e informativos 
referidos a la enseñanza de la lengua y cultura españolas que puedan ser de utilidad, como material didáctico y de apoyo, a los voluntarios que colaboran en programas de enseñanza e integración social de colectivos inmigrantes.

4.7. Promoción del voluntariado en aquellos campos en que su participación es de especial importancia para la resolución de los problemas clave en cl conjunto nacional o internacional como es el caso de la cooperación al desarrollo, la sanidad, la cultura o el deporte.

4.8. Fomento de la elaboración y aplicación de planes sectoriales de voluntariado en espacios protegidos y ámbitos afines, siguiendo el modelo del Plan de voluntariado en Parques Naturales.

4.9. Impulso, por parte de las Administraciones Públicas, de un afianzamiento de los vínculos entre los Parques Naturales y las comunidades locales en que están situados, con el fin de lograr un desarrollo comarcal duradero.

4.10. Promoción del voluntariado en Protección Civil entre grupos de edad tradicionalmentc alejados de este campo, como la población adulta o la jubilada.

4.11. Consolidación de un voluntariado rural por medio de la realización y difusión de estudios, el lanzamiento de campañas, el apoyo a las ONG que trabajan en el mundo rural y a las asociaciones de vecinos, etc.

4.12. Estímulo, por parte de las Administraciones territoriales competentes o por las asociaciones de entidades locales, a la creación de Planes Municipales de voluntariado, con el fin de consolidar en España un movimiento voluntario de fuerte implante local.

4.13. Realización de acciones divulgativas y formativas referidas a las metas y contenidos de los Planes Municipales de voluntariado.

4. 14. Apoyo, desde la Federación Española de Municipios y Provincias, a la elaboración e implementación de políticas locales dirigidas al fomento de la participación ciudadana y el voluntariado.

\section{APOYO}

- Objetivo: Comprometer al sector público, al sector lucrativo y al propio Tercer Sector en la modernización de las ONG y en su dotación, adecuadas al destacado papel social que han de desempeñar.

- Todos los sectores han de asumir, de diferente modo, la responsabilidad que les corresponde en respuesta a los nuevos desafíos y necesidades que los cambios sociales y la globalización traerán, y, en particular, con su apoyo a las organizaciones de voluntariado, aspecto éste en el que cabe señalar algunas propuestas y sugerencias de actuación.

- Por una parte, son especialmente significativas las propuestas relativas a la modernización de las entidades, tanto de su estructura y organización, en virtud de la aplicación de valores democráticos y participativos, como de su funcionamiento y gestión, tomando de la empresa privada aquellos principios, sistemas y prácticas que les puedan resultar más útiles para desarrollar una labor efectiva y de calidad.

- Por otra, el fortalecimiento del movimiento voluntario español exige, más allá de la consolidación del Tercer Sector, su desarrollo pleno, para lo cual le es necesario contar con unos medios humanos, económicos y materiales y unos espacios físicos suficientes y adecuados a sus cometidos, un ordenamiento jurídico adaptado 
a la nueva sociedad del bienestar así como información actualizada y fluida, ya que ésta ha pasado a ser, hoy en día, el instrumento clave para la dirección eficiente de las organizaciones.

- Por último, la creación de una cultura empresarial sensible a los problemas sociales, la inclusión de la participación y la colaboración ciudadana en el marco de la gestión de recursos humanos, y el apoyo económico que las empresas pueden brindar a las ONG, bien optando prioritariamente por sus servicios, bien ofreciendo sus propias prestaciones y productos comerciales en unas condiciones más favorables, constituyen elementos de una relación que puede ser beneficiosa tanto para la empresa como para el Tercer Sector.

- Para las metas del Tercer Sector, dicha colaboración puede suponer la presencia de unos profesionales que les ayuden extraordinariamente a desarrollar su trabajo habitual, puede suponer también la diversificación de sus ingresos, y con ella, lograr independencia, así como la posible realización de actuaciones de mayor envergadura y mayor solidez. Para el sector empresarial la colaboración puede significar la opción por una estrategia de maximización de los márgenes de beneficio que se dan en la actualidad, el aumento de la utilidad de un bien o un servicio y de la satisfacción de los clientes al elegirlo y consumirlo, así como un refuerzo de la motivación del personal y el conocimiento de una forma distinta de trabajar en que Ia flexibilidad, la orientación hacia los objetivos y el trabajo en equipo son prioritarios, afianzando, en definitiva, la configuración de una imagen más humanizada de la cmpresa ante su propio personal y ante la sociedad.

\section{$5^{x}$ línea estratégica:}

- Apoyo a la modernización organizativa y funcional de las entidades del Tercer Sector.

\section{Actuaciones:}

5.1. Apoyo, por parte de las Administraciones Públicas y de las ONG dedicadas al asesoramiento de otras entidades del Tercer Sector, al estudio e implementación de procesos de modernización funcional y organizativa en cada entidad.

5.2. Fortalecimiento, principalmente en las ONG de menor tamaño, de unas estructuras mínimas que les permitan desarrollar su labor con éxito, mediante la consolidación de relaciones con otras entidades de características y ámbito similares.

5.3. Aprovechamiento, por parte de las $\mathrm{ONG}$, de las posibilidades que ofrecen las nuevas tecnologías para el fortalecimiento de sus estructuras y el desarrollo de sus proyectos, como la exploración de nuevas formas de captación de fondos, el voluntariado virtual, la formación a distancia, etc.

5.4. Aprovechamiento, por parte de las $\mathrm{ONG}$, de las posibilidades que ofrecen las nuevas tecnologías para el fortalecimiento de sus estructuras y el desarrollo de sus proyectos, como la exploración de nuevas formas de captación de fondos, el voluntariado virtual, la formación a distancia, etc.

5.5. Facilitación, por parte de las Administraciones Públicas y las entidades privadas, de la presencia activa de las ONG en Internet, mediante el alojamiento de sus propias páginas, la consolidación de portales de voluntariado y colaboración social, o el aprendizaje y la extensión del uso de nuevas tecnologías de la comunicación en el marco de cada entidad. 


\section{6"línea estratégica:}

- Dotación de recursos humanos, económicos y de otro tipo adecuada a las acciones de cada ONG.

\section{Actuaciones:}

6.1. Refuerzo de la capacidad de las ONG para dar cabida en sus estructuras y funcionamiento a los ciudadanos que deseen colaborar en ellas como voluntarios, respetando el perfil singular de cada uno y aprovechando sus potencialidades para cumplir los diferentes cometidos de la entidad.

6.2. Promoción de proyectos para la detección de las verdaderas necesidades y demandas del Tercer Sector en materia de formación, y adaptación a ellas de la oferta de entidades de voluntariado, Administraciones Públicas y otras instancias dedicadas a la capacitación de los trabajadores de las ONG.

6.3. Impartición, por parte de las $\mathrm{ONG}$, de acciones formativas para los voluntarios, tanto con carácter genérico, como relativas al sector concreto de espccialización de la entidad, con el fin de lograr una mayor eficacia del voluntariado.

6.4. Realización de acciones formativas específicas en materia de Protección Civil

6.5. Celebración de cursos de voluntariado en materia de Protección Civil para la autoprotección escolar.

6.6. Elaboración, por parte de las $\mathrm{ONG}$, de planes conjuntos de formación de voluntarios para las diferentes áreas de acción en que desarrollan su labor, y creación, en el marco del Tercer Sector, de centros de capacitación para voluntarios y profesionales.

6.7. Profesionalización, por parte de las $O N G$, de la figura del coordinador de voluntariado, responsable de informar a los voluntarios sobre sus propios cometidos y sobre el conjunto de la organización, guiarles en su proceso de incorporación, dirigirles en la ejecución de su trabajo y motivarles de modo que se afiance su compromiso.

6.8. Realización, por parte de las ONG, de acciones formativas adecuadas para los coordinadores o gestores de voluntariado.

6.9. Celebración de cursos de formación de formadores en diversas materias.

6. 10. Promoción, por parte de las $\mathrm{ONG}$, de principios y prácticas democráticas en el seno de sus estructuras que permitan a voluntarios y profesionales participar en el diseño de los programas y planes de la entidad.

6.11. Formación de los directivos, profesionales y gestores de ONG en sus respectivas tareas, poniendo un énfasis especial en la formación relativa a nuevas tecnologías, cuestiones tributarias e impositivas, aspectos jurídicos, contables y aspectos relacionados con la captación de fondos.

6.12. Apoyo, por parte de las Administraciones Públicas y las entidades empresariales, para que las ONG cuenten con una dotación adecuada de medios técnicos y materiales, y muy especialmente de equipamientos informáticos y electrónicos actualizados.

6.13. Profundización en los aspectos legales relacionados con la facilitación de la labor desarrollada por ONG y voluntarios, y reforma, en lo que sea necesario, del marco jurídico del Tercer Sector.

6.14. Diversificación de las fuentes de financiación de asociaciones y fundaciones, vigorizando aquéllas que permitan la realización de proyectos a largo plazo, la independencia de las ONG respecto a otras instancias, y que conlleven una 
mayor colaboración ciudadana.

6. 15. Apoyo económico, desde las Administraciones Públicas, para la sensibilización y promoción del voluntariado y las $\mathrm{ONG}$, por sectores y ámbitos territoriales.

6.16. Difusión general de informaciones sobre las convocatorias y la concesión de subvenciones nacionales e internacionales a este sector.

6.17. Consolidación de instrumentos de información útiles para la dirección y gestión de las entidades del Tercer Sector, como bases de datos informatizadas, guías de buenas prácticas, fondos documentales, páginas web en Internet dedicadas a las ONG, guías territoriales y sectoriales de voluntariado, centros de información general, etc.

6.18. Apoyo, por parte de las Administraciones Públicas, al refuerzo de las relaciones entre entidades mediante la cesión puntual de espacios físicos para las reuniones o actos de varias ONG.

\section{$7^{a}$ línea estratégica:}

- Consecución de la implicación social de la empresa.

Actuaciones:

7.1. Apoyo, por parte de las Administraciones Públicas, a la consolidación de nuevas concepciones como las de empresa ética y voluntariado corporativo, mediante la orientación de las culturas empresarial y del Tercer Sector hacia valores y prácticas diferentes, basados en la corresponsabilidad y la colaboración intersectorial.

7.2. Incorporación de la acción social externa a la negociación colectiva, de modo que sea considerada en diversos aspectos de la gestión de personal, como la selección, la formación o la preparación para la jubilación.

7.3. Valoración, por parte de los responsables de la gestión de recursos humanos, de la experiencia adquirida por los trabajadores de las $\mathrm{ONG}$, a efectos de su incorporación en la empresa.

7.4. Promoción, a través de las organizaciones empresariales y sindicales, de programas de información y capacitación del personal basados en la cooperación con ONG, por medio de la asignación de un grupo de empleados a una ONG para completar su formación, o por la cesión por la empresa, durante un plazo determinado o por unas horas, de alguno de sus trabajadores cualificados para que se implique en proyectos concretos de una $O N G$

7.5. Apoyo, por las empresas, a las iniciativas sociales promovidas por los propios empleados, como la donación de parte del salario mensual, la creación de fórmulas de reconocimiento entre ONG con las que colaboren los empleados, la constitución por los empleados de una entidad de acción social propia, ctc.

7.6. Fomento de la inclusión, en los programas empresariales de preparación para la jubilación, de informaciones relativas a las diversas posibilidades de colaboración ciudadana y voluntariado, considerando la experiencia y el tiempo libre de los trabajadores jubilados y el enriquecimiento personal que la participación social les puede suponer.

7.7. Promoción del patrocinio y el mecenazgo de acciones de contenido social por parte de las entidades empresariales, financiando proyectos concretos o la actividad global de una ONG mediante compromisos de colaboración permanente. 
7.8. Difusión de las diversas posibilidades de colaboración relacionadas con el marketing con causa, el marketing corporativo y otras formas de comunicación externa que, asimismo, establezcan relaciones de productos y servicios con causas de interés social.

7.9. Cesión, por parte de las entidades empresariales, de servicios de apoyo técnico así como de equipamientos, infraestructuras y otros bienes materiales a entidades del Tercer Sector con las que colaboren.

7.10. Sensibilización de los responsables de empresas para que contraten la fabricación de productos o la prestación de servicios externos preferentemente con entidades no lucrativas y con empresas de iniciativa social.

7.11. Difusión de informaciones, entre las entidades empresariales, acerca de las peculiaridades de gestión y actuación de las organizaciones no lucrativas, con el fin de que oferten a las ONG sus servicios o productos a un menor precio o con unas condiciones más favorables, o bien que diseñen productos y prestaciones adaptadas a esas peculiaridades.

\section{COORDINACIÓN}

- Objetivo: Fortalecer la colaboración entre Administraciones Públicas y ONG, prestando una especial atención a su implicación en las estructuras y redes nacionales e internacionales de cooperación.

- La consecución de este objetivo supone el recurso preferente a una serie de medios, sugerencias y propuestas de acción esenciales para el fomento de la coordinación de todas las instancias, públicas y privadas, Iucrativas o no, implicadas en la promoción del voluntariado y del Tercer Sector.

- El primer ámbito en que se ha de fortalecer la colaboración es el ámbito lucrativo, ya que la intensificación de las relaciones entre ONG ha de suponer un importante intercambio de experiencias y conocimientos sobre necesidades y problemas comunes, demandas, y vías de solución, así como un punto de partida fundamental desde el que alcanzar compromisos y acuerdos sobre aspectos conceptuales y prácticos claves para el desarrollo pleno del Sector. En la misma línea destaca asimismo el apoyo, principalmente por parte de las Administraciones Públicas a las federaciones de $\mathrm{ONG}$, confederaciones y estructuras de diverso tipo que, precisamente, encarnan esta coordinación, así como el apoyo de aquellas cntidades especialmente dedicadas a la concienciación de la sociedad y la promoción del voluntariado, debido, por una parte, al significado de su labor y, por otra, a que en muchas de ellas el trabajo voluntario mismo no tiene una especial significación.

- Paralelamente, también se considera esencial el refuerzo de las unidades administrativas que tienen asignada la función específica de fomento de las ONG y de la participación ciudadana, con el fin de constituirlas en referente público en sus diferentes ámbitos territoriales y comunidades, bien mediante la dotación de recursos humanos, materiales y económicos adecuados a las funciones encomendadas, bien mediante la difusión en el Tercer Sector de una completa información acerca de los servicios prestados por las unidades y de los proyectos realizados en pro de las $\mathrm{ONG}$.

- A su vez, se ha de intensificar la colaboración entre unidades y responsables públicos dedicados al voluntariado en el seno de cada Administración y en el de posibles estructuras o encuentros inter-administrativos, de modo que la promo- 
ción del voluntariado, concebido como vía preferente de participación en la construcción de la Sociedad del Bienestar, sea un proyecto común, aunque a distinto nivel y con diferentes manifestaciones (sanitaria, educativa, medioambiental, social, penitenciaria, etc).

- No obstante, la cobertura de todas las necesidades de los colectivos y de los campos de actuación voluntaria exige una coordinación más amplia que alcance a ONG, Administraciones Públicas, Universidades, entidades empresariales y, en general, cuantos individuos e instancias se hallen implicadas en la acción y la ayuda desinteresadas, aunque priorizando, como no podía ser menos, aquéllas que por su ámbito territorial o por su campo de actuación se puedan considerar como más próximas a cada entidad, ya que es ésta la vía clave para dar una atención integral a cada grupo y a cada problema.

- La implicación de las distintas instancias españolas en redes europeas y, en general, en redes internacionales constituye una respuesta inaplazable al desafío de la globalización, de la acción en un entorno que se hace cada vez más grande, con mercados que abarcan casi todo el conjunto mundial, necesidades que afectan a la mayor parte de la humanidad, organizaciones y estrategias globales. Y ello da lugar a que el núcleo último de dicho desafío sea la cooperación al desarrollo del Tercer y Cuarto Mundo, al crecimiento sostenible de los países y de los sectores más marginados de las sociedades contemporáneas, incrementando la riqueza y su distribución entre la población, y respetando el medio ambiente, los derechos humanos y las singularidades socioculturales de cada grupo y nación.

\section{8alínea estratégica:}

- Fortalecimiento de las relaciones de coordinación entre ONG.

\section{Actuaciones:}

8.1. Impulso del trabajo en red entre ONG, en particular entre las de menor tamaño, para el desarrollo conjunto y complementario de actuaciones por sectores o colectivos similares, con el fin de dar una cobertura completa a los problemas de cada ámbito territorial, cada campo y cada beneficiario, y de fortalecer el Tercer Sector.

8.2. Edición y difusión, por parte de las $\mathrm{ONG}$, de documentos comunes que puedan facilitar la labor de todas aquellas entidades que trabajan en un mismo sector.

8.3. Intercambio de experiencias y conocimientos entre ONG por medio de reuniones, estructuras de coordinación, intercambio de voluntarios, intensificación de las relaciones entre los responsables o coordinadores de voluntariado, creación de plataformas de comunicación, etc.

8.4. Apoyo, por parte de las Administraciones públicas, a la consolidación y funcionamiento de las estructuras de coordinación (federaciones y confederaciones) y plataformas del Tercer Sector, a nivel local, autonómico y estatal.

8.5. A poyo, por parte de las Administraciones Públicas, al nacimiento y consolidación de organizaciones dedicadas específicamente a la promoción del voluntariado en sus distintos ámbitos de acción.

\section{9alinea estratégica:}

- Vigorización de la coordinación en el ámbito administrativo y de la participación de las ONG en la prestación de servicios públicos. 
Actuaciones:

9.1. Fortalecimiento de las unidades administrativas dedicadas a la promoción del voluntariado y al apoyo de las ONG.

9.2. Difusión de informaciones sobre los recursos y las funciones encomendadas a las unidades administrativas para el voluntariado, con el fin de darles una mayor visibilidad ante el sector asociativo y el conjunto del sector público.

9.3. Apoyo, en el marco de cada Administración Pública, a la interrelación de las unidades administrativas con otras unidades pertenecientes a Departamentos o Conserjerías diferentes.

9.4. Fomento de la cooperación entre entidades locales, y de éstas con sus respectivas Comunidades Autónomas, por medio del intercambio de experiencias y conocimientos en materia de voluntariado, en el marco de reuniones periódicas, órganos o redes de colaboración, y por medio de la ejecución de proyectos conjuntos.

9.5. Potenciación del trabajo coordinado entre las Comunidades Autónomas y los Ayuntamientos en materia de servicios sociales.

9.6. Fortalecimiento de la coordinación entre Comunidades Autónomas para el desarrollo de acciones comunes y la difusión de informaciones sobre actuaciones y estructuras dedicadas al voluntariado con el fin de mejorar la organización y funcionamiento de cada Comunidad.

9.7. Promoción de estructuras e instrumentos administrativos para la cooperación entre las Comunidades Autónomas y la Administración General del Estado, y mejora y agilización del funcionamiento de los ya existentes.

9.8. Potenciación a la creación y mantenimiento de órganos de colaboración entre Administraciones Públicas y ONG en los diferentes ámbitos territoriales, para la participación del sector asociativo en el desarrollo de las políticas públicas referidas a los distintos campos de actuación.

9.9. Apoyo a la participación de las ONG en la prestación de servicios públicos mediante la cjecución de proyectos conjuntos, el acceso de las asociaciones y fundaciones a centros públicos, o la opción preferente, por parte de los responsables administrativos, hacia la contratación de organizaciones de voluntariado en lugar de entidades empresariales.

\section{$10^{\alpha}$ línea estratégica:}

- Incorporación de las ONG y de las unidades administrativas al entorno internacional.

Actuaciones:

10.1. Fomento de las relaciones de las Administraciones Públicas españolas con las de otros países y organismos internacionales, principalmente comunitarios, con el fin de poder ofrecer al Tercer Sector una completa visión sobre la situación global del voluntario, problemas concretos y vías de solución.

10.2. Difusión de informaciones de carácter internacional que permita a las ONG tener un conocimiento actualizado de las principales entidades internacionales existentes en cada sector y colectivo, de las redes de mayor consolidación y los cventos internacionales de más importancia.

10.3. Implicación y participación de las $O N G$ en redes internacionales, de acuerdo con su propia fïlosofía y ámbito de actuación, en particular, en aquellas áreas 
que son más cercanas geográficamente a España como el continente europeo, Ibcroamérica y el Mediterráneo.

10.4. Apoyo, por parte de las Administraciones Públicas, a las campañas de sensibilización desarrolladas por ONG en pro de una mayor concienciación y solidaridad de la sociedad española hacia los problemas del Tercer y Cuarto Mundo.

10.5. Mantenimiento de la colaboración española al Programa de Voluntariado de Naciones Unidas.

10.6. Impulso de los programas de partenariado en el ámbito europeo para el desarrollo de acciones formativas y de investigación en materia de voluntariado.

\section{TÍTULO V: SEGUIMIENTO Y EVALUACIÓN DEL PLAN ESTATAL DEL VOLUNTARIADO}

- Una de las debilidades del Plan 1997/2000 que ha sido señalada en el Balance se refiere a su redacción genérica, dado que en el momento de su elaboración se consideró que lo más interesante sería recoger una enumeración de objetivos, deseos y principios, y no la incorporación de instrumentos concretos de seguimiento. y evaluación que permitieran conocer quizá no tanto su grado d ejecución, ya que esto cs sencillo por medio de los informes que se han venido realizando durante los años anteriores, sino principalmente sus resultados periódicos, sus logros y su impacto global en la sociedad y en el movimiento voluntario.

- Por ello, se ha determinado la inclusión en el presente Plan de un apartado específico dedicado a la evaluación, en que se da a conocer la periodicidad de las evaluaciones, las posibilidades de difusión de sus conclusiones, la metodología y fuentes de información, así como los indicadores que permitan medir y, en cierto modo, facilitar datos complementarios para conocer la evolución del Tercer Sector en nuestro país.

- En cuanto a la periodicidad de las valoraciones, como se hizo, aunque informalmente, con cl anterior Plan Estatal, también se prevé llevar a cabo un seguimiento anual de lo realizado en virtud del Plan, que se cierre al finalizar cada uno de los años naturales que abarca el nuevo documento, y dar a conocer sus conclusiones bien en un acto específico; bien durante la celebración de algún cvento suficientemente significativo como para que estos resultados tengan el adecuado eco, como son, entre otros, el Día Internacional del Voluntariado o la organización del Congreso Estatal que se viene celebrando desde 1997.

- Para la realización de este seguimiento, así como para llevar a cabo la evaluación final a la conclusión de los cuatro años, se invitar a todas las instancias interesadas. sean las quc hasta ahora sc han incluido en las valoraciones, sean otras instancias nuevas, pero cuya acción puede ser de especial relevancia (como medios de comunicación social, cntidades empresariales o instituciones educativas) para que den a conocer los proyectos y actuaciones realizadas que mantengan alguna relación con los contenidos del Plan Estatal, con el fin de poder analizar su información y elaborar un documento único que dé una visión de conjunto sobre la promoción del voluntariado en España. 


\section{INDICADORES DE SENSIBILIZACIÓN}

- El objetivo propuesto para el área de sensibilización es el siguiente: Proporcionar información a toda la sociedad acerca del valor, las oportunidades y la necesidad de participación voluntaria, de acuerdo con las características de cada grupo de edad y con los intereses de cada individuo.

- Este objetivo se prevé valorar por medio de los siguientes indicadores:

Indicadores Finalistas
$\mathrm{N}^{\circ}$ de personas que colaboran como voluntarias en ONG y AAPP.
$\mathrm{N}^{\circ}$ medio de horas que colaboran.
$\mathrm{N}^{\circ}$ medio de años que colaboran.
Porcentaje de población global que conoce qué es el voluntariado.

1. Fomento y apoyo de todas aquellas iniciativas que supongan la difusión de las actividades voluntarias, el reconocimiento de los voluntarios y el debate sobre su concepto y papel social:

\begin{tabular}{|l|} 
Indicadores de Proceso \\
$N^{\circ}$ de campañas de sensibilización realizadas en materia de voluntariado. \\
$N^{\circ}$ de actos realizados en celebración de hechos o días conmemorativos. \\
$N^{o}$ de actos o materiales promovidos para dar a conocer el Plan Estatal. \\
$N^{\circ}$ de nuevas iniciativas para reconocer la labor de ONG o voluntarios. \\
$N^{o}$ de estudios realizados sobre aspectos generales o en algún campo específico. \\
$N^{o}$ de documentos o actos conjuntos que aborden temas novedosos o polćmicos.
\end{tabular}

2. Sensibilización y compromiso de los medios de comunicación social hacia las temáticas relativas a las ONG y el voluntariado, y los valores que representan:

Indicadores de Proceso
$\mathrm{N}^{\circ}$ de nuevos medios especializados en prensa, radio, televisión e Internet.
$\mathrm{N}^{\circ}$ de programas, artículos o reportajes emitidos en medios sociales generales.
$\mathrm{N}^{\circ}$ de proyectos realizados para la sensibilización de medios y profesionales.

3. Consolidación de la acción voluntaria en el ámbito educativo:

Indicadores de Proceso
$\mathrm{N}^{\circ}$ de campañas de sensibilización realizadas en el marco educativo.
$\mathrm{N}^{\circ}$ de programas formativos de profesores/alumnos vinculados con esta temática.
$\mathrm{N}^{\circ}$ de ONG con acuerdos con centros educativos.
$\mathrm{N}^{\circ}$ de nuevas agencias o programas universitarios de voluntariado.
$\mathrm{N}^{\circ}$ de nuevas asignaturas universitarias, estudios y cursos sobre $\mathrm{ONG}$.
$\mathrm{N}^{\circ}$ de ONG con acuerdos con centros universitarios.

4. Consolidación de la acción voluntaria en diferentes grupos de edad y con diferentes colectivos:

Indicadores de Proceso
Porcentaje de varones y mujeres sobre el total de los voluntarios.
Porcentaje de mayores de 65 años sobre el total de los voluntarios.
$\mathrm{N}^{\circ}$ de voluntarios que trabajan con SIDA, gitanos, reclusos e inmigrantes.
$\mathrm{N}^{\circ}$ de voluntarios dedicados a los siguientes sectores: cooperación al desarrollo,
protección civil, instituciones penitenciarias, sanidad, educación, acción social,
cultura, deporte y medio ambiente.
$\mathrm{N}^{\circ}$ de nucvos Planes Municipales de voluntariado cstablecidos.




\section{INDICADORES DE APOYO}

- El área de apoyo persigue la siguiente meta: Comprometer al sector público, al privado lucrativo y al propio Tercer Sector en la modernización de las ONG y en su dotación, adecuadas al destacado papel social que han de desempeñar.

- El seguimiento y evaluación de esta meta se prevé conocer mediante diversos indicadores:

\begin{tabular}{l} 
Indicadores Finalistas \\
$\mathrm{N}^{\circ}$ de nuevas ONG inscritas en el Registro de Asociaciones. \\
Porcentaje del PIB correspondiente a las ONG / Tercer Sector. \\
$\mathrm{N}^{\circ}$ medio de voluntarios por entidad. \\
$\mathrm{N}^{\circ}$ medio de socios por entidad. \\
\hline
\end{tabular}

5. Apoyo a la modernización organizativa y funcional de las entidades del Tercer Sector:

Indicadores de Proceso
$\mathrm{N}^{\circ}$ de proyectos orientados hacia la modernación de las ONG.
$\mathrm{N}^{\circ}$ de acciones orientadas hacia la presencia de las ONG en Internet.

6. Dotación de recursos humanos, económicos y de otro tipo adecuada a las acciones de cada ONG:

\begin{tabular}{|l|}
\hline Indicadores de Proceso \\
$\mathrm{N}^{\circ}$ de acciones formativas de voluntarios. \\
$\mathrm{N}^{\circ}$ de acciones formativas de voluntarios en las siguientes materias: cooperación al \\
desarrollo, protección civil, instituciones penitenciarias, sanidad, educación, ac- \\
ción social, cultura, deporte y medio ambiente. \\
$\mathrm{N}^{\circ}$ de ONG que han creado la figura del coordinador o gestor de voluntariado. \\
$\mathrm{N}^{\circ}$ de acciones formativas para profesionales, directivos y gestores de ONG. \\
$\mathrm{N}^{\circ}$ de voluntarios que ocupan puestos directivos. \\
Gasto medio dedicado por las ONG a programas de voluntariado. \\
$\mathrm{N}^{\circ}$ de instrumentos de información creados o editados. \\
\hline
\end{tabular}

7. Consecución de la implicación social de la empresa:

\begin{tabular}{|l|} 
Indicadores de Proceso \\
$\mathrm{N}^{\circ}$ de proyectos realizados para la sensibilización del empresariado. \\
$\mathrm{N}^{\circ}$ de acuerdos de colaboración puntual o permanente entre empresas y ONG. \\
$\mathrm{N}^{0}$ de proyectos orientados al patrocinio empresarial de acciones solidarias. \\
$\mathrm{N}^{\circ}$ de productos o servicios prestados por empresas a ONG. \\
\hline
\end{tabular}

\section{INDICADORES DE COORDINACIÓN}

- El objetivo propuesto para el área de coordinación es el siguiente: Fortalecer la colaboración entre Administraciones Públicas y ONG, prestando una especial atención a su implicación en las estructuras y redes nacionales e internacionales de cooperación.

- Estc objetivo se prevć valorar por medio de los siguientes indicadores:

Indicadores Finalistas
Porcentaje de integración de ONG en coordinadoras, federaciones, confederacio-
nes, plataformas, ...
$\mathrm{N}^{\circ}$ de consejos territoriales creados.
Porcentaje de ONG y AAPP integradas en redes internacionales.


8. Fortalecimiento de las relaciones de coordinación entre ONG:

\section{Indicadores de Proceso}

$N^{\circ}$ de proyectos ejecutados conjuntamente, al menos, por dos entidades.

$N^{\circ}$ de nuevas plataformas o estructuras de coordinación creadas.

9. Vigorización de la coordinación en el ámbito administrativo y de la participación de las ONG en la prestación de servicios públicos:

\section{Indicadores de Proceso}

$N^{\circ}$ medio de empleados en unidades administrativas (generales y autonómicas).

$\mathrm{N}^{\circ}$ de proyectos realizados conjuntamente por distintas Administraciones.

$N^{\circ}$ de proyectos de coordinación entre ONG y Administraciones Públicas.

10. Incorporación de las ONG y de las unidades administrativas al entorno internacional:

\section{Indicadores de Proceso}

$\mathrm{N}^{\circ}$ de $\mathrm{ONG}$ españolas integradas en redes internacionales.

$N^{o}$ de Administraciones españolas integradas en redes internacionales. 


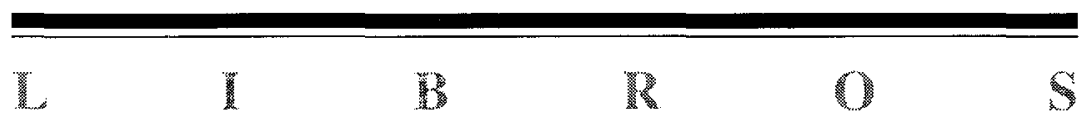



Título: Redes Familiares en el cuidado del Anciano con Demencia. Análisis evolutivo de un estudio poblacional

Autor: Jesús Rivera Navarro

Edita: Consejo Económico y Social de la Comunidad de Madrid, 2001.

La presente obra es el resultado de una investigación llevada a cabo por Jesús Rivera Navarro, doctor en Sociología por la Universidad Complutense de Madrid, para la elaboración de su tesis doctoral bajo la dirección de Máximo Díaz Casanova. Se encuentra dividida en dos partes. En la primera se analiza el marco social en el que se inserta la investigación y la segunda da cuenta en detalle del estudio cuantitativo y cualitativo.

La creciente prolongación de la vida lleva aparejadas problemáticas de nuevo cuño. Las consecuencias de la aparición de enfermedades crónicas como la demencia nos enfrentan a nuevos desafíos en lo que refiere a la atención de las personas ancianas. En esta obra se estudia la manera en que responden y se ven afectadas las redes familiares por este problema a través del cuidado informal. La investigación se llevó a cabo de manera comparativa entre dos zonas urbanas de la Comunidad Autónoma de Madrid con diferente situación socioeconómica. El universo estudiado ha sido de ciento cincuenta familias realizándose un corte longitudinal desde 1994.

El objetivo planteado para la investigación era "analizar la problemática social, económica y familiar de los ancianos afectados de demencia”. Para alcanzar este objetivo, se trabajó analizando dos aspectos. Por un lado, la intensidad de la demencia como generadora de carga social y familiar y, por otro, el entramado social "informal" de ayuda al anciano con demencia y las ayudas formales (institucionales y personal contratado para asistencia a domicilio). 
En los primeros apartados se realiza un recorrido por la historia del envejecimiento como objeto de análisis sociológico donde se encuentra la fundamentación teórica de la investigación. Esta descripción sirve para distinguir el envejecimiento individual (biológico) y el envejecimiento de la población (demográfico) sufrido en los países industrializados a partir del aumento de la población mayor de 65 años. En este marco se incluye una sintética compilación de las diversas teorías utilizadas para el estudio y observación de esta problemática, como la teoría del desacoplamiento, de la actividad, de la continuidad, del etiquetaje y la socio-ambiental, caracterizando cada una y realizando un análisis comparativo. Se describen también las pautas de envejecimiento en el mundo y en Europa desde una perspectiva cualicuantitativa que incluye un análisis del proceso de envejecimiento demográfico en el territorio español en los últimos 40 años del siglo XX. De gran interés resultan los aportes realizados al estudio del envejecimiento y sus consecuencias sobre la estructura familiar española. El proceso de transición demográfica que introduce la presencia creciente de personas de la cuarta edad trae consigo un aumento de las necesidades de asistencia personal. En este paisaje, los procesos de diferenciación funcional entre la familia tradicional y la familia post moderna requieren una urgente reflexión para planificar las líneas de acción en materia de políticas sociales para el sector.

Dentro de esta primera parte, se dedica un capítulo al cuidado informal de los ancianos incapacitados. En el mismo se conceptualizan el apoyo y/o cuidado informal a los ancianos siguiendo las definiciones de la literatura internacional y nacional.

Resulta interesante para el debate el papel otorgado a la familia como portadora bidireccional de apoyo informal y formal. En el primer caso resulta obvia la preeminencia de la institución familiar como base del apoyo informal, pese los cambios funcionales que el propio autor describe, y en segundo lugar también se la sitúa como proveedora de apoyo formal al recibir dinero por parte de la Administración por los cuidados que brinda a los enfermos. También se describen y analizan las características del cuidador principal (cuidadora, deberíamos decir, teniendo en cuenta que, como el propio texto recoge, los ancianos incapacitados son cuidados en nuestro país por mujeres de la familia en un $80 / 90 \%$ de los casos) así como las cargas que implican para la persona encargada de los cuidados y el conjunto del entorno familiar.

La primera parte finaliza con un capítulo dedicado al cuidado y servicios formales dirigidos a los ancianos incapacitados a lo largo del cual se analizan las políticas sociosanitarias en Europa y en España, aportando datos y experiencias concretas. 
La segunda parte de la obra se divide en seis capítulos que desarrollan los resultados y conclusiones del estudio cuantitativo y cualitativo. Dentro del estudio cualitativo destacan los discursos de los cuidadores informales del anciano con demencia, a cuyo estudio se acerca el autor por medio de dos grupos de discusión y tres entrevistas en profundidad. En esta parte se buscó la explicación del rechazo absoluto a la posibilidad de ingresar al anciano en una institución, las causas por las que se asume el cuidado, los niveles de la carga emocional y la elaboración de mecanismos de cuidado. Incluye una visión prospectiva sobre el futuro cuidado de los ancianos.

En el último capítulo se introducen las conclusiones y propuestas. De las conclusiones destacamos la propuesta de analizar el cuidado del anciano con demencia desde una dimensión tripartita: 1) la solidaridad comunitaria (valores tradicionales) 2) la solidaridad orgánica con la consecuente participación de las administraciones públicas y 3) una solidaridad asociativa a través de fórmulas cooperativas. A partir de aquí se desarrollan las diferentes conclusiones a las que arriba el estudio, de cuya mano se llega a las propuestas que, para diversos ámbitos de intervención en el cuidado del anciano con demencia, realiza el autor.

La obra es engarzada con una abundante referencia bibliográfica y cinco anexos que incluyen los instrumentos utilizados (entrevistas, fichas técnicas, cuestionarios...) y un sintético diccionario de términos clínicos. 



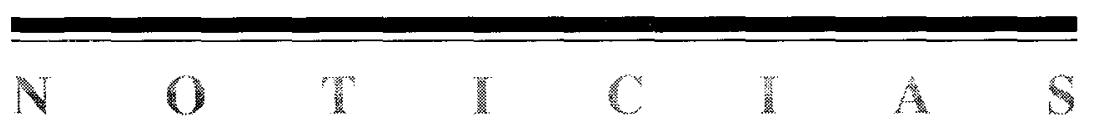



Crónica de la VI Reunión sobre Universidad y Discapacidad. organizada por el Real Patronato sobre Discapacidad. Universidad Nacional de Educación a Distancia (UNED).

Madrid, 17-19 de octubre de 2001.

Los días 17 a 19 de octubre de 2001, mediante la convocatoria y organización de la Universidad Nacional de Educación a Distancia (UNED), se celebró en Madrid la VI edición de la Reunión sobre Universidad y Discapacidad que viene manteniendo el Real Patronato sobre Discapacidad. Se adoptó el lema "Para la igualdad de oportunidades". Durante tres días los diferentes agentes implicados en el quehacer universitario (profesores, alumnos, vicerrectores, representantes de la Administración del Estado, voluntarios...) debatieron, en forma de ponencias-debate y de mesas redondas, acerca de los problemas con que se encuentran las personas con discapacidad que acceden a la Universidad. En la primera mesa Discapacidad y sociedad. Estudiantes con discapacidad en la Universidad, Lucía Rivas expuso la labor de la Unidad de Integración para Alumnos con Discapacidad de la UNED. Por ello, resulta de vital importancia crear y apoyar servicios de asistencia y apoyo a los alumnos y, además, darlos a conocer. Por último, aludió al documento realizado en la Universidad Carlos III de Madrid, en el que se dan las pautas para confeccionar un programa de integración de estudiantes con discapacidad en la Universidad. Joaquín Roca (Universidad Politécnica de Cartagena) recalcó que, cuando un alumno presenta una limitación en sus capacidades que le impide una accesibilidad sin trabas o el desarrollo de una actividad determinada, la solución es la potenciación de servicios y recursos (que pueden ser legales, sociales, tecnológicos, etc.) pero teniendo en cuenta, además, que la forma de solucionar los problemas en la Universidad debe ser la misma que el titulado vaya a utilizar cuando inicie el ejercicio de una profesión para que no se produzca un salto insalvable. Finalizó su exposición enumerando los distintos problemas a los que se tiene que enfrentar un alumno universitario con discapacidad y presentando el concepto europeo de accesibilidad que se basa en los principios del 
diseño universal. José Vicente Carbonell y Antonio Rubio, arquitecto de la UNED, trataron el tema de las Barreras físicas. Entorno urbano, ciudad universitaria, edificios, transportes. Experiencias y demandas pendientes mencionando las ayudas técnicas, los apoyos personales e institucionales y la accesibilidad como los tres pilares fundamentales para las personas con discapacidad que acceden a la Universidad, una Universidad que debe ser accesible por el valor formativo y social que tiene en sí misma y por el valor estratégico que supone para permitir el acceso a otros ámbitos. Se trató el tema de la falta de control en los proyectos urbanísticos e inmobiliarios, apostillando que las condiciones de accesibilidad no deben suponer ningún coste adicional si se plantean desde el inicio y, aunque lo supongan, no son adicionales, ya que son condiciones que deben concurrir obligatoriamente, al igual que ocurre con el tema de las situaciones de emergencia. En el caso de las barreras en el transporte se apostó porque además de transportes públicos adaptados existiera un transporte específico complementario que podría ser, incluso, puerta a puerta.

En cuanto a las Barreras didácticas. Conflictos y soluciones entre la labor docente y el apoyo a los estudiantes con discapacidad. Pilar Ibáñez López (UNED) destacó las tres variables que están incidiendo en el incremento de alumnos con discapacidad en la Universidad: la promulgación de normativas, la difusión del concepto europeo de accesibilidad y los avances tecnológicos que facilitan los desplazamientos y la comunicación. En cuanto a las barreras didácticas señaló las adaptaciones como mejor forma de superarlas y recordó lo expuesto en el Real Decreto 334/1985 de marzo, en el que se insta a acomodar a las peculiaridades físicas, sensoriales o intelectuales del individuo el contenido, la metodología, el material didáctico, las pruebas de evaluación, etc. Francisco Alcantud (Universitat de Valencia) abordó el tema de las adaptaciones curriculares como elemento indispensable para lograr una inclusión, una convivencia en el medio físico y una integración real, ya que si no se adaptan las actividades y si no se da la oportunidad de participar en la sociedad o en los medios académicos a la persona con discapacidad, no se podrá hablar de inclusión. Propone un enfoque habilitador; primero que actúe sobre la persona intentando conseguir el máximo de las capacidades y habilidades y, en segundo lugar, sobre el entorno, modificando el espacio físico, las prestaciones sociales, las actitudes, los conocimientos, con el fin de superar los obstáculos físicos, de comunicación o actitudes desfavorables. El objetivo final es ajustar la demanda de contenidos a las habilidades de las personas, potenciando las habilidades con ayudas técnicas o con acciones de habilitación y de formación específica. También habló de los problemas que se producen al intentar realizar una adaptación curricular y del reglamento desarrollado para tal efecto en la Universidad de Va- 
lencia que explicita que debe ser aprobado por el departamento correspondiente, no sólo por el profesor, y que debe ajustarse a las necesidades del estudiante, lo que implica la participación de personal de los centros de apoyo.

También se abordó el tema de las Ayudas Técnicas al estudio. Nuevas tecnologías aplicadas a la educación. Novedades y líneas de desarrollo. Programa de apoyo a la mejora del rendimiento académico. Santiago Aguilera, (Universidad Politécnica de Madrid), inició su exposición con una breve referencia a las ayudas a la comunicación presencial y telefónica dando ejemplos concretos de dichas ayudas y, rápidamente, pasó a explicar con detalle una herramienta de escritura predictiva diseñada por su departamento, así como el funcionamiento de los teléfonos de texto. Presentó, por último, algunas novedades en telefonía móvil ya en funcionamiento o próximas a aparecer y que pueden servir de ayuda a la comunicación para personas con deficiencia auditiva. José Antonio Muñoz Sevilla (ONCE) hizo una revisión de las ayudas técnicas más comunes existentes para el apoyo a la comunicación y para el acceso a los ordenadores de las personas con deficiencia visual (tanto de hardware como de software) y realizó un análisis sobre la mala accesibilidad a las páginas de Internet, recomendando a los programadores tener en cuenta las normas de la W3C a nivel internacional y del SIDAR a nivel nacional. Además indicó que el futuro es muy prometedor tanto en el campo de la bioingeniería (cirugía, neurocirugía, implantes de prótesis neuronales) como de la informática, donde se trabaja en proyectos como el del Espacio Acústico Virtual para evocar imágenes a través del sonido tridimensional que pueden producir los objetos, y el proyecto REVIT que sirve para percibir formas que hay en el ordenador a través de un brazo articulado que recibe la información que le manda el ordenador. Cristina RodríguezPorrero (CEAPAT) hizo una presentación del CEAPAT, de sus objetivos y los retos que se plantea a través de tres vías: accesibilidad, tecnología y diseño universal. Retomó el tema de la accesibilidad a Internet hablando del TAW (programa para evaluar la accesibilidad de las páginas web), del W3C y del SIDAR como un organismo fundamental en España para potenciar que las páginas web sean accesibles y para adquirir información sobre cómo lograrlo. Mencionó, además, las normas AENOR sobre programas y productos informáticos y el programa de acción europeo e-Europe, que intenta llegar a una Europa digitalizada y en línea para todos los ciudadanos. Por último mencionó el catálogo de ayudas técnicas del CEAPAT y el programa ALBOR que evalúa las posibilidades de acceso al ordenador de las personas con discapacidad.

La voz de los estudiantes corrió a cargo de Ángel Pontones y 
Florentina Llordén (UNED). Ambos narraron sus experiencias como estudiantes universitarios con discapacidad constatando la existencia de barreras arquitectónicas, didácticas, de comunicación y señalando las barreras psicosociales, de incomprensión por parte de profesores, compañeros y personal administrativo, como las más perjudiciales y dolorosas. Explicaron que no es cuestión de presupuestos sino de voluntad y dieron algunas claves o propuestas para ayudar a los alumnos con discapacidad. Ángel Pontones añadió que la función que tendrían que cumplir las unidades de integración no es solamente la de ayudar a los alumnos con necesidades especiales, sino también la de conseguir que aumente el número de personas con discapacidad que acceden a la Universidad.

El jueves 18, las jornadas contaron con la presencia de varios miembros de los Servicios de apoyo de diversas Universidades para presentar sus Experiencias en el curso académico 2000-2001. Lucía Rivas (UNED) describió las funciones y los objetivos de su grupo de trabajo y comentó sus actuaciones durante este primer año de funcionamiento: realización de un censo de estudiantes con discapacidad para conocer los tipos de deficiencias y las necesidades que acarrean cada una de ellas y así poder prestar un apoyo individualizado; atención a las demandas y peticiones de los alumnos que necesitaron algún tipo de ayuda técnica o de adaptación; ventanilla única para resolver trámites con la administración UNED; curso de sensibilización del profesorado, así como orientación y apoyo en todo momento. Antonio Pérez (Univ. Murcia) explicó que su unidad se inició a través del conocimiento de experiencias similares en otras universidades, que lleva funcionando más de tres años y que se incluyó dentro del Servicio de Asesoramiento y Orientación Personal, destinado a resolver las dudas no académicas de los alumnos en general (dudas de tipo jurídico, social, psicológi$\mathrm{co}$, pedagógico), porque consideraron negativo tratar la discapacidad como algo independiente. La Unidad presta asesoramiento y apoyo, cuenta con aula de ayudas técnicas y un servicio de evaluación de necesidades y adaptaciones curriculares. Montserrat Llinares (Univ. Ramón Llull) habló del programa ATENES (Atención a los Estudiantes con Necesidades Especiales) cuya línea de trabajo consiste básicamente en la sensibilización de la comunidad educativa (profesores y personal administrativo a través de cursos de formación), las adaptaciones curriculares, la formación del voluntariado y la orientación personal, académica y social del individuo. Lo lleva a cabo un equipo interdisciplinar que trabaja siempre poniendo énfasis en la idea de inclusión. Alejandra Huertas, directora de la Unidad de Trabajo Social de la Universidad Pontificia de Comillas, expresó que el servicio surgió a raíz de la preocupación mostrada por la Escuela Universitaria de 
Trabajo Social por conocer las necesidades sociales dentro de la Universidad. Se les permitió durante un año académico realizar un estudio en el que se constató que había alumnos con discapacidad que tenían una serie de necesidades y de los que no se sabía nada y, por tanto, por los que no se hacía nada. A raíz de este estudio se desarrollaron una serie de programas entre los que estaba el de apoyo a personas con discapacidad, que trabaja en la atención de las necesidades del alumno y en la sensibilización. También hizo referencia a la necesidad de aumentar presupuestos y de que la Universidad adopte una normativa vinculante para poder lograr avances importantes. Por su parte, Ignacio Jaureguiza (Solidarios para el desarrollo) expuso el Programa de Atención a Universitarios con Discapacidad que ellos coordinan dentro de la Universidad Complutense de Madrid. La Universidad presta infraestructuras a esta ONG para que éstos ejecuten sus programas de acompañamiento, apoyo académico, toma de apuntes, transporte, de los que se benefician las personas con discapacidad que estudian allí. Comentó que debido al aumento del número de estudiantes con alguna necesidad de apoyo y a la próxima finalización de la prestación social sustitutoria, cada vez tienen más problemas para cubrir las necesidades.

Otra mesa debatió la Promoción y formación del voluntariado. Su labor en los Servicios de Apoyo de las Universidades. Nuevas experiencias. Joaquina Murcia, del Centro de Apoyo al Estudiante (CAE) de la Universidad de Alicante, del que ya se había hablado anteriormente, explicó cómo detectaron necesidades que difícilmente se podían cubrir desde el CAE y que era desde la proximidad y desde la cercanía desde donde se podrían cubrir. Por eso se empezó a trabajar dentro de la Universidad con voluntarios y se creó el Proyecto de Voluntariado para Apoyo a los Estudiantes con Discapacidad. Este proyecto nació con unos objetivos muy claros de sensibilizar hacia el tema de la discapacidad, atender las necesidades individuales de la persona, canalizar la voluntad de colaboración de los alumnos y formar a los voluntarios. Eduardo Osuna y María José Carrillo (Univ. de Murcia) explicaron que el Servicio de Voluntariado data de 1994 y realiza actividades de sensibilización y formación, dentro de la Universidad y fuera de ella en colaboración con otras asociaciones. Sus dos objetivos principales son: facilitar la integración y la calidad de vida de los estudiantes discapacitados a su paso por la Universidad a través del apoyo de sus compañeros voluntarios y sensibilizar y formar a la comunidad universitaria sobre el tema de la discapacidad. Cristina Segura (Servicio de Atención al Alumno Universitario con Discapacidad, Universidad Politécnica de Valencia) detalló la forma de funcionar del voluntariado en su Universidad. Subrayó que la acción de los servicios de atención 
universitarios necesitan ser complementados por voluntarios y comentó que han participado en los foros realizados por la plataforma valenciana del voluntariado y que han sido un miembro activo en la creación de la nueva ley del voluntariado. Ángel Gómez (Oficina del Voluntariado de la UNED) comentó los dos objetivos prioritarios de la misma en su primer mes de funcionamiento: dar facilidades a aquéllos que quieren ser voluntarios ofreciéndoles toda la información que puedan solicitar y formar una red de personas que colaboren con los más de 1.600 estudiantes universitarios con alguna discapacidad que hay en la UNED. Introdujo el debate de que las personas con discapacidad no solamente pueden ser receptoras de la acción del voluntariado, sino que pueden y deben ser voluntarios.

Otros temas abordados fueron $\mathrm{La}$ voz de los profesores en la que Gregorio Gómez-Jarabo (Univ. Autónoma de Madrid) destacó la "discapacidad transitoria", en forma de depresión, ansiedad, estrés, que se está creando en la Universidad por no contemplar los factores personales del alumnado y La decisión política, el servicio, el usuario, mesa moderada por Demetrio Casado (Real Patronato sobre Discapacidad) quien tras sentar la base legal del tema tratado abogó por una plasmación jurídica de todas aquellas propuestas que puedan facilitar el avance en este campo. Antonio Pérez (Univ. de Murcia) también habló acerca de la necesidad de una normativa marco a nivel nacional, concreta, específica y clara, que permita cristalizar en las distintas universidades reglamentos que otorguen una capacidad de actuación real, rápida y con respaldo, para que las unidades de apoyo a alumnos con discapacidad no dependan sólo de favores y buenas voluntades en el seno de la Universidad. A continuación, Pilar Barrero García (Secretaría de Estado de Educación y Universidades) que los servicios públicos se establecen por Ley y que a la Administración sólo se le atribuye capacidad de instrumentación de servicios ya creados. Referido a la legislación universitaria se establece que el servicio público de la educación corresponde a la Universidad, que lo realiza mediante la docencia, el estudio o la investigación. Por tanto, argumentó, más que dirigirse a la Administración Pública, la necesidad social debe ser vista desde la Universidad que es a la que la Ley encarga en este caso la gestión. Además reclamó un papel más activo del usuario y no solamente en el terreno de la educación. Eugenio Nasarre (Grupo Popular) tras defender el alto nivel de integración que se ha logrado instaurar en educación primaria y secundaria, instó a conseguirlo también en la educación superior. Expuso tres necesidades: un mayor cambio de mentalidad, más recursos económicos y la creación en todas las universidades de un servicio específico de atención a personas con discapacidad que forme parte de las propias estructuras de la Universidad. 
Finalmente miembros del equipo del Instituto Universitario de Educación a Distancia, presentaron un trabajo de investigación sobre $\boldsymbol{E l}$ alumnado ciego o con baja visión de la UNED. María Teresa Bardisa (directora), Diana Calcerrada, Sara García Cuesta y Pablo Martín describieron Ia labor del Instituto en el que trabajan y expusieron la metodología, desarrollo y conclusiones del trabajo, en el que se pretendía realizar una aproximación al colectivo de alumnos con deficiencia visual de la UNED para, desde el conocimiento, actuar de forma institucional y utilizarlo en beneficio de este grupo de alumnos. 



\section{Jornadas sobre Intervención Familiar en el Siglo XXI. Con- clusiones: ¿Por un nuevo modelo de intervención con familias?} La Vila Joiosa, 25, 26 y 27 de octubre de 2001.

La familia es una unidad microsocial en transformación. Hoy las tendencias al envejecimiento de la población, la reducción de la natalidad, el retraso en la edad de constitución de nuevas unidades familiares, la realidad y diversidad de los modelos familiares, etc. han de inducir a las Administraciones públicas a repensar las estrategias tradicionales de protección a la familia y a incorporar nuevas acciones en respuesta a sus necesidades.

Hoy el nuevo perfil sociodemográfico de la familia, caracterizado por una mayor esperanza de vida y una menor mortalidad, da lugar a la presencia de un mayor grado de personas dependientes a su cargo y a una sobrecarga de su función cuidadora. Si junto a ello consideramos la incorporación reciente de la mujer al mercado de trabajo, tradicional responsable de este apoyo intrafamiliar, y la necesidad consecuente de atención a los hijos menores de 3 años, el panorama de la acción pública se ha de plantear el reto de articular medidas de apoyo familiar compatibles con la consecución de mayores cotas de incorporación social de las mujeres, y no a costa de ellas.

En el ámbito de las políticas públicas, se constatan, a partir de las aportaciones realizadas en estas Jornadas, las diferencias en las políticas públicas dirigidas a la familia en los diferentes Estados miembros de la Unión Europea. En el caso español, la mayoría de las acciones significativas que éstas implican se sitúan todavía en el terreno de lo graciable y no constituidas como derechos ciudadanos reclamables por éstos. Se observa una tendencia escasa todavía a esta transformación en el caso español, con medidas como la regulación relativa a la conciliación de la vida familiar y laboral.

Se hace necesario ampliar el contenido del derecho a la protección 
de la familia con una actuación pública integral y transversal efectiva, en torno a cinco ejes básicos (Salud, Vivienda, Educación, Empleo y Servicios Sociales), y en dos niveles:

- Protección genérica a la familia.

- Protección específica de la familia, dirigida a familias desfavorecidas o en situación de riesgo social.

Un aspecto fundamental de tales políticas se habría de orientar necesariamente al desarrollo de rentas mínimas garantizadas para familias sin recursos, como mínimo imprescindible y punto de partida para el desarrollo de otras acciones con las mismas. Rentas éstas no sujetas a disponibilidad presupuestaria o al nivel competencial asumido por la Administración territorial correspondiente, sino incluidas en los presupuestos generales del Estado o de las Comunidades Autónomas, amparadas por la Ley y sujetas a un sistema de reclamación por parte de los ciudadanos.

Otro de los elementos centrales de estas nuevas acciones, en relación con las nuevas necesidades familiares, se relacionaría con la oferta de servicios para las personas dependientes, tanto en el caso de ancianos/as como en el caso de la infancia de 0 a 3 años.

\section{Desde el punto de vista de los modelos y/o enfoques de inter- vención:}

La mediación se constituye hoy como una técnica de resolución de conflictos, útil no sólo en el ámbito de la intervención familiar sino también en otros contextos (las organizaciones y sus profesionales, las relaciones interinstitucionales, etc.). Además supone una nueva línea de especialización profesional que, desde un espacio de neutralidad, ayuda a las partes a llegar a acuerdos sobre asuntos comunes que les afectan, relativizando las posturas rígidas de las partes y ayudándolas a definir la "mejor solución" para las dos.

La perspectiva ecológica del enfoque de redes ofrece a la intervención familiar nuevos caminos para explorar, nuevos imaginarios desde una nueva forma de mirar la realidad, tejiendo redes que vinculen y relacionen a los miembros de la comunidad entre sí y con los profesionales, creando espacios para la reflexión que conduzcan a iniciativas y proyectos compartidos.

La perspectiva sistémica aportó en las Jornadas su visión de un tipo de familias habituales en las organizaciones de intervención familiar. La familia multiproblemática cuestiona la omnipotencia de la sociedad de consumo y, lamentablemente, estimula en demasiadas ocasiones el afán benefactor y paliativo de los equipos de base. Desde una perspectiva sistémica, las aportaciones de los siguientes autores pre- 
tenden focalizar sobre elementos de comprensión y de intervención con dichas familias, entendiendo la intervención como algo concreto y finito en el tiempo y en la involucración de los profesionales.

El psicoanálisis busca el cambio psíquico, tratando de poner en circulación la energía bloqueada que produce inmovilidad, a través de la escucha del inconsciente, se trata de buscar alternativas para romper un círculo vicioso que impide avanzar hacia un movimiento madurativo.

Desde esta línea se trata de pasar de los modelos asistenciales clásicos a otros más flexibles y variados que permitan resituar las demandas y poder responder lo más adecuadamente posible según el tipo de problema, las condiciones de la familia y los recursos con que cuenta o que se puedan desarrollar.

Desde todas estas perspectivas se hacen necesarios programas de tipo preventivo-educativo-promocionales dirigidos a personas, familias y colectivos, desde la red primaria, en un contexto comunitario, superadores de la intervención individual:

- Programas de tipo preventivo, concienciadores de problemas sociales que afectan a la comunidad.

- Programas de intervención familiar, con un enfoque claramente dirigido a grupos o familias en situación de conflicto intrafamiliar.

- Programas sociosanitarios de detección precoz de situaciones de riesgo dirigidos a la infancia de 0-3 años, donde deben coordinarse los sistemas de salud, educación y servicios sociales.

- Programas dirigidos a jóvenes con conductas inadaptadas y/o medidas judiciales en medio abierto, con el objetivo de su integración social y laboral.

- Programas de seguimiento de la intervención, con el objetivo de consolidación de los logros conseguidos.

Desde la perspectiva de las organizaciones de intervención familiar, la reflexión realizada en estas Jornadas revela que los servicios humanos son sistemas complejos y abiertos, en interacción con el entorno que define sus metas organizacionales y las legitima o desacredita. De este modo, las organizaciones realizan un trabajo moral en la medida en que no son ajenas a un contexto social y a un tiempo dados que definen qué es lo normativo y funcional y qué es lo asocial o disfuncional.

Pero las organizaciones están formadas por un sistema de profesionales que no es ajeno a las características de la misma organización puesto que ambos mantienen una relación circular por la que se retroalimentan y se definen mutuamente. 
Los profesionales así se encuentran en una situación de vulnerabilidad derivada de su actividad laboral, por la ambigüedad de las metas organizacionales, por la implicación emocional que supone y requiere el trabajo con familias, por la complejidad del objeto y sujeto de la intervención, por los riesgos y consecuencias que asume en el ejercicio de esta actividad, etc.

Así, estas aportaciones de las Jornadas plantean algunos de los retos que quedan pendientes para encarar un nuevo camino:

- Vigilancia a los procesos de rigidificación de sus estructuras organizativas.

- Es urgente establecer mecanismos de evaluación de los resultados obtenidos.

- Desde esta perspectiva, el trabajo de estas organizaciones debería pasar de la "actividad silenciosa" a la difusión de sus proyectos y acciones y del resultado de las mismas.

- Es necesario relativizar las soluciones intentadas y repensarlas desde una postura crítica, especialmente en un momento como el actual donde la mixtura de culturas parece redefinir la construcción de lo social y por tanto del sistema de valores y creencias. 
Crónica de las V Jornadas del SIDAR. Seminario de Iniciativas sobre Discapacidad y Accesibilidad en la Red, organizadas por el Real Patronato sobre Discapacidad.

Mar del Plata (Argentina), 25-27 de octubre de 2001.

El Seminario de Iniciativas sobre Discapacidad y Accesibilidad en la Red (SIDAR), del Real Patronato sobre Discapacidad, celebró sus V Jornadas entre los días 25 y 27 de octubre de 2001 en Mar del Plata (Argentina) compartiendo la convocatoria con Iberdiscap (II Congreso Iberoamericano de Tecnologías de Apoyo a la Discapacidad y IV Congreso Iberoamericano de Comunicación Alternativa y Aumentativa). Prestó su colaboración técnica y personal la Fundación Telefónica. La organización técnica fue asumida por Ricardo Koon y por la Fundación Evolución.

El acto de apertura se realizó conjuntamente con Iberdiscap y en él hicieron uso de la palabra Demetrio Casado, Presidente de SIDAR, Luis Campos, Presidente de Iberdiscap, Emmanuelle Gutiérrez, coordinadora de SIDAR, y Rafael Sánchez Montoya, coordinador de Iberdiscap. Emmanuelle Gutiérrez presentó las V Jornadas SIDAR recordando que el Seminario se creó en 1997 dentro del programa de actuaciones del Real Patronato sobre Discapacidad para la mejora de la comunicación social sobre discapacidad y teniendo en cuenta la creciente importancia de Internet. SIDAR tiene entre sus fines: promover la buena utilización de la red para todo tipo de asuntos relativos a la discapacidad, contribuir a la calidad de los contenidos de Internet concernientes a la discapacidad, promover el acceso a la Red por parte de las personas con discapacidad y potenciar la accesibilidad para quienes estén afectos de limitaciones de uso. Destacó que el Seminario, además de sus sesiones presenciales y de su participación en los foros nacionales e internacionales más importantes sobre diseño accesible, trabaja a lo largo de todo el año organizado en dos áreas: iniciativas y accesibilidad. El área de accesibilidad cuenta, además, con tres grupos de interés: Gl o grupo sobre herramientas de edición, navegación y 
evaluación, G2 o grupo de contenidos sobre discapacidad y G3 o grupo sobre diseño accesible. Todas las iniciativas y toda la información que se desprende de su trabajo (en forma de documentos, traducciones, pautas, herramientas, etc.) se encuentra recogida en su página web www.sidar.org

Seguidamente describió el programa de las Jornadas que incluyeron un tiempo para la reflexión sobre las posibilidades que ofrece Internet en la gestión de entidades de o para la discapacidad, una sesión dedicada a la web como medio ideal para promocionar la interacción entre usuarios, de modo que sea verdaderamente un espacio participativo, y una sesión especial dedicada a medidas gubernamentales para conseguir que los Servicios Públicos sean accesibles. En cuanto a la accesibilidad, se dedicó un tiempo a las metodologías de formación tanto para autores como para usuarios y otro para hablar sobre los últimos avances en pautas y lenguajes para la accesibilidad. Por último se dedicó un tiempo a trabajar en talleres en torno a las acciones realizadas y los proyectos a desarrollar durante el próximo año en los tres grupos de interés.

Se ofrece una síntesis del Panel 1. "Internet en la Gestión de Entidades de/o para la Discapacidad"

El primer módulo, "Internet en la gestión de entidades de/o para la discapacidad", fue moderado por José Félix Sanz Juez, director del Centro Especial de Empleo Polibea (www.polibea.com) y responsable de iniciativas dentro del SIDAR. En una breve intervención describió las estrategias de actuación que está llevando a cabo en la gestión de Iniciativas en la Red: localización de las mismas, contacto para identificar a los responsables y ofrecerles información sobre SIDAR, clasificación de la iniciativa según el tipo de página, de los temas que aborda, de las deficiencias de las que se preocupa, etc., difusión entre los medios, los profesionales o personas que pudieran estar interesados en ese sitio web y revisión de las actuaciones realizadas para constatar las consecuencias de dicha intervención. Tras pedir la colaboración de todos a través de los talleres previstos en el programa para el último día, presentó a los participantes en su módulo, cuyas intervenciones ocuparían el resto de la mañana y buena parte de la tarde.

\section{Red Solidaria - Fundación Telefónica}

Ricardo Gaitán Pacheco, gerente de proyectos para la mejora de grupos desfavorecidos de la Fundación Telefónica, presentó la página Red Solidaria (www.risolidaria.org). Comenzó por justificar la creación de este portal por la necesidad de ofrecer infraestructura a las entidades sin ánimo de lucro englobadas en lo que se llama el tercer 
sector. Se puso en marcha en octubre de 1998 y tiene como objetivos: difundir las actividades de estas entidades, facilitar las relaciones entre ellas y favorecer su gestión, mediante la utilización de unas herramientas telemáticas que se ponen a su alcance y sirven para abaratar costes. También se pretende fomentar la participación social en las actividades del tercer sector, ofreciendo para ello un espacio de foro y de chat con el objeto de facilitar la comunicación y alentar su concurso. Indicó que se puede participar como entidad promotora o como miembro.

Carlos San Martín, responsable de Red Solidaria en Argentina, resumió muy brevemente y de forma cronológica lo que es la Red Solidaria en Argentina, donde lleva trabajando dos años, desde la conformación del grupo promotor hasta la creación de un boletín de actualidad social para alrededor de 3.000 asociaciones en Argentina.

\section{AdValens}

Posteriormente correspondió presentar la iniciativa AdValens (www.advalens.com.ar) a Liliana Pantano, asesora, e Ignacio Méndez, presidente y creador del sitio. Liliana Pantano indicó el hecho de que este sitio es la conjunción entre el mundo empresarial y los auténticos protagonistas de la discapacidad, con la idea de promover, hacer conocer, difundir y generar una creciente conectividad.

Por su parte, Ignacio Méndez describió la misión de AdValens como la de una empresa con fuerte contenido social que, utilizando toda la técnica de la gestión empresarial moderna y la tecnología informática, facilita a las personas con discapacidad su desarrollo e integración social y humana. En su descripción del sitio destacó entre otras cosas: la creación de valor a través de la interacción con las organizaciones gubernamentales y no gubernamentales, el que las personas con discapacidad tengan prioridad para trabajar en el proyecto y el que se trate de una iniciativa autofinanciable por medio de los ingresos de publicidad.

Concluyó con un resumen de los desafíos para el futuro de AdValens, entre los que citó: superar el punto de equilibrio financiero, alcanzar las 40.000 visitas, autofinanciar el crecimiento, transparentar los mercados, expandir aún más la internacionalización, considerar AdValens como el referente iberoamericano en el tema de la deficiencia motriz y facilitar la búsqueda de información por intermedio de desarrollo tecnológico y ordenamiento temático.

\section{Mercadis}

Ricardo Gaitán Pacheco retomó la palabra para presentar otra ini- 
ciativa de la Fundación Telefónica, el proyecto Mercadis (www.mercadis.com), consistente en un sistema informático, residente en Internet, para el intercambio de información relacionada con el trabajo y la discapacidad. Su principal objetivo es crear un mercado laboral para las personas con discapacidad en el que confluyan ofertas y demandas de empleo y sea posible una respuesta inmediata. El sistema, además, proporciona información de interés a los grupos representativos del proyecto, asociaciones de personas con discapacidad y empresarios interesados en la contratación de estos trabajadores. El sistema recoge información útil sobre aspectos laborales, legales, bonificaciones y ventajas de la contratación de personas con discapacidad, etc. (de interés para las empresas) y sobre cursos de formación, becas y convocatorias, etc. (de interés para los trabajadores con discapacidad y las asociaciones).

Mostró el nuevo diseño de la página de Mercadis, explicando las modificaciones introducidas y realizó una simulación de búsqueda de empleo, rellenando la ficha destinada a ello. Además, mencionó la labor del Centro de Servicios.

\section{Turismo Accesible}

A continuación, Claudio Segovia y Luis Grunewald presentaron la Fundación Turismo Para Todos. Luis Grunewald explicó que dicha fundación es una institución sin fines de lucro orientada a colaborar en acciones que permitan aumentar el grado de satisfacción de las personas en la realización de actividades durante el tiempo libre destinado al turismo y la recreación. Mencionó sus objetivos y actividades y pasó a mostrar su página web (www.turismoaccesible.com.ar). Una página que apunta a generar información y servicios para la comunidad buscando una aproximación hacia un turismo para todos, un turismo que permita la plena integración de todas las personas, incluidas aquéllas que puedan en el presente o en el futuro tener una minusvalía con el medio.

Claudio Segovia se centró en los aspectos técnicos relacionados con la accesibilidad y narró los pasos que tuvieron que ir acometiendo para cumplir con las pautas del Test de Accesibilidad Bobby. Comentó que actualmente cumple con todos los requisitos básicos (prioridad 1) y que se está trabajando para cumplir con la prioridad 2.

\section{Fundación Braille Uruguay}

Alejandro Schinca presentó la página de la Fundación Braille Uruguay (www.fbraille.com.uy) que él diseña y actualiza. Comenzó explicando que la razón de ser de la Fundación es la de aportar los apoyos psicológicos, educativos y técnicos que las personas con deficiencia 
visual necesitan para desarrollar al máximo sus potencialidades y, posteriormente, mencionó los principales servicios que ofrece: imprenta Braille, libro hablado, atención temprana y rehabilitación visual. Explicó la evolución que ha sufrido la página, desde su origen en 1996 en un entorno OS, hasta la construcción del sitio en entorno Windows en 1997-1998, y mencionó sus contenidos y características principales. Por último comunicó como planes de futuro, entre otros, el hacer la web más interactiva y el acabar con la separación tajante entre el texto puro y el texto con imagen.

\section{Asociación de Ayuda al Ciego}

Una segunda iniciativa sobre deficiencia visual, en esta ocasión en Argentina, fue presentada por el Dr. Francisco J. Elizalde. La Asociación de Ayuda al Ciego, a la que pertenece, tiene casi cuarenta años de historia y se dedica a la rehabilitación de personas con deficiencia visual. Ofrece formación laboral y se está ultimando un Centro de Día y un hogar. Durante su exposición hizo hincapié en la utilidad que pueden tener la Informática e Internet como salida laboral y mostró varios casos de personas a los que la formación recibida les permitió encontrar un puesto de trabajo. Finalmente describió su página web (www.asac.org.ar), explicando todo lo que se puede encontrar en ella y la definió como una página básicamente informativa.

\section{Humanfun}

Eduardo Horacio Cerván mostró, como último turno de intervención antes del coloquio, la página web de Humanfun, un grupo de consultores universitarios especializados en el Diagnóstico de Funcionalidad, Valoración y Tratamiento de los estados disfuncionales en las diversas áreas de la actuación humana. Además de su sitio web (www.humanfun.com.ar), pretenden promover el uso de la CIF (Clasificación Internacional del Funcionamiento, de la Discapacidad y de la Salud) y facilitar la creación de informes de caso (de discapacidad o simplemente de funcionamiento) utilizando los códigos definidos en ella.

Tras una breve reflexión sobre la Clasificación Internacional, pasó a navegar por los distintos apartados de la página y a explicar el funcionamiento del programa Clinter, que sirve para crear informes de casos basados en la nueva Clasificación, imprimirlos o almacenarlos y extraer estadísticas de los casos acumulados. Cerró su intervención con una serie de conclusiones acerca de la nueva Clasificación. 
Simposio: Impacto de la edad en las deficiencias y discapacidades derivadas. Organizado por el Real Patronato sobre Discapacidad en el Congreso Internacional Discapacidad y Envejecimiento. Oviedo, 28, 29 y 30 de noviembre y 1 de diciembre de 2001 .

El día 1 de diciembre tuvo lugar un simposio sobre El impacto de la edad en las deficiencias y discapacidades derivadas, organizado por el Real Patronato sobre Discapacidad. Esta actividad formó parte del Congreso Internacional Discapacidad y Envejecimiento, promovido por la Consejería de Asuntos Sociales del Principado de Asturias y organizado por el IMSERSO y la Fundación Asturiana de Atención a Personas con Discapacidad que se celebró en Oviedo, en el Auditorio del Palacio de Congresos Príncipe Felipe, durante los días $28,29,30$ de noviembre y 1 de diciembre.

El incremento progresivo de la población de personas con discapacidad que llegan a alcanzar edades avanzadas es paralelo al envejecimiento demográfico, derivado de los avances e innovaciones en las ciencias de la salud y en la mejora de las condiciones de vida. Como consecuencia del envejecimiento, las personas con discapacidad presentan una serie de necesidades adicionales, que van a modificar su situación anterior, añadiendo mayores complejidades.

Consciente de las repercusiones sociales y sanitarias de este hecho, el Real Patronato sobre Discapacidad ha organizado o ha colaborado en la organización de diferentes actividades relacionadas con este tema. El Simposio fue coordinado por el Dr. Jesús Flórez Beledo, del Departamento de Fisiología y Farmacología de la Universidad de Cantabria. Constó de tres intervenciones a cargo de la Dra. Ana Águila Maturana, quien expuso una serie de consideraciones sobre el síndrome post-polio; el Dr. José Mendoza Sarmiento, quien habló sobre el impacto de la edad en las personas con lesión medular y el Dr. Jesús Flórez, quien se refirió al impacto en personas con Síndrome de Down. 
III Jornadas del Mediterráneo sobre Voluntariado Voluntariado y Personas Mayores.

Valencia, 12, 13 y 14 de marzo de 2002.

La Fundación de la Solidaridad y el Voluntariado de la Comunidad Valenciana organiza las III Jornadas del Mediterráneo sobre Voluntariado que este año se dedican a «Voluntariado y Personas Mayores». Las Jornadas se celebrarán en Valencia los próximos días 12 a 14 de marzo de 2002 contando con la presencia de D. Aurelio Fernández, Comisario del Comité Organizador de la II Asamblea Mundial del Envejecimiento, expertos, representantes del mundo asociativo y del voluntariado. Las conclusiones se aportarán a los trabajos de la Asamblea Mundial.

Más información en:

Fundación de la Solidaridad y el Voluntariado de la Comunidad Valenciana.

Fuencaliente, 1

46023 Valencia

Tel. 963301109

Fax 963306111 


\section{Congreso Europeo sobre las Personas con Discapacidad.} Madrid, 20-23 de marzo de 2002.

Del 20 al 23 de marzo de 2002, en el marco de la presidencia española del Consejo de la Unión Europea, se celebrará en Madrid la primera edición del Congreso Europeo sobre las Personas con Discapacidad. Promovido por la Fundación Luis Vives, la Fundación ONCE, y el Ministerio de Trabajo y Asuntos Sociales de España, contando con el apoyo y asesoramiento del Foro Europeo de la Discapacidad (EDF). Durante estos cuatro días más de cuatrocientos participantes representantes de todos los sectores sociales, procedentes de diferentes países europeos e iberoamericanos, se darán cita en la capital de España. El Congreso sobre las Personas con Discapacidad nace con el objetivo de servir de foro de análisis, debate, propuesta e impulso de nuevas políticas comunitarias que permitan promover un nuevo modelo de plena inclusión social de las personas con discapacidad en Europa. En este contexto se enmarcará la "Declaración de Madrid", manifiesto de carácter político, en el que se van a incluir propuestas legislativas, políticas y de acción para el año 2003, fecha en la que se celebrará el "Año Europeo de las Personas con Discapacidad". El Congreso contará tanto con la presencia del movimiento asociativo de personas con discapacidad en Europa, como con la participación de representantes de las administraciones públicas de los Estados miembros, de los países candidatos, de las instituciones comunitarias, de las asociaciones empresariales y sindicales y de otros agentes sociales, cuya colaboración y compromiso es imprescindible para que las personas con discapacidad consigan una verdadera integración social. Más información, incluyendo los documentos de las sesiones de trabajo, se puede encontrar en www.disabilityeuropeancongress.org. 


\section{Congreso de Escuelas de Trabajo Social Los desafios de} la violencia. Compromisos del Trabajo Social por una sociedad más justa.

Alicante, 24, 25 y 26 de abril de 2002.

La Escuela de Trabajo Social de la Universidad de Alicante ha asumido la responsabilidad de organizar el IV Congreso de Escuelas de Trabajo Social en el año 2002, continuando así la tarea de dotar a nuestras Escuelas de un foro para el encuentro y el debate científico. En esta ocasión, pretendemos encarar un problema de gran envergadura que con frecuencia enfrentamos en el ámbito profesional sin disponer de las herramientas suficientes. Hemos decidido abordarlo en el Congreso porque creemos que la violencia, y especialmente algunas manifestaciones de la violencia, forman parte de las preocupaciones más urgentes de muchos profesores y profesionales. En atención a todo ello, el Congreso se propone los siguientes objetivos:

- Generar una reflexión teórica, necesariamente interdisciplinar, sobre la violencia en general y, más en concreto, sobre aquellas manifestaciones de la violencia que con mayor frecuencia se producen en el campo del Trabajo Social

- Proponer, para su incorporación al Trabajo Social, modelos de intervención e instrumentos, desarrollados en otras disciplinas, para la prevención y el tratamiento de la violencia.

- Abrir tanto la enseñanza como la práctica del Trabajo Social a nuevas preocupaciones que surgen de la dinámica social y ofrecer respuestas desde nuestra perspectiva profesional y disciplinar.

La estructura del Programa trata de responder a estos objetivos y de establecer el marco para el debate abierto de todas las cuestiones. Por ello, además de un número reducido de ponencias, se ha previsto la organización de mesas redondas, moderadas por especialistas en cada materia. Las mesas contarán con la presencia de los responsables de las comunicaciones que se presenten al Congreso y que, a criterio de 
los organizadores, sean de interés más relevante. El criterio para el diseño de las mesas y la elección de los especialistas ha sido el aunar la reflexión teórica más amplia con las experiencias concretas de intervención más novedosas.

El Congreso será además ocasión para el encuentro de los directores de Escuelas de Trabajo Social, cuya cooperación está produciendo tantas iniciativas de interés. Además, los profesores de las áreas de conocimiento implicadas en la docencia de las Escuelas de Trabajo Social han sido invitados a debatir sobre sus aportaciones respectivas a la Diplomatura. Finalmente, tanto los profesionales del Trabajo Social como los alumnos tendrán ocasión en el Congreso para el intercambio y el debate.

Más información en:

www.ua.es/centros/trabajosocial/index.htm. 
NUMEROS PUBLICADOS 



\section{NUMERO 1 (1992)}

Jesús Daza Martíncz, director.

Presentación

María José Escartín Caparrós. Profesora de Trabajo Social. E.U.T.S. Alicante

Comsideraciones preliminares

\section{Estudios sobre la familia}

Isabel Ramírez de Mingo. Titular de Trabajo Social. Universidad Complutense. Madrid.

El Trabajo Social con familias

María Asunción Martínez Román, María Teresa Mira-Perceval Pastor, Hortcnsia Redero Bellido. E.U.T.S. de Alicante.

Función especificica de la Familia en la atención social comunitaria: su valor como recurso para la sociedad

María José Escartín Caparrós. Profesora E.U.T.S. Alicante.

El Sistema familiar y el Trabajo Social

Dr. D. Agustín Bueno Bueno. Profesor del Departamento de Psicología de la Salud. Universidad de Alicante.

Estilos de vida familiar y riesgo social infantil

María Asunción Martínez Román. Profesora de Servicios Sociales. E.U.T.S. Alicante.

Participación de la Familia en el proceso de rehabilitación de los enfermos crónicos: Los Insuficientes Respiratorios Crónicos Graves (I.R.C.G.) y el Bienestar Social

Josefa Lorenzo García, Manuela Palomar Villena, Esperanza Suárez Soto. Trabajadoras sociales. Profesoras de Ia E.U.T.S. Alicante.

Mujer y Familia. Reflexiones críticas desde nuestra experiencia profesional

Dr. Don Francisco Ortega Beviá. Director Master Terapia Familiar y Profesor Terapia Familiar, Curso Superior Psicosociológico. Da Elisa Pérez de Ayala Morenos Santa María. Profesora de Trabajo Social Familiar. Universidad de Sevilla.

La ilusión de las alternativas: vivir en pareja

Antonio Bellido Alonso, Esther Villegas Castrillo. Profesores del Area de Trabajo Social y Servicios Sociales. E.U.T.S., Alicante.

Influencia de la Familia en el desarrollo de pautas inadecuadas de conducta

Josep-Lluís Orts Molines. Profesor de Valencià a I'E.U.T.S. Universitat d'Alacant.

Idees sobre la familia a la tardor medieval a través de Lo Libre de les dones de Francesc Eiximenis (1327-1490)

M. ${ }^{a}$ Dolores Vargas Llovera. Profesora del Area de Antropología. Universidad de Alicante.

La función familiar en el actual pluralismo religioso: El caso de los Testigos de Jehová

Jcsús Daza Martínez. Catedrático de Derecho Romano.

La ley de Divorcio de 1932. Presupuestos ideológicos y significación politica 
II. Tribuna Libre

Manuel Moix Martínez. Catedrático de Trabajo Social y Serv. Sociales.

Problematismo del Bienestar Social

Esther Villegas Castrillo, Antonio Bellido Alonso. Profesores de Trabajo Social. E.U.T.S. Alicante.

La Teoría Sistémica en Trabajo Social. Criterios de apli-cación y observaciones críticas

Ana M. ${ }^{a}$ Herthogue. Trabajadora Social jubilada de la «Family Welfare Association» de Londres.

Relevancia de algunos conceptos y arquetipos de C. Jung para la labor profesional de los trabajadores sociales

Jorge Garcés Ferrer, M. José Lahoz Campos, Fco. José Ródenas Riga, Estrella Durá Ferrandis. Profesores de SS.SS. en la Escuela de Trabajo Social. U. de Valencia.

Valores y características de personalidad en estudiantes de Trabajo Social de la Comunidad Valenciana

\section{Actualidad bibliográfica}

María Asunción Martínez Román, María Teresa Mira-Perceval, Hortensia Redero Bellido. E.U.T.S. de Alicante. Jorge Garcés Ferrer. Escola Universitària de Treball Social. Universitat de València.

La familia

\section{Apéndice documental}

Decreto 23/1988 de 8 de febrero, del Consell de la Generalitat Valenciana, de medidas de protección de menores en situación de desamparo en la Comunidad Valenciana

Orden de 20 de marzo de 1986, de la Conselleria de Trabajo y Seguridad Social, por la que se establece el recurso de familias Educadoras en la Comunidad Valenciana

Ley $21 / 1987$, de 11 de noviembre, por la que se modifican determinados artículos del Código Civil y de la Ley de Enjuiciamiento Civil en materia de adopción

Decret 23/1988, de 8 de febrer, del Consell de la Generalitat Valenciana, de mesures de protecció de menors en situació de desamparament a la Comunitat Valenciana

Ordre de 20 de març de 1986, de la Conselleria de Treball i Seguretat Social, per la qual s'estableix el recurs de Famílies Educadores de la Comunitat Valenciana

\section{NUMERO 2 (1993)}

Jesús Daza Martínez.

Presentación

I. Algunas claves del Estado social contemporáneo

Jorge Hurtado Jordá. Profesor del Departamento de Ciencias Sociales y de la Educación. Universidad de Alicante.

Sociedad, Estado, tal vez mercado

Fermín Aliaga Aliaga. Profesor del Departamento de Economía Aplicada y Política Económica. Universidad de Alicante.

Política econónica y calidad de vida

Ramón Martín Mateo. Catedrático de Derecho Administrativo.

La cultura del ocio 


\section{Cuestiones teórico-prácticas sobre el Trabajo Social}

M. José Escartín Caparrós. Profesora titular de Trabajo Social de la EUTSA de Alicante

Influencia de las diferencias culturales en la relación de ayuda

Esperanza Suárez Soto, Manuela Palomar Villena. Profesoras titulares de Trabajo Social en la EUTSA de Alicante.

El cliente en Trabajo social. Cuestiones conceptuales y análisis tipológico....

Esther Villegas Castrillo. Profesora titular de Trabajo Social en la EUTSA de Alicante.

El Trabajador Social en el trabajo de grupo

Antonio José Bellido Alonso. Profesor titular de Trabajo Social en la EUTSA de Alicante.

La primera entrevista en la relación de ayuda del Trabajo Social Individualizado

Josefa Lorenzo García. Profesora Titular de Trabajo Social en la EUTSA de Alicante.

La intervención profesional con familias multiproblema desde los Servicios Sociales Municipales

Manuela Palomar Villena y Esperanza Suárez Soto. Profesoras Titulares de Trabajo Social en la EUTSA de Alicante.

El modelo sistémico en el Trabajo Social familiar. Claves teóricas e intervención práctica

\section{Problemas y perspectivas de los servicios sociales}

Manuel Moix Martínez. Catedrático de Trabajo Social y Servicios Sociales.

«Universalidad» versus «Selectividad» en los Servicios Sociales. La «discriminación positiva».

María del Carmen Alemán Bracho. Catedrática de Servicios Sociales de la EUTS de la Universidad de Granada.

Una perspectiva de los Servicios Sociales en España.

M. ${ }^{a}$ Asunción Martínez Román, M. ${ }^{a}$ Teresa Mira-Perceval Pastor y Hortensia Redero Bellido. Prof. titulares de SS.SS. de la EUTS de Alicante.

¿Viejos o nuevos? Orientaciones actuales de los Servicios Sociales en España

Rafael Barranco Vela. Profesor de Derecho Administrativo de la EUTS de la Universidad de Granada.

El principio de participación en las Leyes de Servicios Sociales

\section{Miscelánea}

Manuel Oliver Narbona y M. Dolores Vargas Llovera. Profesores del Departamento de Humanidades Contemporáneas. Y M. José Escartín Caparrós, Josefa Lorenzo García, Antonio Bellido Alonso, Roberto Mohedano Menéndez, Manuela Palomar Villena, Esperanza Suárez Soto y Esther Villegas Castrillo. Profesores de la EUTS de Alicante.

Innigración y cultura: Reflexiones críticas sobre las diferencias sociales $y$ culturales que produce el hecho migratorio

Carmen Gimeno Escrig, Médica Experta Universitaria en Drogodependencias; $M^{a}$ Angeles Amérigo Martínez, Trabajadora Social y Experta Universitaria en Drogodependencias; $\mathbf{M}^{*}$ José Martí García, Psicóloga Experta Universitaria en Drogodependencias.

Perfil de los drogodependientes y familias atendidos en el Servicio Municipal de Drogodependencias de la Vila Joiosa 
Francisco Martínez Carrasco y M. Dolores Vargas Llovera. División de Antropología. EUTS de Alicante.

Cultura y salud mental. Influencia del medio institucional en los enfermos profundos adultos

Agustín Bueno Bueno. Departamento de Psicología de la Salud. Universidad de Alicante

Autoconcepto adolescente y clase social

\section{Actualidad bibliográfica}

M. ${ }^{a}$ Asunción Martínez Román, Ma Teresa Mira-Perceval Pastor y Hortensia Redero Bellido. Prof. titulares de SS.SS. de la EUTS de Alicante.

Bienestar Social y Política Social

NUMERO 3 (1995)

M. ${ }^{a}$ Teresa Mira-Perceval Pastor. Directora E.U. Trabajo Social. Universidad de Alicante.

Presentación

M. ${ }^{a}$ José Escartín Caparrós, Esperanza Suárez Soto.

Editorial

I. Trabajos sobre la mujer

Jose Manuel Díez Fuentes. Universidad de Alicante.

República y Primer Franquismo: La mujer española entre el esplendor y la miseria, 1930-1950

M. ${ }^{a}$ José Frau Llinares. Departamento Ciencias Sociales y de la Educación. Universidad de Alicante.

La tipificación sexual del trabajo mercantil. El caso valenciano

M. a Dolores Díez García y Sergio Quesada Rettschlag. Catedráticos Matemáticas E.U. Trabajo Social. Departamento de Economía Aplicada. Universidad de Alicante. Silvia M. ${ }^{a}$ Quesada Díez. ICADE. Madrid.

Una empresaria de los 90 . Análisis y valoración de un caso

María José Escartín Caparrós. Profesora titular de Trabajo Social. Universidad de Alicante.

Violencia y Mujer. La intervención de crisis con mujeres maltratadas y sus hijos

Trinidad Pablo Cervera, Ruth Pérez Segovia y M. ${ }^{a}$ Dolores Vargas Llovera. Area de Antropología. Escuela Universitaria de Trabajo Social. Universidad de Alicante.

Mujer, Familia y mundo rural. Dos modelos para un cambio social

Yolanda Domenech López. Profesora ayudante del Area de Trabajo Social y Servicios Sociales. Universidad de Alicante.

La situación de la mujer en Honduras

\section{Tribuna Libre}

Carmen Gimeno Escrig. Médica Servicio Municipal de Alcoholismo y Drogodependencia. Villajoyosa. Angeles Amérigo Martínez. Trabajadora Social, Servicio Municipal de Alcoholismo y Drogodependencia. Villajoyosa.

Programa de intervención en familias. Evaluación con el cuestionario de salud general de Goldberg

Agustín Bueno Bueno. Profesor titular de Psicología Social de la Escuela Universitaria de Trabajo Social. Universidad de Alicante. $\mathrm{M}^{\mathrm{a}}$ Teresa MiraPerceval Pastor. Profesora titular de Servicios Sociales de la Escuela Uni- 
versitaria de Trabajo Social. Universidad de Alicante.

Reflexiones ante la Ley de la Infancia de la Comunidad Valenciana.

Antonio Gutiérrez Resa. Profesor titular de Servicios Sociales. Universidad de Zaragoza.

Las ONGs y su papel en el futuro de la sociedad

María José Gallego Ayllón. Trabajadora Social. Estrella Gualda Caballero. Socióloga. Octavio Vázquez Aguado. Trabajador Social. Departamento de Filosofía, Sociología y Trabajo Social. Universidad de Huelva.

Las ideas previas de los alumnos de $1^{\circ}$ de Trabajo Social de Huelva respecto a la profesión

Yolanda Domenech López. Profesora ayudante del Area de Trabajo Social y Servicios Sociales. Universidad de Alicante. Juan Carlos Gómez Díaz. Licenciado en Ciencias Económicas y Empresariales. Universidad de Alicante.

Una alternativa al trabajo social institucionalizado: El trabajo social en la empresa privada

\section{Apéndice documental}

Ley $7 / 1994$, de 5 de diciembre, de la Generalitat Valenciana, de la Infancia. DOGV n.. 2 .

La Declaración de Pekin. Conclusiones de la IV Conferencia Mundial sobre las Mujeres. Beijing. Septiembre 1995

\section{Libros}

M." Carmen Santos Aguado. Profesora de la E.U. de Trabajo Social de la Universidad Complutense de Madrid.

Título: «Las enseñanzas de Trabajo Social en España: 1932-1983. Estudio socio-educativo». Autora: M. ${ }^{a}$ Victoria Molina Sánchez.

\section{NUMERO 4 (1996)}

Esperanza Suárez Soto. Directora técnica del consejo editorial de la revista «Alternativas. Cuadernos de Trabajo Social».

Presentación

I. Trabajos sobre migración

Abel Albet-Mas. Departamento de Geografía. Universidad Autónoma de Barcelona. Maria Dolors Garcia-Ramon. Universidad Autónoma de Barcelona. Joan Nogué-Font. Departamento de Geografía. Universidad de Gerona. Lluis Ruidor-Gorgas. Facultad de Humanidades. Universidad Pompeu Fabra. Barcelona.

Geografia, ordenación del territorio y colonialismo español en Marruecos.

Mikel de Epalza. Catedrático de Estudios Arabes e Islámicos. Universidad de Alicante

Estructuras de acogida de los moriscos emigrantes de España en el Magreb (siglos XIII a XVIII).

Joan Lacomba. Departamento de Trabajo Social y Servicios Sociales.

Escuela Universitaria de Trabajo Social. Universidad de Valencia.

ldentidad y religión en inmigración. A propósito de las estrategias de inserción de los musulmanes senegaleses.

M." Dolores Vargas Llovera. Area de Antropología. Universidad de Alicante.

Inmigración, etnicidad y pluralismo cultural.

José Cabanes Hernández. Sociólogo. Luz Vera García. Trabajadora social. 
Asociación P.G. Arakerando. Alicante. María Isabel Bertomeu Martínez. Trabajadora social. Asociación P.G. Arakerando. Alicante.

Gitanos: historia de una migración.

D. Ribera, A. Reig, M. Carrillo, J.L. Talavera, A. Caruana, C. Ferrera, A. Majos, R. Climent, C. Clavijo, M. Verdú. Escuela Universitaria de Enfermería. Universidad de Alicante. Hospital General de Alicante. Facultad de Medicina. Universidad de Alicante. Ayto. de Alfaz del Pi (Alicante).

Hábitos y necesidades de cuidados en el colectivo de extranjeros de 80 y más años residentes en la costa mediterránea.

Mcrcedes González. Octavio Vázquez. Departamento de Filosofía, Sociología y Trabajo Social. Universidad de Huelva.

Trabajo social e inmigrantes. Las intervenciones del trabajo social

Carmen Santos Aguado. Escuela Universitaria de Trabajo Social. Universidad Complutense de Madrid.

Trabajo social en el campo de actuación de inmigración y refugio.

Socorro Escobar Rubio. Trabajadora social. IRCOSAN. Madrid. Nieves Gascón Navarro. Trabajadora social. Mancomunidad Intermunicipal de La Encina. Madrid.

Metodología del trabajo social con inmigrantes y refugiados.

Ana M." Ortiz Duque. Trabajadora social. Ayutamiento de Majadahonda. Madrid.

Fases de la intervención social con inmigrantes.

M. Jesús Vega Pascual. Trabajadora social. Alto Comisariado de las $\mathrm{Na}$ ciones Unidas para los Refugiados (ACNUR). Secretaria de la sección legal.

Fases de la intervención social con refugiados.

\section{Tribuna libre}

Nieves Lillo Herranz. Trabajadora social. Area de biencstar social del Excmo. Ayuntamiento de Elche (Alicante)

El educador gitano, profesional clave para una intervención integral con el pueblo gitano.

Sonia Ródenas Picardat. Trabajadora social. Asociación ciudadana contra el SIDA de la provincia de Alicante.

Grupos de ayuda mutua: una respuesta alternativa en la práctica del trabajo social.

Alfredo Hidalgo Lavié. E.U. Relaciones Laborales - Trabajo Social. Jercz. Universidad de Cádiz.

El marco juridico-administrativo de los Servicios Sociales de la Conunidad Autónoma Andaluza.

Jorge Hurtado Jordá. Departamento de Ciencias Sociales. Universidad de Alicante.

Lecciones de la informalidad.

Idris M. Iwaki. Hector O. Beaton. Emesto A. López. Departamento dc Sociología. Universidad de Oriente-Santiago. Cuba. Javicr M. Ferrer. Dcpartamento de Trabajo Social. Universidad de Alicante.

Turismo y cambio social en Santiago de Cuba.

\section{Actualidad bibliográfica}

Carmen Santos Aguado. M. Jesús Vega Pascual. Socorro Escobar Rubio. Ana M. ${ }^{a}$ Ortiz Duque.

Actualidad bibliográfica sobre inmigración y refugio. 


\section{Libros}

Gonzalo Musitu. Coordinador del Area de Psicología Social. Universidad de Valencia.

Título: "Estudio longitudinal de la presencia de la mujer en los medios de comunicación de prensa escita». Cuadernos de Investigación de Psicología Comunitaria. Universidad de Valencia. Nau Llibres. Valencia, 1996. Autor: José Ramón Bueno Abad.

\section{NUMERO 5 (1997)}

Esperanza Suárez Soto. Directora técnica del consejo editorial de la revista «Alternativas. Cuadernos de Trabajo Social».

Presentación

\section{Trabajos sobre violencia}

M. ${ }^{a}$ Asunción Martínez Román. Departamento de Trabajo Social y Servicios Sociales. Universidad de Alicante.

"Pobreza y exclusión social como formas de violencia estructural". La lucha contra la pobreza y la exclusión social es la lucha por la paz.

Gonzalo Musitu Ochoa. Profesor y director del Area de Psicología Social. Facultad de Psicología. Universidad de Valencia.

Violencia y terrorismo: Un análisis desde la perspectiva ecológica.

E. Bosch-Fiol, M. Gili-Planas y V.A. Ferrer-Pérez. Departamento de Psicología. Universidad de las Islas Baleares.

La violencia doméstica como una forma de expresión deactitudes misóginas.

Dra. M. ${ }^{a}$ Dolores Díez García. Profesora de la E.U. de Trabajo Social. Universidad de Alicante. Dr. Sergio Quesada Rettschlag. Profesor de la E.U. de Trabajo Social. Universidad de Alicante. M. ${ }^{a}$ Dolores Sala Bonmatí. Trabajadora social.

El maltrato a menores en la provincia de Alicante en el periodo 1980-1997.. Agustín Bueno Bueno. Profesor de Psicología Social. Universidad de Alicante.

El maltrato psicológicolemocional como expresión de violencia hacia la infancia.

Javier Domínguez, José R. Brocal, José J. Cases, Virginia Tovar y Agustín Bueno.

Análisis del progranta de seguimiento de medidas judiciales de régimen abierto en la ciudad de Alicante durante 1996.

José Conrado Moya Mira. Psicólogo. Jefe de la Sección de Familia, Infancia y Juventud de la Dirección Territorial de Bienestar Social de Alicante Organización de los Servicios de Protección a la Infancia en la Comunidad Valenciana. Análisis normativo y funcional.

M. ${ }^{x}$ José Escartín Caparrós. Profesora Titular de Trabajo Social. Departamento de Trabajo Social y Servicios Sociales. Universidad de Alicante.

Los niños maltratados y sus familias. Algunas indicaciones para la intervención del trabajador social.

\section{Tribuna libre}

Salvador Amigó Borrás. Profesor asociado de la Facultad de Psicología. Universidad de Valencia.

El "problema de la droga" y la prevención del consumo de drogas: mitos $y$ alternativas, con una especial referencia al consumo de cannabis...

M." José Salvador Pedraza, Eva Domínguez Sánchez, Raquel Carracedo Manzanera. Técnicos de la Consejería de Sanidad y Bienestar Social de la 
Junta de Castilla y León.

Marco operativo de las intervenciones de inserción asociadas a la percepción de rentas minimas.

Jesús Moragón Nava. Trabajador Social. Centro de Salud de Atención Primaria. INSALUD. Albacete.

La realidad rural: situación en una región. La organización de equipamientos.

Trinidad Banda Gallego. Profesora titular de la Escuela Universitaria de Trabajo Social. Universidad de Huelva.

El debate sobre la provisión pluralista de los Servicios Sociales.

Víctor M. Giménez Bertomeu. Trabajador Social. Coordinador del Centro Social n. ${ }^{\circ}$ 4. Servicios Municipales del Ayuntamiento de Alicante.

El trabajador social en la direción de un Centro de Servicios Sociales.

Enrique di Carlo. Equipo E.I.E.M. Universidad Nacional de Mar del Plata. Argentina.

El paradigma humanista como sustancia del Trabajo Social. El Trabajo Social y el paradigma humanista dialéctico. Alternativa de reorganización teorética y metodologia del trabajo social profesional

\section{Libros}

M. ${ }^{a}$ José Escartín Caparrós. Profesora Titular del Departamento de Trabajo Social y Servicios Sociales. Universidad de Alicante.

Titulo: "Violencia. Memoria amarga». Siglo XXI de España Editores, S.A. Madrid, 1997, 303 páginas. Autor: Javier Urra Portillo. Defensor del Menor en la Comunidad de Madrid.

M. Asunción Martínez Román. Departamento de Trabajo Social y Servicios Sociales. Universidad de Alicante.

Titulo: «Los Modelos en Trabajo Social. Intervención con personas y familias». Siglo XXI de España Editores, S.A. Madrid, 1996, 405 páginas. Autora: Mathilde du Ranquet.

M." Victoria Molina Sánchez. Catedrática de Trabajo Social. Universidad Complutense de Madrid.

Título: "Introducción al Trabajo Social II. Trabajo Social con individuos y familias». Editorial Aguaclara. Alicante, 1997, 287 páginas. Autoras: Escartín Caparrós, M.J., Palomar Villena, M., Suárez Soto, E.

\section{NÚMERO 6 (1998)}

M." Asunción Martínez Román y Hortensia Redero Bellido. Directora técnica y Secretaria respectivamente del Consejo Editorial de la Revista «Alternativas. Cuadernos de Trabajo Social».

Presentación.

I. EI marco actual de la acción social: ¿Servicios Sociales públicos o privados?

M. ${ }^{2}$ del Carmen Alemán Bracho. Catedrática E.U. de Servicios Sociales. Universidad de Granada. Mercedes García Serrano. Univ. de Granada.

Tercer sector: buscando el equilibrio entre solidaridad y eficiencia.

Michael Barratt Brown. Universidad de Sheffield (Reino Unido).

Defending the Welfare State.

Antonio Gutiérrez Resa. Catedrático E.U. de Trabajo Social y Servicios Sociales. Universidad de Zaragoza.

Público-privado. Un modo de intervenir en la sociedad global-local.

Manuel Enrique Medina Tornero. Profesor titular de Servicios Sociales. E.U. de Trabajo Social. Universidad de Murcia.

El debate de lo público y lo privado en Servicios Sociales. 


\section{Tribuna libre}

Agustín Bueno Bueno y Conrado Moya Mira. Area de Psicología Social. Universidad de Alicante.

La delincuencia juvenil como sintoma: perspectivas de intervención psicosocial.

José Cabancs Hernández. Sociólogo. Servicios Sociales Municipales de Villena (Alicante). Monitor de minorías étnicas.

La escolarización de los niños gitanos en el País Valenciano.

Yolanda Domenech López. Profesora titular de Trabajo Social de la E.U.T.S. Universidad de Alicante.

Los grupos de autoayuda como estrat. de intervención en el apoyo social.

Alfredo Hidalgo Lavié. Profesor de Servicios Sociales y Política Social. E.U. de Trabajo Social de Jercz de la Frontera. Universidad de Cádiz.

Ciencia Politica y Servicios Sociales. Del entendimiento al «concubinage».

Silvia Quesada Díez. Universidad Pontificia de Comillas, ICADE.

La acción social en la Unión Europea: evolución historica.

Elena Roselló Nadal. Profesora ayudante del Depto. de Trabajo Social y Servicios Sociales. Universidad de Alicante.

Reflexiones sobre la intervención del trabajador social en el contexto educativo.

Ana Rosser Limiñana. Psicóloga de la Unidad de Adopción de la Conselleria de Bienestar Social. Alicante.

Marco legislativo del acogimiento familiar.

Octavio Vázquez Aguado. Profesor titular de E.U. Depto de Sociología y Trabajo Social. Universidad de Huelva.

Pensar la epistemología del Trabajo Social.

III. Libros

José María Tortosa. Catedrático de Sociología. Universidad de Alicante. Titulo: «Trabajo Social Experimental». Tirant lo Blanch. Valencia, 1998. Autora: Rosario Conde Megias.

\section{NÚMERO 7 (1999)}

M. Asunción Martínez Román. Directora técnica del Consejo Editorial de la Revista «Alternativas. Cuadernos de Trabajo Social».

Editorial

I. Integración sociolaboral.

Idoia Martín Aranaga. Profesora de la E.U. de Trabajo Social. Departamento de Sociología, Área de Trabajo Social y Servicios Sociales. Universidad del País Vasco.

Las Políticas de Inserción en la Union Europea: una comparación Francia - Reino Unido - España.

Joaquín García Roca. Profesor de Ia E.U. de Trabajo Social. Departamento de Trabajo Social y Servicios Sociales. Universidad de Valencia.

Tercer secror e inserción social.

Carlos Arias. Ccntro Especial de Empleo Limencop, S.L.

Empresa de inserción. Centro Especial de Empleo Limencop, S.L.

Herminia Torreblanca y M. $^{2}$ Francisca Albert. Trabajadoras Sociales del Departamento de Empleo de la Asociación de Padres y Amigos de Niños y Adolescentes Hipoacúsicos (A.P.A.N.A.H.)

Integración socio-laboral de personas con deficiencia auditiva. 


\section{Tribuna libre}

Esther Villegas Castrillo. Profesora de la E.U. de Trabajo Social. Departamento de Trabajo Social y Servicios Sociales. Universidad de Alicante. Autoconciencia personal y creatividad femenina. Un proceso abierto......

Víctor M. Giménez Bertomeu. Trabajador Social. Coordinador del Ccntro Social Comunitario "Gastón Castelló". Servicios Sociales Municipales del Ayuntamiento de Alicante.

Polivalencia versus especialización. Aproximación a un modelo saludable de intervención primaria.

José Ramón Bueno Abad. Catedrático E.U. de Psicología Social. José Vicente Pérez Cosín. Profesor Asociado del Departamento de Trabajo Social y Servicios Sociales. E.U. de Trabajo Social. Universitat de València. Acogimiento familiar. Estudio de las interacciones ante las visitas familiares.

III. Documentos

Dictanen del Comité Económico y Social de la Unión Europea sobre la «Aplicación de las directrices para el empleo en 1999».

Ley 39/1999, de 5 de noviembre, para promover la conciliación de la vida familiar y laboral de las personas trabajadoras.

IV. Libros

M. ${ }^{a}$ Asunción Martínez Román. Catedrática de Trabajo Social y Servicios Sociales. Universidad de Alicante.

Título: "Hacia una economía plural. Un trabajo, una actividad, una renta para todos». Miraguano-Promocions. Madrid, 1999. Autores: Aznar, G., Caillé, A., Laville, J.L., Robin, J. y Sue, R.

Título: «Trabajar para vivir. Una propuesta innovadora de inserción sociolaboral». Miraguano-Promocions. Madrid, 1999. Autores: Frago, E., Jover, D., López, V.M., Márquez, F. y Mora, G.

Titulo: «Trabajo Social. Orientaciones y prácticas formativas». Editorial Gules. Valencia, 1999. Autores: Gómez Moya, J., Julve Negro, M. y Pérez Cosín, J.V. Prólogo de Cristina de Robertis.

Titulo: «Los inmigrantes irregulares en España. La vida por un sueño». Universidad de Deusto-Serie Derechos Humanos, vol. 4. Bilbao, 1999. Autores: Ruiz Olabuénaga, J.L., Ruiz Vieytez, E.J. y Vicente Torrado, T.L Isabel Pla Julián. Departamento de Economía Aplicada. Universidad de Valencia.

Título: "Crítica y futuro del Estado del Bienestar. Reflexiones desde la izquierda». Tirant lo Blanch. Valencia, 1999. Coordinadores: Fernández García, T. y Garcés Ferrer, J.

V. Noticias

"Il Curso de Especialista en Dificultad y Conficto Social: Técnicas de Intervención». Universidad Pontificia de Comillas - Fundación Universidad-Empresa. Madrid. Enero-diciembre 2000

Federación Internacional de Trabajadores Sociales (IFSW) Conferencias de Trabajo Social 2000-2001: «Promoting equitable societies in the global economy: Social work in the 21st century», Montreal (Canadá), del 29 de julio al 2 de agosto del 2000; "Managing conflicts in Social Work. Dealig with contradictions», Viena (Austria) y Bratislava (Eslovaquia), del 7 al 30 de agosto del 2000 .

Conclusiones del Congreso Internacional "Una sociedad para todas las edades». Alicante, 5-7 mayo 1999. 


\section{NÚMERO 8 (2000)}

M. Asunción Martínez Román. Directora técnica del Consejo Editorial de la Revista "Alternativas. Cuadernos de Trabajo Social».

Editorial

I. Servicios Sociales para menores en Europa.

Bernd Seidenstücker. Prf. Dr. Hab. Escuela Técnica Superior de Darmstdat y Universidad Técnica de Berlín (Instituto de Pedagogía Social). Barbara Mutke, Diplomada en Pedagogía. Colaboradora científica Universidad Técnica de Berlín (Instituto de Pedagogía Social).

Servicios Sociales para menores en Alemania.

Hortensia Redero Bellido. Departamento de Trabajo Social y Servicios Sociales Universidad de Alicante.

Servicios Sociales para menores en Francia.

M. Asunción Martínez Román. Departamento de Trabajo Social y Servicios Sociales. Universidad de Alicante.

Cambios reciente en los Servicios Sociales para menores en Inglaterra.

Miguel Angel Mateo Pérez. Departamento de Sociología II, Psicología, Comunicación y Didáctica. Universidad de Alicante.

"Pobreza infantil en veinticinco países industrializados". Datos y evidencias desde el Luxembourg Income Study.

\section{Tribuna libre}

Johan Galtung. Senior Advisor, UNRISD, in preparation for the World Summit for Social Development, Copenhagen, march 11-12, 1995. Professor of Peace Studies; Universitaet Witten/Herdecke, University of Hawai'i. European Peace University, Universidad de Alicante, TRASCEND Member, International Scientific Board, Swiss Academy for Development. On the social costs of modernization. Social disintegration. Atomiefanomie and social development.

Jorge Hurtado. Departamento de Sociología II, Psicología, Comunicación y Didáctica. Universidad de Alicante.

La infancia en un mundo desbocado.

Clarisa Ramos Feijóo. Departamento de Trabajo Social y Servicios Sociales. Universidad de Alicante.

Enfoque comunitario, modernidad y postmodernidad. El Trabajo Social con la Comunidad en tiempos de la globalización.

José Francisco Campos Vidal. Departamento de Filosofía. Sección Trabajo Social y Servicios Sociales. Universidad de las Islas Baleares.

Los factores terapéuticos: ¿Qué es lo que produce cambios en los grupos?

Raúl Soriano. Trabajador Social. Marisa Dorado. Médica. Médicos del Mundo. Valencia.

VIH/SIDA y reducción de daños entre usuarios de drogas inyectables.

Alfredo Hidalgo Lavié. Escuela Universitaria de Trabajo Social de Jerez. Universidad de Cádiz.

Pros y contras de la política de cooperación española. La Ley de Cooperación Internacional para el Desarrollo a examen.

\section{Documentación}

Ley Orgánica 5/2000, de 12 de enero, reguladora de la responsabilidad penal de los menores. BOE $n^{\circ}$ 287-2000. Sección $I$.

Ley Orgánica 7/2000, de 22 de diciembre, de modificación de la Ley Orgánica 10/1995, de 23 de noviembre, del Código Penal de los Menores, en relación con los delitos de terrorismo. BOE $n^{\circ}$ 307-2000. Sec. $I$. 
IV. Libros

$\mathrm{M}^{\mathrm{a}}$ José Escartín Caparrós. Departamento de Trabajo Social y Servicios Sociales. Universidad de Alicante.

Título: La violencia doméstica. Una nueva visión de un viejo problema. Editorial Paidós, Colección Trabajo Social, 9. Barcelona, 2000. Autora: A. Mullender. Traducción: M.Jimenez .

Hortensia Redero Bellido. Departamento de Trabajo Social y Servicios Sociales. Universidad de Alicante.

Titulo: Nuevas perspectivas de los Servicios Sociales. Universidad Nacional de Educación a Distancia, Madrid, 2000. Coordinadores: José Antonio Diaz Martínez y $M^{a}$ José Salvador Pedraza.

Begoña San Miguel del Hoyo. Departamento de Sociología II, Psicología, Comunicación y Didáctica. Universidad de Alicante.

Titulo: Politica Social. Editorial Ariel. Barcelona, 2000. Autora: $M^{a}$ Teresa Montagut.

V. Noticias

Seminario de la Federación Internacional de Trabajadores Sociales Asia Pacífico. "Millenium Challenges and Action for Social Work Education and Practice". Singapur, del 31 de julio al 3 de agosto de 2001.

Seminario Europeo de la Federación Internacional de Trabajadores Sociales. "Managing Conflicts in Social Work-Dealing with Contradictions". Viena y Bratislava, del 27 al 30 de agosto de 2001 .

Congreso Mundial de la Federación Internacional de Trabajadores Sociales "Building Effective Strategies in Social Work Practice in a New Era". Zimbawe, del 28 de julio al 2 de agosto de 2001.

Programa de Doctorado. Curso 2000-2001. "Análisis del Estado de Bienestar: estrategias de intervención social". Departamento de Trabajo Social. Universidad Pública de Navarra. 


\section{PAUTAS GENERALES PARA LA PRESENTACION DE ARTICULOS}



1. La Revista «Alternativas. Cuadernos de Trabajo Social» está abierta a aportaciones, investigaciones, trabajos teóricos y metodológicos, de carácter profesional o académico, tanto del trabajo social, política social y servicios sociales, como de otras disciplinas y profesiones que desde un punto de vista multi e interdisciplinar enriquecen y complementan la acción profesional.

2. Contenido de los artículos.

El Consejo Editorial solicitará el asesoramiento de expertos independientes quienes, valorando la calidad técnica y científica de los artículos, realizarán la correspondiente selección. Los autores de los artículos publicados recibirán un ejemplar de la Revista.

3. Los artículos publicados quedan en propiedad de la Revista, siendo necesaria la autorización del Consejo Editorial para su reproducción total o parcial.

4. Los artículos que no sean inéditos se publicarán bajo la valoración del Consejo editorial y en función de:

- Que su difusión haya sido en algún medio de difícil acceso a la profesión y disciplina del trabajo social.

- Que haya sido publicado en otro idioma.

- Que se consideren de particular relevancia e interés científico profesional.

5. Normas de presentación

- Los artículos deberán ser remitidos a la Redacción de la Revista "Altemativas. Cuademos de Trabajo Social». Escuela Universitaria de Trabajo Social. Universidad de Alicante. 03690 San Vicente del Raspeig. Alicante.

- Tres copias escritas y diskette (Microsoft Word y Word Perfect para Windows). Mecanografiados en papel tamaño DIN-A4, a doble espacio (escritura en $12 \mathrm{CPI}$ ), por una sola cara.

- La extensión deberá ajustarse a un mínimo de $10-12$ páginas y un máximo de 40.

- De cada uno de los artículos los autores presentarán las claves conceptuales y un «abstract» de 12/15 líneas al comienzo del trabajo.

- Todos los artículos deberán ir acompañados en folio aparte de los datos personales del autor/res: nombre y apellidos, D.N.I., dirección, teléfono, profesión, actividad, cargo, teléfono de con- 
tacto, indicando claramente el título del artículo y si ha sido publicado en algún otro medio.

- Las anotaciones a pie de página se numerarán por orden de aparición en el texto y se mecanografiarán en hoja aparte.

- Las referencias bibliográficas se presentarán al final del texto y por orden alfabético de autores, en la forma siguiente:

- Para los libros: Apellidos e inicial del nombre del autor/a/ o autores/as, título de la obra (cursiva), editorial, ciudad, año y número de las páginas a que se hace referencia.

- Para las revistas: Apellidos e inicial del nombre del autor/a o autores/as, título del artículo (entre comillas), nombre de la revista (en cursiva), nombre de la entidad editora, ciudad, año, número de la revista y el de las páginas a que se hace referencia.

- Las tablas y figuras deberán presentarse en hoja aparte numerándose correlativamente e indicando el lugar de colocación en el artículo.

- Los apartados y subapartados se confeccionarán de manera homogénea utilizando la numeración I, II, III; 1.1., 1.2; etc. 
Próxima sección monográfica:

\section{LOS DESAFÍOS DE LA VIOLENCIA. COMPROMISOS DEL TRABAJO SOCIAL POR UNA SOCIEDAD MÁS JUSTA}

IV Congreso de Escuelas de Trabajo Social 



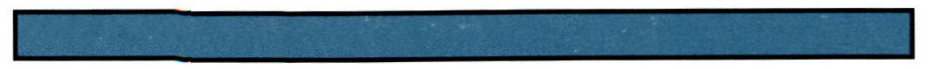

